SIMONE VASCONCELOS RIBEIRO GALINA

\title{
DESENVOLVIMENTO GLOBAL DE PRODUTOS: O PAPEL DAS SUBSIDIÁRIAS BRASILEIRAS DE FORNECEDORES DE EQUIPAMENTOS DO SETOR DE TELECOMUNICAÇÕES
}

Tese apresentada à Escola Politécnica da Universidade de São Paulo para a obtenção do título de Doutor em Engenharia 


\section{DESENVOLVIMENTO GLOBAL DE PRODUTOS: O PAPEL DAS SUBSIDIÁRIAS BRASILEIRAS DE FORNECEDORES DE EQUIPAMENTOS DO SETOR DE TELECOMUNICAÇÕES}

Tese apresentada à Escola Politécnica da Universidade de São Paulo para a obtenção do título de Doutor em Engenharia

Área de Concentração: Engenharia de Produção

Orientador: Prof. Dr. Guilherme Ary Plonski 
Este exemplar foi revisado e alterado em relação á versão original, sob responsabilidade única do autor e com a anuência do orientados

São Paulo, 30 de agosto de 2003

Simone Vasconcelos Ribeiro Galina

(Autora)

Guilherme Ary Plonski

(Orientador)

Galina, Simone Vasconcelos Ribeiro

Desenvolvimento global de produtos: o papel das subsidiárias brasileiras de fornecedores de equipamentos do setor de telecomunicações. São Paulo, 2003 $311 \mathrm{p}$.

Tese (Doutoramento) - Escola Politécnica da Universidade de São Paulo. Departamento de Engenharia de Produção.

1. Desenvolvimento Global de Produtos 2. Telecomunicações I. Universidade de São Paulo, Escola Politécnica. Departamento de Engenharia de Produção II. T. 
"O homem deve criar as oportunidades e não somente encontrá-las" Francis Bacon

Ao Pi, à minha mãe e ao Vas

A todas as pessoas que acreditam ser possível e trabalham para criar oportunidades para que nossa nação e nosso povo se desenvolvam. 


\section{Agradecimentos}

Este - e tantos outros trabalhos de doutorado - não é simplesmente mais um estudo realizado com objetivos, métodos e busca pela tal contribuição científica. Além disso, ele também incorpora o que passei nesses anos de aprendizado intenso e de grandes mudanças pessoais e profissionais. Tal crescimento só foi possível pelo apoio que recebi ao longo dessa jornada.

Portanto, gostaria de agradecer a todos, que direta ou indiretamente colaboraram. Primeiramente, a Deus, pela presença real e constante em todos os momentos. Agradeço também à minha família, que me apoiou - e muitas vezes me agüentou durante todo o tempo. Ao meu marido, Pi, que sempre esteve torcendo e auxiliando desde o início - com sábados intermináveis preparando trabalhos das disciplinas, durante o período do estágio-sanduíche na Suécia, para onde ele não queria ter ido, na etapa final - com vários finais de semanas e feriados sem tempo para sair, para conversar, para viajar. À minha mãe e ao meu irmão pelo carinho e estímulo, e por, apesar das cobranças para visitá-los, sempre respeitarem e apoiarem minhas decisões.

Agradeço ao Prof. Guilherme Ary Plonski, pela orientação, incentivo e amizade dispensados durante o desenvolvimento deste trabalho. Ao prof. Prasada Reddy, pela orientação, apoio e calorosa acolhida no exterior. Aos Profs. Anders Granberg e Rikard Stankiewicz pela contribuição tão pertinente durante o estágio na Lund University. Agradeço também a vários outros professores do Brasil e do exterior, que colaboraram.

Às instituições que apoiaram financeiramente este trabalho, CNPq e CAPES, e ao Departamento de Engenharia de Produção da Escola Politécnica da USP, pelo auxílio financeiro para viagens e participações em congressos. Também quero deixar meus agradecimentos aos funcionários do departamento, que me auxiliaram de diferentes maneiras, em especial à Vanda, Lídia, Olívia, Vera, Paulo, Sami, D. Ana, D. Olga. Agradeço também aos funcionários e colaboradores do Research Policy Institute em Lund, pelo apoio e hospitalidade, especialmente Birgitta, Ann, Jeanne. 
Não poderia deixar de expressar meu agradecimento às empresas e a seus funcionários, que deram abertura e permitiram a utilização de seus dados e informações, sem os quais não seria possível a realização desta pesquisa.

Este trabalho não seria o mesmo se eu não tivesse contado com o apoio e a torcida de vários parentes, amigos e colegas professores, aos quais sou muito grata. E por fim, quero agradecer profundamente aos meus colegas e amigos da pós-graduação, seja pelas festas e happy hours ou pelas discussões - muitas vezes inflamadas - sobre assuntos dos mais diversos, variando desde novas teorias e idéias, até futebol, fofocas e novelas. Essas lembranças ficarão para sempre, e esses amigos já fazem parte da minha vida. Para não ser injusta, cito apenas os mais "constantes" (alfabeticamente): Alexandra, Ana Valéria, Carla, Cristiano (o agregado), Davi, Gabriela, Juan, Marta, Neida, Pledson, Sérgio Gouvea, Sérgio Muniz, Susana, Thaise. 


\section{Resumo}

O desenvolvimento tecnológico é fundamental para a competitividade das empresas, especialmente em setores dependentes da inovação como o de telecomunicações. E, na busca por melhores condições para o desenvolvimento tecnológico, cada vez mais, pesquisa e desenvolvimento nas companhias globais são realizados por equipes localizadas em diferentes países. A participação ativa de vários países no Desenvolvimento Global de Produtos (DGP) pode possibilitar o crescimento desses países, uma vez que, para estarem inseridos no desenvolvimento mundial, eles recebem investimentos locais para se capacitarem.

Dessa forma, este trabalho analisa a participação das equipes brasileiras das companhias transnacionais estrangeiras fabricantes de equipamentos de telecomunicações no DGP e apresenta um modelo para tal envolvimento, a fim de que seja possível traçar tendências e discutir mecanismos para potencializar essa participação e, consequentemente, o desenvolvimento local. Para atender aos objetivos deste trabalho, a metodologia utilizada engloba estudos de casos e análises de dados quantitativos. Essas duas abordagens metodológicas foram combinadas e serviram para melhor análise dos resultados obtidos.

Entre os resultados desta pesquisa, três se sobressaem. Primeiro, a análise dos fatores que influenciam as empresas quando localizam P\&D fora de seus países de origem, em especial no Brasil. Segundo, após identificar que há envolvimento das subsidiárias brasileiras no DGP, analisou-se como essas atividades ocorrem, com o intuito de avaliar possíveis dinâmicas em comum, o que caracteriza o segundo resultado desta pesquisa. Essa análise é apresentada sob três diferentes aspectos: características do envolvimento das equipes brasileiras; cooperação entre as companhias e os demais agentes de inovação no setor; e dinâmica para formação e interações da equipes no DGP, com a apresentação de um modelo que retrata as estruturas de P\&D Internacional mais utilizadas no setor de telecom. Terceiro, a avaliação dos resultados da participação brasileira no DGP em termos de análises quantitativas de dados secundários e do levantamento de dois indicadores de C\&T para as companhias: dados de patentes e dados bibliométricos. 


\section{Abstract}

Technological development is used as means of boosting competition for industrial companies especially in technological innovation sectors like the Telecommunication. Intending to be more competitive, companies spread their Research and Development activities worldwide, involving team members who work overseas. The involvement of different countries in the Global Product Development (GPD) activities may let them to grow technologically because, in order to sustain their participation in GPD processes, investments must be done in the development of their local capacity.

Thus, this work analyses the involvement in GPD of Brazilian subsidiaries of transnational telecommunication equipment suppliers and presents a model for depicting such involvement, aiming to draw tendencies and to discuss mechanisms to improve this participation. The methodology used for reaching the goals combines case studies (qualitative analysis) and quantitative studies.

Among the results of this research, three of them stand out. First, an analysis of the factors which influence companies when they are localizing R\&D activities abroad, especially in Brazil, once it was proved the existence of Brazilian involvement in GPD activities. Second, an analysis of this activities considering three issues: characteristics of niches of products developed by local teams; cooperation between the companies' subsidiaries and other local innovation players (especially universities and research centers); the dynamics for composition of international GPD units and the interactions between them, presenting a model developed during this research, which represents the most applied structures of international R\&D in telecom industry. Finally, the third result of this work attempts to evaluate the Brazilian participation in GPD in terms of quantitative data. For thus, it was used secondary data from other researches and analyzed two S\&T indicators from the studied companies: patents and bibliometrical data. 


\section{SUMÁRIO}

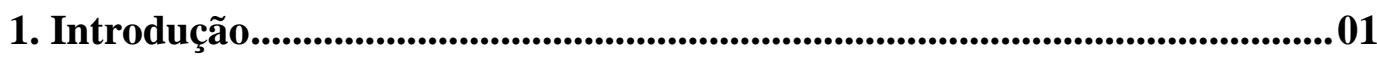

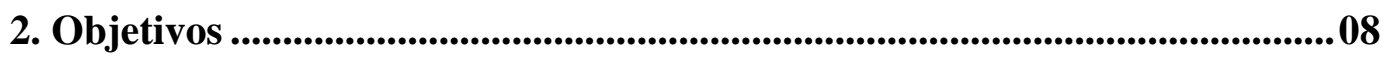

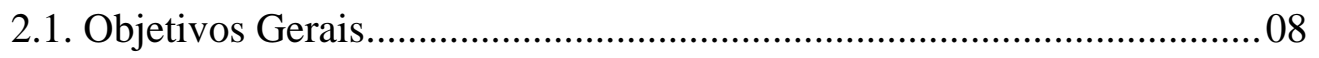

2.2. Objetivos Específicos (Hipóteses e Questões de Tese) ...........................11

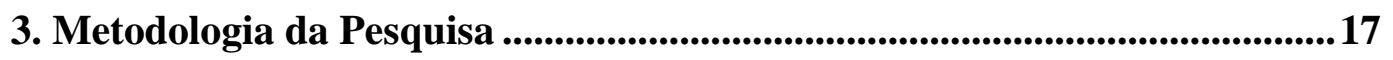

3.1. A Escolha do Setor e dos Casos/Amostras ........................................... 19

3.2. Instrumentos Utilizados nos Estudos de Casos com as Empresas ..........22

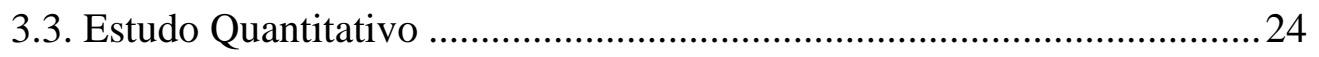

4. Globalização e Desenvolvimento de Produtos .............................................227

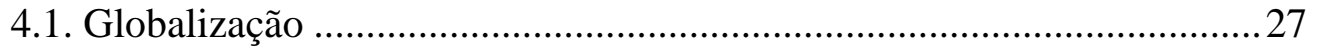

4.1.1. Distribuição das Subsidiárias Globalmente .................................28

4.1.2. Papéis das Unidades Externas........................................................ 32

4.1.3. Internacionalização de Atividades de Desenvolvimento

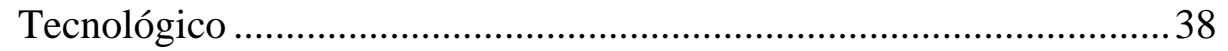

4.1.3.1. Razões para Internacionalização de P\&D............................43

4.1.3.2. Papéis das Unidades de P\&D.............................................49

4.1.3.3. Pontos Negativos da Internacionalização de P\&D .............53

4.2. Desenvolvimento de Produtos ...............................................................54

4.2.1. Processo de Desenvolvimento de Produtos ..................................57

4.2.2. Desenvolvimento Global de Produtos ..........................................62 62

4.2.3. Gestão de Desenvolvimento de Produtos Globais .........................63

4.2.3.1. Estruturas para divisão de tarefas entre as equipes.............64

4.2.3.2. Estruturação Organizacional para P\&D descentralizada ...73

5. Setor de Telecomunicações.........................................................................................74

5.1. Aspectos Históricos .............................................................................. 74

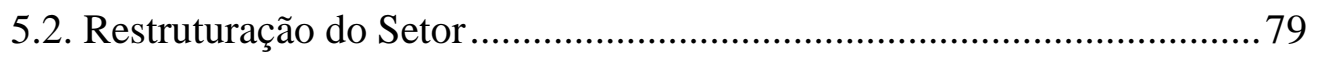

5.3. Configurações Organizacionais do Setor............................................... 84 


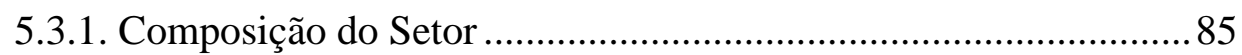

5.3.1.1. Governo / Órgão Regulador................................................. 86

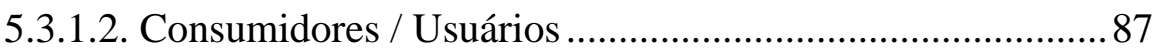

5.3.1.3. Operadores: Serviços e Redes...............................................89

5.3.1.4. Fornecedores de Equipamentos .......................................... 95

5.3.1.5. Universidades e Centros de Pesquisa .................................. 102

5.3.2. Cadeia Produtiva do Setor de Telecomunicações ......................... 104

5.3.2.1. Proposta de uma Nova Estrutura para a Cadeia de

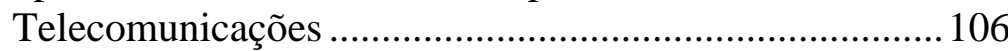

5.3.2.2. Mudanças de Papéis na Cadeia.......................................... 111

5.4. Desenvolvimento Tecnológico no Setor de Telecomunicações .............. 115

5.4.1. Retrospectiva Histórica ............................................................... 115

5.4.2. Características Atuais ................................................................. 119

5.4.3. Aspectos Propulsores do Desenvolvimento Tecnológico............. 122

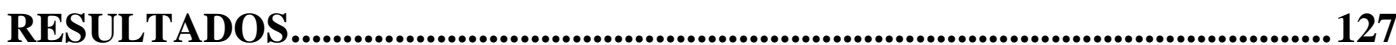

6. Atrativos para Atividades de Desenvolvimento Tecnológico no Brasil ....128

6.1. Fatores que atraem atividades de P\&D para subsidiárias brasileiras...... 128

6.2. Classificações para os fatores de atração de atividades tecnológicas

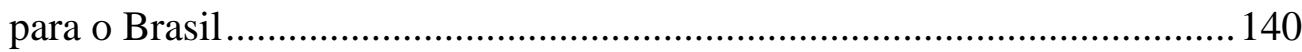

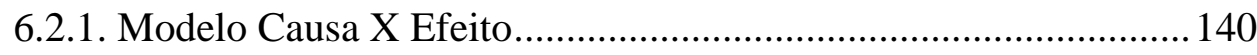

6.2.2. Modelo para Generalização dos Fatores ...................................... 143

7. Envolvimento das equipes brasileiras no DGP................................................147

7.1. Desenvolvimento de Produtos das Subsidiárias Brasileiras - Estudos de

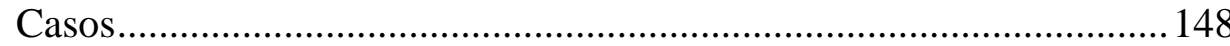

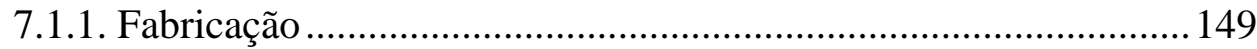

7.1.2. Pesquisa e Desenvolvimento.................................................... 150

7.2. Análise da Cooperação entre Empresas e Universidades/Centros de

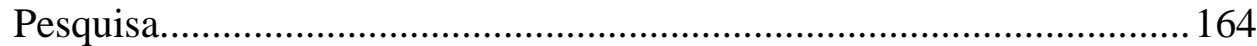

7.3. Estrutura Organizacional para P\&D Internacionalizada....................... 173

7.4. Análise da Cooperação entre Empresas e Universidades / Centros de Pesquisa no Setor de Telecomunicações 
8. Pesquisa quantitativa com indicadores de C\&T ...........................................186

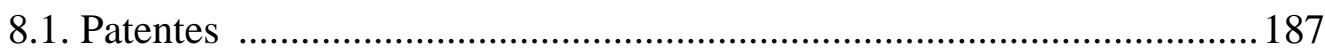

8.1.1. Patentes Internacionais …....................................................... 189

8.1.2. Patentes Domésticas................................................................. 194

8.2. Dados Bibliométricos........................................................................... 196

8.3. Síntese dos Resultados Quantitativos Obtidos.......................................201

8.4. Análise de Dados Secundários...............................................................2205

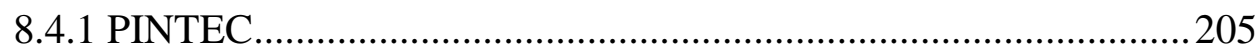

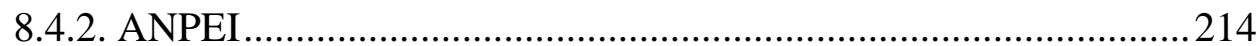

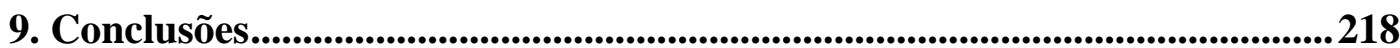

9.1. Considerações Finais ......................................................................... 218

9.2. Propostas para Trabalhos Futuros ......................................................2. 236

Anexo - Estudos de Casos com Empresas ...........................................................240

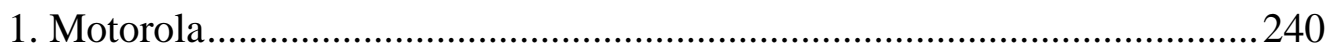

2. NEC

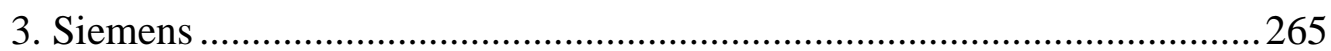

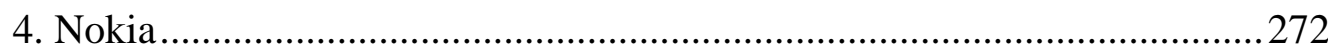

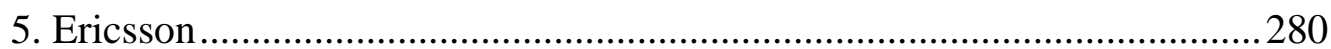

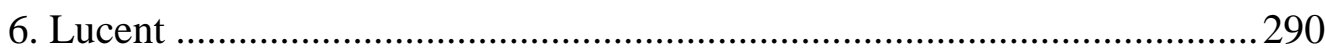

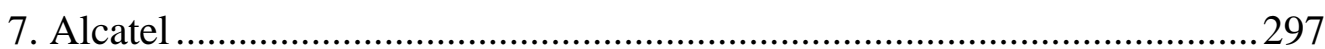

10. Referências Bibliográficas .....................................................................................302

Apêndice - Roteiro Utilizado nas Entrevistas 


\section{Lista de Figuras}

Figura 2.1 - Estrutura geral do trabalho com principais áreas pesquisadas ......10

Figura 2.2 - Relações entre Premissas, Questões, Hipóteses e Resultados da

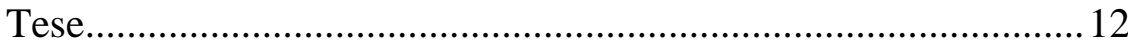

Figura 4.1 - Papéis Genéricos das Organizações Locais....................................33

Figura 4.2 - Papéis Estratégicos das empresas na cadeia produtiva ..................34

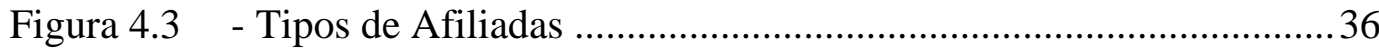

Figura 4.4 - Estrutura I-R para o setor de telecomunicações .............................45

Figura 4.5 - Classificação de tipos de Projetos de DP ........................................56

Figura 4.6 - Modelos de Estratégia de Desenvolvimento .................................56

Figura 4.7 - Ciclo de Vida Tradicional de Produtos .........................................57

Figura 4.8 - Fases de Desenvolvimento de Produto..........................................58

Figura 4.9 - Modelo de Referência para processo de DP.................................59

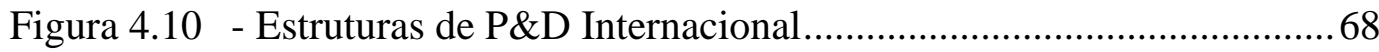

Figura 4.11 - Organização Internacional de P\&D............................................. 70

Figura 5.1 - Modelo para operação do setor de telecomunicações e interligação entre seus players ..................................................... 86

Figura 5.2 - Modelo em camadas para o Setor de telecomunicações ................ 105

Figura 5.3 - Cadeia de valores do setor de telecomunicações...........................106

Figura 5.4 - Proposta para Cadeia Produtiva de Telecomunicações ..................110

Figura 6.1 - Investimento por Tipo de Atividade (1993 a 1997) ...................... 136

Figura 6.2 - Investimento por Tipo de Atividade (1993 a 1997)..................... 137

Figura 7.1 - Modelo Representativo das Estruturas de P\&D Internacional mais usadas pelos casos estudados ............................................... 172

Figura 7.2 - Investimentos provenientes da Lei de Informática nos centros de pesquisa

Figura 8.1 - Percentual de empresas que implementaram inovações entre os fabricantes de equipamentos de comunicações, por grau de importância e por utilização das fontes de informação ....

Figura 8.2 - Percentual por localização das fontes de informação empregadas para indústria de aparelhos e equipamentos de comunicações......213

Figura I - Interligação entre as unidades globais de P\&D da área de comunicações $(\mathrm{CE})$ 
Figura II - Estrutura dos Centros de Desenvolvimento de Semicondutores...245

Figura III - Localização de Fábricas e Centros de Pesquisa da Nokia..............275

Figura IV - Organização Ericsson - Dimensão Mercado/Clientes ................... 281

Figura V - Organização Ericsson - Dimensão de Produtos/Soluções ..............2282

Figura VI - Relacionamento entre as unidades de desenvolvimento e a divisão CFT da Ericsson............................................................283 


\section{Lista de Tabelas}

Tabela 3.1 - Empresas estudadas e os principais produtos enfocados na

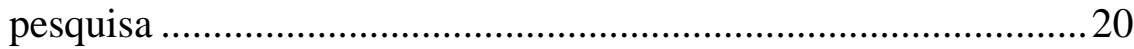

Tabela 3.2 - Entrevistas realizadas nas empresas ………................................23

Tabela 4.1 - Características Organizacionais das companhias Multinacionais, Globais, Internacionais e Transnacionais ....................................229

Tabela 4.2 - Posicionamento das TNCs com relação ao papel da subsidiária...37

Tabela 4.3 - Processo Histórico para a globalização de P\&D ............................42

Tabela 5.1 - Divisão do território brasileiro para telefonias fixa e de longa distância antes e após privatização..............................................82

Tabela 5.2 - Divisão do território brasileiro para telefonia móvel celular com operadoras atuantes antes e após privatização do sistema Telebrás e entrada de novos concorrentes - Banda B ....................83

Tabela 5.3 - Relação das Prestadoras do Serviço Móvel Celular das Bandas A e B

Tabela 5.4 - Participação dos segmentos nas áreas de atividade em 200 -

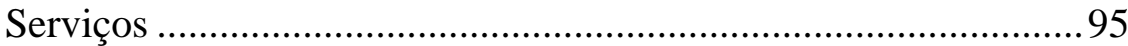

Tabela 5.5 - Principais fabricantes de equipamentos e sua posição no Brasil...98

Tabela 5.6 - Empresas de serviços de manufatura em telecomunicações .......... 113

Tabela 5.7 - Investimento em P\&D - 1999 ........................................................... 118

Tabela 5.8 - Percentuais de investimentos adicionais pelas empresas beneficiárias da lei de informática no período de 1994 a 1996.....126

Tabela 6.1 - Indicadores de investimentos em atividades de P\&D. ...................136

Tabela 6.2 - Maiores Fabricantes beneficiados com incentivos da lei..............139

Tabela 6.3 - Modelo Causas X Efeitos da Participação das Subsidiárias no DP

Tabela 6.4 - Principais fatores de atração para o desenvolvimento tecnológico na subsidiária brasileira das TNCs.

Tabela 7.1 - Quadro-Resumo comparativo entre as empresas estudadas ..........182

Tabela 8.1 - Patentes concedidas a empresas e inventores residentes em cada país - Seção H.

Tabela 8.2 - Patentes concedidas às empresas estudadas - participação dos países selecionados através do número de patentes por subsidiárias (unidades) e por inventores 
Tabela 8.3 - Patentes concedidas à matriz e a algumas subsidiárias no período de 1996 a 2000 .

Tabela 8.4 - Participação de inventores das patentes concedidas à matriz e a algumas subsidiárias no período de 1996 a 2000 ........................... 193

Tabela 8.5 - Solicitação de patentes regionais pelas empresas estudadas ..........194

Tabela 8.6 - Patentes concedidas à matriz, à subsidiária brasileira e a outras subsidiárias

Tabela 8.7 - Artigos científicos e técnicos na área de ciência e engenharia (\% do total)

Tabela 8.8 - Distribuição de artigos por países e empresas ................................198

Tabela 8.9 - Unidades das empresas e instituições brasileiras com artigos publicados em conjunto no período de 1996 a 2000

Tabela 8.10 - Indicadores de Inovação Tecnológica do Setor de Telecomunicações Fonte: PINTEC 2000

Tabela 8.11 - Indicadores de Capacitação e Inovação Tecnológica no Setor de Telecom (Valores Médios por Empresa).

Tabela I - Mercado destino dos produtos fabricados na subsidiária

Tabela II - Divisões X Produtos desenvolvidos no Brasil pela NEC 259 


\section{Lista de Siglas e Abreviaturas}

$3 \mathrm{G}$

ADSL

Anatel

ANPEI

BRISA

C\&T
Terceira Geração

Asynchronous Digital Subscriber Line

Agência Nacional de Telecomunicações

Associação Nacional de Pesquisa, Desenvolvimento e Engenharia das Empresas Inovadoras

Sociedade para o Desenvolvimento da Tecnologia da Informação

Ciência e Tecnologia

C.E.S.A.R. Centro de Estudos Avançados do Recife

CDMA Code Division Multiple Access

CDT Centro de Apoio ao Desenvolvimento tecnológico da UnB

CEFET Centro Federal de Educação Tecnológica

CEITEC Centro de Excelência Ibero-Americano em Tecnologia Eletrônica Avançada

CEM Contract Electronics Manufacturers

CERTI Fundação Centros e Referência em Tecnologias Inovadoras

CEU Cooperação Empresa-Universidade

CITS Centro Internacional de Tecnologia de Software

CMM Capability Maturity Model for Software

CNAE Classificação Nacional de Atividades Econômicas

Contel Conselho Nacional de Telecomunicações

CPDIA Centro de Pesquisa e Desenvolvimento de Informática e Automação

CPqD Centro de Pesquisa e Desenvolvimento Padre Roberto Landell de Moura

CTU Corporate Technology Units 


\begin{tabular}{|c|c|}
\hline DDD & Discagem Direta a Distância \\
\hline DDI & Discagem Direta Internacional \\
\hline Dentel & Departamento Nacional de Telecomunicações \\
\hline DGP & Desenvolvimento Global de Produtos \\
\hline DP & Desenvolvimento de Produtos \\
\hline DPG & Desenvolvimento Produtos Globais \\
\hline DPP & Diretório da Pesquisa Privada \\
\hline EMS & Electronics Manufacturing Services \\
\hline ERB & Estações Rádio Base \\
\hline FEI & Faculdade de Engenharia Industrial \\
\hline FINEP & Financiadora de Estudos e Projetos \\
\hline FITec & Fundação para Inovações Tecnológicas \\
\hline FNDCT & Fundo Nacional de Desenvolvimento Científico e Tecnológico \\
\hline FNT & Fundo Nacional de Telecomunicações \\
\hline GICEG & $\begin{array}{l}\text { Gestão da inovação para a competitividade empresarial brasileira no } \\
\text { contexto de globalização e informatização da economia: o caso do } \\
\text { setor de telecomunicações }\end{array}$ \\
\hline GPD & Global Product Development \\
\hline GPRS & General Packet Radio Service \\
\hline GSM & Global System for Mobile Communications \\
\hline GTU & Global Technology Units \\
\hline IBGE & Instituto Brasileiro de Geografia e Estatística \\
\hline Inatel & Instituto Nacional de Telecomunicações \\
\hline INFORMAT & Instituto de Pesquisas em Informática e Automação \\
\hline INPI & Instituto Nacional de Propriedade Intelectual \\
\hline IP & Internet Protocol - Protocolo de Internet \\
\hline
\end{tabular}


IPC

IPI

IPT

ITS

ITS-SP

ITU

ITU

LACTEC Instituto de Tecnologia para o Desenvolvimento

LGT

MC

MCT

MEC

MNC

NGN

NPT

OEM

P\&D

Paste

PC

PCT

PGT

PINTEC

PPB

PUC-PR

RTU

International Patents Classification

Imposto sobre Produtos Industrializados

International Telecommunications Society

Indigenous Technology Units

Lei Geral das Telecomunicações

Ministério das Comunicações

Ministério da Ciência e Tecnologia

Ministério da Educação

Next Generation Networks

Original Equipment Manufacturers

Pesquisa e Desenvolvimento Telecomunicações e do Sistema Postal

Personal Computers

Programa de Capacitação Tecnológica

Núcleo de Política e Gestão Tecnológica

Pesquisa Industrial: Inovação Tecnológica 2000

Processo Produtivo Básico

Pontifícia Universidade Católica do Paraná
Instituto de Pesquisas Tecnológicas de São Paulo

Instituto de Tecnologia de Software de São Paulo

International Telecommunications Union - Órgão ligado à ONU

Multinational Company - Companhia Muntinacional

Núcleo de Pesquisas tecnológicas da PUC de São Paulo

Programa de Recuperação e Ampliação do Sistema de

Regional Technology Units 
SEI

SEPIN Secretaria de Política de Informática - Ligada ao MCT

SMC Serviço Móvel Celular

TDMA Time Division Multiple Access

TNC Transnational Company - Companhia Tarnsnacional

TTU Technology Transfer Units

UFMG Universidade Federal de Minas Gerais

UFPE Universidade Federal de Pernambuco

UFRGS Universidade Federal do Rio Grande do Sul

UFSC Universidade Federal de Santa Catarina

UnB Universidade de Brasília

UNCTAD United Nations Conference on Trade and Development

UNICAMP Universidade de Campinas

USP Universidade de São Paulo

USPTO United States Patent Trade Office

WLL Wireless Local Loop

\section{Referentes às Companhias Estudadas:}

BCS Broadband Communications Sector-Motorola

BSTC Brazil Semiconductor Technology Center - Motorola

BU Business Units - Ericsson

CALA $\quad$ Caribe and Latin America - Lucent

CE Communication Enterprise - Motorola

CGISS Commercial, Government and Industrial Solutions Sector-Motorola

GTSS Global Telecom Solutions Sector-Motorola 


$\begin{array}{ll}\text { ICM } & \text { Information and Communication Mobile }- \text { Simens } \\ \text { ICN } & \text { Information and Communication Networks }- \text { Simens } \\ \text { ING } & \text { Internet and Networking Group }- \text { Motorola } \\ \text { KAM } & \text { Key Account Management }- \text { Ericsson } \\ \text { NMP } & \text { Nokia Mobile Phones }- \text { Nokia } \\ \text { PCS } & \text { Personal Communications Sector }- \text { Motorola } \\ \text { SBS } & \text { Siemens Business Services }- \text { Simens } \\ \text { SPS } & \text { Semiconductor Products Sector }- \text { Motorola }\end{array}$




\section{Capítulo 1}

\section{Introdução}

O desenvolvimento de produtos tem um papel importante na competição industrial, a ponto de ser possível afirmar a supremacia das empresas que saírem à frente na colocação de novos produtos no mercado e detiverem o conhecimento tecnológico desses produtos. Clark e Fujimoto (1991) já citaram que "nunca a tecnologia foi tão importante como nos tempos atuais, apesar de, sozinha, não ser suficiente para garantir vantagem competitiva".

Há vantagem competitiva nas organizações que mobilizam conhecimento, habilidades tecnológicas e experiência para criar novos produtos, processos e serviços (Tidd, 1997). Vários são os exemplos de empresas que tiveram (e têm) sucesso em grande medida através de inovações em seus produtos e/ou serviços, como a inglesa Richardson ${ }^{1}$ ou o banco UK First Direct $^{2}$.

Os novos produtos embutem novo conhecimento ou novas informações (Clark e Fujimoto, 1991), características centrais para a inovação, que pode envolver equipes de uma mesma empresa ou de empresas diferentes, que unem esforços e trocam conhecimentos no Desenvolvimento de Produtos (DP).

A formação das equipes de trabalho pode se dar com membros que trabalham num mesmo local ou até em países diferentes. No desenvolvimento intra-empresa é

\footnotetext{
${ }^{1}$ Passou de pequeno produtor de facas em 1974 a principal empresa na área em 1989 (as vendas aumentaram cerca de 23 vezes no período), graças, principalmente, ao sucesso do produto 'Laser', introduzido em 1980 com um tipo diferenciado de lâmina (Tidd, 1997).

${ }^{2}$ Se tornou o banco mais competitivo, atraindo cerca de 10.000 novos clientes por mês, graças ao oferecimento pioneiro de serviços bancários por telefone com avançada tecnologia de informação, $o$ que foi espelhado e imitado pelas principais organizações do setor (Tidd, 1997).
} 
possível a cooperação entre pessoas que estejam na sede da empresa mundial e pessoas que trabalham nos países onde a empresa possui subsidiárias. Mesmo entre empresas, o DP pode se dar com equipes de diferentes nacionalidades. Hoje, as transnacionais querem vantagem competitiva identificando necessidades em um país, criando com recursos localizados num segundo e difundindo os resultados das inovações no mercado mundial (Bartlett e Ghoshal, 1992).

Os interesses em envolver diferentes países, globalizando o desenvolvimento de produtos são diversos, entre eles o aproveitamento das competências das subsidiárias, a redução de custos de desenvolvimento e a convergência mundial das preferências dos consumidores. Esse último fator é bastante discutido porque a padronização das preferências dos consumidores facilita o desenvolvimento de produtos globais, mas por outro lado, o envolvimento de diferentes países no DP é uma maneira de reconhecer as características próprias de mercados locais.

O Desenvolvimento Global de Produtos (DGP) está cada vez mais presente nas empresas transnacionais (Cantwell, 1989; Dunning,1999; Ghoshal e Bartlett, 1988; Reddy, 1997; Subramaniam et. al., 1998; Zander, 1994). A participação ativa de vários países no Desenvolvimento de Produtos pode possibilitar a troca de conhecimento e tecnologia entre eles. Os países em que o DGP está presente têm maiores chances de sucesso na economia globalizada uma vez que a detenção de conhecimento e tecnologia é importante para o êxito das nações globais.

Porter (1990) afirma que para que uma nação atinja sua principal meta econômica, que é possibilitar um padrão de vida elevado e ascendente para os seus cidadãos, as empresas deste país devem elevar incessantemente a produtividade das indústrias existentes, melhorando a qualidade do produto, acrescentando elementos desejáveis, apurando a tecnologia do produto ou intensificando a eficiência da produção. $\mathrm{O}$ mesmo autor afirma também que o objetivo é manter altos salários e obter preços elevados nos mercados internacionais.

Pode-se conseguir isso com produtos tecnologicamente diferenciados de alto valor agregado. Para exemplificar, sem se preocupar com o rigor científico, se dermos uma olhada em grandes lojas de departamento no Brasil - aliás, em sua maioria, 
estrangeiras - vemos que a maioria dos produtos diferenciados são fabricados no exterior ou produzidos aqui por empresas cuja matriz se encontra em países desenvolvidos. À indústria brasileira cabem produtos de menor valor agregado e tecnologicamente inferiores.

Talvez isso exemplifique também uma outra afirmação de Porter (1990), de que os países em desenvolvimento tendem a estar ligados a custo de fatores e a competir por preço. O mesmo autor afirma que as nações nessa situação enfrentarão a ameaça constante de perder posição competitiva e de enfrentar problemas crônicos na manutenção dos salários e lucros. O país de baixo custo de trabalho hoje é rapidamente deslocado pelo país de amanhã. A fonte de menor custo de um recurso natural pode mudar rapidamente quando uma nova tecnologia permite a sua exploração em outros locais. Essas são vantagens passageiras e não garantem a competitividade empresarial. As companhias líderes em determinados segmentos da indústria são, com freqüência, fontes de conhecimento e tecnologia, sustentáculos da vantagem competitiva (Porter, 1990).

Considerando a importância do desenvolvimento de produtos como gerador de conhecimento e tecnologia para a competitividade das empresas e dos países que atuam globalmente, é fundamental o envolvimento do Brasil entre as equipes que participam do desenvolvimento global de produtos.

Essa participação pode ser influenciada positivamente pelo crescente interesse mundial na América Latina, que possui um amplo mercado regional a ser explorado e, apesar das atuais turbulências, se mostra direcionada à estabilização política e econômica (Peña e Reis, 1999). Trata-se de uma região importante como receptora de investimentos diretos internacionais (FDI - Foreign Direct Investments). Países como o Brasil, com uma estrutura de apoio razoável ${ }^{3}$ à $\mathrm{P} \& \mathrm{D}$ se comparado com os países vizinhos, podem se tornar alvos prediletos para o investimento de empresas

\footnotetext{
${ }^{3}$ Segundo critérios sugeridos por Terpstra (Terpstra, 1977) para a escolha do país para investimentos em P\&D, têm vantagens países com: amplos mercados, operações de manufatura das TNC, recursos humanos suficientes (técnico e científico).
} 
transnacionais no desenvolvimento de novos produtos, mesmo que seja para regionalização ${ }^{4}$ dos mesmos.

Um pesquisa realizada pela Sobeet - Sociedade Brasileira de Estudos de Empresas Transnacionais e da Globalização Econômica - permite compreender melhor o comportamento tecnológico das empresas transnacionais em operação no país, (Sobeet, 2000). A pesquisa centrou-se em dois enfoques básicos: o primeiro, a identificação e análise do perfil inovador das transnacionais, sob os aspectos: montante de recursos destinado à atividade de inovação (P\&D) e capacitação tecnológica. O outro aspecto considerado foi a avaliação das expectativas presentes e futuras dos empresários quanto à necessidade de realização de atividade inovadora como estratégia de competição nos mercados local e internacional. Para tal estudo foi pesquisado um grupo de 85 empresas, com um faturamento total equivalente a $5 \%$ do PIB global (US\$ 750 bilhões) e a 15\% do PIB industrial, no ano de 1998. Os resultados mostraram que as empresas investiram um montante de US\$ 959,7 milhões em atividades inovadoras, ou 0,13\% do PIB, em 1998. Deste total, US\$ 546,7 milhões destinarem-se à P\&D e o restante, US\$ 413 milhões, foi alocado em atividades de capacitação tecnológica. Em valores médios por empresas, as transnacionais despenderam US\$ 12,4 milhões de dólares em P\&D e capacitação tecnológica. Também foi possível constatar que as universidade e institutos tecnológicos no Brasil e a matriz no exterior, constituem os principais parceiros das empresas em seus projetos tecnológicos.

A participação no Desenvolvimento Global de Produtos pode influenciar a troca de conhecimento entre o Brasil e outros países, contribuindo com o crescimento tecnológico e colocando alguns setores industriais em vantagem competitiva no mercado mundial. Esse crescimento pode também ser alavancado com os investimentos feitos por empresas nacionais e estrangeiras em $P \& D$ no país, uma vez que há uma tendência de empresas transnacionais em colocar alguns de seus centros estratégicos de $\mathrm{P} \& \mathrm{D}$ em países em desenvolvimento. Isso se deve à boa qualidade de pesquisadores com baixa remuneração e adequada estrutura desses países (Reddy,

\footnotetext{
${ }^{4}$ Mesmo que consumidores nos países em desenvolvimento pareçam querer os mesmos produtos vendidos no exterior, alguma "modificação" é necessária para refletir diferenças relacionadas a uso, distribuição ou venda (Prahalad, 1998).
} 
1997). Isso acontece em países como Índia, já reconhecida como fonte de conhecimento técnico em engenharia, ciências e software (Prahalad, 1998).

Assim, alavancar o crescimento tecnológico do país é fundamental para criar e manter vantagem competitiva, especialmente na atual fase de globalização e diminuição de fronteiras entre países. Dessa forma, a proposta deste trabalho é analisar as características da dinâmica empresarial no desenvolvimento tecnológico, no intuito de discutir mecanismos para potencializar a participação brasileira no DGP em empresas transnacionais, especificamente no setor de telecomunicações, que é um setor dinâmico e bastante dependente da inovação, cujo histórico no Brasil é de relativo sucesso e relevância no que se refere ao desenvolvimento de tecnologia ${ }^{5}$.

Nesse setor, as empresas fornecedoras de equipamentos são os principais agentes do desenvolvimento tecnológico para a cadeia produtiva de telecomunicações e elas formam o principal objeto de estudo neste trabalho de doutorado. É importante ressaltar que as empresas transnacionais estrangeiras dominam o mercado brasileiro no segmento de telefonia, sendo assim, o propósito é analisar o envolvimento das subsidiárias locais dessas companhias no DGP, no intuito de avaliar a relevância das atividades realizadas por elas para a corporação como um todo, e identificar características que possam estimular esse envolvimento.

Esse e outros objetivos da tese são tratados no capítulo 2 deste trabalho, no qual é feita uma abordagem diferenciada para objetivos gerais e para objetivos específicos. Para este último, são apresentadas as hipóteses e as questões levantadas, e são discutidas as relações entre elas.

Para atender aos objetivos do trabalho, a metodologia utilizada, apresentada no capítulo 3, engloba estudos de casos com empresas fornecedoras de equipamentos de telecomunicações (estudo qualitativo) e análises de dados quantitativos. Essas duas abordagens serviram para uma melhor análise dos resultados obtidos, seja com a utilização dos dados quantitativos para aprimorar a avaliação das informações provenientes dos casos, ou com a análise qualitativa para entender e avaliar os dados qualitativos conseguidos e utilizá-los da melhor maneira possível.

\footnotetext{
${ }^{5}$ Especialmente quando esse histórico é comparado aos demais países em desenvolvimento.
} 
Nos capítulos 4 e 5 são feitas as revisões bibliográficas pertinentes a este trabalho. Uma discussão sobre globalização, abordando principalmente a distribuição de tarefas entre as diversas unidades das companhias que atuam mundialmente e os aspectos da internacionalização de P\&D, é feita no capítulo 4. No mesmo capítulo, são trabalhados assuntos referentes a Desenvolvimento de Produtos, enfatizando o Desenvolvimento Global de Produtos, no qual são tratados, entre outros, os processos de desenvolvimento e os aspectos relacionados à gestão desse desenvolvimento.

Assuntos referentes a telecomunicações merecem um capítulo à parte (capítulo 5) por vários motivos, entre eles, porque trata-se de um setor em que a história no Brasil esteve diretamente ligada à promoção do desenvolvimento tecnológico e porque não há muito trabalho acadêmico na área, valendo ter um relato mais aprofundado de suas características. Ainda neste capítulo, é proposta uma estrutura para a cadeia produtiva de telecom, que procura ser abrangente suficiente para abordar as interrelações entre os players, mas aprofundada o necessário para que cada grande segmento seja descrito da maneira clara.

Nos capítulos 6, 7 e 8 são apresentados os resultados desta pesquisa. A começar pelos fatores que influenciam as empresas quando localizam P\&D fora de seus países de origem, em especial o Brasil, uma vez que os resultados foram baseados nos estudos de casos feitos com subsidiárias localizadas neste país (capítulo 6). Os atrativos identificados são classificados de acordo com um modelo proposto e apresentado neste mesmo capítulo. Tal modelo baseia-se em algumas características comuns entre os casos estudados referentes à motivação e à origem dos fatores. Esse resultado é a resposta à questão de tese: "Por que as subsidiárias brasileiras envolvem-se com DGP?"6.

Uma vez que foi identificado que há atividades de DP sendo realizadas pelas subsidiárias brasileiras das empresas transnacionais (TNC), foi preciso analisar como essas atividades ocorrem, com o intuito de avaliar possíveis dinâmicas em comum e procurando responder a outras questões levantadas neste trabalho. Sendo assim, o

\footnotetext{
${ }^{6}$ Todas as hipóteses e questões levantadas nesta tese são mostradas no capítulo 2, e a relação entre elas, na figura 2.2.
} 
capítulo 7 apresenta os resultados referentes a essas questões sob três diferentes aspectos: como é o envolvimento das equipes brasileiras no DGP em termos de tipo de produto desenvolvido localmente, etapas em que há envolvimento da equipe brasileira, etc.; como é a cooperação entre as companhias e os demais agentes de inovação no setor (especialmente universidades e centros de pesquisa); qual a dinâmica de interações de equipes no DGP - sua formação, sua estrutura hierárquica, etc.

Para analisar este último aspecto, ou seja, as características mais comuns de relacionamento e integração entre as equipes globais de desenvolvimento das empresas estudadas, utilizou-se algumas estruturas de P\&D internacional levantadas na literatura (Chiesa e Manzini, 1996; Chiesa, 2000; Gassmann e von Zedtwitz, 1999) e apresentadas no capítulo 4. Essas estruturas foram analisadas e adaptadas para que um modelo mais apropriado para as companhias estudadas pudesse ser desenvolvido, tal modelo é apresentado no capítulo 7.

Após analisar as formas de participação das unidades brasileiras no DGP das transnacionais, fez-se necessário avaliar os resultados dessa participação em termos de alguns indicadores de C\&T. Para tanto, levantou-se dois dos mais utilizados: dados de patentes e dados bibliométricos, ambos tendo a subsidiária brasileira das companhias da amostra como ponto de avaliação. Ou seja, buscou-se, para patentes, depósitos em bases nacional e estrangeira - norte-americana - em nome das unidades brasileiras das TNCs, e para bibliométricos, artigos publicados por essas mesmas subsidiárias. Os resultados encontrados, apresentados no capítulo 8, não são otimistas. Nesse mesmo capítulo, fez-se uma análise de dados secundários, utilizando pesquisas realizadas no Brasil e avaliando o comportamento do setor de telecomunicações como um todo.

Este trabalho termina com a apresentação das conclusões no capítulo 9, a descrição dos estudos de casos em anexo, as referências bibliográficas e o roteiro utilizado para as entrevistas (apêndice). 


\section{Capítulo 2}

\section{Objetivos}

\section{1- Objetivos Gerais}

O propósito geral deste trabalho é analisar algumas características das empresas transnacionais atuantes no Brasil, que permitam traçar tendências e potencializar, de alguma maneira, a participação brasileira no Desenvolvimento Global de Produtos no setor de telecomunicações. Como esse é um objetivo muito amplo e vago para um projeto de doutorado, foi necessário descrever melhor as questões a serem respondidas e especificar quem serão os beneficiados com os resultados da pesquisa.

O setor de telecomunicações é muito dinâmico e está em profunda transição, o que determinará as configurações tecnológicas e organizacionais futuras da área. Além disso, esse setor passou recentemente por uma fase de crescimento no país, proveniente da sua abertura e reestruturação. É preciso estabelecer o que pode ser feito nessa fase tão importante da história do setor para que haja crescimento tecnológico local. Um envolvimento significativo no desenvolvimento global de produtos e na geração de conhecimento hoje, pode influenciar fortemente na determinação dos papéis das subsidiárias locais nas redes das TNCs e a sua importância para todo o grupo. O tipo de inserção das unidades locais pode levar à melhoria - ou não - das atividades tecnológicas realizadas no país, sejam elas nas próprias empresas ou em centros de pesquisa / universidades locais. 
Os resultados obtidos podem ser úteis para análises governamentais, orientando a determinação de políticas, a priorização de investimentos na área de educação e a realização de financiamentos. O encaminhamento de recursos corretamente será possível a partir da identificação de fatores que indiquem como aumentar e fortalecer a participação das empresas ou subsidiárias brasileiras no Desenvolvimento Global de Produtos.

Este trabalho também pode ser útil para as empresas do setor de telecomunicações, uma vez que elas podem ter acesso a informações sobre os processos de desenvolvimento global de produtos no setor e sobre as estratégias gerais utilizadas pelos seus competidores.

A comunidade acadêmica também se beneficia com os resultados desta pesquisa. Duas são as áreas principais relacionadas especificamente a este trabalho: internacionalização no desenvolvimento de produtos (que engloba os segmentos de desenvolvimento de produtos e de estratégias de internacionalização usadas pelas empresas) e telecomunicações. A contribuição mais acentuada se deu na primeira área, especificamente em desenvolvimentos de produtos, com descrição mais detalhada dos processos de desenvolvimento global de produtos no setor e análise do envolvimento das subsidiárias brasileiras nele. As duas outras áreas - estratégias usadas pelas transnacionais e o setor de telecomunicações - foram investigadas de maneira menos aprofundada, mas, são também importantes para esta pesquisa, uma vez que conhecer os papéis internacionais das unidades distribuídas mundialmente foi interessante para generalizar os dados obtidos nos estudos de casos, e as particularidades do setor de telecomunicações foram importantes para melhor caracterizar os processos de desenvolvimento.

Ao desenvolver esta pesquisa, foi necessário organizar a teoria existente nas áreas de desenvolvimento global de produtos e de formação das equipes globais de DP, e analisar / descrever a participação das subsidiárias brasileiras nestas redes internacionais de desenvolvimento. Isso irá auxiliar a comunidade científica em trabalhos futuros. Além disso, o produto desta tese poderá facilitar a detecção e o entendimento de barreiras e facilitadores para a P\&D no Brasil, especificamente no 
setor de telecomunicações. A figura 2.1 mostra a estrutura geral deste trabalho e explicita os principais assuntos tratados.

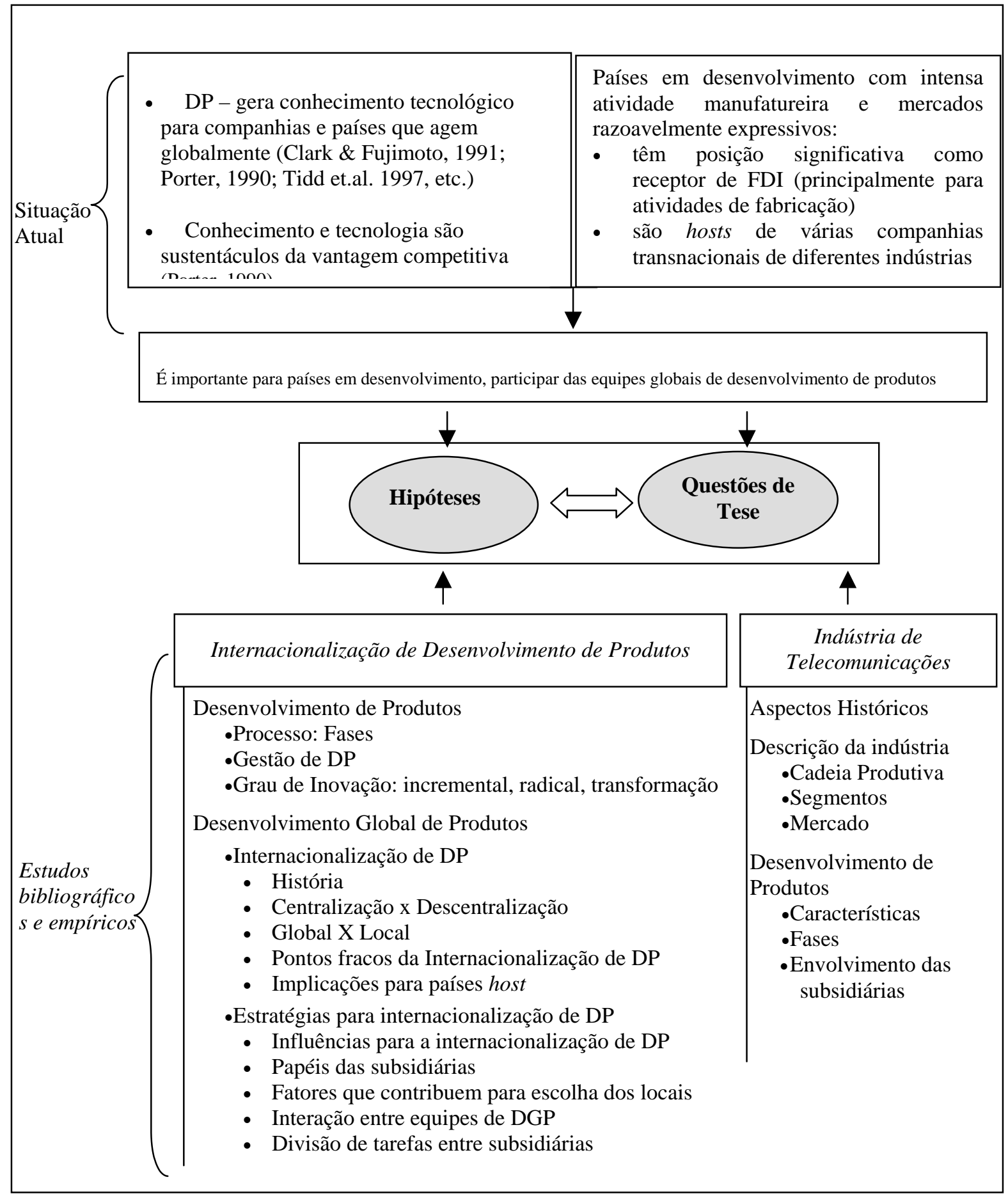

Figura 2.1- Estrutura geral do trabalho com principais áreas pesquisadas

As principais questões e hipóteses deste trabalho são originárias de estudos bibliográficos, estudos empíricos (casos realizados com empresas) e análise do 
cenário atual, que intensifica a importância da geração de conhecimento tecnológico para a garantia de competitividade de empresas e países.

\section{2- Objetivos Específicos (Hipótese e Questões de Tese)}

Para atender aos objetivos propostos será necessário responder algumas questões (Q) relevantes para o trabalho. Tais questões surgem a partir de afirmações ou premissas (P) baseadas na literatura e a partir de hipóteses $(\mathrm{H})$, algumas já respondidas através de estudos empíricos (estudos de campo).

A figura 2.2 apresenta um esquema que resume as questões, as premissas e as hipóteses desta tese, e as relações entre elas. Ela também mostra o sumário dos resultados encontrados. Vale destacar que, apesar de não apresentada explicitamente na figura 2.2, os resultados obtidos têm uma relação com as premissas levantadas da literatura, contribuindo para enriquecê-las ou contestá-las.

Baseada nas discussões sobre desenvolvimento de produtos no que se refere à centralização versus descentralização e à realização das atividades globalmente versus localmente, algumas pesquisas como as de Ronstadt (1977, 1982 e 1984), Behrman \& Fischer (1980), Reddy (1997, 2000), Subramanian (1998), UNCTAD (1999), entre outros, levam à primeira premissa (Premissa 1 - P1), de que a internacionalização de $P \& D$ é inevitável e as equipes de desenvolvimento de produtos das empresas estão localizadas em unidades por todo o mundo.

Algumas pesquisas sobre envolvimento de subsidiárias no desenvolvimento tecnológico - Reddy (1997), UNCTAD (1999), Pearce (1997), Cantwell (1995), Granstrand et. al. (1992); Casson (1991), afirmam que as atividades de desenvolvimento de produtos nos países em desenvolvimento são relacionadas principalmente a atividades para adaptação ou desenvolvimento de produtos ao mercado local. Daí surge a premissa 2 (Premissa 2 - P2).

Essas afirmações levaram à questão primordial deste trabalho: "O Brasil tem participação no desenvolvimento global de produtos do setor de telecomunicações?" (Questão 1 - Q1). 


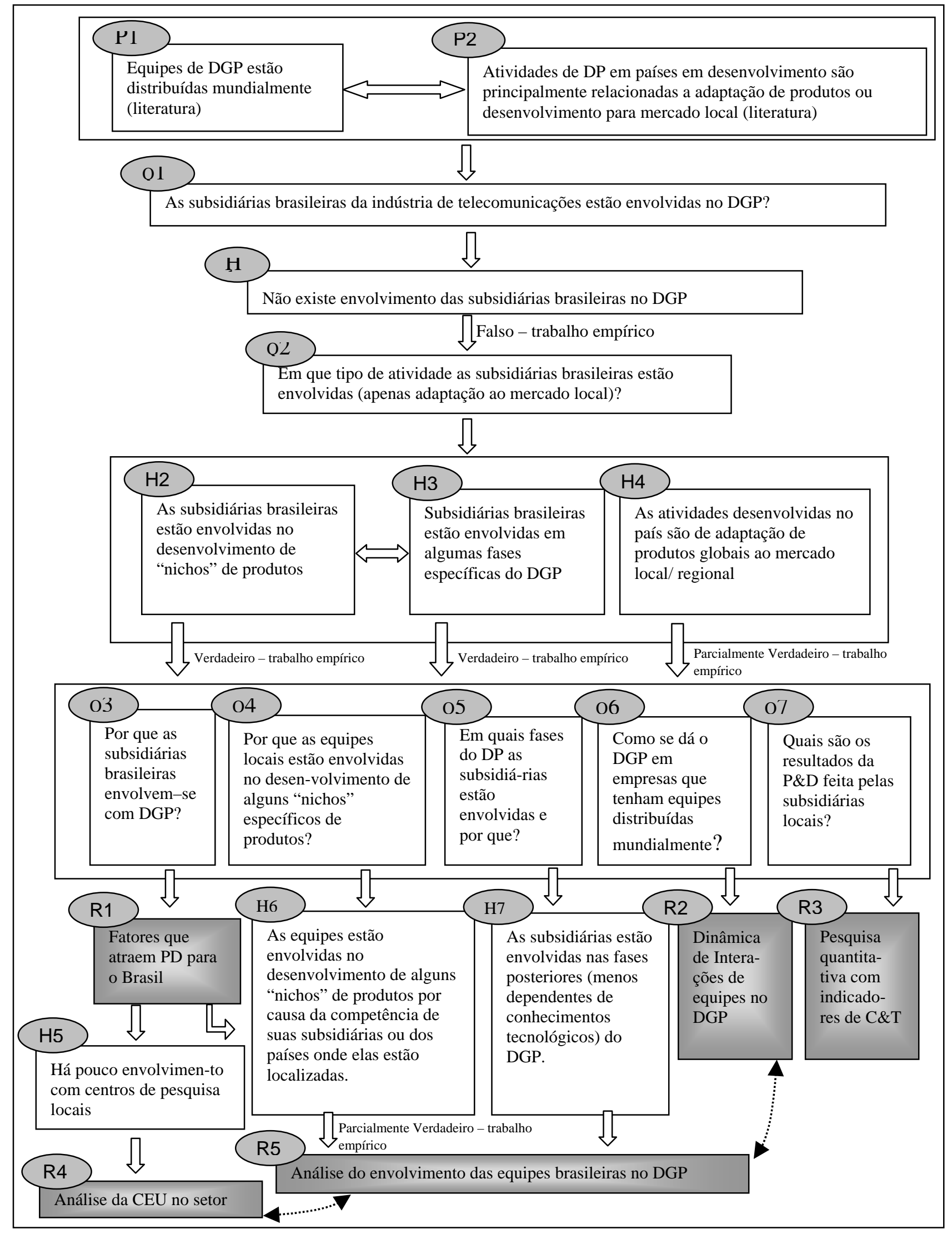

Figura 2.2- Relações entre Premissas, Questões, Hipóteses e Resultados da Tese 
Ou seja, as subsidiárias brasileiras das empresas transnacionais do setor de telecom especificamente os fornecedores de equipamentos para a indústria de telecomunicações, que atualmente são os principais responsáveis pelo desenvolvimento tecnológico no setor - estão envolvidas no desenvolvimento global de produtos? A partir dessa questão e considerando a premissa 1, de que atividades de DP em países em desenvolvimento são principalmente relacionadas a adaptação de produtos ou desenvolvimento para mercado local, uma hipótese foi criada: Não existe envolvimento das subsidiárias brasileiras no DGP. (Hipótese 1 - H1).

Essa hipótese não foi validada. Através dos estudos de casos realizados, foi possível verificar que as unidades das empresas localizadas no Brasil estavam envolvidas em alguns projetos de DGP. Assim, uma outra questão foi formulada: Em que tipo de atividades as subsidiárias locais são envolvidas? (Questão 2 - Q2).

A partir dessa questão e de informações oriundas das entrevistas iniciais com empresas, três hipóteses foram criadas e posteriormente verificadas e validadas através de trabalho de campo:

- As empresas transnacionais localizadas no Brasil estão envolvidas no DGP de alguns nichos / categorias específicos de produtos da indústria de telecomunicações. (Hipótese 2 - H2)

- As subsidiárias brasileiras estão envolvidas em fases específicas no desenvolvimento de alguns nichos específicos de produtos. (Hipótese 3 - H3)

- As equipes brasileiras apenas estão envolvidas para regionalização / adaptação local dos produtos desenvolvidos no exterior (Hipótese 4 - H4)

As principais questões provenientes dessas hipóteses são:

- Em que circunstâncias ou com que objetivos as empresas TNC envolvem equipes brasileiras no desenvolvimento de produtos? Ou seja, por que as subsidiárias localizadas no Brasil envolvem-se com DGP? (Questão 3 - Q3)

- Por que as equipes locais estão envolvidas no desenvolvimento de alguns nichos / 
categorias de produtos e não estão participando de outros? (Questão 4 - Q4)

- Em quais fases do desenvolvimento de produtos as subsidiárias brasileiras estão envolvidas e por que? (Questão 5 - Q5)

- Como se dá o desenvolvimento global de produtos em empresas que tenham equipes distribuídas mundialmente, especialmente empresas que tenham desenvolvimento aqui no Brasil? (Questão 6 - Q6)

- Quais são os resultados obtidos com a P\&D realizada no país pelas subsidiárias das empresas estudadas? Isso pode implicar na verificação do tipo de pesquisa feita no país, ou seja, é possível verificar se de fato as equipes brasileiras apenas estão envolvidas para adaptação dos produtos ou participam no desenvolvimento de novos produtos, gerando conhecimento local? (Questão 7 - Q7)

Essas questões foram trabalhadas, o que levou aos resultados desenvolvidos neste trabalho de doutorado. A resposta à questão 3 levou a um resultado (Resultado 1 $\mathrm{R} 1$ ), que engloba um conjunto de fatores que atraem as atividades de pesquisa para determinados locais, ou seja, os critérios que as empresas analisam quando estão definindo o local em que as atividades de $\mathrm{P} \& \mathrm{D}$ serão realizadas ou as vantagens das regiões/locais que influenciam a tomada de decisão relacionada à distribuição internacional de $\mathrm{P} \& \mathrm{D}$. O Resultado 1 corrobora com a Premissa 1, incorporando à literatura na área de internacionalização de $\mathrm{P} \& \mathrm{D}$, características de países em desenvolvimento, especialmente o Brasil.

Desses resultados, especialmente dos incentivos fiscais existentes no Brasil para a realização de P\&D local, uma outra hipótese foi identificada: Existe envolvimento de centros de pesquisa e universidades locais no desenvolvimento global de produtos realizado por essas empresas, mas ele ainda não é muito comum (Hipótese 5 - H5). A obrigatoriedade de ter envolvimento entre empresa e universidades ou centros de pesquisa exigida pela lei de informática levou a um crescimento das parcerias entre eles, mas as próprias empresas reconhecem que elas são pequenas e estão melhorando. Na tentativa de investigar a hipótese 5, chegou-se a um estudo da 
Cooperação entre Empresa-Universidade (CEU) para as companhias estudadas neste trabalho.

A partir da questão 4, uma nova hipótese é criada: As equipes estão envolvidas no desenvolvimento de alguns "nichos" de produtos porque as suas subsidiárias ou os países onde elas estão localizadas possuem competências na área (Hipótese 6 - H6).

O questionamento sobre as fases do desenvolvimento de produtos em que há envolvimento das subsidiárias brasileiras (Q5), levou à uma outra hipótese, a de que as subsidiárias não estão envolvidas nas fases iniciais de desenvolvimento, ou seja, naquelas de concepção dos produtos, elas se envolvem mais nas etapas posteriores do Desenvolvimento Global de Produtos ou naquelas menos dependentes de conhecimentos tecnológicos ou de pesquisa básica (Hipótese 7 - H7).

O estudo baseado nas hipóteses 6 e 7 proporcionou uma análise do envolvimento das equipes de desenvolvimento de produtos pertencentes às subsidiárias brasileiras no DGP (Resultado 5 - R5). Esse resultado contribuiu para contradizer a premissa 2, colaborando assim com o crescimento da pesquisa existente na área de internacionalização de $\mathrm{P} \& \mathrm{D}$ em países em desenvolvimento, assim como os Resultados 2 e 3.

A questão 6 está diretamente relacionada à área de pesquisa em internacionalização de desenvolvimento de produtos, e gerou uma contribuição para ela: o modelo de interações de equipes no DGP (Resultado 2 - R2). Através desse modelo, apresentado no capítulo 7, é possível analisar as estruturas de trabalho, através das quais as equipes de desenvolvimento de produtos se organizam e trocam conhecimento internacionalmente. Essa avaliação (resultado 2) está bastante relacionada às análises feitas para o envolvimento brasileiro no DGP (resultado 5).

Apesar da evidência da participação brasileira no DGP em alguns nichos de algumas companhias levantadas pelas questões Q1 e Q4 e comprovadas pelas respostas às hipóteses H1, H6 e pelo resultado R1, é preciso, de alguma forma, avaliar o tipo de envolvimento que as companhias localizadas no Brasil, abordadas nesta pesquisa, têm com seus pares internacionais e a relevância da $\mathrm{P} \& \mathrm{D}$ realizada no país. Isso para 
que sejam analisados os efeitos das atividades de desenvolvimento tecnológico realizadas para as empresas e principalmente para o país (Questão 7). Uma maneira de fazer isso, e que foi abordada neste trabalho, é através de um levantamento dos resultados de P\&D através de indicadores de Ciência e Tecnologia (C\&T).

O resultado desse levantamento (Resultado 3 - R3) é apresentado no capítulo 8 e trata de uma pesquisa quantitativa com dois dos principais indicadores de C\&T utilizados para tais avaliações: patentes e dados bibliométricos. Assim, verifica-se, de uma maneira mais geral, tanto os resultados de pesquisas feitas quanto os de desenvolvimento específico de produtos, englobando as duas facções de P\&D. Além desses dados levantados e analisados, a pesquisa quantitativa também é composta por análise de dados secundários, especialmente os levantados pela PINTEC (IBGE, 2002) e ANPEI (ANPEI, 1999).

O resultado referente a fatores de atração de P\&D para o país (R1) é apresentado no capítulo 6. Os resultados referentes às análises da participação brasileira no DGP (R2, R4, R5) são mostrados no capítulo 7. 


\section{Capítulo 3}

\section{Metodologia da Pesquisa}

Para atender aos objetivos deste trabalho, descritos no capítulo anterior, foi necessária a realização de um estudo para observar e analisar as variações do desenvolvimento global de produtos, ou seja, foi preciso saber como se dá o desenvolvimento global de produtos trabalhando com cada uma das questões levantadas. Para responder questões como as levantadas nesta pesquisa ${ }^{7}$, é aconselhável a utilização de estudos de casos (Yin, 1994).

Além das características dessas questões da tese, o caráter da pesquisa é descritivo, com o intuito de analisar / descrever a participação das subsidiárias brasileiras nestas redes internacionais de desenvolvimento. Essa característica da pesquisa está relacionada à análise contemporânea da situação e à ausência de influência/controle do pesquisador, tornando o estudo de caso um método apropriado para essa investigação (Yin, 1994).

Será utilizada a metodologia de múltiplos casos, que permite identificar a natureza específica das rotinas de Desenvolvimento Global de Produtos e os fatores que as influenciam. Além de possibilitar a análise das formações das equipes de desenvolvimento de produtos.

\footnotetext{
7 Perguntas que questionam "como" e "por que" podem ser bem analisadas com estudos de casos (Yin, 1994, pp. 6). As questões são apresentadas no capítulo 2.
} 
Essa metodologia emprega técnicas comparativas, permitindo a construção do conhecimento indutivamente a partir dos dados colhidos e analisados, ao invés de dedutivamente pela extensão e teste de teoria determinada previamente. Enquanto a teoria existente pode ser útil para conduzir à generalização das observações, os dados serão a principal fonte de entendimento ou de geração de conhecimento neste trabalho (Eisenhardt, 1989).

Os estudos de caso serão a base para a coleta dos dados relevantes para a pesquisa. Foram feitas entrevistas pessoais semi-estruturadas com questões abertas, que foram criadas com base em temas levantados a partir da revisão bibliográfica.O questionário utilizado nas entrevistas realizadas nas subsidiárias brasileiras das empresas transnacionais encontra-se no apêndice.

Em cada empresa foram entrevistados funcionários de duas ou mais áreas, que tivessem algum relacionamento com o desenvolvimento tecnológico. Pelo teor das questões, que exigem conhecimentos estratégicos e gerais da companhia, procurou-se trabalhar com pessoas que ocupem cargos de nível alto nas companhias. Sendo assim, foram entrevistados gerentes ou diretores das áreas de $\mathrm{P} \& \mathrm{D}$, engenharia e produção (essa última, em menor número).

Além de estudos de casos com empresas, estão sendo entrevistados alguns centros de pesquisa nacionais, para avaliar os projetos de $\mathrm{P} \& \mathrm{D}$ realizados entre eles e as empresas, alavancados principalmente pela lei de informática. Esses convênios são intermediados, em geral, por fundações que se responsabilizam por tarefas administrativas. Estudar os centros de pesquisa nos permite confirmar algumas das informações fornecidas pelas empresas e verificar se está havendo disseminação de conhecimento tecnológico ${ }^{8}$.

A metodologia de estudos de caso como método de pesquisa tem sido usada e defendida por diversos autores, mas ela recebe algumas críticas no que se refere à sua confiabilidade para pesquisa acadêmica e generalização de resultados. A questão da confiabilidade pode ser resolvida com uma determinação cuidadosa das perguntas de pesquisa, das suas proposições, do relacionamento entre os dados e as proposições e

\footnotetext{
${ }^{8}$ Em resposta à questão 7 da tese, citada na seção 2.2 .
} 
dos critérios de interpretação a serem utilizados (Yin, 1994). Os problemas relacionados à generalização dos dados podem ser solucionados através do estudo de múltiplos casos (Stake, 1994). Dessa forma, embasada na teoria metodológica, este trabalho de pesquisa procurou através de estudos múltiplos de casos, fazer o levantamento de dados, o confronto com a teoria existente na área e a análise dos resultados da situação problema.

Essa foi a metodologia empregada na parte qualitativa deste trabalho. No entanto, a questão 7, "Quais são os resultados da P\&D feita pelas subsidiárias locais?” somente pode ser analisada e respondida com um levantamento de dados quantitativos. Esse estudo foi feito através de dois indicadores de ciência e tecnologia: patentes e dados bibliométricos. Para o levantamento de dados de patentes utilizou-se a base do INPI (Instituto Nacional de Propriedade Intelectual) e para analisar a participação brasileira nas patentes requeridas internacionalmente usou-se a base do USPTO (United States Patent and Trademark Office). Os dados bibliométricos são provenientes do SCI (Science Citation Index), editado pelo ISI (Institute for Scientific Information).

\subsection{A Escolha do Setor e dos Casos/Amostra}

Para os casos, as empresas escolhidas (tabela 3.1) são transnacionais, possuem Desenvolvimento Global de Produtos e têm presença no Brasil. São empresas do setor de telecomunicações e são as maiores no seu segmento presentes no Brasil (Anuário Telecom, 2001).

A escolha do setor de telecomunicações deu-se por algumas razões, entre elas está o fator histórico, ou seja, o país tem uma história de relativo sucesso na área, com incentivos e investimentos em pesquisa ${ }^{9}$, que colaboraram para a capacitação e o desenvolvimento de competências. Esperava-se, com a pesquisa, verificar a real capacitação do setor no país e as chances de ter-se as equipes nacionais envolvidas no desenvolvimento global de produtos das grandes TNCs.

\footnotetext{
${ }^{9}$ Melhor apresentado no capítulo 5 deste trabalho.
} 


\begin{tabular}{|l|l|l|}
\hline \multicolumn{1}{|c|}{ Empresa $^{*}$} & \multicolumn{1}{c|}{ Nacionalidade } & \multicolumn{1}{c|}{ Produtos de Telefonia Relevantes no Brasil } \\
\hline Alcatel $^{(8)}$ & Francesa & Centrais Telefônicas \\
\hline Ericsson & \\
\hline Lucent $^{(6)}$ & Sueca & $\begin{array}{l}\text { Centrais Telefônicas; Estações Rádio-Base, Terminais } \\
\text { celulares }\end{array}$ \\
\hline Motorola $^{(3)}$ & Norte-americana & Centrais Telefônicas; Estações Rádio-Base \\
\hline NEC $^{(5)}$ & Norte-americana & $\begin{array}{l}\text { Estações Rádio-Base; Terminais celulares e fixos, } \\
\text { semicondutores }\end{array}$ \\
\hline Nokia $^{(2)}$ & Japonesa & Centrais Telefônicas; Estações Rádio-Base \\
\hline Siemens & Finlandesa & Terminais celulares \\
\hline * Entre parênteses, a posição da empresa, segundo Anuário Telecom (2001) & Alemã & Centrais Telefônicas; Estaç̃̃es Rádio-Base \\
\hline
\end{tabular}

Tabela 3.1- Empresas estudadas e os principais produtos enfocados na pesquisa

Mas a principal razão que contribuiu para sua escolha foi o crescimento do setor nos últimos anos e a sua relevância no mundo globalizado. Quando este trabalho teve início, o setor de telecomunicações foi dos que mais cresceram no Brasil. Segundo o IBGE (IBGE, 2000), o crescimento foi de 17,21\% nos três primeiros trimestres do ano de 2000.

Entre os diversos segmentos do setor de telecomunicações ${ }^{10}$, foram enfocados os fabricantes de equipamentos porque são eles os principais responsáveis pelo desenvolvimento de tecnologia para o setor. No capítulo 5, isso é apresentado e discutido em profundidade. Além disso, foram enfocados para o estudo, os fabricantes de produtos de telefonia (fixa e móvel) porque, no país, essa é a área em cujo desenvolvimento tecnológico o Brasil estaria mais envolvido, principalmente por questões históricas.

Vale destacar que o setor de telecomunicações é extremamente dinâmico e que, qualquer estudo na área pode correr o risco de ficar obsoleto rapidamente, portanto, por prudência, tentou-se, neste trabalho, ficar o mais isento possível das mudanças ocorridas no setor enquanto da realização dos levantamentos e análises de dados, mas, obviamente, essa é uma tarefa difícil.

\footnotetext{
${ }^{10}$ Descritos na seção 5.3.
} 
Sendo assim, este trabalho de pesquisa analisou as companhias selecionadas para amostra em duas etapas - conforme citado na seção subseqüente, no intuito de responder objetivamente às questões e hipóteses levantadas nesta tese (apresentadas no capítulo 2) e de levantar as características determinantes do comportamento das empresas e do setor, tentando ser objetivo para que as mudanças do setor em decorrência do seu dinamismo influenciassem o mínimo possível os resultados.

Uma vez que o setor já é um limitador dos tipos de casos e a obtenção dos dados nos estudos de caso é de fundamental importância para o sucesso desta pesquisa, foi necessário que a metodologia de trabalho possibilitasse maior generalização da área estudada para que os resultados fossem os melhores possíveis.

Sendo assim, procurou-se trabalhar com produtos que tivessem chances de levar a diferenciados resultados em termos de integração para o desenvolvimento global. $\mathrm{Ou}$ seja, as empresas escolhidas deveriam compreender características diferenciadas que abrangessem configurações diferentes para que os resultados sejam os mais amplos possíveis. Uma maneira de escolher os casos e as áreas dentro das empresas a serem estudados foi através da estrutura Integração-Receptividade (I-R) desenvolvida por Prahalad e Doz (1987) e utilizada por outros pesquisadores como Bartlett e Ghoshal (1992), que fizeram um estudo de caso com nove companhias, entre elas, três do setor de telecomunicações.

A estrutura Integração-Receptividade, apresentada na seção 4.1, procura diferenciar as ações das empresas em relação à globalização ou à regionalização para o desenvolvimento dos produtos, considerando as características e necessidades dos produtos. A estrutura I-R foi um objeto de auxílio na escolha das empresas, dos setores a serem estudados nas companhias, e na organização da pesquisa, como pode ser visto na diferenciação dos produtos entre os diversos casos mostrada na tabela 3.1 .

As divergências entre os produtos desenvolvidos pelas empresas estudadas com relação às necessidades globais e locais podem orientar diferentemente as estratégias de integração entre subsidiária e matriz. Isso possibilita o estudo em uma mesma 
empresa de ações diferenciadas dependendo do produto e da sua estratégia. Fazer o estudo sob esse corte é uma maneira de deixar o trabalho mais generalizado para a obtenção dos objetivos propostos.

Portanto, em cada empresa, procurou-se estudar, à medida do possível, as áreas de desenvolvimento de centrais telefônicas, estações radio-base, aparelhos celulares, e até serviços de integração ${ }^{11}$. Para os produtos estudados, analisou-se o desenvolvimento de software e de hardware, caso existisse.

\section{2- Instrumentos Utilizados nos Estudos de Casos com as Empresas}

Para os estudos de casos feitos com as subsidiárias, foram realizadas entrevistas semi-estruturadas orientadas por um questionário com questões referentes a estratégias de desenvolvimento de produtos, interface com universidades e centros de pesquisa, aquisição de tecnologia e um pouco sobre fabricação local de produtos desenvolvidos ou não com a unidade local.

O questionário foi elaborado para ser respondido por profissionais que tenham grande envolvimento com as áreas de desenvolvimento de produtos e que possuam conhecimento abrangente dos processos de desenvolvimento e das estratégias da companhia nessa área. As respostas a alguns dados precisaram da colaboração de outros funcionários, especialmente os relacionados à fabricação de produtos. Algumas perguntas foram respondidas antes da realização da entrevista e foram apenas conferidas com o entrevistado.

As entrevistas foram realizadas em duas etapas, a primeira aconteceu no ano de 2000, quando o setor estava numa fase de crescimento acentuado, e a segunda foi feita em 2002, após a turbulenta fase pela qual passou toda a área de telecomunicações no Brasil e no mundo ${ }^{12}$. Foram realizadas, ao todo, 24 entrevistas, conforme tabela 3.2 .

A coleta de dados não se deu apenas através de entrevistas, também foram utilizadas

\footnotetext{
${ }^{11}$ Área em que vem crescendo a participação das empresas fornecedoras de equipamentos para telecomunicações, conforme discutido no capítulo 5 deste trabalho.

${ }^{12}$ No capítulo 5 é feita uma descrição mais aprofundada sobre a crise do setor no ano de 2001.
} 
fontes documentais como artigos publicados na imprensa especializada e relatórios e documentos internos das empresas. Além da confirmação de informações com alguns institutos de pesquisa parceiros das empresas, conforme mencionado anteriormente.

\begin{tabular}{|c|c|c|c|c|}
\hline$\underbrace{\text { Setor Entrevistado }}_{\text {Empresa }}$ & $\mathbf{P} \& \mathbf{D}^{\#}$ & Produção & Outros & Total \\
\hline Alcatel & 2 & & 1 (Financ.) & 2 \\
\hline Ericsson & 4 (2-matriz) & 1 & $\begin{array}{l}1 \text { (Sistemas) } \\
1^{*}\end{array}$ & 6 \\
\hline Lucent & 2 & & 1 (Engenh.) & 3 \\
\hline Motorola & 3 & 1 & $1^{* *}$ & 5 \\
\hline NEC & 1 & 1 & 1 (Planejam.) & 3 \\
\hline Nokia & 2 & 1 & 1 (Engenh.) & 4 \\
\hline Siemens & 3 & & & 3 \\
\hline \multicolumn{5}{|r|}{24} \\
\hline $\begin{array}{l}\text { \# Compreende as áreas de } \\
\text { * Responsável pela subsi } \\
\text { ** Da área de relaçôes go }\end{array}$ & $\begin{array}{l}\text { esquisa, Desen } \\
\text { iria brasileira na } \\
\text { rnamentais }\end{array}$ & & & \\
\hline
\end{tabular}

Tabela 3.2 - Entrevistas realizadas nas empresas

Fazendo um comparativo entre os objetivos traçados para este trabalho e as questões propostas nesta tese, é possível analisar o questionário, verificando como ele orienta o trabalho para alcançar o esperado.

A seção de desenvolvimento de produtos permite conhecer o investimento das empresas em P\&D local. É possível descrever o processo de desenvolvimento da transnacional, envolvendo as subsidiárias, bem como saber as fases do DP em que o equipes do Brasil participam e as integrações existentes com centros de pesquisa locais. Tais respostas ajudaram, a princípio, a levantar as hipóteses, como foi citado no capítulo anterior. Essa parte do questionário também permitiu responder às questões de número $1,2,3,4,5$ e 7.

A parte com questões relacionadas ao desenvolvimento global de produtos foi útil para discutir mais profundamente as estratégias da TNC no envolvimento da 
subsidiária brasileira e as barreiras no desenvolvimento de produtos no país. A seção de desenvolvimento tecnológico e treinamento permitiu descobrir como é feito o desenvolvimento de processos e responder a questão 6 .

A escolha das instituições de pesquisa para se avaliar os trabalhos realizados conjuntamente com as empresas foi feita considerando-se, principalmente, a importância delas para a área de telecomunicações, o grau de envolvimento com as empresas e a facilidade de acesso a essas unidades. Além disso, foram consideradas as instituições conveniadas ao Ministério de Ciência e Tecnologia e que, segundo dados do próprio Ministério (MCT, 2000), mais recebem investimentos em P\&D. Sendo assim, os centros / instituições de pesquisas selecionados para estudo são: CPqD, USP (Escola Politécnica), Informat.

\section{3- Estudo Quantitativo}

Como mencionado anteriormente, para o trabalho quantitativo, pesquisou-se dados de patentes nacionais e internacionais, e dados bibliométricos. Os mesmos levantamentos foram feitos para outros países em desenvolvimento que competem diretamente com o Brasil no setor de telecomunicações: China, Índia e Israel.

As consultas às bases de dados de patentes, em ambos as organizações - USPTO e INPI - foram feitas através das informações disponibilizadas na internet. Em ambas, as informações contemplavam os últimos dez anos, período escolhido para a pesquisa. Procurou-se comparar os cinco primeiros anos da década passada (1991 a 1995) com os últimos cinco anos (1996 a 2000), quando aconteceram importantes mudanças na área, como a entrada de novas tecnologias de comunicação e o fortalecimento da telefonia celular. Especificamente no Brasil, esse foi um período de grande reestruturação depois da privatização do sistema Telebrás em 1998, com a entrada de novas empresas fornecedoras de equipamentos e o fortalecimento das já estabelecidas no país. 
Geralmente, quando uma empresa transnacional solicita patentes internacionais, significa que o produto patenteado, obviamente é inovador e relevante para a companhia, assim como a equipe envolvida no processo de inovação. A participação de funcionários ligados a alguma subsidiária na equipe pode ser um indício de que há envolvimento entre tal subsidiária e a rede global de desenvolvimento tecnológico da TNC.

Para análise de patentes internacionais, foi escolhida a base do USPTO pois o sistema norte-americano é o que faz o maior número de registro de patentes de empresas estrangeiras do mundo, daí sua relevância. Os dados sobre patentes disponíveis para consulta na base do USPTO são bem mais detalhados do que os provenientes da base disponibilizada pelo INPI. Isso implica numa flexibilidade muito maior da base norte-americana se comparada à brasileira, o que significa que no USPTO é possível fazer diferentes tipos de consultas e receber um conjunto de dados mais específico do que através do INPI.

Por outro lado, a consulta à base de dados de patentes domésticas foi fundamental para os resultados desta pesquisa. Isso porque ela possui uma quantidade muito maior de dados relevantes a serem tratados aqui e, por isso, possibilita uma análise mais fundamentada e, em conjunto com os resultados dos estudos de casos, conclusões mais aprofundadas.

Um outro indicador escolhido para medir o envolvimento entre matrizes e subsidiárias brasileiras se refere a dados bibliométricos, ou seja, quantidade de artigos científicos publicados em periódicos de destaque. Vale citar que, enquanto as patentes estão ligadas a pesquisa aplicada e desenvolvimento experimental (para posterior produção e comercialização do produto), as publicações científicas geralmente se referem a pesquisa básica e aplicada. Dessa forma, com esses dois indicadores de resultados de C\&T, cobre-se todos os tipos de atividades realizadas em P\&D (OECD, 1994).

As consultas aos dados bibliométricos do ISI foram feitas também através da base de dados disponível na internet. O SCI é multidisciplinar e compreende cerca de 5300 periódicos relacionados a ciências humanas, meio ambiente, tecnologia e 
medicina. Além disso, ele é a base multidisciplinar que compreende o número mais significativo de publicações da América Latina. Em 1997, as publicações da região representaram 2,3\% do total das publicações registradas no SCI (RICYT, 1999).

Para qualquer um dos indicadores selecionados, os dados encontrados para a participação do Brasil serão confrontados com os dados de outros países em desenvolvimento, cujas subsidiárias foram amplamente citadas nos estudos de casos como participantes do desenvolvimento de produtos, tornando-se as principais concorrentes das subsidiárias brasileiras. Em geral, as unidades localizadas na Índia e em Israel competem com as unidades brasileiras em desenvolvimento de software e as da China em hardware. 


\section{Capítulo 4}

\section{A Globalização e o Desenvolvimento de Produtos}

\section{1- Globalização}

A globalização tem sido discutida amplamente e sob vários aspectos porque ela se faz sentir em diversas áreas (Baumann, 1996): financeira, com aumento de volume e de velocidade de circulação de recursos; comercial, caem barreiras do comércio internacional e cresce a homogeneidade da estrutura de oferta em diferentes regiões; produtiva, com a redefinição dos modelos de produção a partir de perspectivas para mercados globais e convergência das características do processo produtivo; institucional, pela convergência dos requisitos de regulamentação, levando a homogeneidade entre países; econômica, com perda de diversos atributos de soberania econômica e política por parte de um número crescente de países.

Entre esses aspectos, o que mais importa para esta pesquisa é o produtivo. A partir de trabalhos de autores como Dunning (1994), Shi \& Gregory (2000), Bartlett \& Ghoshal (1992) e outros, é possível traçar um panorama cronológico sobre a atuação global das companhias. As empresas atuam internacionalmente há algum tempo, mas com algumas mudanças importantes de comportamentos. Nas últimas décadas, as diferenças intensificaram-se. Na década de 60, a principal atividade mundial era relacionada a exportação, seja de produtos finais ou de componentes para montagens simplificadas de produtos para os mercados nacionais/regionais. A partir da década 
de 70, a construção de fábricas em países estratégicos começou a ser feita para melhorar o desempenho das unidades locais e dos produtos.

A concorrência acirrada dos anos 80 pressionou as empresas para uma internacionalização da produção mais acentuada, mas ainda não tão ajustada como a que foi vista na década de 90, quando as atividades produtivas mostram-se bastante integradas mundialmente, ou seja, as empresas "passam a ser descritas como coordenadoras de uma rede de atividades inter-relacionadas para adição de valores" (Dunning, 1994, p. 28).

Uma das questões que emerge de trabalhos feitos sobre globalização produtiva é a da coordenação da distribuição das subsidiárias e a dos papéis de cada unidade produtiva no exterior. Existem diversas abordagens para ambas, que são tratadas nas próximas seções deste trabalho.

A importância desse assunto para esta pesquisa se dá porque, entre as atividades da companhia distribuídas globalmente, estão as de desenvolvimento tecnológico, e a coordenação das unidades envolvidas com o desenvolvimento é fundamental para entender as estratégias de distribuição das atividades e conseqüentemente a inserção das subsidiárias brasileiras neste desenvolvimento.

\subsection{1- Distribuição de Subsidiárias Globalmente}

$\mathrm{Na}$ literatura, existem várias classificações para as companhias que atuam globalmente, ou seja, que possuam atividades localizadas fora dos seus países. Bartlett e Ghoshal (Bartlett; Ghoshal, 1989) classificam as empresas com atuação global da seguinte forma (Tabela 4.1):

- Multinacionais (MNC) - trabalham com toda a cadeia produtiva num outro país, com unidades independentes umas das outras; criam forte presença local através de sensibilidade e receptividade às diferenças nacionais.

- Global - são muito mais centralizadas em suas decisões operacionais e estratégicas do que as MNC; obtém vantagem competitiva em termos de custos 
através de operações centralizadas em escala global; tratam o mercado mundial como um todo integrado.

- Internacional - exploram conhecimentos e recursos da matriz através da difusão e adaptação mundiais; a matriz possui influência e controle consideráveis, mas menos do que em uma companhia global; as unidades nacionais podem adaptar produtos e idéias da matriz, mas com menos autonomia que as MNC.

- Transnacionais (TNC) - integram processos globalmente, otimizando-os, racionalizando recursos, eliminando redundâncias, atuando com produtos globais; buscam eficiência para alcançar a competitividade global; vêem a receptividade local como ferramenta para obter flexibilidade nas operações internacionais; vêem as inovações como resultado de um processo que engloba vários membros da companhia.

\begin{tabular}{|c|c|c|c|c|}
\hline $\begin{array}{l}\text { Atuaçao } \\
\text { Garacterística Global } \\
\text { Prganizacional }\end{array}$ & Multinacional & Global & Internacional & Transnacional \\
\hline $\begin{array}{l}\text { Configuração de } \\
\text { ativos e } \\
\text { re ursos }\end{array}$ & $\begin{array}{l}\text { Descentralizada } \\
\text { e auto-suficiente } \\
\text { nacionalmente }\end{array}$ & $\begin{array}{l}\text { Centralizada e } \\
\text { em escala global }\end{array}$ & $\begin{array}{l}\text { Fontes de } \\
\text { competências } \\
\text { básicas } \\
\text { centralizadas, } \\
\text { outras } \\
\text { descentralizadas }\end{array}$ & $\begin{array}{l}\text { Dispersa, } \\
\text { interdependente } \\
\text { e especializada }\end{array}$ \\
\hline $\begin{array}{l}\text { Papel das } \\
\text { subsidiárias no } \\
\text { exterior }\end{array}$ & $\begin{array}{l}\text { Sentir e explorar } \\
\text { as oportunidades } \\
\text { locais }\end{array}$ & $\begin{array}{l}\text { Implementar } \\
\text { estratégias da } \\
\text { matriz }\end{array}$ & $\begin{array}{l}\text { Adaptar e } \\
\text { alavancar } \\
\text { competências da } \\
\text { matriz }\end{array}$ & $\begin{array}{l}\text { Contribuições } \\
\text { diferenciadas das } \\
\text { unidades } \\
\text { nacionais a } \\
\text { operações } \\
\text { mundiais } \\
\text { integradas }\end{array}$ \\
\hline $\begin{array}{l}\text { Desenvolvimento } \\
\text { e difusão do } \\
\text { onhe imento }\end{array}$ & $\begin{array}{l}\text { Conhecimento } \\
\text { desenvolvido e } \\
\text { mantido em cada } \\
\text { unidade }\end{array}$ & $\begin{array}{l}\text { Conhecimento } \\
\text { desenvolvido e } \\
\text { mantido no } \\
\text { centro }\end{array}$ & $\begin{array}{l}\text { Conhecimento } \\
\text { desenvolvido no } \\
\text { centro e } \\
\text { transferido para } \\
\text { as unidades no } \\
\text { exterior }\end{array}$ & $\begin{array}{l}\text { Conhecimento } \\
\text { desenvolvido em } \\
\text { conjunto e } \\
\text { compartilhado } \\
\text { em todo o mundo }\end{array}$ \\
\hline
\end{tabular}

Tabela 4.1 - Características Organizacionais das companhias Multinacionais, Globais, Internacionais e Transnacionais (Bartlett; Ghoshal, 1989) 
As diferenças entre essas classes podem ser sutis, e, muitas vezes, uma empresa pode ter comportamentos semelhantes a mais de uma delas. Para facilitar a comparação entre os tipos de atuação global, a tabela 4.1 traz um resumo das características organizacionais das empresas Multinacionais, Globais, Internacionais e Transnacionais. A característica "Desenvolvimento e difusão do conhecimento" pode ser a mais claramente distinta, nas demais, as diferenças são menos perceptíveis, por exemplo, o "papel da subsidiária no exterior" de uma MNC - explorar oportunidades locais - é também comum à TNC e pode ser fundamental para a sobrevivência também das globais e das internacionais.

A influência na determinação da atuação global da empresa e a coordenação da distribuição das unidades possui enfoques diferenciados. A pesquisa desenvolvida por Bartlett e Ghoshal (1989) conclui que a origem da companhia - japonesa, americana e européia - é um importante fator para estabelecer a herança administrativa e, conseqüentemente, a forma de atuação internacional.

Segundo os autores, a coordenação centralizada é o processo dominante nas empresas japonesas. O processo de tomada de decisão é mais fortemente dependente da cultura e exige intensa comunicação. Sempre foi grande a dificuldade em transferir os processos para o exterior principalmente por causa do idioma e dos aspectos culturais de trabalho. Além disso, as companhias japonesas expandiram suas atividades primeiramente para os mercados asiáticos, onde os aspectos culturais são similares. Os autores afirmam ainda que atualmente as empresas japonesas estão tornando mais descentralizadas suas formas de gestão.

As empresas norte-americanas seguem um processo de coordenação baseado em sistemas, políticas e padrões formais. É um processo mais descentralizado, mas bastante formalizado. A formalização tende a diminuir o poder tanto da matriz quanto da subsidiária. A padronização da tomada de decisões pode ser eficiente para delegar responsabilidades e cobrá-las, mas pode, por outro lado, estar tirando a liberdade necessária ao processo de criação. Outro fator desfavorável é a dificuldade de se reproduzir, em países diferentes, as mesmas abordagens e políticas. 
As companhias européias começaram a internacionalizar-se numa época em que a comunicação era deficitária e os sistemas organizacionais pouco sofisticados, portanto a centralização não era viável e ainda não era possível utilizar as estruturas formais de forma eficiente. Sendo assim, tais empresas confiavam a administração das subsidiárias a membros da família, portanto criaram uma estrutura de coordenação fundamentada no relacionamento pessoal e baseada no desenvolvimento e aculturação dos responsáveis pelas decisões, abordagem chamada por Bartlett \& Ghoshal (1992) de socialização. Além disso, as empresas européias, por terem as matrizes localizadas em países pequenos, são, já de longa data, aculturadas a terem unidades fora de seus limites territoriais em função de vários fatores, por exemplo, a necessidade maior de mão-de-obra qualificada, a busca por novos e maiores mercados, etc.

A influência da origem da empresa na centralização ou não das atividades de $P \& D$ também é citada por outros autores. Fleury e Fleury (2000, p. 114) citam que "as empresas japonesas são as que tradicionalmente concentram suas atividades-chave, como P\&D, no Japão, tendendo a localizar nos países, mesmo os desenvolvidos, atividades mais operacionais. As empresas européias e americanas apresentam comportamentos diferenciados, dependendo do setor, em termos de localização das atividades-chave. As americanas, mais do que as francesas, preocupam-se em fortalecer a cultura corporativa, centralizando a definição de políticas de gestão de RH, que possibilitam reforçar os valores básicos da organização".

No entanto, Asakawa (2001), estudando cinco empresas multinacionais japonesas, afirma que "em contraste com várias MNCs norte-americanas, que não vêm benefício em internacionalizar suas atividades de pesquisa básica, as MNCs japonesas estudadas são estimuladas a fortalecerem a distribuição de pesquisa básica através de seus laboratórios mundiais" (Asakawa, 2001, p. 5).

Independentemente de como é feita e coordenada a internacionalização das empresas, elas têm propósitos similares quando decidem por atuar no exterior. Em geral, as organizações procuram com isso (Dunning, 1994): 
- Redução de custos - Aproveitar ao máximo os benefícios provenientes de cada país para reduzir custos de produção, seja com relação a matéria prima, mão de obra, organização logística, carga tributária, etc.

- Transposição de barreiras tarifárias - Atuar em um país ou bloco econômico/ comercial com as vantagens tarifárias das empresas locais.

- Construção de fontes fornecedoras - Explorar os recursos do país, desenvolvendo fornecedores para atuar não apenas nas subsidiárias locais, mas na organização como um todo.

- Aquisição de conhecimento com fornecedores, clientes e competidores locais.

- Aprendizado com centros de pesquisa - É necessário conhecer e desenvolver centros de pesquisa e desenvolvimento para que atuem em toda a companhia, para isso as empresas buscam "locais de excelência" em determinadas áreas de atuação.

- Atração de talentos humanos competentes.

\subsection{2- Papéis das Unidades Externas}

Seguindo os objetivos traçados ao atuarem globalmente, as organizações estruturamse com o intuito de obter o máximo das unidades no exterior. Para isso, as subsidiárias possuem papéis e responsabilidades estratégicos e são distribuídas mundialmente de tal forma que os recursos de cada país sejam explorados racionalmente. Várias são as classificações existentes para os papéis das subsidiárias das empresas globais (Bartlet \& Ghoshal, 1989; Birkinshaw, 1996; Ferdows, 1997; Gupta \& Govindarajan, 1991, 1995; Pearce \& Papanastassiou, 1996; Roth \& Morrison, 1992; UNCTAD, 1999 e outras), algumas serão tratadas a seguir.

Bartlett e Ghoshal (1992) desenvolveram um padrão, considerado por eles de "simplificado e vago", para as atitudes das companhias na diferenciação dos papéis e responsabilidades das suas unidades. A classificação é feita através da intersecção das considerações estratégicas e organizacionais, gerando quatro papéis genéricos 
que as organizações de cada país desempenham para satisfazer os objetivos globais da organização transnacionais.

Nessa classificação, mostrada na figura 4.1, a principal consideração estratégica é a importância dos ambientes nacionais para a estratégia global e a consideração organizacional fundamental é a competência da subsidiária nacional - em tecnologia, produção, marketing ou qualquer outra área. Dependendo da posição que ocupam nestas dimensões, as organizações nacionais (subsidiárias) podem ser:

- Líderes Estratégicas - são a força propulsora da inovação nas companhias transnacionais. Muitas das inovações locais são difundidas em toda a organização.

- Contribuidoras - têm potencial para promover os processos de inovação global, mas carecem de exposição a ambientes estimuladores.

- Buracos Negros - sensores vitais por estarem em locais estratégicos, mas não conseguem responder devido a limitações de recursos e competências.

- Implementadoras - são pobres no desafio ambiental e de aptidões organizacionais. Adotam e implementam as inovações centrais e globais de maneira eficiente, são capazes de representar as necessidades de seus mercados locais e fazer pequenas modificações necessárias nos produtos globais, mas não conseguem criar inovações para toda a companhia.

\begin{tabular}{|c|c|c|c|}
\hline \multirow{4}{*}{$\begin{array}{l}\text { Importância } \\
\text { Estratégica } \\
\text { do } \\
\text { Ambiente } \\
\text { Local }\end{array}$} & Alto & Buraco Negro & Líder Estratégica \\
\hline & Baixd & Implementadora & Contribuidora \\
\hline & & Baixo & Alto \\
\hline & & \multicolumn{2}{|c|}{$\begin{array}{l}\text { Nível de Recursos e } \\
\text { Aptidões Locais }\end{array}$} \\
\hline
\end{tabular}

Figura 4.1 - Papéis Genéricos das Organizações Locais (Bartlett e Ghoshal, 1992)

Uma outra classificação para estabelecer os papéis de cada fábrica no exterior foi desenvolvida por Ferdows (1997) e está baseada em 3 eixos principais na escolha dos 
papéis estratégicos das fábricas (Figura 4.2): acesso a baixo custo de produção (Offshore, Source), proximidade do mercado (Server, Contributor), e acesso a habilidades e conhecimento (Outpost, Lead). É possível, ao longo do tempo, alterar esses papéis das fábricas estrangeiras.

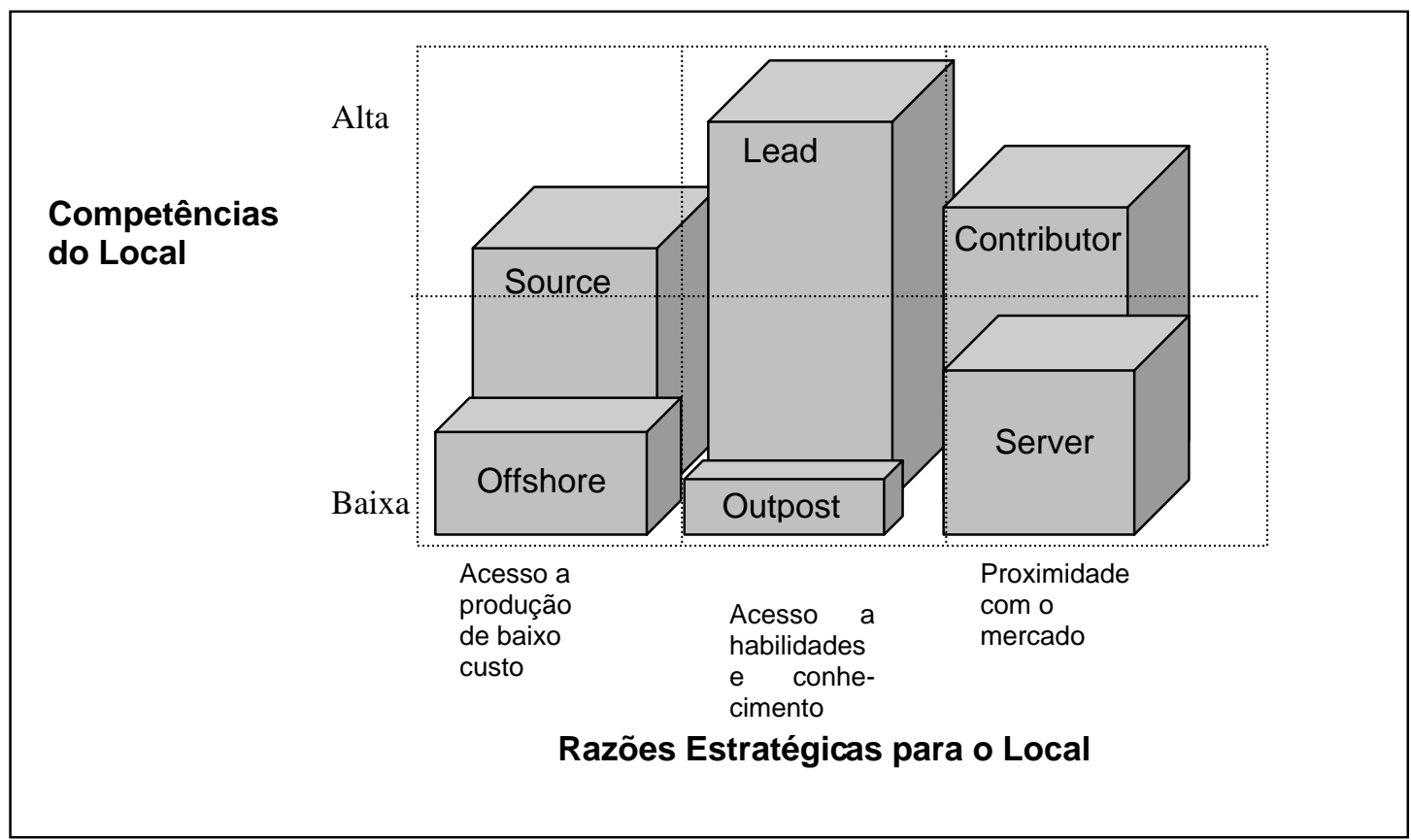

Figura 4.2 - Papéis Estratégicos das empresas na cadeia produtiva (Ferdows, 1997)

- Offshore - produz itens específicos a baixo custo; não é inovativa; segue métodos preestabelecidos.

- Source - Objetivo primário é produzir a baixo custo, mas possui uma autonomia maior que das offshore, realizando, por exemplo, alterações de processos, planos de produção e escolha de fornecedores.

- Server (Servidora) - Produz para mercados nacionais ou regionais específicos. Busca transpor barreiras tarifárias e diminuir custos logísticos, estando próximas do mercado consumidor.

- Contributor (Contribuidora) - Também atende o mercado nacional/regional, mas possui engenharia de processo e produto; atua na escolha e desenvolvimento de fornecedores (inclusive para toda a companhia). 
- Outpost (Posto Avançado) - Seu papel principal é coletar informações para a organização, para tal, essas fábricas localizam-se em áreas que possuem fornecedores, clientes, laboratórios de pesquisa e competidores avançados.

- Lead (Líder/Direcionadora) - Cria novos processos, produtos e tecnologias para toda a organização.

No relatório anual de desenvolvimento mundial, desenvolvido em 1999 pela UNCTAD (1999), também é mostrado que existem vários tipos de relacionamento entre matrizes e subsidiárias de empresas transnacionais. Focalizando no nível de desenvolvimento tecnológico e nas políticas econômicas dos países que hospedam as subsidiárias, a UNCTAD apresenta cinco tipos de afiliadas relacionadas: ao desenvolvimento de processos e produtos, às atividades realizadas localmente pelas unidades, e caracterizando o nível de independência tecnológica com relação à matriz. São eles (Figura 4.3):

- Afiliada 1 - é localizada em economia desenvolvida e serve mercado regional, executa amplamente atividades de gestão, marketing e desenvolvimento tecnológico.

- Afiliada 2 - localizada em países recentemente industrializados, serve mercados regionais e locais, executam determinadas funções de projeto e desenvolvimento interagindo com firmas locais, centros de pesquisa e universidades, mas se submetem à matriz para várias funções estratégicas.

- Afiliada 3 - localizada em países menos industrializados, em economias orientadas à exportação. As principais funções produtivas são montagens de kits. A transferência tecnológica ocorre através de treinamento para produção e gestão de qualidade.

- Afiliada 4 - localiza-se em economia fortemente protegida, fabrica produtos menos sofisticados para mercado local. Suas performances de qualidade e custo estão longe dos padrões mundiais.

- Afiliada 5 - localizada nos países menos desenvolvidos, apresenta algumas operações de montagem. As demandas locais são pequenas e a mão-de-obra pouco especializada. A transferência tecnológica é restrita a treinamentos 
operacionais. Não há localmente boa base instalada de fornecedores e centros de pesquisa ou universidades.

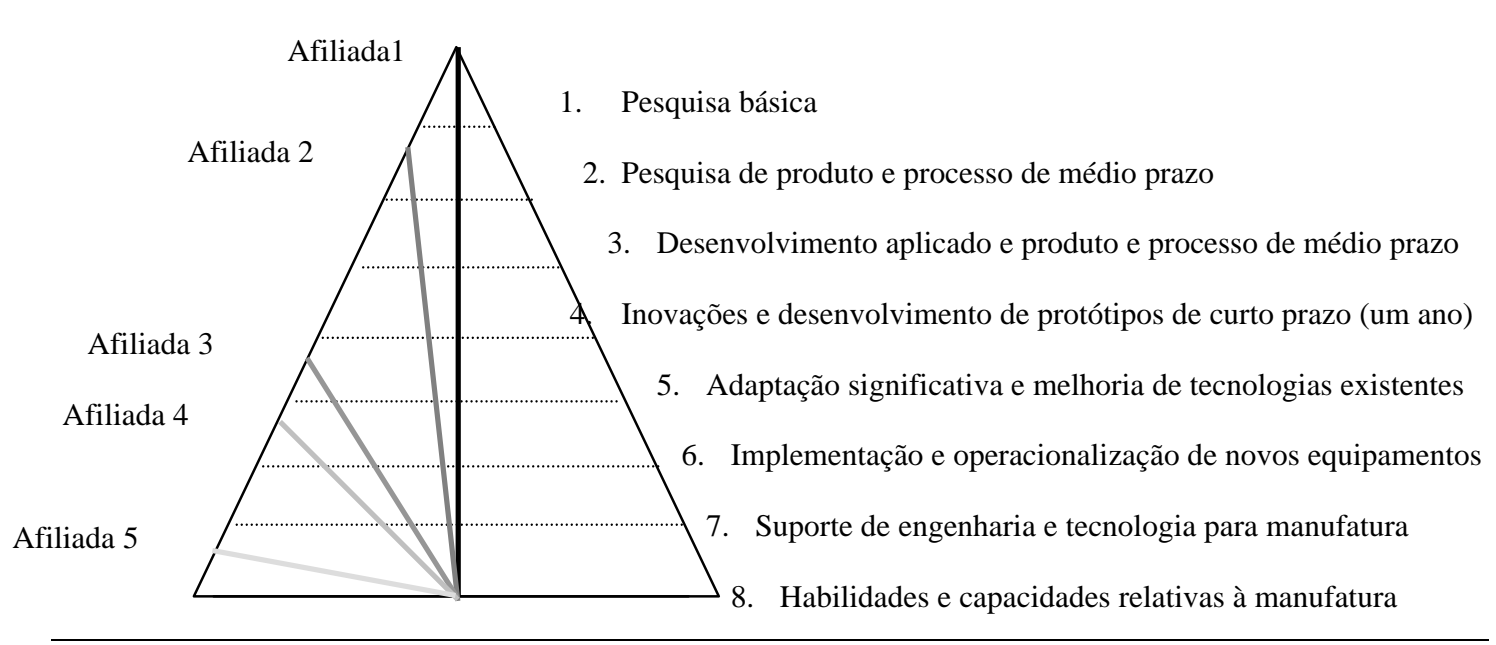

Figura 4.3 - Tipos de Afiliadas (Fonte: UNCTAD, 1999)

Além das classificações estudadas, existem algumas outras e uma delas merece destaque, especialmente por ter sido feita no Brasil, portanto retrata melhor a realidade dos papéis das unidades presentes no país. Fleury (1999) analisou 11 subsidiárias brasileiras de diferentes setores, caracterizando suas trajetórias no Brasil. A primeira fase (1950 a 1970) é a fase de instalação, quando as TNCs transferiram tecnologia e políticas de gestão para as subsidiárias. A segunda etapa (1970 a 1990) foi a fase de acomodação, quando a transferência tecnológica foi reduzido porque o as subsidiárias se tornaram mais independentes de suas matrizes, nessa fase, algumas competências foram consolidadas. A última fase, após 1990, com a inserção do país na globalização produtiva, as afiliadas brasileiras foram re-inseridas nas estratégias globais das organizações. Para essa reintegração, o autor identifica três papéis distintos para as subsidiárias (tabela 4.2):

- Tipo I - subsidiárias agem como braço operacional da companhia, cabem a elas pouquíssimas decisões sobre processos e produtos.

- Tipo II - unidade relativamente autônoma para gerenciar seus recursos financeiros. Também é autônoma para desenvolver alguns processos/produtos localmente. 
- Tipo III - subsidiária é considerada centro de excelência na companhia. É autônoma para negociações e desenvolvimentos locais.

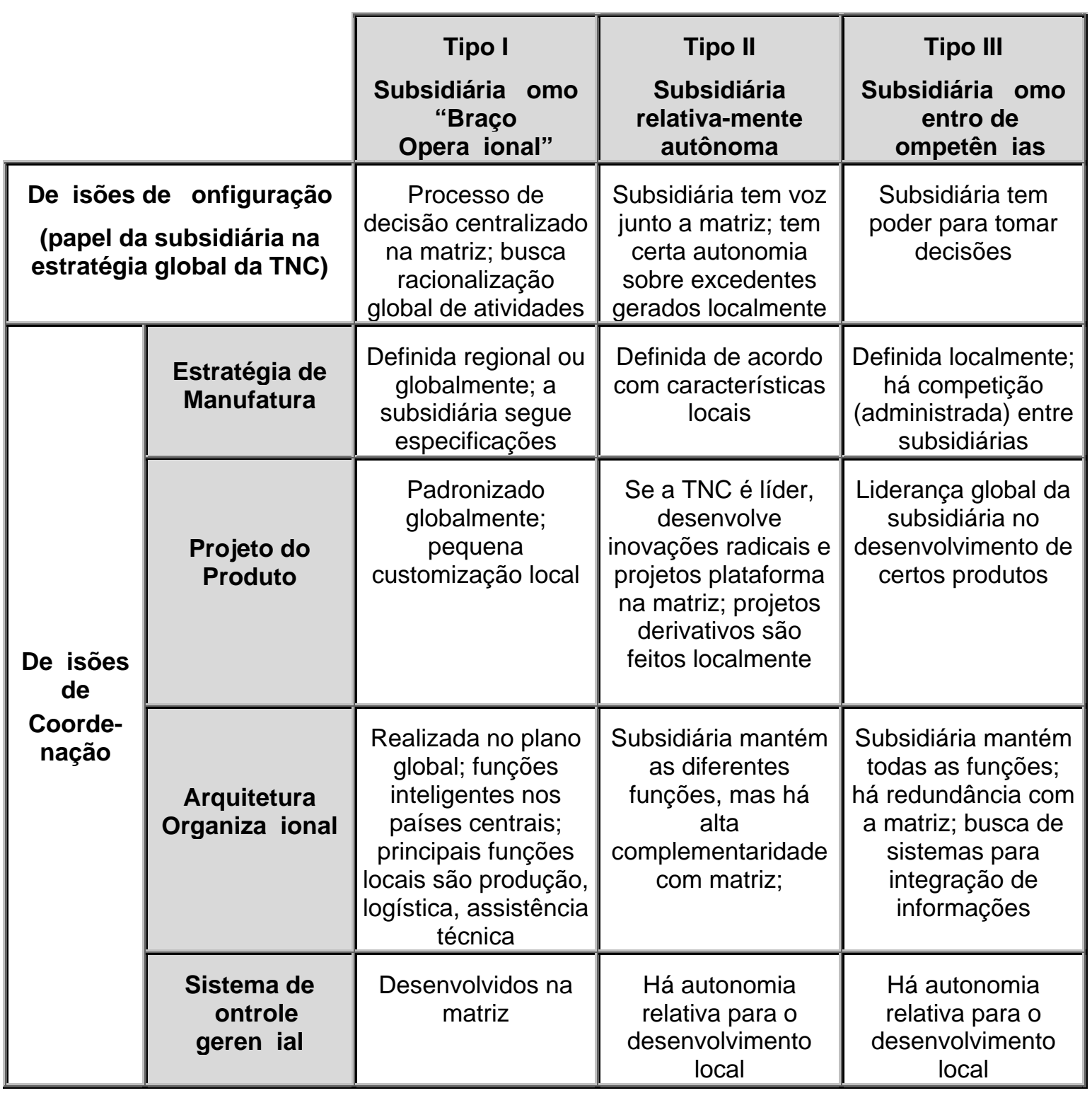

Tabela 4.2 - Posicionamento das TNCs com relação ao papel da subsidiária (Fleury e Fleury, 2000)

A maioria dessas classificações, de alguma forma, gradua os diferentes papéis das subsidiárias, atribuindo, freqüentemente, o papel de "melhores unidades" das companhias àquelas que realizam desenvolvimento de produtos de maneira autônoma, seja para mercados locais, regionais ou globais (Gammelgaard, 1999). Dessa forma, as unidades locais das TNC buscam ter "melhores papéis" nos seus grupos corporativos. Isso significa que, muitas vezes, as subsidiárias procuram, por si 
mesmas, oportunidades de negócios e desenvolvem soluções para atendê-las, sem ter que pedir permissão à matriz.

Essa abordagem independente pode levar a subsidiária a deter conhecimento específico sobre uma linha de produto, transformando-se em product owner, ou seja, o centro de excelência da empresa num determinado segmento/linha de produtos da mesma. Tais subsidiárias têm um alto grau de $\mathrm{P} \& \mathrm{D}$ e uma forte influência estratégica nas suas próprias trajetórias tecnológicas (Gammelgaard, 1999). Ou seja, os centros de excelência tecnológica possuem um papel de destaque. A subsidiária que hospeda tal centro pode ter maior importância para a TNC tornando-se indispensável para a companhia como um todo.

Alguns poucos trabalhos discutem as mudanças de papéis das subsidiárias ao longo do tempo (Papanasstasiou e Pearce, 1984, Birkinshaw e Hood, 1998; Gassman e von Zedtwitz, 1999; Chiesa, 1995). A evolução das subsidiárias são direcionadas basicamente pelas decisões da matriz, por escolha da própria subsidiária ou por influência do ambiente local (que interfere nas decisões tomadas tanto pelo escritório central quanto pela subsidiária) (Birkinshaw e Hood, 1998).

Com o intuito de entender melhor o comportamento das empresas que possuem atividades de desenvolvimento tecnológico internacionalmente dispersas, as próximas seções deste capítulo apresentam discussões relacionadas a esse tema sob vários enfoques: as características da internacionalização de $\mathrm{P} \& \mathrm{D}$, as divisões das unidades mundiais de $\mathrm{P} \& \mathrm{D}$, os pontos negativos da internacionalização e as configurações para a realização de desenvolvimento global.

\subsubsection{Internacionalização de Atividades de Desenvolvimento Tecnológico}

Como foi citado nas seções anteriores, os papéis das subsidiárias das TNCs fora dos países sede das matrizes não se restringem somente ao atendimento do mercado local, elas são dispostas em redes integradas para que tenham condições necessárias para explorar capacidades ou conhecimentos em cada país não apenas para produção, mas também para desenvolvimento de tecnologia (Cantwell e Santangelo, 1999). As 
empresas transnacionais buscam localizar suas atividades onde existe vantagem comparativa. "Essas atividades não são apenas relacionadas a produção, mas também a distribuição, propaganda e P\&D” (Prasada, 2000, p. 10). As TNCs são os principais agentes da globalização produtiva e, consequentemente da internacionalização de P\&D (Cantwell, 1994; Gerybadze e Reger, 1999).

Sendo assim, com o intuito de serem mais competitivas, as empresas estão distribuindo globalmente suas atividades de P\&D (Cantwell, 1989, Ghoshal e Bartlett, 1988; Reddy, 1997; Subramaniam et. al., 1998; Dunning, 1999). Alguns estudos comprovam claramente o aumento dessa tendência. Zander (1994) mostra que em 1980, 30\% de toda atividade tecnológica das TNCs suecas eram realizados fora da Suécia; 10 anos depois, o número representava $40 \%$ das empresas. Kuemmerle (1999), analisando 32 TNCs, mostra que, em trinta anos (de 1965 a 1995) o percentual de $P \& D$ que era feito fora dos países de origem das empresas passou de $6,2 \%$ para $25,8 \%$.

Existem vários trabalhos de diferentes naturezas relacionados à internacionalização de P\&D. Alguns tratam o assunto sob o ponto de vista das empresas transnacionais e das estratégias usadas por elas para a globalização de atividades de $\mathrm{P} \& \mathrm{D}$, tomando vantagem das situações locais para desenvolvimento global (Ronstadt, 1977; Terpstra, 1977; Hakanson, 1990; Bartlett e Ghoshal, 1989). Influenciando tais estratégias estão os fatores que orientam o investimento em P\&D para determinados países / regiões, e alguns trabalhos com esse enfoque foram desenvolvidos (Cantwell 1992; Reddy, 1997, Reddy, 2000; Subramaniam, 1998; Niosi, 1999; Gerybadze e Reger, 1999). Além desses estudos, e ainda considerando as estratégias de internacionalização de $\mathrm{P} \& \mathrm{D}$, há também trabalhos de autores que seguem a linha de análise de mercado, estabelecendo características de produtos que podem ser padronizadas para mercados mundiais ou aqueles que devem seguir contingências de mercados internacionais, o que influencia ou não na centralização ou descentralização de P\&D (Hult et. al., 2000).

Outros trabalhos na área (De Meyer, 1989; Chiesa, 2000; Gassmann e von Zedtwitz, 1999; Moenaert, R. et. al., 1998) são referentes às maneiras de gerenciar os centros de P\&D mundiais e as atividades de desenvolvimento tecnológico sob diferentes 
aspectos, principalmente sobre gerenciamento de troca de dados/informações entre grupos (exemplo: tipo, custos, codificação e infra-estrutura do processo de comunicação) e sobre organização das equipes de trabalho espalhadas mundialmente (exemplo: estruturas organizacionais, liderança e formalização de equipes).

Existem ainda trabalhos que utilizam alguns indicadores quantitativos, sejam para avaliar as vantagens obtidas com a descentralização do projeto de produto (Mallick e Mukhopadhyay, 2001) ou para analisar as formas de interação entre as equipes de desenvolvimento tecnológico distribuídas mundialmente (Guellec e Potterie, 2001)

A internacionalização de P\&D não é fato recente. Vernon (1966) mostra que as empresas exploravam recursos internacionalmente, inclusive para obtenção de conhecimento tecnológico. Em 1971,o investimento em P\&D fora dos EUA pelas empresas norte-americanas já representava 10\% do total aplicado em P\&D (Terpstra, 1977). Prasada (1997) cita que a US Tariff Commission afirmou, em 1973, que as empresas norte-americanas realizavam P\&D fora dos EUA nos anos 60. As principais indústrias envolvidas eram: mecânica, elétrica e de engenharia (inclusive a automotiva). Mas as maiores evidências dessa prática começa com trabalhos realizados na década de 70. É quando surge a famosa classificação de Ronstadt (1977), descrita na seção 4.1.3.2, que distingue os diferentes tipos de unidades mundiais de $\mathrm{P} \& \mathrm{D}$, confirmando as práticas de internacionalização das atividades de desenvolvimento pelas TNCs.

Um outro trabalho realizado na década de 70 (Behrman e Fischer, 1980) apresenta evidências de alocação de unidades de $\mathrm{P} \& \mathrm{D}$ em países em desenvolvimento como Brasil e Índia, especialmente por causa de algumas características desses países: subsidiárias lucrativas, mercado em crescimento e estrutura adequada de Ciência e Tecnologia (C\&T). As principais indústrias que internacionalizavam $P \& D$ neste período eram a química e a de alimentos.

A realização dispersa de $P \& D$ até meados da década de 70 era difícil especialmente pelos problemas enfrentados para supervisionar e controlar as atividades internacionais. Essa dificuldade veio a ser minimizada com a introdução de novas tecnologias de informação e de comunicação. 
Embora internacionalização de $\mathrm{P} \& \mathrm{D}$ tenha começado nos anos 70 , se tornou 'fenômeno' apenas no final da década de 80 (Cantwell, 1995). Nessa época, as unidades mundiais estavam envolvidas não apenas com o desenvolvimento de processos e produtos para mercados locais, mas também para globais, incluindo, também, realização de pesquisa básica (Reddy, 1997). Nessa época, as empresas buscavam, com a internacionalização, novos conhecimentos e tecnologias. Desde os anos 80, a cooperação existe não apenas entre firmas, mas também entre empresa e universidades ou centros de pesquisa localizados tanto dentro quanto fora do país sede da TNC (Reddy, 1997). Na época, as principais indústrias envolvidas com a globalização das atividades de P\&D eram as de microeletrônicos, farmacêutica e aeronáutica civil. Essas tendências apresentadas para a década de 80 continuam até os dias atuais, especialmente, nos países desenvolvidos, com o aumento das necessidades por mão-de-obra altamente qualificada.

A tabela 4.3, adaptada de Prasada Reddy (1997), apresenta o processo histórico da globalização de P\&D nas empresas. Para cada uma das décadas relevantes para a internacionalização do desenvolvimento tecnológico nas TNCs, ele mostra os fatores propulsores, ou seja, os que alavancaram e que facilitaram essa internacionalização; o tipo de $\mathrm{P} \& \mathrm{D}$ feito no exterior e as características das unidades de $\mathrm{P} \& \mathrm{D}$.

Com a distribuição mundial de $\mathrm{P} \& \mathrm{D}$, as empresas procuram maior vantagem competitiva. São vários os argumentos favoráveis à internacionalização do desenvolvimento de produto, não apenas para apoio à produção local, mas também para criar interfaces com sistemas de inovação locais (Ohmae, 1990). Assim sendo, entre esses argumentos estão a oportunidade de estar em contato com novos conhecimentos e tecnologias; a flexibilidade e a agilidade para adaptação de produtos, viabilizando melhor atendimento ao cliente; diminuição de custos do desenvolvimento; incentivos fiscais obtidos em alguns países / regiões; exigências para atuação local; e outros. Na seção 4.1.3.1 são discutidas as principais razões das empresas ao internacionalizarem $\mathrm{P} \& \mathrm{D}$ e resultados concernentes a elas obtidos com os estudos de caso feitos neste trabalho são mostrados no capítulo 6. 


\begin{tabular}{|c|c|c|c|c|}
\hline & Propulsores & Facilitadores & Tipo de P\&D & Formas de P\&D \\
\hline $1960 \mathrm{~s}$ & $\begin{array}{l}\text { Entrada em mercados } \\
\text { internacionais }\end{array}$ & $\begin{array}{l}\text { Mercado amplo e } \\
\text { proximidade da } \\
\text { produção }\end{array}$ & $\begin{array}{l}\text { Adaptação; } \\
\text { transferência de } \\
\text { tecnologia p/ subsid. }\end{array}$ & $\begin{array}{l}\text { P\&D própria ligada a } \\
\text { subsidiária de } \\
\text { fabricação }\end{array}$ \\
\hline $1970 \mathrm{~s}$ & $\begin{array}{l}\text { Políticas } \\
\text { governamentais; } \\
\text { obter market-share } \\
\text { no exterior }\end{array}$ & $\begin{array}{l}\text { Mercados amplos } \\
\text { protegidos; } \\
\text { proximidade de } \\
\text { produção e } \\
\text { consumidores }\end{array}$ & $\begin{array}{l}\text { Desenvolvimento de } \\
\text { produtos para } \\
\text { mercado local com a } \\
\text { tecnologia local }\end{array}$ & $\begin{array}{l}\text { Aquisições ou } \\
\text { investimentos em } \\
\text { P\&D própria. }\end{array}$ \\
\hline $1980 \mathrm{~s}$ & $\begin{array}{l}\text { Necessidade de } \\
\text { conhecimento de } \\
\text { novos conhecimentos } \\
\text { e tecnologias }\end{array}$ & $\begin{array}{l}\text { Tecnologias de } \\
\text { informação e } \\
\text { comunicação; } \\
\text { flexibilidade para } \\
\text { interligar P\&D e } \\
\text { produção (pela } \\
\text { especialização - } \\
\text { papéis das } \\
\text { subsidiárias) }\end{array}$ & $\begin{array}{l}\text { Desenvolvimento de } \\
\text { produtos e de } \\
\text { processos para } \\
\text { mercado global; } \\
\text { desenvolvimento de } \\
\text { pesquisa básica }\end{array}$ & $\begin{array}{l}\text { Unidades próprias de } \\
\text { P\&D; cooperação } \\
\text { entre empresas; P\&D } \\
\text { por joint-venture; } \\
\text { envolvimento de } \\
\text { universidades e } \\
\text { centros de pesquisa; } \\
\text { subcontratação de } \\
\text { P\&D (intuito: diluir } \\
\text { riscos) }\end{array}$ \\
\hline $1990 \mathrm{~s}$ & $\begin{array}{l}\text { Acesso a recursos } \\
\text { humanos } \\
\text { especializados; } \\
\text { aumento de custos de } \\
\text { P\&D (nos países } \\
\text { sede) }\end{array}$ & $\begin{array}{l}\text { Divisão de P\&D em } \\
\text { atividades core ou } \\
\text { não-core; } \\
\text { disponibilidade de } \\
\text { recursos humanos } \\
\text { para pesquisa; } \\
\text { liberalização de } \\
\text { políticas exteriores }\end{array}$ & $\begin{array}{l}\text { Desenvolvimento do } \\
\text { produtos e processos } \\
\text { para mercados } \\
\text { globais e regionais e } \\
\text { desenvolvimento de } \\
\text { pesquisa básica }\end{array}$ & $\begin{array}{l}\text { Unidades próprias de } \\
\text { P\&D; cooperação } \\
\text { entre empresas; P\&D } \\
\text { por joint-venture; } \\
\text { envolvimento de } \\
\text { universidades e } \\
\text { centros de pesquisa; } \\
\text { subcontratação de } \\
\text { P\&D }\end{array}$ \\
\hline
\end{tabular}

Tabela 4.3 - Processo Histórico para a globalização de P\&D - Adaptado de Reddy (1997)

Como pode ser observado, a internacionalização de P\&D é fato, no entanto, "o país de origem da TNC é geralmente o local mais importante para o desenvolvimento tecnológico da corporação" (Cantwell, 1995, p. 172). Algumas pesquisas (Granstrand et. al., 1992; Casson, 1991; Reddy, 1997) mostram que as unidades de P\&D localizadas no exterior (fora do país sede da empresa) são usadas principalmente para a adaptação de produtos ao mercado local e para dar suporte às unidades fabris. "Existem poucas firmas com P\&D realmente global, ou seja, com distribuição, em diferentes países, de laboratórios realizando atividades de P\&D originais ou únicas, coordenados centralizadamente" (Chiesa, 1995, p. 19). Reddy (2000) afirma que 
existe uma tendência para localizar $\mathrm{P} \& \mathrm{D}$ em países em desenvolvimento, mas isso não implica que uma proporção significativa dela está indo para eles, já que, como cita o mesmo autor, mais de $90 \%$ da $P \& D$ realizada internacionalmente ainda é feita nos países desenvolvidos. Esse número é semelhante ao levantado por Fusfeld (1995), que afirma que 95\% das atividades de P\&D industrial são realizadas em países da OECD.

De acordo com um estudo apresentado pela UNCTAD (1999), baseado em trabalhos de Patel e Vega (1999) e Patel e Pavitt (1998), “os locais mais importantes para P\&D internacional são os EUA (41\%), seguido da Alemanha (17\%) e do Reino Unido (12\%)" (UNCTAD, 1999, p. 201). O mesmo estudo mostra que menos de $1 \%$ das patentes depositadas no exterior são feitas por países fora da tríade EUA / União Européia / Japão. "Isso sugere que adaptação e suporte técnico ainda são os principais motivos para unidades de P\&D no exterior, com tendência em usar competências de centros de excelência no exterior" (UNCTAD, 1999, pp. 200)

De fato, as unidades estrangeiras das TNCs estão mais relacionadas a atividades de desenvolvimento de produtos do que de pesquisa (Pearce, 1989; Pearce, 1997), ou seja, a pesquisa básica e o desenvolvimento de novos produtos (inovação) geralmente permanece na matriz ou, em alguns casos, centralizadas em subsidiárias localizadas em países desenvolvidos. Isso é confirmado nas TNCs do setor de telecomunicações no Brasil, conforme resultados dos estudos de caso realizados neste trabalho, cujas atividades dos departamentos específicos ligados à tecnologia, geralmente chamados de $\mathrm{P} \& \mathrm{D}$, são quase que exclusivamente relacionadas a desenvolvimento de produtos, ou seja, os setores de "P\&D" nas empresas são, na verdade, setores de "D" (desenvolvimento de produtos). Sendo assim, este trabalho analisa mais especificamente a o desenvolvimento global de produtos.

\subsubsection{Razões para Internacionalização de P\&D}

Segundo Bartlett e Ghoshal (1992), as inovações em produtos e processos centralmente desenvolvidos ainda desempenham um importante papel na TNC, mas 
as inovações são criadas também pelas subsidiárias. Normalmente, em vez de encontrar uma solução central para uma nova oportunidade global (como ocorre em organizações globais e internacionais) ou diferentes situações locais em cada ambiente (como nas MNC), a transnacional junta os recursos das instalações e de muitas subsidiárias nacionais para desenvolver uma solução mundial para a organização dispersa.

As TNCs reconhecem que partes diferentes da companhia possuem diferentes aptidões. A exposição de uma companhia mundial a uma variedade de estímulos ambientais representa uma grande vantagem em potencial sobre uma companhia nacional. O gerentes das transnacionais não vêem razão para impedir que os recursos fora do ambiente doméstico beneficiem toda a corporação (Bartlett e Ghoshal, 1992).

Prahalad e Doz (1987) afirmam que as relações entre matrizes e subsidiárias ou entre as subsidiárias de uma companhia são dependentes da natureza dos negócios das empresas. As características econômicas, tecnológicas e competitivas de um negócio habilitam as organizações a definir as pressões para coordenações globais de atividades e para receptividade local.

Esses autores desenvolveram uma estrutura chamada Integração-Receptividade (I-R), que provê uma maneira de identificar necessidades (econômicas, tecnológicas e de competitividade) de um determinado negócio. Essas necessidades envolvem um nível de coordenação global e um nível de receptividade local. Ou seja, nessa estrutura é possível identificar os produtos que exigem coordenação de desenvolvimento centralizada ou global e os produtos que exigem um envolvimento grande do local onde estão sendo fabricados elou utilizados. Para exemplificar, a figura 4.4 mostra como ficaria a matriz no setor de telecomunicações para alguns produtos de telefonia.

$\mathrm{Na}$ verdade, as razões pelas quais os recursos para P\&D são direcionados a outros países que não o da sede da empresa são várias. Terpstra (1977) cita as mais freqüentemente encontradas entre as TNCs: transferir tecnologia da matriz para as subsidiárias estrangeiras, em resposta a pressões de países onde suas subsidiárias estão localizadas, para melhorar as relações internacionais, para obter acesso a talentos e recursos estrangeiros, para reduzir os custos de desenvolvimento com mãode-obra mais barata, obter vantagem de idéias e produtos locais, acelerar o desenvolvimento através do esforço paralelo de vários laboratórios trabalhando 
simultaneamente, para continuar com as atividades de desenvolvimento realizadas numa companhia adquirida no exterior, para obter vantagens de algumas leis locais de incentivos públicos.

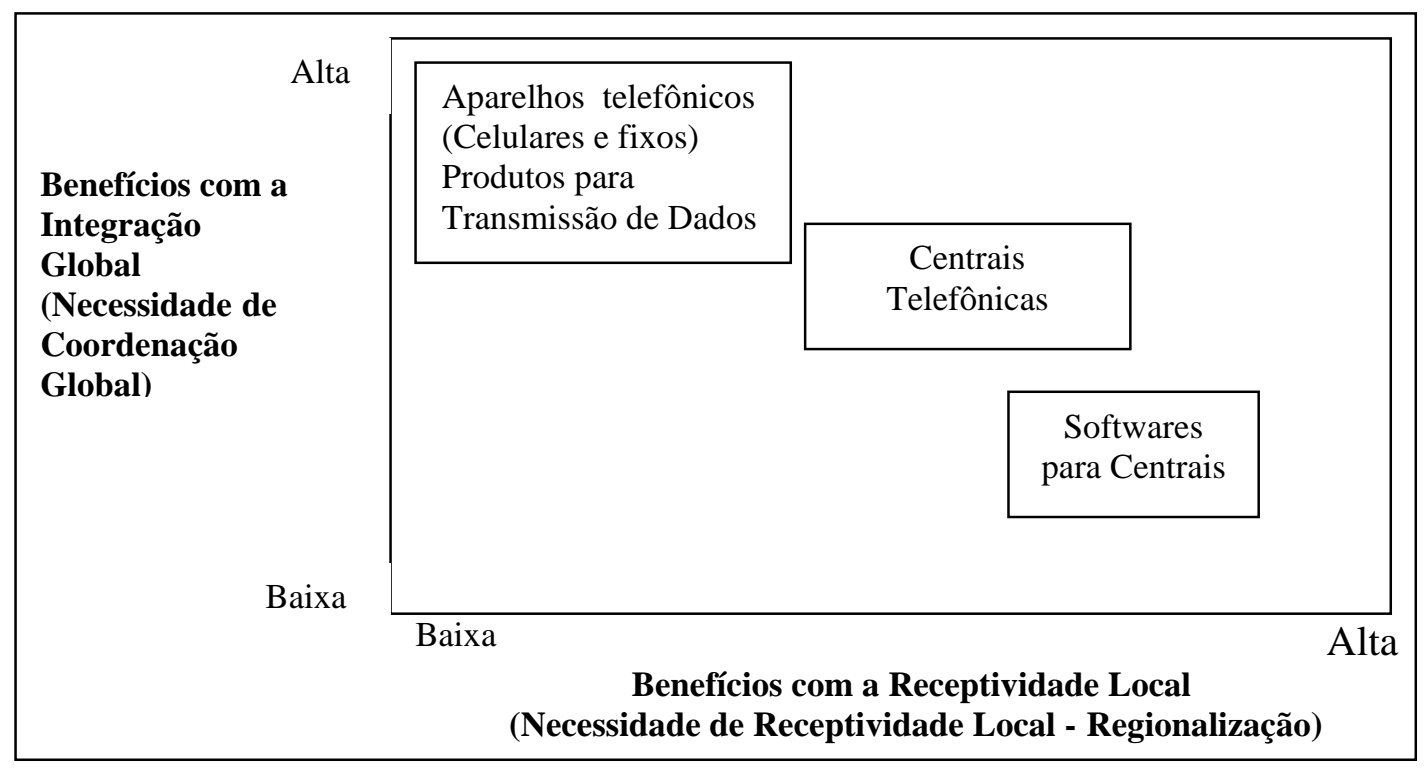

Figura 4.4 - Estrutura I-R para o setor de telecomunicações (Prahalad e Doz, 1987)

De maneira geral, a literatura apresenta duas vertentes para alinhar as principais razões da internacionalização de P\&D (Chiesa, 1995; Florida, 1997): fatores mercadológicos (necessidade de acesso a mercados, respondendo às necessidades locais e aumentando a proximidade com os clientes); e os fatores relativos à tecnologia (recrutamento a pessoal qualificado, acesso a talentos estrangeiros, acesso a tecnologias diferenciadas). Os desdobramentos das razões levantadas para internacionalizar P\&D são classificados em um desses dois grandes segmentos/ fatores.

O fator relacionado a mercado é motivado principalmente para adaptação de produtos a mercados estrangeiros e para suporte técnico a fábricas. As TNCs buscam, com a localização de suas unidades no exterior, atender melhor aos clientes, com adaptações mais adequadas de seus produtos e, principalmente, realizadas mais rapidamente. Estabelecendo as atividades de desenvolvimento em locais próximos dos clientes, as empresas são melhor estruturadas para terem competência no entendimento da necessidade local e agilidade para atenderem e proverem produtos para seus clientes, especialmente porque, em geral, as TNCs possuem estruturas 
organizacionais gigantescas e extremamente burocráticas, dificultando o processo decisório. O fator "mercadológico" é considerado menos relevante ou mais superficial, como nomeia Inzelt (2000): "skin-deep collaboration".

O segundo fator, ligado a tecnologia, tem por principais objetivos assegurar acesso a C\&T e capital humano especializado e criar vínculos com comunidades científicas locais. Esse fator é mais intrínseco ao processo de desenvolvimento, por isso é considerado mais relevante, pois estabelece uma relação mais profunda de dependência entre a empresa e as regiões onde a subsidiária está localizada, Inzelt (2000) chama-o de "soul-deep collaboration".

Ainda relacionado aos fatores tecnológicos, Cantwell (1992) cita duas abordagens como principais razões para internacionalização de P\&D: obter vantagens a partir de distintas características de inovação em diferentes sistemas nacionais, ganhando assim, acesso a tecnologias complementares; e ter contato com novas linhas de inovação.

O estudo sueco de Hakanson e Sander (1986) resume algumas razões pelas quais as TNCs internacionalizam $\mathrm{P} \& \mathrm{D}$, que são também relacionadas aos fatores tecnológicos e mercadológicos. Entre as razões indicadas por eles estão as vantagens obtidas com a proximidade de clientes e de centros de pesquisa locais, a exploração de talentos locais, a falta de mão-de-obra qualificada (em quantidade) na Suécia, o aumento da dependência causada com aquisições no exterior (muitas vezes com incorporação de unidades de P\&D também), o aumento de unidades especializadas na manufatura (fortalecendo a necessidade de envolvimento dessas unidades nos processos de desenvolvimento tecnológico, especialmente para realização de atividades mais relacionadas ao processo produtivo).

Mesmo sendo considerados mais ou menos relevantes, tanto os tecnológicos, quanto os mercadológicos são fatores importantes para atrair investimentos locais em P\&D, possibilitando transformar, assim, países menos avançados em mais progredidos. É comum também encontrar empresas que apresentam características dessas duas classificações apresentadas. 
Outro fator considerado na escolha do local para onde são destinadas as unidades de $\mathrm{P} \& \mathrm{D}$ é o relacionado ao tipo de conhecimento (tácito ou explícito) em produtos e processos (Subramaniam et. al.,1998; Cantwell e Santangelo, 1999). Conhecimento explícito é aquele codificado, ou seja, facilmente documentado. A inovação que depende deste tipo de conhecimento é "reduzida à criação, e transmissão de uma informação livremente disponível para os agentes envolvidos na pesquisa" (Carrincazeaux e Lung, 1997, p. 51). Conhecimento tácito, por sua vez, não pode ser padronizado ou documentado, ele é cumulativo e depende "de interações duráveis e de relações faca-a-face entre os atores da inovação" (Carrincazeaux e Lung, 1997, p. $51)$.

Segundo Cantwell e Santangelo (1999), quanto mais tácito o conhecimento necessário no desenvolvimento tecnológico, mais intensa deverá ser a relação cooperativa entre as equipes envolvidas. Esses autores afirmam ainda que é difícil coordenar um processo distribuído de criação de tecnologia em que o conhecimento tácito tem papel fundamental. Eles também citam que a coordenação e a dispersão de atividades de desenvolvimento de tecnologias baseadas em conhecimentos explícitos (documentados) é facilitada.

Ou seja, o que os autores afirmam é que, quanto mais dependente do conhecimento tácito uma inovação está, mais concentrada / centralizada ela deverá ser desenvolvida. Subramanian et. al. (1998) afirmam que as chances das subsidiárias participarem dos desenvolvimentos tecnológicos são maiores quanto mais conhecimento tácito elas deterem, uma vez que sua importância intensifica-se à medida que aumenta a necessidade de integração entre os agentes da inovação para centralização das atividades.

Muitas vezes, a internacionalização de $\mathrm{P} \& \mathrm{D}$ é resultado de ações não relacionadas às estratégias das empresas, como exigências governamentais, aquisição de unidades estrangeiras que possuam departamentos de P\&D, etc. (Granstrand et. al., 1992). Inclusive, De Meyer e Mizushima (1989) apontam como um dos problemas do modelo de Ronstadt - descrito na próxima seção -, exatamente a falta de tratamento para os "laboratórios 'criados' a partir de aquisições de companhias estrangeiras" (De Meyer e Mizushima , 1989, p. 138). Terpstra (1977) afirma que os governos de 
países onde as MNCs possuem afiliadas tentam maximizar o desenvolvimento tecnológico local através de incentivos e/ou de pressões, e eles obtêm mais sucesso com empresas estrangeiras que adquirem companhias nacionais e dão continuidade aos processos de $\mathrm{P} \& \mathrm{D}$ do que através de pressões a essas firmas estrangeiras para que iniciem atividades locais de $\mathrm{P} \& \mathrm{D}$.

Uma classificação para os fatores que levam as empresas a internacionalizarem P\&D é a de Gerybadze e Reger (1999), que, considerando apenas a indústria "dinâmica, ou seja, com regimes rápidos de inovação" (Gerybadze e Reger, 1999, p. 264), apresentam uma arquitetura para análise de $\mathrm{P} \& \mathrm{D}$, na qual eles dividem a inovação global em quatro tipos, dois deles baseados em critérios ligados à inovação altamente dependente de recursos de ciência e pesquisa (ex. engenharia genética, biotecnologia) - tipos A e B - e os outros dois relacionados à inovação orientada para o mercado (ex. telecomunicações, eletrônica de consumo) - tipos C e D. Como pode ser observado, trata-se de mais um trabalho que liga os fatores a tecnologia ou a mercado.

Essa classificação também considera o tamanho (do mercado) e/ou a importância (em termos tecnológicos) do país sede da TNC, se ele é grande ou significativo (Tipos A e C) ou pequeno / desprezível (Tipo B e D). Os quatro tipos genéricos de empresas apresentados por eles são:

Tipo A - a corporação precisa ter acesso a P\&D avançada e a matriz está localizada em um país grande e desenvolvido, com fortes capacidades de P\&D em campos específicos de atuação da companhia. Ela não terá estímulos significativos para localizar partes de $\mathrm{P} \& \mathrm{D}$ no exterior, no entanto poderão ter $\mathrm{P} \& \mathrm{D}$ complementar fora do país sede.

Tipo B - a corporação é dependente de excelência de P\&D, mas está localizada em um pequeno país ou num país com capacidades de $\mathrm{P} \& \mathrm{D}$ menos desenvolvidas num segmento específico. Serão fortemente estimuladas para localizar P\&D no exterior.

Tipo C - a corporação pode ser beneficiada pela proximidade com mercados mundialmente importantes e estabelecer liderança neles. Geralmente as companhias 
deste tipo são provenientes de países / regiões relevantes comercialmente. As atividades de P\&D são feitas no país de origem da TNC, até mesmo pela necessidade de uma ligação fortalecida entre unidades de desenvolvimento e produtivas.

Tipo D - a corporação é fortemente dependente do acesso a mercados estrangeiros, por qualquer razão (tamanho limitado ou nível de sofisticação do mercado da sede). Ela precisa concentrar competências fora do país sede. A empresa é obrigada a localizar importantes funções de $\mathrm{P} \& \mathrm{D}$ no exterior.

No capítulo 6, será retomada a discussão sobre as razões que levam as companhias à internacionalização de $\mathrm{P} \& \mathrm{D}$, mais especificamente no que se refere aos fatores que estimulam as empresas a envolverem as subsidiárias brasileiras no desenvolvimento de produtos.

\subsubsection{Papéis das Unidades de P\&D}

A globalização dos mercados, a regionalização de competências técnicas e científicas e as rápidas mudanças tecnológicas são alguns dos fatores que forçam as companhias, especialmente as fortemente dependentes de tecnologia, a ajustarem suas estruturas mundiais de P\&D. Em todas as classificações para papéis das subsidiárias, citadas na seção 4.1.2, existem unidades da companhia responsáveis pela geração de tecnologia para a própria subsidiária e até mesmo para toda a companhia.

Ronstadt (1977) mostra diferentes tipos de unidades que realizam atividades de P\&D no exterior (fora do país originário da companhia) pelas $\mathrm{TNC}^{13}$ :

- Technology Transfer Units (TTUs) - facilitam a transferência da tecnologia da matriz para a subsidiária e provêm serviços técnicos locais.

- Indigenous Technology Units (ITUs) - desenvolvem novos produtos para o mercado local com a tecnologia local.

\footnotetext{
${ }^{13}$ A terminologia usada por Ronstadt permanece em inglês neste trabalho porque é muito conhecida / utilizada, inclusive - e principalmente - seus acrônimos.
} 
- Global Technology Units (GTUs) - desenvolvem novos produtos e processos para os principais mercados mundiais.

- Corporate Technology Units (CTUs) - geram tecnologia básica duradoura exploratória para uso pela matriz da empresa.

Para complementar essa classificação desenvolvida por Ronstadt, Reddy (1997) apresenta, muito apropriadamente, uma outra classe de unidades mundiais de P\&D, uma vez que, "apesar dos mercados estarem integrando-se em termos de padrões e tecnologias, alguns clusters regionais também estão fortalecendo-se" (Reddy, 1997, p. 1822):

- Regional Technology Units (RTUs) - desenvolvem produtos e processos para mercados regionais.

As unidades de P\&D tendem, com o tempo, a mudar de propósito para desenvolver novos produtos ou melhorar produtos e processos, principalmente para nações específicas ou mercados regionais (Ronstadt, 1984).

A classificação de Ronstadt nos ajuda a ver que as subsidiárias estão tendo papéis importantes na inovação. Tradicionalmente o fluxo de tecnologia é da matriz para as subsidiárias, mas ultimamente as companhias estão considerando atividades de P\&D no exterior como fontes de conhecimento e tecnologia (Reddy, 2000).

Ainda segundo o mesmo autor (Reddy, 1997), a localização de unidades de P\&D no exterior pode beneficiar a TNC e seu país de origem de várias maneiras: pela adaptação de produtos e processos às condições locais; pela geração de novos produtos/processos melhorando a condição da subsidiária local; pela integração com a comunidade de ciência e tecnologia local possibilitando benefícios para a empresa e contribuindo com a capacitação dos recursos locais de C\&T. O local em que a unidade está instalada pode ser fonte de estímulo para a inovação.

Reddy (1997) cita ainda que algumas TNC localizam P\&D nos principais países em desenvolvimento como Brasil, Índia, Israel e México. Essas empresas estão atentas para os talentos disponíveis em alguns países em desenvolvimento e para os ganhos 
com os custos localizando as unidades de P\&D neles, mas, na maioria das vezes, essas unidades se limitam a TTU e, em alguns casos, a ITU.

Terpstra (1977) sugere que quanto mais engajada nos negócios internacionais uma firma está e quanto mais significativos são esses negócios, mais descentralizadas são as atividades de P\&D desta companhia. Uma discussão mais ampla sobre os fatores que interferem na internacionalização de $P \& D$ foi feita na seção 4.1.3.1 e uma classificação, como mencionado anteriormente, é apresentada no capítulo 6, especialmente sob o ponto de vista dos atrativos brasileiros para localizar uma dessas unidades de desenvolvimento no país. Isso é parte dos resultados obtidos através da pesquisa de campo (estudos de caso) deste trabalho.

Retomando a discussão sobre as classificações relacionando transferência de tecnologia/conhecimento à estratégia das corporações, uma outra existente, também com o foco nos papéis das subsidiárias na estrutura da companhia, é a desenvolvida por Gupta e Govidarajan (1995). Eles identificaram quatro papéis genéricos para as unidades externas das TNCs:

- Inovador Global - a subsidiária serve como líder no desenvolvimento de conhecimento para as outras unidades numa tecnologia particular de um grupo de produtos.

- Parceiro Integrado (Integrated Player) - a subsidiária é tanto uma fonte para criação de tecnologia, quanto um usuário chave dessa tecnologia desenvolvida por outra unidade.

- Implementador - o engajamento da subsidiária na criação de conhecimento é pequeno e ela depende fortemente de transferência tecnológica de outras unidades da TNC.

- Inovador Local - a subsidiária tem responsabilidade de desenvolver tecnologia para áreas funcionais chave, mas quase que totalmente para uso local, ou seja, o conhecimento desenvolvido por ela é muito idiossincrático para ser usado em outros países. 
Essa classificação foi testada pelos autores em empresas norte-americanas, européias e japonesas, o que sustentou tal modelo, no entanto, eles encontraram diferenças internas nas organizações no que se relaciona ao papel do conhecimento e ao seu fluxo para as subsidiárias. Isso mostra que o papel da tecnologia para as unidades das TNCs não varia apenas de acordo com a nacionalidade e o setor industrial, mas depende também da característica da empresa. Isso indica que essa situação é bastante complexa e que tentar criar um padrão ou modelo sistemático de estratégia e prática na transferência e alocação de tecnologia pode ser bastante problemático (Howells, 2000).

Uma outra classificação para unidades globais de P\&D encontrada na literatura, também semelhante às demais, é apresentada por Chiesa (2000). Ele estabelece quatro categorias:

- Unidades de Suporte ou Adaptativas - provê suporte técnico para as funções da subsidiária e, se necessário, adapta produtos globais aos requisitos internos. Seu escopo geográfico é local ou, quando muito, regional.

- Laboratórios de Desenvolvimento - gerencia projetos com duração de um a três anos com o objetivo de ter uma inovação, tal como um novo produto a ser comercializado ou um novo processo a ser usado. Possuem foco de negócio e de mercado. Geograficamente, podem atuar como laboratórios de desenvolvimento global ou local, sendo que os do primeiro tipo, estão envolvidos com projetos globais de desenvolvimento e os do segundo com projetos orientados para inovações puramente locais.

- Laboratórios de Pesquisa - gerenciam projetos com maior duração (mais que três anos), objetivando a exploração de novas tecnologias / novos paradigmas ou acumulando conhecimento num certo campo, não diretamente relacionado a uma simples inovação. Alguns laboratórios estão focados numa tecnologia específica, enquanto outros conduzem pesquisa em várias tecnologias. São globais porque não servem determinado mercado ou negócio, mas desenvolvem tecnologias a serem exploradas para atividades de desenvolvimento de novos produtos. 
- Unidades de Monitoramento - monitoram localmente o progresso tecnológico e/ou a evolução de mercados. Embora essas unidades não realizam atividades técnicas, elas fazem parte da estrutura de P\&D internacional e são relevantes para ela, conforme descrito posteriormente neste trabalho.

\subsubsection{Pontos Negativos da Internacionalização de P\&D}

Apesar de todas as vantagens buscadas e obtidas por empresas que internacionalizam suas atividades de pesquisa ou de desenvolvimento de produtos, há alguns pontos que exigem cautela para a companhia quando ela se propõe a realizar $P \& D$ fora da sua matriz. Não é fácil gerir o desenvolvimento tecnológico disperso geograficamente, especialmente dividido em vários países. "A globalização de P\&D é tipicamente aceita mais com resignação do que com prazer" (De Meyer e Mizushima, 1989, p. 139). Argumentos contra a internacionalização de P\&D incluem a necessidade de garantir a segurança dos projetos de pesquisa ou de desenvolvimento e a economia de escala para o desenvolvimento (Chiesa, 1995).

O mesmo autor complementa esses argumentos afirmando que, para assegurar sigilo nos projetos de inovação, crucial para competitividade, as empresas preferem manter suas atividades de P\&D no país de origem. Para o outro fator, o argumento é que, com a descentralização, atingir um volume razoável para garantir economia de escala é muito difícil. Além disso, os custos de coordenação e controle das atividades distribuídas geograficamente são maiores com a descentralização e a comunicação é mais difícil.

Um outro ponto negativo da internacionalização é a confiabilidade dos projetos, ou seja, a dificuldade em coordenar de maneira eficiente as atividades de P\&D realizadas mundialmente é bastante grande, o que pode levar mais facilmente a erros e problemas com os resultados obtidos. É óbvio que as modernas tecnologias de comunicação facilitaram muito a realização dessa coordenação, mas ainda há problemas de gestão do desenvolvimento tecnológico, dificultando a internacionalização de $\mathrm{P} \& \mathrm{D}$. 
Os problemas da ineficácia no controle do desenvolvimento descentralizado levam a outro ponto também colocado como negativo na internacionalização de $\mathrm{P} \& \mathrm{D}$, o aumento do tempo de desenvolvimento de projetos, que, segundo Bartlett e Ghoshal (1990), é reduzido no desenvolvimento centralizado.

Outro fator desfavorável da descentralização de P\&D é o aumento de custos de coordenação e controle, dificultando a comunicação (Chiesa, 1995). De fato, a gestão do desenvolvimento descentralizado é extremamente difícil, especialmente por dois problemas (De Meyer e Mizushim, 1989):

- encontrar o equilíbrio entre realizar um controle centralizado das atividades (evitando ineficiência e duplicação de esforços, por exemplo) e dar autonomia às unidades que seja suficiente para permiti-las utilizar / explorar competência local.

- Otimizar os fluxos de informações entre os diversos laboratórios e entre os pesquisadores individuais em cada laboratório.

\section{2- Desenvolvimento de Produtos}

Uma vez que, no Brasil, conforme apresentado na seção 4.1.3, as atividades de inovação realizadas pelas empresas estão particularmente ligadas a desenvolvimento do produto (DP), esse assunto terá relevância neste trabalho e é descrito mais profundamente nesta seção. É apresentada, de maneira sucinta, uma revisão bibliográfica na área de DP, enfatizando as fases do processo de desenvolvimento, aspecto relevante para a condução dos resultados desta pesquisa, que são apresentados em capítulos posteriores. Em seguida, são apresentadas características do Desenvolvimento Global de Produtos (DGP), ou seja, é feito um aprofundamento num segmento particular da área DP, que foi fundamental para a realização deste trabalho.

Antes de serem apresentados esses tópicos sobre desenvolvimento de produtos, vale a pena uma discussão sucinta sobre inovação. Ela é caracterizada pela mudança tecnológica, seja em produtos ou em processos (Tidd et. al., 1997). Essas mudanças, 
dependendo do grau de "novidade", ou seja, de mudança tecnológica, gerado, podem ir de melhorias incrementais (que proporciona uma alteração pequena nos produtos e processos) a mudanças radicais (que transformam a maneira de pensarmos sobre o uso dos produtos ou processos).

Uma maneira de classificar a evolução dos produtos de acordo com a tecnologia foi desenvolvida por Wheelwright e Clark (1992). Conforme mostrado na figura 4.5, o autor considera o grau de mudança em produto e em processo para criar a classificação dos projetos de desenvolvimento:

- P\&D Avançados - geralmente é o precursor dos desenvolvimentos comerciais e servem para provar a viabilidade técnica de uma determinada concepção de produto e validar o conhecimento técnico existente de modo a verificar a possibilidade de comercialização;

- Único/Radical - gera um novo produto totalmente inovador;

- Plataforma ou próxima geração - o grau de inovação é menor que no anterior, mas há geração de produtos com novos conceitos (novas plataformas);

- Derivados e híbridos - desenvolvimento de produtos com pequenas variações numa mesma plataforma tecnológica, são considerados de uma mesma família;

- Sustentação - trata-se de projetos para manter, suportar ou adaptar os produtos existentes.

A vantagem competitiva sustentada é criada quando a empresa opera simultaneamente em múltiplos modos, seja gerenciando a inovação incremental ou descontínua, e promovendo mudanças radicais, visando eficiência de curto prazo ou a inovação a longo prazo (Tushman e Anderson, 1997). Sendo assim, a habilidade para gerir tipos diferentes de inovação é fundamental para a competição das companhias.

Isso porque as inovações tecnológicas, assim como os fatores ligados ao mercado, são fundamentais para o desenvolvimento de produtos. Clark e Wheelwright (1993) apresentam um modelo de estratégia de desenvolvimento, que considera ambos fatores - tecnológico e mercadológico - como sendo fundamentais para os 
desenvolvimentos de projetos. Nesse modelo, mostrado na figura 4.6, os autores consideram dois pontos ligados ao pré-projeto do produto - objetivos do desenvolvimento e plano de projeto agregado, nos quais as estratégias tecnológicas e mercadológicas podem ser discutidas e integradas, antes da execução do projeto propriamente. Isso permite que políticas da companhia sejam direcionadas e que, consequentemente, a gestão do desenvolvimento de projetos cooperativos ou individuais seja melhorada (Clark e Wheelwright, 1993).

\begin{tabular}{|c|c|c|c|c|c|}
\hline \multirow{2}{*}{\multicolumn{2}{|c|}{$\begin{array}{c}\text { P\&D } \\
\text { Avançados }\end{array}$}} & \multirow{2}{*}{$\begin{array}{l}\text { Maior } \\
+ \\
\text { Púcleo de } \\
\text { rowos } \\
\text { produtos }\end{array}$} & \multicolumn{2}{|c|}{ Mudarģa no Froduto } & Merwor \\
\hline & nçados & & $\begin{array}{l}\text { Produtos de } \\
\text { gerarótes } \\
\text { subsequertes }\end{array}$ & $\begin{array}{l}\text { Adiçáa a } \\
\text { Farrilia de } \\
\text { Produtos }\end{array}$ & $\begin{array}{l}\text { Derivativos e } \\
\text { Melhoramentos }\end{array}$ \\
\hline M & \multirow{2}{*}{$\mid \begin{array}{l}\text { Hücleo de } \\
\text { rovos } \\
\text { processos } \\
\text { Processos de } \\
\text { geracónes } \\
\text { subsequertes }\end{array}$} & $\begin{array}{l}\text { Üricol' } \\
\text { radical }\end{array}$ & & & \\
\hline $\begin{array}{ll}\mathrm{d} & \mathrm{P} \\
\mathrm{a} & \mathrm{r} \\
\mathrm{n} & \mathrm{o} \\
\mathrm{c} & \mathrm{c} \\
\mathrm{a} & \mathrm{e} \\
\mathrm{a} & \mathrm{s}\end{array}$ & & & \multirow[t]{3}{*}{$\begin{array}{l}\text { Platafor } \\
\text { geraçäo }\end{array}$} & ou próxima & \\
\hline $\begin{array}{ll}\mathrm{n} & \mathrm{s} \\
\mathrm{o} & \mathrm{o}\end{array}$ & Atualização & & & $\begin{array}{l}\text { Derivado } \\
\text { lubridos }\end{array}$ & \\
\hline Meror & $\begin{array}{l}\text { Mindarugs } \\
\text { Irorementais }\end{array}$ & & & & ustentação \\
\hline
\end{tabular}

Figura 4.5. Classificação de tipos de Projetos de DP (Wheelwright e Clark 1992)

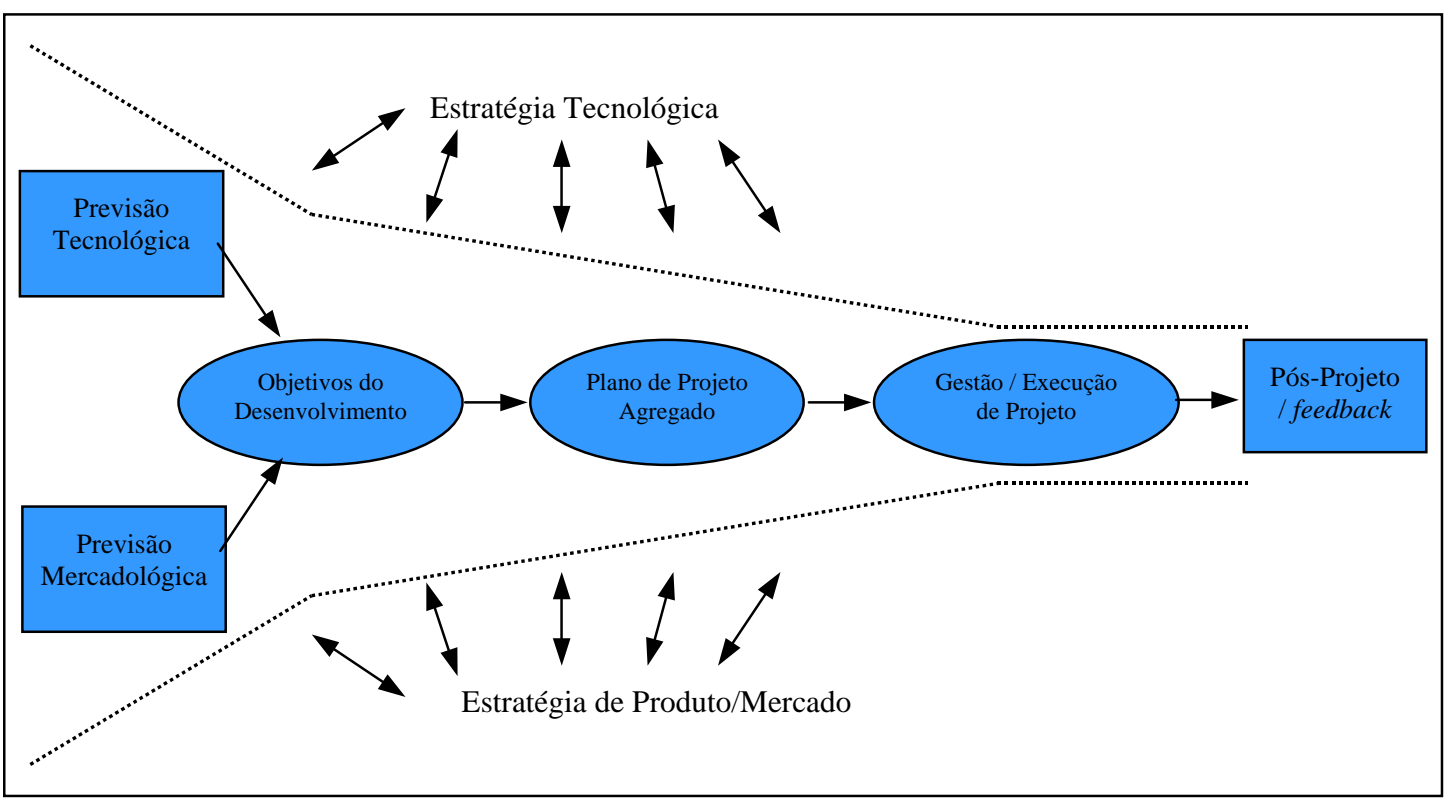

Figura 4.6. Modelos de Estratégia de Desenvolvimento (Clark e Wheelwright, 1993) 
Vernon (1966), na sua teoria do "ciclo de vida de produtos", considera três estágios para os produtos: inovação, crescimento e maturidade. No primeiro, o projeto do produto é freqüentemente alterado, a tecnologia não é estável e o produto é uma novidade para o mercado. Nessa fase, P\&D é muito importante para a competição das empresas. Durante o estágio de crescimento, uma vez que a aceitação do produto pelo mercado já está consolidada, a produção em massa é estabelecida e a competição / concorrência torna-se acirrada, nessa fase, são realizados ainda alguns incrementos no produto. No último estágio do ciclo de vida, o produto já possui características e tecnologia padronizadas, e, para a competitividade, custos de produção tornam-se mais importantes do que inovação; é quando a fabricação passa a ser realizada em países de baixo custo de mão-de-obra.

Sendo assim, o ciclo pelo qual passa um produto, englobando atividades que vão desde a concepção do projeto até a demanda do produto no mercado e eventualmente o seu desaparecimento, é referenciado como ciclo de vida do produto. A figura 4.7 ilustra um ciclo de vida tradicional. Nela podemos ver suas diversas etapas e as ligações existentes entre elas, tanto as que indicam seqüência de atividades, quanto as que mostram ofeedback para a etapa anterior.

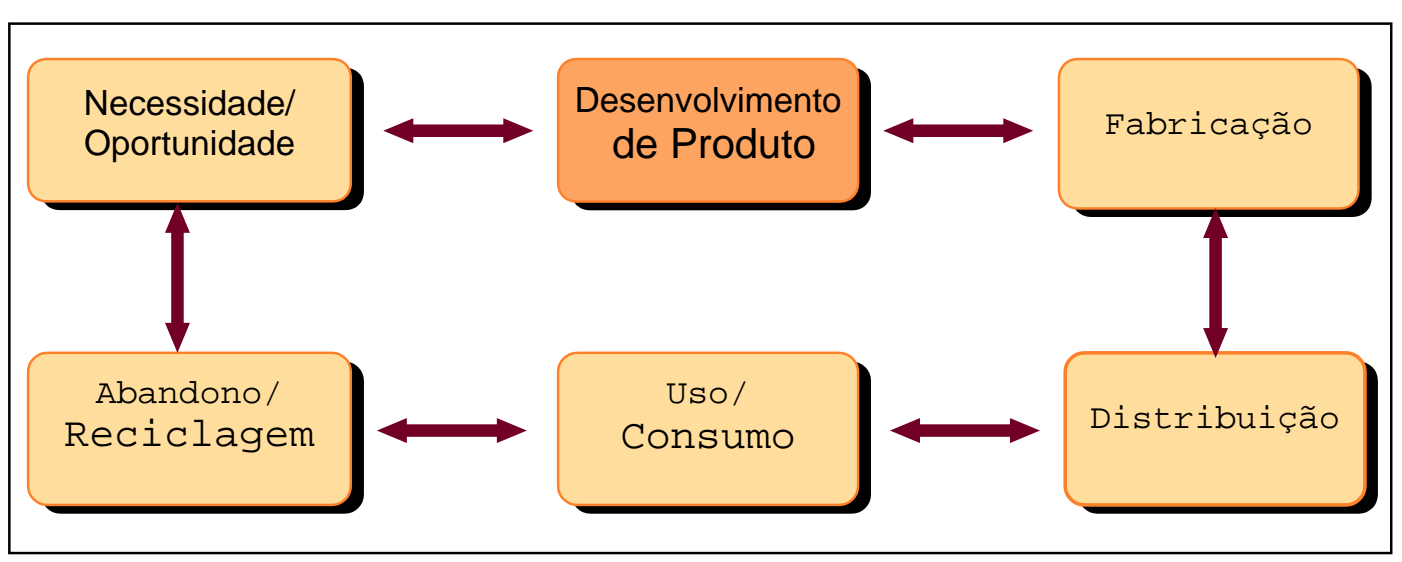

Figura 4.7 - Ciclo de Vida Tradicional de Produtos (Zhang e Zhang, 1995)

\subsubsection{Processo de Desenvolvimento de Produtos}

No ciclo de vida, o processo de "desenvolvimento de produto" em si (caixa em destaque na figura 4.7) será mais detalhado neste trabalho, uma vez que é o foco de 
atenção desta pesquisa. As fases típicas do desenvolvimento de um produto são (Wheelwright e Clark, 1992):

1. Concepção do Produto - informações sobre oportunidades de mercado; definição do mercado alvo; arquitetura do produto; projeto conceitual;

2. Planejamento do Produto - Construção do modelo; requisitos para investimentos; impactos financeiros;

3. Engenharia de Produto e de Processo - projeto detalhado do produto; desenvolvimento de ferramentas/equipamentos para a produção; criação e teste de protótipos (virtuais ou reais);

4. Produção Piloto / Lançamento - início da fabricação em volume reduzido (piloto); fabricação passa para escala comercial.

Nas primeiras duas fases - concepção e planejamento do produto - combinam-se informações referentes a mercado, requisitos de produção e possibilidades técnicas no intuito de criar a arquitetura do novo produto. Isso gera um projeto que deve ser aprovado para que o processo de desenvolvimento seja continuado, com o detalhamento da engenharia do produto e do processo (fase 3). No final dessa fase, deve-se ter uma versão final do produto para que possa ser iniciada a produção piloto e, finalmente, a introdução no mercado. Muitas vezes, essas fases acontecem simultaneamente conforme mostrado na figura 4.8 .

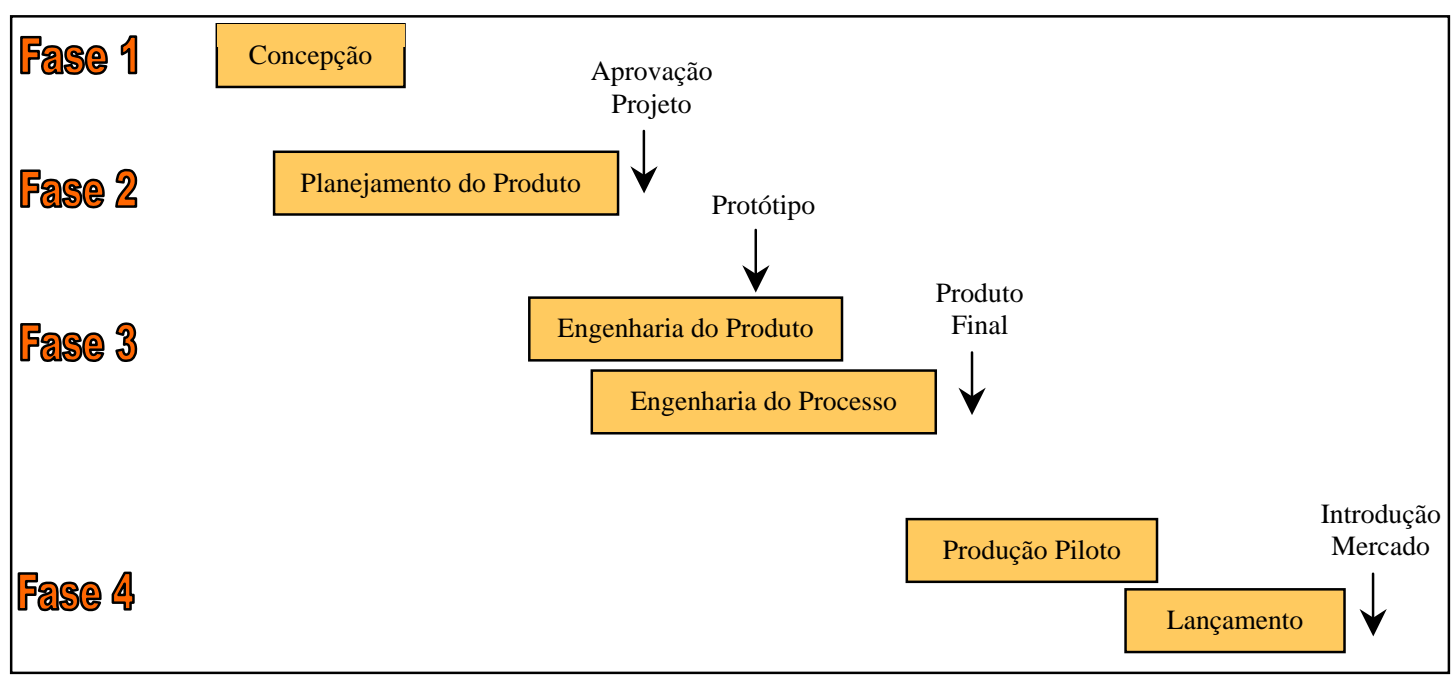

Figura 4.8 - Fases de Desenvolvimento de Produto (Wheelwright e Clark, 1992) 
Vários modelos semelhantes para o DP existem na literatura. Estudos feitos por pesquisadores de Harvard e do MIT (Massachusetts Institute of Technology) são considerados clássicos na área de DP e são referências para a maioria dos trabalhos científicos no segmento. Entre eles, além das abordagens de Wheelwright e Clark (1992, 1993), estão as pesquisas de Clark e Fujimoto (1991), desenvolvidas principalmente com casos oriundos da indústria automotiva.

Uma outra abordagem para representar o processo de DP é apresentada por Rozenfeld (1997). Nela (figura 4.9), as fases de concepção, conceituação e projeto de produto e processo são semelhantes às de concepção, planejamento e engenharia do modelo de Wheelwright e Clark (1992). A novidade fica com as fases de homologação, tanto de produto quanto de processo (que no modelo de Wheelwright e Clark fica implícito na fase de engenharia), e de "ensinar empresa". Essa última etapa antes da produção, consiste na transmissão de informações sobre o produto e seus processos para as demais áreas da empresa, tais como marketing, vendas, assistência técnica e fabricação, que tratarão, de alguma forma, do novo produto/processo. Além disso, o modelo mostra explicitamente a necessidade de em todas as fases estar fazendo avaliação e propondo ações corretivas.

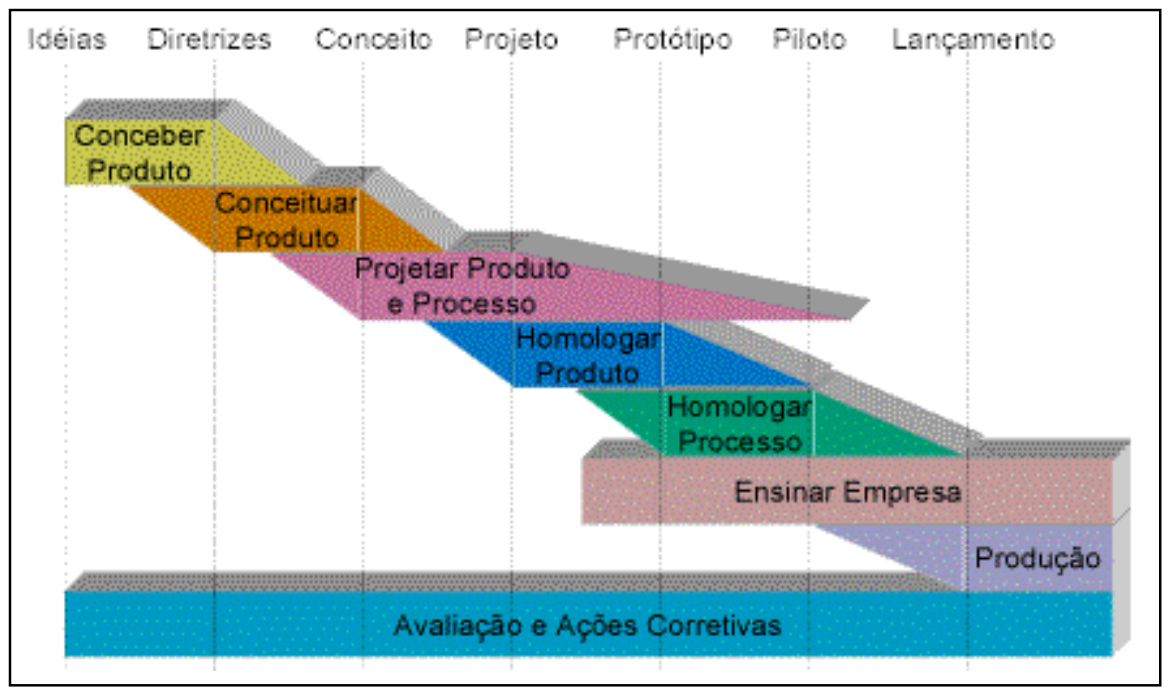

Figura 4.9. Modelo de Referência para processo de DP 
É evidente que algumas das etapas dessa forma tradicional de desenvolvimento de produtos podem ser diferenciadas de empresa para empresa, de setor para setor ou de um segmento tecnológico para outro. Essas diferenças ocorrem por influência de diversos fatores, como o tamanho das organizações, a complexidade do produto e do processo para a sua fabricação e a disponibilidade de recursos financeiros, humanos e tecnológicos. Fatores menos evidentes e de detecção não tão objetivas, como a motivação das pessoas e o envolvimento da gerência, também podem gerar as diferenças que ocorrem no processo de desenvolvimento de produtos nas empresas.

No entanto, geralmente, a idéia de um novo produto vem do setor de Marketing, que está atento às necessidades dos clientes. As pessoas ligadas a esse setor discutem então a idéia com o departamento de Desenvolvimento de Produtos (dependendo da complexidade do produto, fazem parte dele um engenheiro de projeto, um grupo de engenheiros de projeto ou vários grupos de engenheiros responsáveis pelo desenvolvimento do produto). É feita então a definição do projeto, que é usualmente baseada em requisitos funcionais do produto, características técnicas, objetivos econômicos e uma variedade de restrições, dependendo da natureza do produto (Zhang e Zhang, 1995).

Uma vez que os engenheiros de projeto completam a tarefa de especificação do produto e de seus componentes, as informações de projeto são, então, passadas para os engenheiros de processo no departamento de manufatura (Zhang e Zhang, 1995). Esse estágio cobre várias funções. Primeiramente, os processos de manufatura são planejados, isso inclui a seleção das máquinas a serem utilizadas e a definição da sequiência de operações necessárias para a produção de peças individuais e para a montagem de componentes. Depois dessa fase, é feita a programação da produção, com definição dos prazos das tarefas e das pessoas responsáveis por elas. O processo de planejamento e programação da produção é seguido pelo trabalho de preparação de materiais a serem manipulados pelos equipamentos, ferramentas necessárias, etc. Finalizada essa fase, as peças do produto são produzidas e montadas. Enquanto isso, a área de controle de qualidade desenvolve um programa para garantir a qualidade do produto, que é aplicado em todas as etapas do processo produtivo. Antes da finalização deste, equipes da área financeira fazem análises dos custos e lucros 
obtidos no seu desenvolvimento. Finalmente, o produto é entregue para distribuição no mercado e as pessoas da área de pós-venda se responsabilizam pela análise da satisfação dos clientes (feedback).

Em todos os modelos de processo de DP, as etapas/fases são dependentes das estratégias de negócios das áreas de Marketing, Engenharia e Manufatura, e do envolvimento eficaz entre elas. Por isso, essa representação do processo de DP em etapas seqüencialmente dispostas, ou seja, um processo sem muito envolvimento das diversas áreas participantes, com as pessoas recebendo as informações que são passadas e fazendo o trabalho sem conhecer o projeto como um todo, não é exatamente a maneira mais produtiva de desenvolvimento.

Segundo Ziemke e Spann (1991), a abordagem serial para projeto, desenvolvimento, manufatura e marketing de produtos tem várias desvantagens. Um problema é a duração do ciclo de desenvolvimento de produto, que costuma ser longo e demorado. Um outro é o fato de que mais de $90 \%$ dos custos de manufatura podem estar comprometidos antes que os engenheiros de manufatura definam o projeto do produto. Uma terceira desvantagem refere-se à possibilidade do produto não ser ótimo para atender às expectativas do mercado. Zhang e Zhang (1995) enfatizam que o ciclo de vida seqüencial de produtos não apenas prolonga o tempo de desenvolvimento e de aumento dos custos do produto, mas também facilita a ocorrência de conflitos entre os participantes dos projetos, uma vez que existe uma grande separação entre as áreas responsáveis pela criação do produto.

A solução atualmente encontrada para superar problemas dessa natureza é a utilização da Engenharia Simultânea (ES), que proporciona a realização simultânea das atividades relacionadas com o desenvolvimento de produtos, tornando o processo mais dinâmico e integrado que o desenvolvimento seqüencial de produtos.

A implantação da ES é uma maneira de facilitar a globalização do desenvolvimento de produtos, uma vez que permite, através da existência de várias técnicas específicas para aplicá-la e do desenvolvimento de tecnologia de informação e comunicação, o trabalho cooperativo de equipes distribuídas mundialmente. No 
entanto, o estudo desta área foge do escopo deste trabalho de doutorado, portanto não será abordado aqui.

\subsection{2- Desenvolvimento Global de Produtos (DGP)}

Como resultado da globalização, cresce a demanda por mais e melhores produtos, revitalizando o processo de desenvolvimento dos mesmos (Yelkur e Herbig, 1996). A globalização também influencia a convergência mundial das preferências dos consumidores.

Cresce assim, apesar da necessidade de regionalização de muitos produtos, a tendência em criar produtos globais, que se diferem dos produtos domésticos por serem comuns a vários mercados e, portanto, possuírem características de múltiplos países, povos e culturas. O sucesso dos produtos globais depende das estratégias usadas no desenvolvimento dos mesmos.

Numa empresa, o desenvolvimento de produtos pode acontecer integralmente numa mesma unidade ou pode dar-se em diversas unidades localizadas em diferentes países, globalizando assim o processo de DP. Dessa forma, o processo de DP tornase global porque envolve equipes distribuídas geograficamente e os produtos desenvolvidos nesse processo são geralmente direcionados para o mercado mundial. No entanto, nem todo produto global é desenvolvido mundialmente, muitos são desenvolvidos na matriz ou numa subsidiária específica da TNC e distribuídos para os mercados globais, ou seja, nem todo desenvolvimento de produto global (DPG) é feito através de um processo de desenvolvimento global de produtos (DGP).

No caso de DGP, entre as equipes mundiais de desenvolvimento devem estar pessoas com conhecimentos técnicos e tecnológicos sobre os produtos, sobre as necessidades dos consumidores locais espalhados globalmente, e sobre as características da infraestrutura de países e regiões sob vários aspectos como logística de distribuição, cadeias produtivas locais ou capacidade das fábricas locais. Como as fontes dessas informações, na maioria das vezes, estão geograficamente dispersas, deve haver troca de conhecimento entre fronteiras para a inovação de produtos, isso não necessariamente ocorre no DPG. 
Para a formação das equipes de desenvolvimento, as empresas reúnem pessoas da matriz, de algumas subsidiárias e de regiões que detêm tecnologia para contribuir com a inovação desejada. A integração das equipes de desenvolvimento de produtos possibilita a troca de conhecimento entre elas, permitindo benefícios para subsidiárias e matriz. Os talentos das subsidiárias devem ser utilizados apropriadamente para beneficiar a companhia como um todo.

De maneira geral, considerando o ciclo de vida de Vernon (1966), o primeiro estágio do produto, referente à inovação ${ }^{14}$, é realizado na matriz (Pearce,1997). No segundo estágio, quando o produto atinge maturidade e aumenta a demanda para novos mercados no exterior, há envolvimento das subsidiárias para produção e adaptação local de produtos. No estágio final, ou seja, quando o produto já está totalmente padronizado, as plantas voltadas para exportação, que possuem baixos custos de produção, são envolvidas fortemente. Ou seja, a internacionalização do DP é realizada nas fases mais adiantadas do ciclo de desenvolvimento de produtos (Cantwell e Janne, 1999).

No entanto, várias são as estratégias de gestão para o desenvolvimento de produtos globais encontradas nas companhias, até mesmo numa única empresa, diferentes estratégias são utilizadas para projetos distintos. As estratégias de gestão são discutidas na seção posterior deste trabalho.

\subsubsection{Gestão de Desenvolvimento de Produtos Globais}

As formas de gestão do desenvolvimento de produtos globais podem diferir de setor para setor e de empresa para empresa, mas em geral elas possuem algumas características semelhantes e são classificadas por alguns autores. Vários são os aspectos relevantes a considerar no processo de gestão de DPG, dois são mais fortemente discutidos, um deles está relacionado à divisão do trabalho entre as equipes e o outro refere-se à estrutura organizacional das unidades funcionais de $\mathrm{P} \& \mathrm{D}$ distribuídas geograficamente.

\footnotetext{
${ }^{14}$ Especificamente o desenvolvimento de novos produtos
} 
Um outro aspecto considerado na gestão de DPG está relacionado aos mecanismos utilizados pelas empresas para conduzir a transferência de conhecimento/ informações entre as equipes mundiais para desenvolvimento, mas este aspecto não será tratado com profundidade aqui, por não ser objetivo deste trabalho.

\subsubsection{Estruturas para divisão de tarefas entre as equipes}

Hakason (1990) sugere, simplificadamente, que a estrutura utilizada pelas TNCs para realização de P\&D global tem três estágios: centralizada, descentralizada e integrada. Gammelgaard (1999) apresenta um modelo para divisão de trabalho em P\&D internacional que estabelece, primeiramente, a diferenciação entre centralização e descentralização, seguida da especificação caso a empresa opte por desenvolvimento descentralizado. Nessa circunstância, é preciso estabelecer se a companhia irá atuar com estratégia top-to-bottom, com tarefas ditadas pela matriz - do topo para as bases, ou com a estratégia bottom-to-top, que reflete uma autonomia maior das afiliadas da TNC - desenvolvendo produtos na subsidiária (bottom) e repassando para a matriz (top) e para a organização como um todo.

De maneira um pouco mais ampla, Bartlett e Ghoshal (1990) apresentam quatro diferentes estruturas para gerenciamento de processos de inovação:

- Centro para Global (Central-for-global Innovations) - desenvolvimento de novos produtos e processos é feito no país de origem da companhia e transferido para os mercados globais;

- Local para Local (Local-for-local Innovations) - desenvolvimento de produtos e processos é independente em cada unidade de P\&D distribuída mundialmente e orientado para o mercado local da subsidiária;

- Influência Local (Locally-leveraged Innovations) - desenvolvimento de produtos e processos é feito nas subsidiárias e distribuído para a companhia como um todo; 
- Rede Global (Globally-linked Innovations) - desenvolvimento é feito com a colaboração de unidades de P\&D localizadas em diferentes países para exploração de mercados globais.

Cada uma dessas formas de gestão possui vantagens e desvantagens e são aplicadas de acordo com as estratégias das empresas e das características do negócio delas. Elas abrangem as várias possibilidades de desenvolvimento tecnológico numa empresa transnacional, seja ele centralizado ou não.

No entanto, para descentralizar Pesquisa e Desenvolvimento, as companhias utilizam diferentes estratégias ao distribuir suas atividades e o controle delas mundialmente. A tipologia de Ronstadt (1984), apresentada na seção 4.1.3.2, não inclui as relações intra-organizacionais, apesar de ser amplamente usada como padrão de estrutura de P\&D internacional das TNCs.

A literatura mostra vários modelos para gestão do desenvolvimento descentralizado, mesmo que a coordenação seja central. Uma dessas classificações define quatro estilos de gestão de atividades de P\&D (Behrman e Fisher, 1980): centralização absoluta, centralização participativa, liberdade supervisionada e total liberdade. Os autores afirmam que o segundo e o terceiro tipos são os dominantes, ou seja, os mais utilizados pelas instituições e que pouquíssimos exemplos foram observados para o primeiro e o quarto.

A "Centralização Participativa" caracteriza-se pela forte autoridade centralizada sobre o orçamento, os programas e a seleção de projetos internacionais. No entanto, há evidência da participação das subsidiárias na gestão das atividades de P\&D.

No modelo de "Liberdade Supervisionada", as firmas possuem vários laboratórios internacionais e têm a tendência de deixar a responsabilidade por decisões operacionais nas mãos das subsidiárias. A coordenação das atividades parece ser bem menos formal do que a no modelo de Centralização Participativa.

Um trabalho mais recente, desenvolvido por Chiesa e Manzini (1996), analisou os tipos de subsidiárias internacionais de várias empresas mundiais e as interações entre elas, identificando estruturas de $\mathrm{P} \& \mathrm{D}$ em cada tecnologia ou produto dessas 
empresas. Tal estudo levou à criação de uma classificação com quatro estruturas (figura 4.10):

- Estrutura de Especialização Isolada - um laboratório estrangeiro tem total responsabilidade pelo desenvolvimento de certo(a) tecnologia/produto/processo globais. Este centro de pesquisa é o único da TNC no referido campo/área, ele é considerado centro de excelência da companhia. Não existe interação entre as unidades no desenvolvimento de projeto. A transferência de conhecimento é limitada principalmente à fase de introdução de produtos nos mercados das subsidiárias, passando do centro de excelência para as unidades da TNC. Isso pode ser feito de diferentes maneiras, seja com a transferência temporária de técnicos da unidade central para a subsidiária (mais comum quando a fabricação do produto vai acontecer na unidade local) ou funcionários da subsidiária que são treinados no centro de competência para darem suporte técnico à introdução do produto no mercado local (normalmente usado quando a fabricação é feita em outra localidade, que não a subsidiária). Essa estrutura é também conhecida por Estrutura de Centro de Excelência (Chiesa, 2000).

- Estrutura de Especialização Suportada - existe um centro global responsável pelo trabalho de $\mathrm{P} \& \mathrm{D}$, assim como na estrutura de especialização isolada. No entanto, existem várias unidades em diferentes países que provêem o centro global com informações para a inovação e para o desenvolvimento de novos produtos, originadas dos requisitos (tecnológicos e mercadológicos) do ambiente local. Tal estrutura alia os benefícios da especialização / concentração (eficiência, economias de escala, baixos custos para coordenação de projetos) com a possibilidade de monitorar oportunidades locais para inovação. "Nesta estrutura, a única fase que não implica em transferência de conhecimento tecnológico é a de desenvolvimento em si" (Chiesa e Manzini, 1996, p. 472). A fase de criação/concepção acontece na unidade central, mas com informações provenientes das demais unidades de monitoração. As estratégias para transferência de conhecimento são semelhantes às utilizadas na estrutura isolada.

- Estrutura de Contribuidores Especializados - é estabelecida uma divisão de tarefas entre as unidades, mantendo a coordenação centralizada e atribuindo a 
cada subsidiária atividades individuais ${ }^{15}$ dentro do programa estabelecido. $\mathrm{O}$ conhecimento desenvolvido em cada unidade é transferido para a central. Nesta estrutura, as interações entre as unidades dispersas globalmente são muito mais complexas do que na estrutura de Especialização Suportada. $\mathrm{Na}$ fase de concepção, o fluxo de informações é contínuo das unidades para o centro e entre as próprias subsidiárias. As fases de definição do projeto e de desenvolvimento técnico são realizadas pelas equipes internacionais, envolvendo várias unidades. Ou seja, neste tipo de estrutura, existe muito mais interação nas fases de definição e de desenvolvimento tecnológico, de produto ou de processo.

- Estrutura de Laboratórios Integrados - composta por diferentes laboratórios dispersos em diferentes países e operando nos mesmos segmentos de produto ou áreas tecnológicas. As TNCs com esta estrutura tendem a dar liberdade aos laboratórios estrangeiros para inovação, mas suas iniciativas e atividades são monitoradas centralmente para evitar duplicações, coordenar esforços dispersos e envolver diferentes mercados. Como na estrutura de contribuidores especializados, a transferência de conhecimento acontece com forte interação entre as várias unidades nas fases de planejamento, formulação e desenvolvimento tecnológico. Um outro nome recebido por esta estrutura é Estrutura de Rede (Chiesa, 2000).

Vale destacar que essas diferentes estruturas são mais freqüentemente utilizadas para o desenvolvimento de produtos. Para as atividades de pesquisa, a Estrutura de Rede é mais comum porque cada unidade realiza seus próprios programas com alguma coordenação, mas a duplicação de esforços é, de certa forma, permitida (Chiesa, 2000). A realização de projetos semelhantes paralelamente pelas várias unidades é uma maneira de acelerar o processo de aprendizagem, uma vez que cada afiliada trabalha de diferentes maneiras e sob perspetivas distintas. Isso pode levar a uma competição interna entre as unidades independentes, aumentando a criatividade delas, assim beneficiando a companhia como um todo (Chiesa, 2000).

\footnotetext{
${ }^{15}$ Cada unidade é especializada num determinado segmento tecnológico ou em certo componente de produto (Chiesa, 2000)
} 


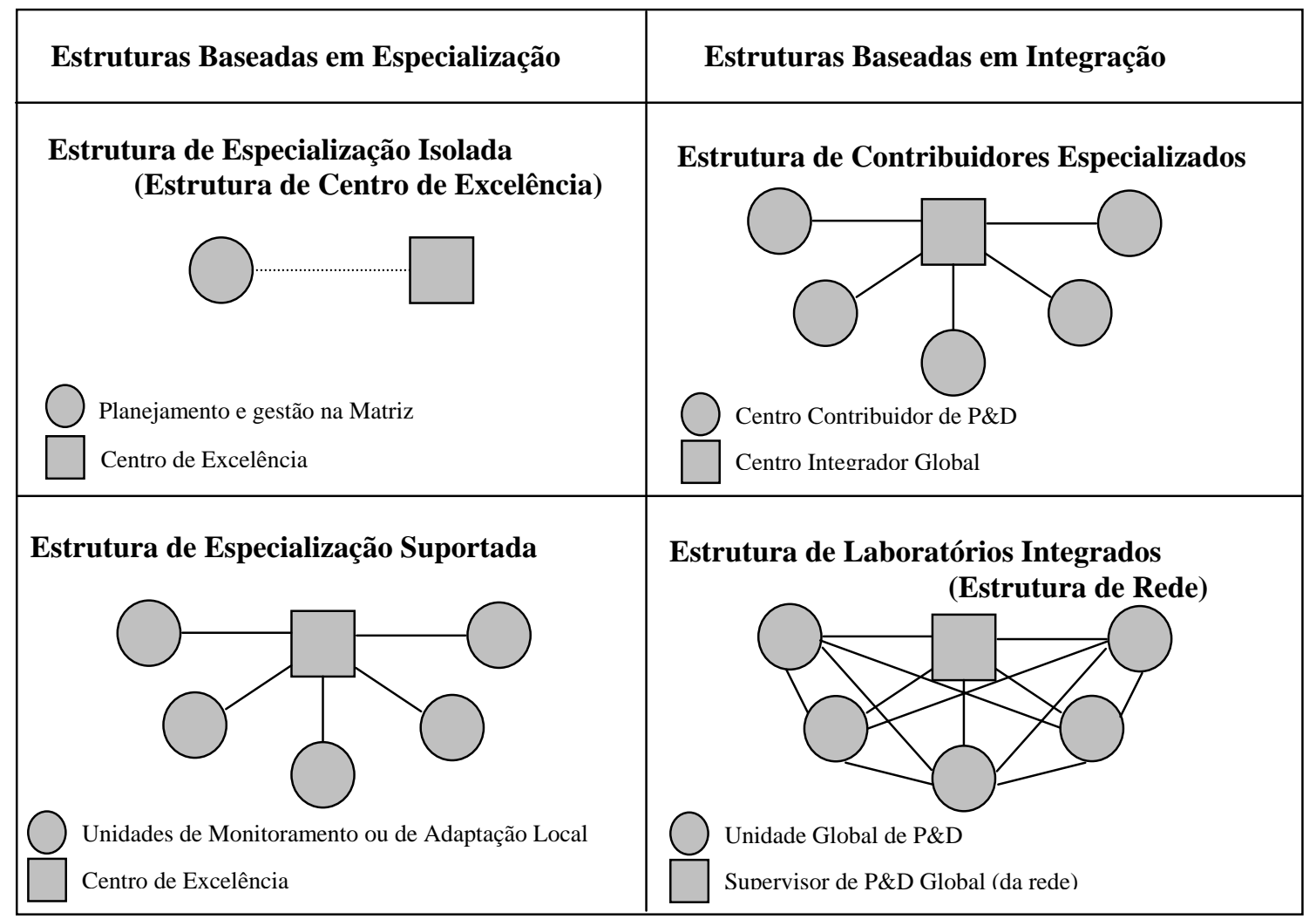

Figura 4.10- Estruturas de P\&D Internacional (Baseada em Chiesa, 2000)

Chiesa (2000), retomando sua classificação, divide essas estruturas em duas categorias principais: baseadas em Especialização, onde aparecem as duas primeiras estruturas descritas (Estrutura de Especialização Isolada ou de Centro de Excelência e Estrutura de Especialização Suportada), e baseadas em Integração, com as outras duas estruturas (Estrutura de Contribuidores Especializados e Estrutura de Laboratórios Integrados ou de Rede) (figura 4.10).

Uma classificação similar à de Chiesa para estruturas de P\&D mundiais foi desenvolvida por Gassmann e von Zedtwitz (1999). Esses autores apresentam cinco modelos de orientação estrutural e comportamental em organizações de P\&D internacionais (figura 4.11):

- Centralizado Etnocêntricamente (Ethnocentric Centralized $R \& D$ ) - Todas as atividades de $\mathrm{P} \& \mathrm{D}$ são concentradas no país da matriz, considerado tecnologicamente superior aos das subsidiárias. O intuito é "proteger" tecnologias que sejam fundamentais para a companhia, dos competidores. 
- Centralizado Geocêntricamente (Geocentric Centralized R\&D) - Centraliza conhecimento obtido globalmente e tecnologias disponíveis em países fora da matriz através do envio de funcionários de P\&D para o exterior, no intuito de intensificar o relacionamento e colaborar com a manufatura, os fornecedores e os clientes-chave locais. Dessa forma, é adotado em companhias mais dependentes de mercados estrangeiros e competências locais do que as que utilizam o modelo etnocêntrico.

- Descentralizado Policêntricamente (Polycentric Decentralized R\&D) Caracterizado por laboratórios locais de desenvolvimento sem supervisão da P\&D central da corporação, cujas relações limitam-se a relatos das atividades de P\&D dos laboratórios locais para a matriz. O diretor de $\mathrm{P} \& \mathrm{D}$ da subsidiária reporta-se ao gerente da própria unidade.

- Controle Central (R\&D Hub Model) - A unidade central de P\&D, geralmente localizada na matriz, é líder tecnológico da corporação por ser o principal laboratório para pesquisa e desenvolvimento avançados. As atividades de P\&D são descentralizadas, mas fortemente controladas pela sede. Esses laboratórios estrangeiros, geralmente envolvidos com monitoramento local, focalizam suas atividades em segmentos tecnológicos pré-determinados.

- Rede Integrada (Integrated $R \& D$ Network) - Trata-se de uma estrutura na qual cada unidade da rede integrada especializa-se em um produto, componente ou área tecnológica, tornando-se centro de competência no segmento e o responsável mundial pelo produto ("world product mandate"), tanto para a continuidade de seu desenvolvimento quanto para introdução em outros mercados. Diferentemente da estrutura $H u b$, as unidades estrangeiras de $\mathrm{P} \& \mathrm{D}$ assumem papéis estratégicos, ou seja, um centro de competência não deve apenas agir monitorando possíveis mudanças na sua área, mas também envolver-se em definição de estratégias e desenvolvimento de novos negócios, afetando a TNC como um todo. Uma vez que são estabelecidas conexões entre as unidades de $\mathrm{P} \& \mathrm{D}$ participantes da rede, esta estrutura exige uma complexa coordenação das atividades internacionais de P\&D. 

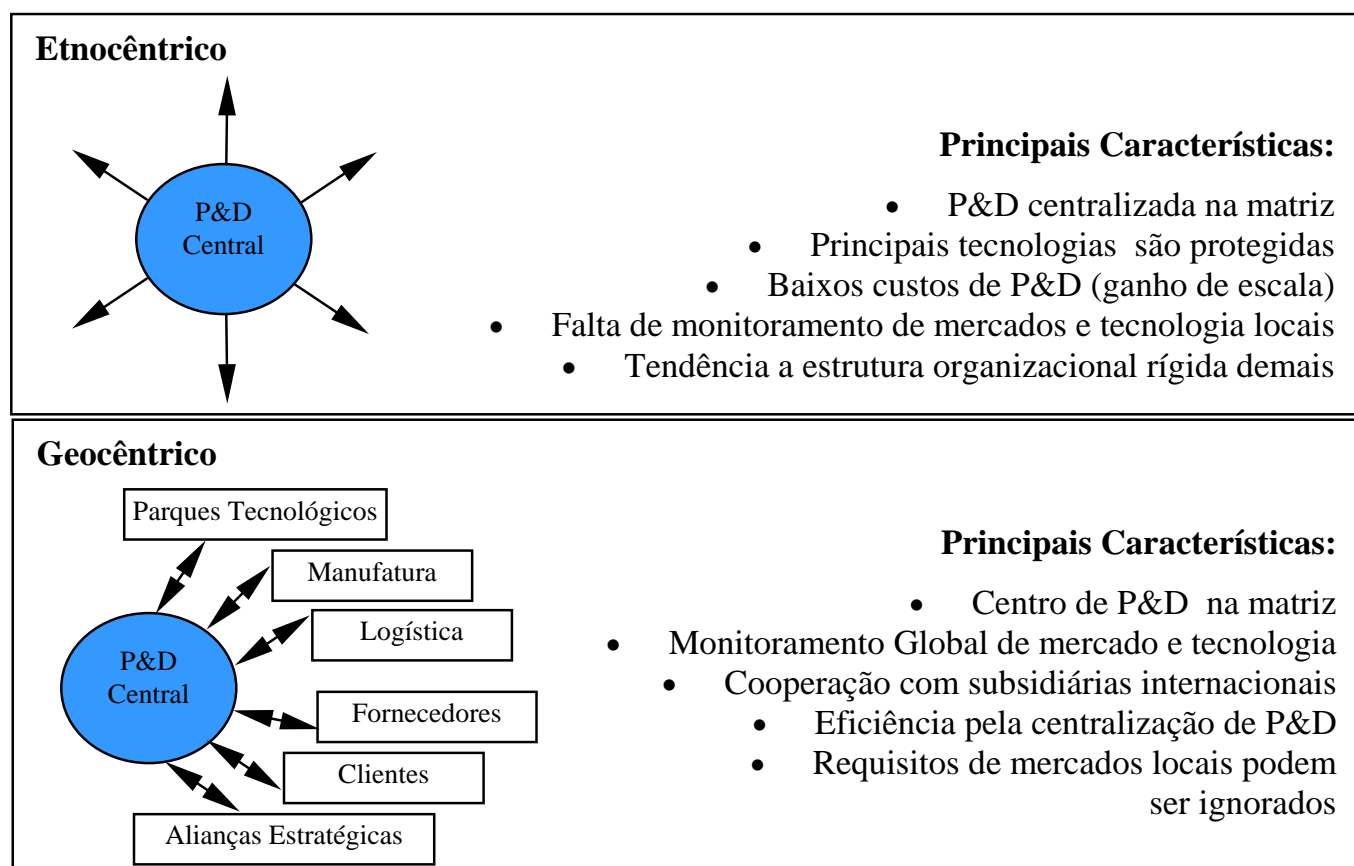

Principais Características:

- Centro de P\&D na matriz

- Monitoramento Global de mercado e tecnologia

- Cooperação com subsidiárias internacionais

- Eficiência pela centralização de P\&D

- Requisitos de mercados locais podem ser ignorados

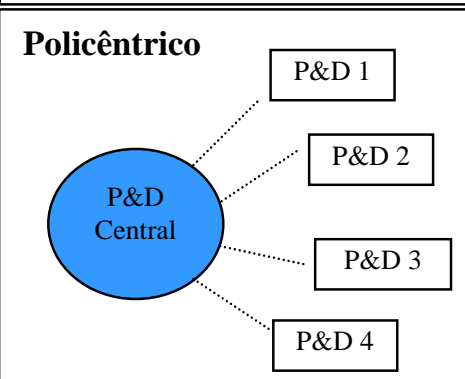

Principais Características:

- $\quad P \& D$ descentralizada sem supervisão central

- Unidades de P\&D (1,2,3...) fortemente ligadas a desenvolvimento de produtos - Adaptação local

- Uso de recursos locais

- Ineficiência e desenvolvimentos paralelos

\section{Controle Central (Hub Model)}

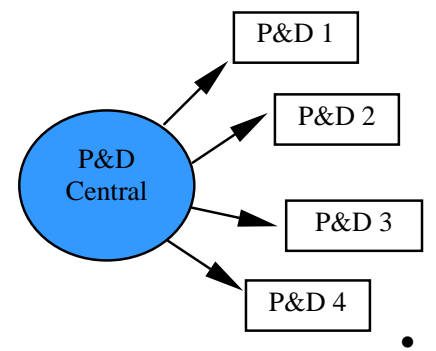

Principais Características:

- P\&D Central é líder tecnológico - Coordenação central de condução e orçamento de P\&D

- Estrutura em nó com dominância do centro

- Eficiência (evita redundância, etc.)

- Exploração de forças locais

- Alto custo para coordenação

Pode inihir criatividade e flexihilidade nelo controle central

\section{Rede Integrada}

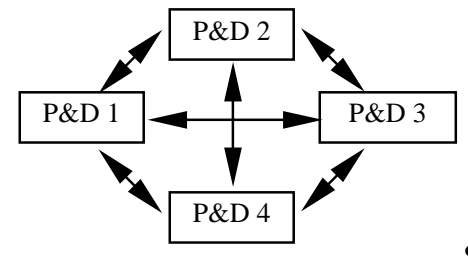

Principais Características:

- Atividades de P\&D são altamente internacionalizadas

- Centros de competência atuam globalmente

- Exploração e refinamento de forças locais

- Custos altos para coordenação

- Regras institucionais e processos decisórios complexos

Figura 4.11 - Organização Internacional de P\&D (Baseada em Gassmann e von Zedtwitz,1999) 
Essas estruturas não são estabelecidas definitivamente numa companhia, ou seja, a organização de P\&D internacional de uma empresa pode - e geralmente é continuamente modificada, com o intuito de promover a evolução nos processos de P\&D. Gassmann e von Zedtwitz (1999) apontam cinco tendências para essa mudança, baseadas em dois critérios: localização (centralizada ou descentralizada) de atividades de $\mathrm{P} \& \mathrm{D}$ e tipo de integração entre equipes de $\mathrm{P} \& \mathrm{D}$ (competição ou cooperação).

A primeira das tendências apontadas pelos autores vem da necessidade de alinhar o processo de $\mathrm{P} \& \mathrm{D}$ com os requisitos de mercados internacionais (aumentando a cooperação para o desenvolvimento de produtos ou processos), então o centro de P\&D passa a obter informação e feedback externos. Essa tendência caracteriza a alteração de uma estrutura etnocêntrica para uma geocêntrica. Outra tendência apresentada por Gassmann e von Zedtwitz (1999) procura criar uma descentralização de $\mathrm{P} \& \mathrm{D}$, caracterizando a passagem de uma das estruturas centralizadas (etnocêntrica ou geocêntrica) para o modelo de coordenação central $(H u b)$.

À medida que as unidades locais de P\&D (espalhadas mundialmente) aumentam suas competências tecnológicas, uma terceira tendência de mudança estrutural é identificada. Trata-se de uma evolução baseada na autonomia que a unidade central de controle de $\mathrm{P} \& \mathrm{D}$ concede às unidades locais, que, com isso, tornam-se mais flexíveis e livres para a realização do desenvolvimento tecnológico. Essa mudança caracteriza a passagem de uma estrutura de Coordenação Central $(H u b)$ para uma Rede Integrada.

Uma quarta tendência de mudança organizacional identificada por Gassmann e von Zedtwitz está relacionada às empresas que tiveram um histórico de crescimento e fortalecimento de P\&D internacional baseado em laboratórios relativamente autônomos. A partir do momento que tais empresas reconhecem os benefícios da integração e interconexão de suas atividades internacionais de $\mathrm{P} \& \mathrm{D}$, criam-se centros de competências, e mecanismos para coordená-los são introduzidos. Essa tendência caracteriza a passagem de uma estrutura Policêntrica para uma de Rede Integrada. 
No entanto, para reduzirem custos, as companhias que adotaram a estrutura de Redes Integradas são forçadas a focalizarem seus esforços em um número menor de centros de competências, caracterizando uma re-centralização de P\&D. O intuito é, com essa consolidação, explorar efeitos de escala e melhorar a coordenação de atividades de P\&D globais, reduzindo, com isso, a duplicação de tarefas e intensificando a transformação de tecnologia entre os laboratórios por (Gassmann e von Zedtwitz, 1999, p. 246).

Vale destacar que o modelo Descentralizado Policêntricamente "é o modelo, entre os cinco, que está morrendo" (Gassmann e von Zedtwitz, 1999, p. 241). Nessa estrutura, embora haja benefícios com a forte orientação para mercados locais, a falta de coordenação central aumenta os custos e esforços para P\&D. Segundo os próprios autores que criaram tal classificação (Gassmann e von Zedtwitz, 1999), a configuração Policêntrica dá lugar à estrutura de Controle Central $(H u b)$ ou à de Rede Integrada.

Com essa consideração feita por Gassman e von Zedtwitz, crescem as similaridades entre essas estruturas e as desenvolvidas por Chiesa, apresentadas anteriormente. Mais que isso, essas duas classificações complementam-se. Existem pontos em comum entre elas, em especial os relacionados às divisões claras entre duas principais características das estruturas: a centralização do desenvolvimento (com ou sem a participação de unidades locais de desenvolvimento) e a integração para o desenvolvimento (com maior ou menor conexão entre as próprias unidades locais de desenvolvimento). Essas diferenças são discutidas no capítulo 7, como parte dos resultados deste trabalho.

Esses dois modelos apresentados são também semelhantes à classificação desenvolvida por Behrman e Fischer (1980), mostrada anteriormente, na qual são considerados dois principais tipos de estruturas para desenvolvimento tecnológico internacional: centralização participativa, liberdade supervisionada. Essas duas características de gestão consideram o envolvimento das subsidiárias com coordenação de atividades de $\mathrm{P} \& \mathrm{D}$, a primeira centraliza as atividades, que são realizadas com a participação de outras, e a segunda distribui o desenvolvimento entre várias subsidiárias, coordenando o processo. 
Além desse tipo de classificação para distribuição de tarefas entre as unidades que realizam $\mathrm{P} \& D$, são também pontos de discussão quando se trata de $P \& D$ internacional, os diferenciados tipos de estruturas organizacionais para as unidades descentralizadas, que serão discutidos na próxima seção.

\subsubsection{Estruturação Organizacional para P\&D descentralizada}

As unidades de P\&D das companhias transnacionais distribuídas geograficamente podem ser organizadas de diferentes formas no que se refere às estruturas organizacionais para gestão de P\&D, adotada pelas empresas. De Meyer e Mizushima (1989) consideram três estruturas organizacionais possíveis:

- Funcional - organização na qual os vários laboratórios de P\&D reportam-se à função de P\&D na presidência da TNC e o centro de P\&D tem força para coordenar todas as funções de desenvolvimento tecnológico distribuídos.

- Divisional - nessa organização, cada divisão da companhia tem seu próprio núcleo de $\mathrm{P} \& \mathrm{D}$ reportando-se à gerência da divisão na matriz. Nessa estrutura, o centro de P\&D tem um papel de coordenação e de consultoria.

- Matricial - organização em que a unidade de $\mathrm{P} \& \mathrm{D}$ reporta-se tanto à gerência de $\mathrm{P} \& \mathrm{D}$ divisional quanto à central.

Na estrutura Divisional, a gerência da divisão pode, em alguns casos, ser a própria direção da subsidiária local. Também a estrutura Matricial pode ser um pouco diferente da estabelecida acima, e tornar-se, por exemplo, uma estrutura tridimensional, na qual a $\mathrm{P} \& \mathrm{D}$ local tem que reportar-se ao centro de $\mathrm{P} \& \mathrm{D}$, à direção da subsidiária e à gerência divisional ou de produto.

Uma outra discussão importante a respeito da internacionalização de P\&D relacionase à difusão do conhecimento, ou seja, aos métodos, técnicas e tecnologia da informação utilizados para que as equipes dispersas globalmente tenham o suporte necessário na troca de informações para a realização das atividades de P\&D. No entanto, esse aspecto não é tratado neste trabalho. 


\section{Capítulo 5}

\section{Setor de Telecomunicações}

Juntamente com a área de internacionalização de desenvolvimento de produtos, a indústria de telecomunicações é fundamental para o embasamento bibliográfico deste trabalho de pesquisa ${ }^{16}$. Entender mais profundamente o setor em alguns aspectos foi essencial para que a obtenção dos resultados.

Para tanto, foi preciso avaliar, entre outras, características relacionadas aos aspectos históricos do setor no Brasil e no mundo, à sua estruturação organizacional e às particularidades do desenvolvimento tecnológico. Sendo assim, este capítulo apresenta um levantamento bibliográfico da área, a configuração atual e algumas perspectivas a respeito do setor de telecom, que serão retomados nas discussões dos resultados e das conclusões deste trabalho.

\section{1- Aspectos Históricos}

As telecomunicações nasceram com a invenção do telégrafo em 1844, evoluíram com a criação do telefone em 1876 e o rádio em 1895 e trilharam uma escalada impressionante até os dias atuais. $\mathrm{O}$ advento dos computadores na metade do século XX contribuiu fortemente para mudanças tecnológicas na área de telecomunicações direcionando as inovações mais recentes.

\footnotetext{
${ }^{16}$ Conforme mostrado na figura 2.1, capítulo 2.
} 
O Brasil foi o primeiro país do mundo a utilizar o telefone depois dos EUA, isso aconteceu em 1877. Mas a telefonia no país se expandiu lentamente. O início da telefonia no país se deu pela prestação de serviços (instalações e operações). A fabricação se resumia a uma adaptação do produto ou este era simplesmente etiquetado com legendas em português (Capellaro, 1990).

O primeiro grande esforço para a integração nacional acontece com a interligação da Amazônia com as linhas já existentes de 1890 a 1916. Segundo Siqueira (Siqueira, 1997), o período entre os anos 20 e os anos 60 é de completa estagnação, com um ritmo muito lento de desenvolvimento da telefonia brasileira.

Capellaro (Capellaro, 1990) cita, entretanto, que foi na década de 20 que aconteceram as primeiras instalações de radiodifusão no Brasil, como conseqüência, permitiu o nascimento de uma incipiente indústria de equipamentos de entretenimento e a vinda de seus fabricantes estrangeiros para o país. Se instalaram aqui empresas como Telefunken e Philips, que importavam os equipamentos para serem comercializados no país. Alguns produtos eram montados no Brasil com componentes importados, levando o nome de origem e usando, geralmente, caixa de madeira nacional como invólucro. Ou seja, a nacionalização de componentes estava longe de ser significativa; isso é importante para se entender a atual falta de desenvolvimento tecnológico na área de rádio freqüência no Brasil. Mas até então, equipamentos de telefonia ainda não eram montados no país.

Na década de 30, com a revolução constitucionalista, os problemas financeiros são acentuados, fazendo desaparecerem muitas empresas pioneiras e aparecerem outras no mesmo ramo ou em ramos paralelos. Nessa década existiram pequenos fabricantes de equipamentos para rádio fazendo concorrência aos grandes empreendimentos multinacionais (G.E., Philips, Philco, Scott, Emerson, Admiral) e nacionais (PEB - Produtos Elétricos Brasileiros, Rádio Cacique S..A.).

As décadas de 40 e 50 passam sem grandes conquistas no Brasil ao contrário do que acontece em outros países, onde invenções relevantes para a área de telecomunicações se fazem presentes, como o desenvolvimento dos satélites e dos computadores. O salto da economia nacional, com a industrialização, a implantação 
de rodovias e o crescimento do país prometido por Juscelino Kubitschek, estava comprometido pois o tripé fundamental da infra-estrutura - transpostes, energia e telecomunicações - estava desequilibrado, com absoluta carência do terceiro pilar (Siqueira, 1997). A situação geral do setor se torna dramática no início dos anos 60, quando o país não encontrava-se numa situação sequer razoável.

Assim, a telefonia começou a crescer no Brasil a partir da década de 60. Um fator teve relevância na determinação desse crescimento: o discurso da segurança nacional e a integridade geográfica do país. Construir uma rede de telecomunicações densa e coesa era considerada uma tarefa fundamental para se conservar íntegro o território (Brandão, 1996). Considerava-se estratégico para a autonomia e a soberania nacionais, o crescimento das indústrias de armamento, aviação e de telecomunicações, informática e energia nuclear.

Em 1961 cria-se o Código Brasileiro de Telecomunicações (Lei n. 4.117), na primeira tentativa oficial de formulação de uma política nacional para o setor e inicia o sistema de comunicações a longa distância. Essa legislação, entre outras ações, cria o Sistema Nacional de Telecomunicações (que coloca sob jurisdição da União os serviços de telégrafo, radiocomunicação e telefonia interestadual - início da futura empresa que irá explorar tais serviços, a Embratel); institui o Conselho Nacional de Telecomunicações - Contel (que tem o poder de estabelecer especificações das redes telefônicas e os critérios para fixação do sistema tarifário nacional); institui o Departamento Nacional de Telecomunicações - Dentel; cria o Fundo Nacional de Telecomunicações - FNT (que, com recursos de uma sobretarifa de até 30\% sobre as tarifas dos serviços de telefonia, financia os grandes investimentos da empresa que presta serviços de telefonia a longa distância - a futura Embratel).

O governo que emerge da revolução de 1964 implementou "reformas de base" para ter uma nova e complexa estrutura institucional e regulatória. Tem-se que reconhecer que foi no regime militar que se deram as grandes transformações do setor até então. Em 1965 foi criada a Embratel, uma empresa pública com a finalidade de explorar os troncos do Sistema Nacional de Telecomunicações. Em 1966, o Contel regulamenta o autofinanciamento para aquisição de linhas telefônicas, um importante instrumento de apoio á expansão da telefonia no país. Como as concessionárias de serviços não 
contam com recursos suficientes para investimentos, cabe aos usuários financiar o próprio telefone.

Em 1967, surge uma legislação específica que atribui exclusivamente à União o poder de explorar ou outorgar os serviços públicos de telecomunicações e a fixação de tarifas para eles. Até então, esse tipo de atividade era extremamente confuso e poderia ser realizado tanto pela União, quanto pelos estados e pelos municípios. Nesse mesmo ano foi criado o Ministério de Comunicações, que assume as funções do Contel, com o objetivo de coordenar as ações da área. A constituição de 1967 consolidou essa lei e a de 1988 a confirmou.

Com a reestruturação da telefonia interna e o plano de interligar o país todo, era necessário repensar a estrutura das comunicações internacionais. Elas ainda eram realizadas por empresas estrangeiras, que não atendiam as necessidades do país. Assim, a partir de 1969 a Embratel começa a assumir esses serviços e até 1972 os assume integralmente.

Segundo o afirmações do Livro Verde/Ministério de Ciência e Tecnologia (Takahashi, 2000), em termos concretos, o primeiro passo para um efetivo controle governamental do setor de telecomunicações foi dado com a criação da Embratel, inicialmente dedicada à telefonia de longa distância e transmissão de sinal de TV. Em seguida, foi criada a Telebrás, empresa holding de praticamente todas as operadoras do país, que também tinha a Embratel como subordinada.

A década de 70 constitui o período de maior crescimento do setor no Brasil até então. A TV em cores é inaugurada, a Telebrás se instala, a Embratel implanta os serviços de Discagem Direta a Distância (DDD) e Discagem Direta Internacional (DDI). Nessa mesma época, especificamente em 1976, é criado o CPqD (Centro de Pesquisa e Desenvolvimento Padre Roberto Landell de Moura). Segundo Siqueira (Siqueira, 1997), o maior centro de desenvolvimento do setor no hemisfério sul e que concentrava a melhor parcela do conhecimento tecnológico em Telecomunicações do país. Foi o responsável por algumas conquistas notáveis como a criação de centrais telefônicas digitais (Sistemas Trópico), a criação do telefone público a cartão, o 
desenvolvimento da fibra óptica brasileira e numerosos avanços nas comunicações via satélite, na comunicação de dados e em software.

A criação do $\mathrm{CPqD}$ visou reunir (e verticalizar) em um lugar, projetos de $\mathrm{P} \& \mathrm{D}$ de equipamentos e serviços de infra-estrutura para telecomunicações. Essa iniciativa ambiciosa - propiciou a geração de diversas tecnologias, particularmente em fibras óticas e em comutação (Takahashi, 2000).

Nessa época, o setor é razoavelmente protegido e com mercado garantido. Isso faz com que a indústria cresça e as empresas brasileiras atendam a totalidade da demanda por centrais telefônicas, cabos, rede externa e equipamentos de transmissão (Siqueira, 1997). A política industrial estabelecida na época dá seus frutos, mas também contribui para a elevação dos custos ao impor à produção local, índices de nacionalização superiores a $95 \%$.

A capacitação industrial brasileira foi responsável pelo êxito do setor nos anos 70 e em parte dos anos 80. Mas os problemas gerados pelo o monopólio estatal se agravam na década de 80 e persistem até meados da década seguinte. Nessa época os investimentos na empresas caem, os serviços se degradam, a demanda por telefones é muito maior que a oferta, os preços são impraticáveis e os prazos estipulados pelas operadoras não são cumpridos.

Esse ambiente não é propício para acompanhar a evolução mundial do setor de telecomunicações, cujo desenvolvimento tecnológico é crescente e cuja aplicação é cada vez mais ampla, alterando os aspectos culturais e comportamentais da sociedade. As mudanças no mercado e nas necessidades dos consumidores são enfatizadas por aspectos como a globalização econômica e industrial, que torna inevitável o aumento da utilização de produtos e serviços de comunicações.

Enquanto no Brasil, a insuficiência de investimentos impede a necessária expansão e melhoria dos serviços, "nos países desenvolvidos a acelerada digitalização de linhas e sistemas era acompanhada do surgimento de novas tecnologias e produtos de comunicação, baseados em novas linguagens e protocolos" (Takahashi, 2000) 


\subsection{Reestruturação do Setor}

O Brasil começou a reestruturar o setor em 1995. Essa reestruturação define, entre outros fatores, a quebra do monopólio estatal, a privatização das empresas de telefonia, o programa de ampliação e recuperação do sistema de telecomunicações com investimentos de US\$ 90 bilhões em 8 anos e a substituição do Código Brasileiro de Telecomunicações pela Lei Geral das Telecomunicações (LGT - lei 9472) em julho de 1997, que define as linhas gerais do novo modelo institucional para o setor. Essa lei aprova os processos de privatização das operações de telecomunicações no país (sistema Telebrás foi privatizado em 1998) e promove a abertura da chamada Banda B de telefonia celular ao setor privado com a divisão do país em regiões.

Ao final de 1995, na mesma época em que foram efetuados os preparativos iniciais para a abertura da telefonia celular privada, o Ministério das Comunicações (MC) efetuou projeções referentes ao crescimento do mercado das telecomunicações do País por meio do Paste (Programa de Recuperação e Ampliação do Sistema de Telecomunicações e do Sistema Postal). O Paste configura, basicamente, um plano de metas setorial. De certa forma, é uma modalidade de planejamento indicativo, antecipando o tipo de atuação que caracteriza o MC após a privatização da Telebrás: formulação de políticas gerais de longo prazo.

O Paste, basicamente, pretende reverter a concentração do atendimento nas camadas de renda mais alta da população bem como eliminar as pressões da demanda. Sua continuidade requer soluções adequadas a cada segmento do mercado, garantindo simultaneamente, a rentabilidade dos serviços e a prestação do serviço universal.

Em 15 de maio de 1998, o Decreto presidencial 2.592 estabeleceu o Plano Geral de Metas para a Universalização do Serviço Telefônico Fixo Comutado Prestado no Regime Público, que deveria ser cumprido pelas concessionárias privatizadas e prevê a evolução dos acessos instalados ao serviço e do número de telefones de uso público para cada unidade da Federação no período 1998-2001. 
Além de metas quantitativas, o programa também indica a evolução dos indicadores de qualidade dos serviços. A avaliação do desempenho da qualidade deve ser feita não englobando os serviços como um todo, mas tratando cada um deles de forma específica. Até o final de 2001, grande maioria das operadoras de telefonia fixa haviam atendido às metas de universalização e de qualidade, estando aptas a atuarem em outras áreas de concessão, o que começou a ocorrer, por parte delas, em 2002.

Um ponto a ser destacado é que, apesar dos enormes investimentos na rede de telecomunicações, estabelecidos pelo Paste, não se identifica, em nenhum dos documentos públicos de governo, qualquer movimento para que essa oportunidade seja aproveitada, visando estabelecer no País bases de produção de bens e componentes de telecomunicações que possibilitem não só o atendimento ao mercado interno e a utilização desse mercado como alavanca para atender mercados internacionais, mas também para gerar tecnologia que leve a uma atuação mais efetiva do País pelas próximas dezenas de anos numa das áreas econômica e tecnologicamente mais dinâmicas (PGT/USP, 2002). Na verdade, o risco que existe é o de se perder, inclusive, a própria tecnologia que já foi desenvolvida (PGT/USP, 2002).

Também fazendo o papel de Estado no setor (além do MC), foi criada, em 1997, a Agência Nacional de Telecomunicações (Anatel), cuja missão é "promover o desenvolvimento das telecomunicações do País de modo a dotá-lo de uma moderna e eficiente infra-estrutura de telecomunicações, capaz de oferecer à sociedade serviços adequados, diversificados e a preços justos, em todo o território nacional" (Anatel, 2003).

Em linhas gerais, a reestruturação e a privatização deram-se segundo os seguintes passos:

- Introdução da competição na telefonia celular, com a licitação para as concessionárias para a Banda $\mathrm{B}$, tendo sido criado para isso um arcabouço regulatório mínimo (Lei Mínima) que desse aos investidores as garantias necessárias ao seu investimento e que permitisse o controle e o acompanhamento do setor pelas autoridades brasileiras. 
- Estabelecimento, pela Anatel, dos planos de outorgas, de metas de universalização, de qualidade e do sistema tarifário, do contrato de concessão e outros requisitos fundamentais para a privatização do setor.

- Cisão de cada operadora do Sistema Telebrás em operadoras de telefonia fixa e de telefonia celular.

- Divisão do território brasileiro (exceto as áreas das operadoras que não faziam parte do Sistema Telebrás) em três regiões para a telefonia fixa e uma região para a telefonia de longa distância, conforme apresentado na Tabela 5.1.

- Divisão do território brasileiro (exceto as áreas das operadoras que não faziam parte do Sistema Telebrás), em dez áreas, para telefonia celular, conforme a Tabela 5.2.

- Reorganização da Telebrás, que foi desmembrada em três grandes holdings de concessionárias de serviços locais de telefonia fixa para atender a distintas regiões geográficas definidas pelo Plano Geral de Outorgas - PGO (a Telesp, a Tele Norte-Leste e a Tele Centro-Sul), uma operadora de longa distância (Embratel), e oito operadoras de telefonia celular de Banda A, para operar os serviços oferecidos até então pelas subsidiárias da Telebrás, como pode ser visto nas tabelas 5.1 e 5.2 .

- Assinaturas de contratos de concessão de serviços de telefonia fixa com as novas empresas, os quais foram outorgados, a título gratuito, com termo final em 31 de dezembro de 2005, quando poderão ser prorrogados, a título oneroso, por mais 20 anos.

- Leilão das novas empresas, disputadas por diversos consórcios, levando em conta tarifas cobradas no futuro e preços pagos pela concessão.

- Introdução da competição na telefonia local, com licitação para as "empresasespelho", que já estão prestando serviços de telefonia fixa nas áreas de concessão de empresas privatizadas, conforme mostra a tabela 5.1. 


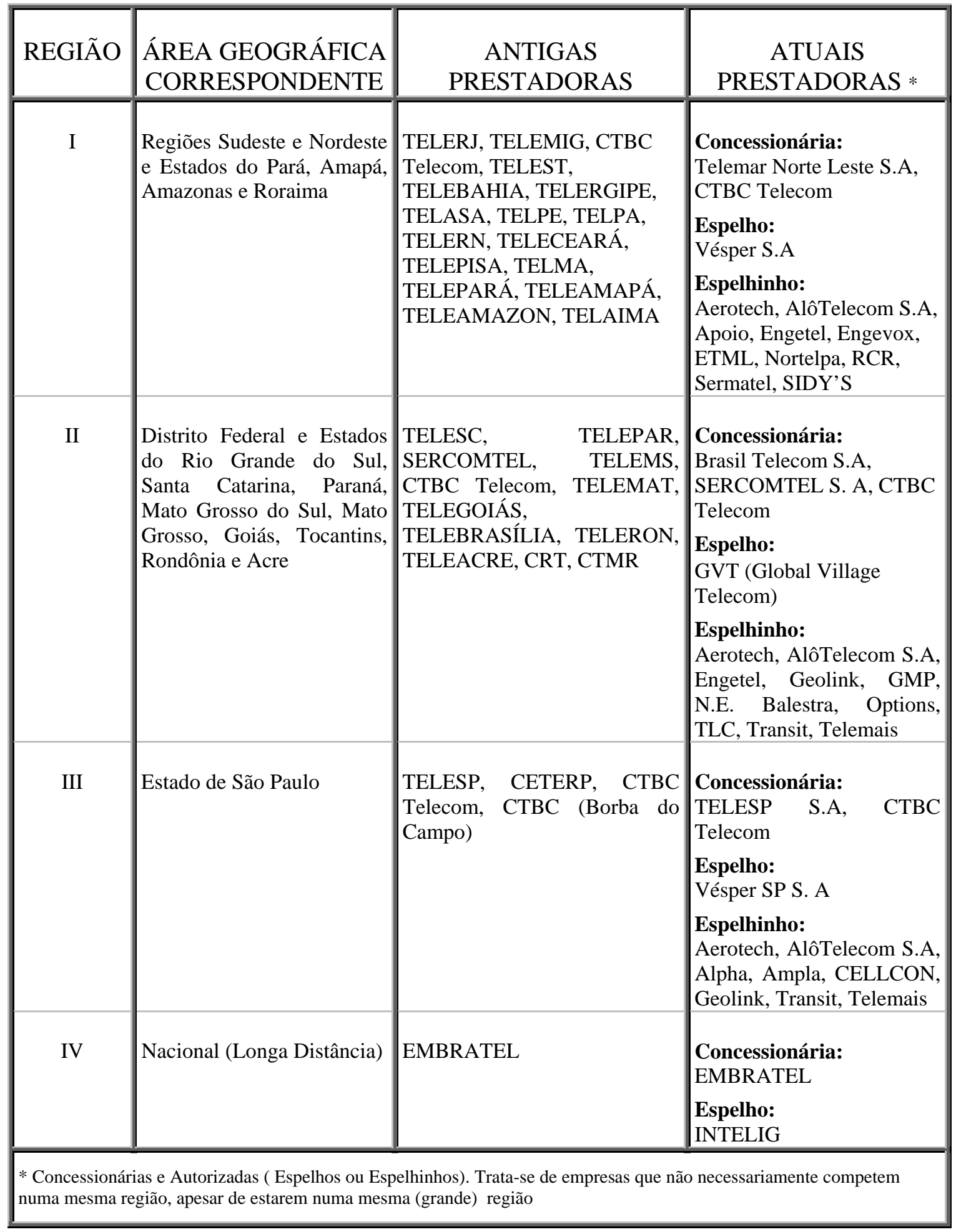

Tabela 5.1 - Divisão do território brasileiro para telefonias fixa e de longa distância antes e após privatização (Fonte: Anatel, Março/2003). 


\begin{tabular}{|c|c|c|c|c|}
\hline ÁREA & $\begin{array}{c}\text { ÁREA } \\
\text { GEOGRÁFICA }\end{array}$ & $\begin{array}{c}\text { ANTIGAS } \\
\text { ATUANTES }\end{array}$ & $\begin{array}{c}\text { PRESTADORAS } \\
\text { BANDA A }\end{array}$ & $\begin{array}{c}\text { PRESTADORA } \\
\text { BANDA B }\end{array}$ \\
\hline 1 & Grande São Paulo & TELESP & $\begin{array}{l}\text { TELESP CELULAR } \\
\text { CETERP CELULAR } \\
\text { CTBC CELULAR }\end{array}$ & BCP S.A. \\
\hline 2 & Estado de São Paulo & TELESP, CETERP & $\begin{array}{l}\text { TELESP CELULAR } \\
\text { CETERP CELULAR } \\
\text { CTBC CELULAR }\end{array}$ & TESS S.A \\
\hline 3 & RJ e ES & TELERJ, TELEST & $\begin{array}{l}\text { TELE SUDESTE CELULAR } \\
\text { S.A (TELERJ CELULAR, } \\
\text { TELEST CELULAR) }\end{array}$ & $\begin{array}{l}\text { ATL ALGAR } \\
\text { TELECOM LESTE }\end{array}$ \\
\hline 4 & MG & TELEMIG & $\begin{array}{l}\text { TELEMIG CELULAR } \\
\text { CTBC CELULAR }\end{array}$ & MAXITEL S.A \\
\hline 5 e 6 & PR, SC e RS & $\begin{array}{l}\text { TELEPAR, } \\
\text { TELESC, CTMR }\end{array}$ & $\begin{array}{l}\text { TELE CELULAR SUL } \\
\text { (TELEPAR CELULAR, } \\
\text { TELESC CELULAR, CTMR } \\
\text { CELULAR) } \\
\text { SERCOMTEL CEL } \\
\text { CELULAR S.A CRT }\end{array}$ & $\begin{array}{l}\text { GLOBAL } \\
\text { TELECOM } \\
\text { TELET S.A }\end{array}$ \\
\hline 7 & $\begin{array}{l}\text { GO, TOs, MS, MT, } \\
\text { RO, AC e DF }\end{array}$ & $\begin{array}{l}\text { TELEBRASÍLIA, } \\
\text { TELEMS, } \\
\text { TELEGOIÁS, } \\
\text { TELEMAT, } \\
\text { TELERON } \\
\text { TELEACRE }\end{array}$ & $\begin{array}{l}\text { TELE CENTRO OESTE } \\
\text { CELULAR S.A } \\
\text { (TELEACRE CEL, } \\
\text { TELEBRASÍLIA CEL, } \\
\text { TELEMS CEL, TELEGOIÁS } \\
\text { CEL, TELEMAT CEL, } \\
\text { TELERON CEL) } \\
\text { CTBC CELULAR }\end{array}$ & AMERICEL S.A \\
\hline 8 & $\begin{array}{l}\text { AM, RR, AP, PA e } \\
\text { MA }\end{array}$ & \begin{tabular}{|l} 
TELEAMAZON, \\
TELEAIMA, \\
TELEPARÁ, \\
TELEAMAPÁ \\
TELMA
\end{tabular} & $\begin{array}{l}\text { TELE NORTE CELULAR } \\
\text { S.A (TELEAMAZON CEL, } \\
\text { TELEAIMA CEL, } \\
\text { TELEPARÁ CEL, } \\
\text { TELEAMAPÁ CEL, } \\
\text { TELMA CELULAR) }\end{array}$ & $\begin{array}{l}\text { NORTE BRASIL } \\
\text { TELECOM S.A }\end{array}$ \\
\hline 9 & BA, SE & $\begin{array}{l}\text { TELEBAHIA } \\
\text { TELERGIPE }\end{array}$ & $\begin{array}{l}\text { TELE LESTE CELULAR } \\
\text { S.A (TELEBAHIA CEL, } \\
\text { TELESERGIPE CEL) }\end{array}$ & MAXITEL S.A \\
\hline 10 & $\begin{array}{l}\text { PI, CE, RN, PB, PE } \\
\text { e AL }\end{array}$ & $\begin{array}{l}\text { TELASA, TELPE, } \\
\text { TELPA, TELEM, } \\
\text { TELECEARÁ } \\
\text { TELEPISA }\end{array}$ & $\begin{array}{l}\text { TELE NORDENTE } \\
\text { CELULAR S.A (TELASA } \\
\text { CEL, TELPE CEL, TELPA } \\
\text { CEL, TELEM CEL, } \\
\text { TELECEARÁ CEL, } \\
\text { TELEPISA CEL) }\end{array}$ & BSE S.A \\
\hline
\end{tabular}

Tabela 5.2 - Divisão do território brasileiro para telefonia móvel celular com operadoras atuantes antes e após privatização do sistema Telebrás e entrada de novos concorrentes - Banda B (Fonte: Anatel, Março/2003).

As empresas transnacionais se voltaram para o país depois das alterações promovidas pela LGT e da situação de rápido crescimento do mercado. Tal interesse trouxe para o Brasil empresas que atuam como prestadoras de serviços de telefonia e intensificou 
a presença de empresas globais fabricantes de aparelhos de telecomunicações. Essas últimas são as que mais se enquadram no perfil de empresa traçado para este trabalho, conforme discutido posteriormente no capítulo sobre metodologia da pesquisa. Dessa forma, estão sendo estudados os principais fabricantes mundiais de equipamentos de telefonia.

Algumas das empresas fabricantes de aparelhos de telecomunicações montaram unidades no Brasil com a compra de empresas nacionais ou de parte delas. Enquanto algumas dessas aquisições foram responsáveis pela extinção do setor de P\&D local, ou pela sub-utilização deles, outras fizeram com que a unidades brasileiras fossem líderes mundiais em algumas tecnologias como veremos nos casos estudados.

Com a privatização do setor, o $\mathrm{CPqD}$ tornou-se uma fundação de direito privado, os pacotes tecnológicos por ela gerados, em particular o da família Trópico de estações de comutação. $\mathrm{O} \mathrm{CPqD}$ passou a desenvolver e vender serviços para as empresas do setor, especialmente as operadoras de telefonia e hoje também apóia a Agência Nacional de Telecomunicações (Anatel) em áreas de normatização e certificação. Além disso, o centro de pesquisa é, juntamente com a Promon e a CISCO Systems, acionista da empresa Trópico S.A., principal responsável pela comercialização, fabricação e desenvolvimento dos produtos da família Trópico e de sua continuidade tecnológica, gerando como principal resultado, a linha Vectura, voltada para convergência de redes de voz e dados para rede de acesso (usando Internet Protocol IP), o chamado "redes de nova geração" - NGN (Next Generation Networks).

\section{3- Configurações Organizacionais do Setor}

Essa retrospectiva histórica é fundamental para entender o atual mapeamento industrial do setor. As competição global está cada vez mais acirrada e as empresas estão alterando suas configurações organizacionais para serem mais competitivas. Um outro fator que tem influência nessas alterações das organizações é o relacionado às mudanças tecnológicas que foram e são extremamente relevantes para o setor, uma vez que elas interferem diretamente na atuação e, consequentemente, na hegemonia das empresas. A era digital, por exemplo, transformou a indústria e teve extrema relevância para que se chegasse ao atual modelo organizacional para o setor, 
com uma integração bastante acentuada entre as indústrias de telecomunicações e computação.

É necessário considerar também a relevância da internet atualmente, sua disseminação e natural incorporação tecnológica às telecomunicações, já que há fortes indícios de que IP (Internet Protocol) deverá ser a tecnologia usada como padrão de comunicações de todos os tipos de dados, incluindo voz.

\subsubsection{Composição do setor}

Em termos gerais, o setor é composto por cinco principais players, que são completamente inter-relacionados: fornecedores de equipamentos telefônicos (para redes de telefonia ou usuários finais), de equipamentos para transmissão de dados, para componentes de infra-estrutura (antenas, cabos, fios, etc.) e outros; operadores de rede (telefonia) ou de serviços (internet, paging e trunking, TV, etc.); governo e órgãos reguladores; usuários, que não são passivos, ao contrário, influenciam na dinâmica do setor, se dividem em clientes corporativos ou físicos; universidades e centros de pesquisa. Neste modelo, por não estarem diretamente ligados à operação de telecom (cadeia produtiva), alguns agentes importantes que atuam no setor não estão explicitamente listados, como os prestadores de serviços para instalação da rede pública, no entanto, no modelo proposto para a cadeia produtiva do setor apresentado na seção 5.3.2, eles - e outros agentes relevantes - são considerados.

Há uma integração bastante grande entre esses agentes, que acontece em maior ou menor escala, mas todos eles se relacionam uns com os outros. Por exemplo, os órgãos reguladores governamentais, como a Anatel - Agência Nacional de Telecomunicações - no Brasil, estabelecem padrões para as operadoras de rede, mas isso interfere diretamente nos produtos fabricados pelos fornecedores. Muitas vezes esses padrões são criados em conjunto com universidades e centros de pesquisa e, evidentemente, visam melhorias nos serviços para os usuários. A figura 5.1 representa a interligação entre eles. Vale a pena apresentar melhor o papel desses players, especificamente no Brasil, para que seja enriquecida a discussão sobre a cadeia produtiva do setor de telecomunicações nas próximas seções. 


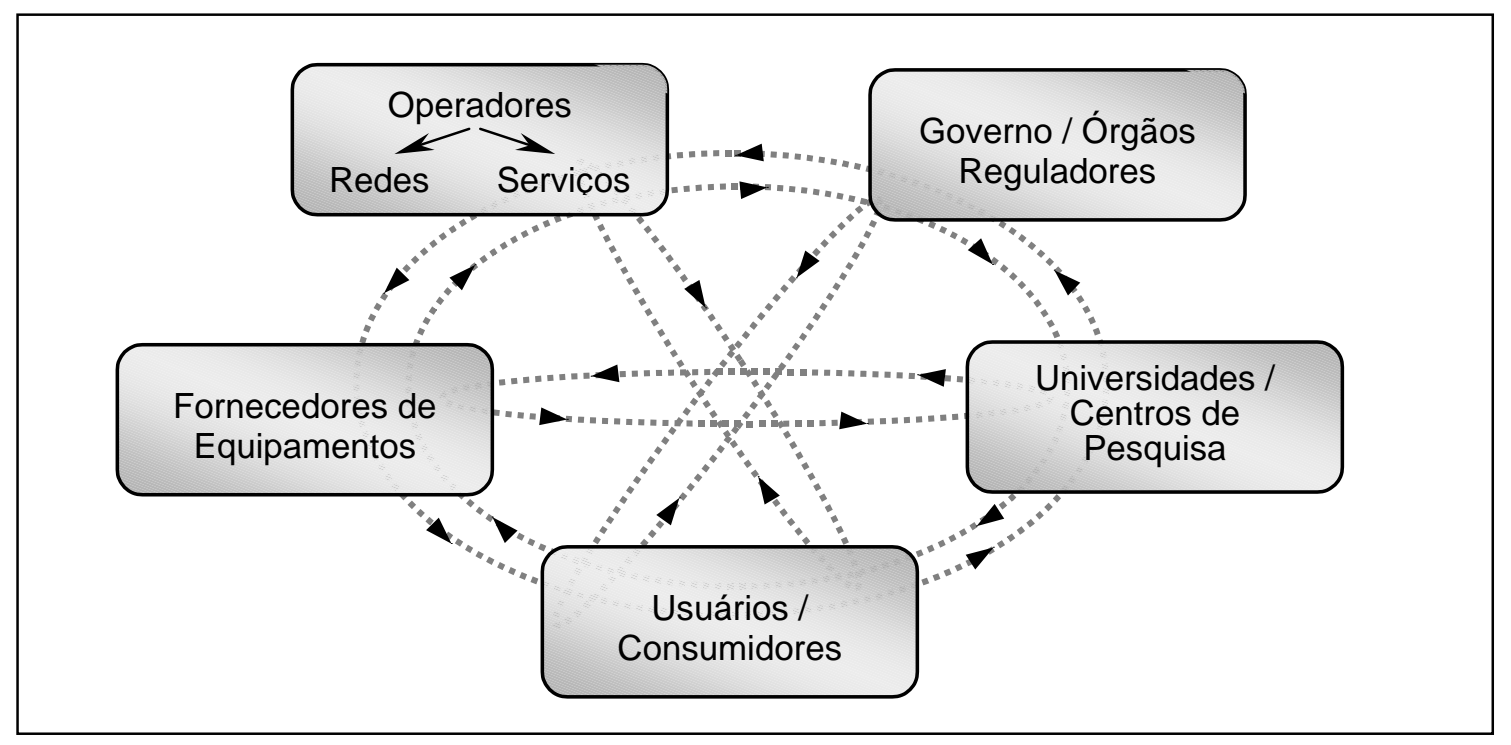

Figura 5.1 - Modelo para operação do setor de telecomunicações e interligação entre seus players

\subsubsection{Governo / Órgão Regulador}

No país, o principal papel do agente "Governo / Órgão Regulador" é do Ministério das Comunicações, órgão do poder Executivo Federal encarregado da elaboração e do cumprimento das políticas públicas do setor de comunicações, que abrange três áreas fundamentais: radiodifusão, serviços postais e telecomunicações. No entanto, o órgão que mais se destaca no setor de telecomunicações é a Anatel, que está mais ligada ao Ministério das Comunicações para assessorá-lo, principalmente através de atividades de fiscalização e regulamentação do setor. A Anatel também atua diretamente no que compete à proteção ao consumidor.

No entanto, a Anatel não está subordinada ao Ministério, como afirma o decreto que aprova o Regulamento da Agência Nacional de Telecomunicações (decreto n. ${ }^{\circ}$ 2.338, de 07/10/1997), quando diz que a Anatel “... é administrativamente independente, financeiramente autônoma, não se subordina hierarquicamente a nenhum órgão de governo, seus dirigentes têm mandato fixo e estabilidade".

Como foi dito, o papel fundamental da Anatel é de regulamentação, outorga e fiscalização de serviços de telecomunicações no país. Dentre suas atribuições, destacam-se as seguintes: 
- Implementar a política nacional de telecomunicações.

- Propor a instituição ou eliminação da prestação de modalidade de serviço no regime público.

- Propor o Plano Geral de Outorgas.

- Propor o plano geral de metas para universalização dos serviços de telecomunicações.

- Administrar o espectro de radiofreqüências e o uso de órbitas.

- Compor administrativamente conflitos de interesses entre prestadoras de serviços de telecomunicações.

- Atuar na defesa e proteção dos direitos dos usuários.

- Atuar no controle, prevenção e repressão das infrações de ordem econômica, no âmbito das telecomunicações, ressalvadas as competências legais do Cade.

- Estabelecer restrições, limites ou condições a grupos empresariais para obtenção e transferência de concessões, permissões e autorizações, de forma a garantir a competição e impedir a concentração econômica no mercado.

- Estabelecer a estrutura tarifária de cada modalidade de serviços prestados em regime público.

- Expedir regras quanto à outorga e extinção de direitos de exploração de serviços no regime público, inclusive as relativas à licitação, observada a política nacional de telecomunicações.

Vale destacar que as ações nas definições regulatórias do órgão governamental, a Anatel no Brasil, são fundamentais para a dinâmica da cadeia produtiva do setor, influenciando inclusive, na determinação da estrutura da cadeia - e consequentemente das empresas que irão atuar - em função da tecnologia adotada para o país. Isso pode ser comprovado através das mudanças recentes na telefonia móvel celular, ocorridas nos últimos anos no Brasil em virtude das diferentes tecnologias adotadas (CDMA, TDMA e GSM), conforme será discutido nas próximas seções.

\subsubsection{Consumidores / Usuários}


Atualmente, o papel das telecomunicações é de extrema importância no cenário mundial, pois sua utilização, especialmente com sua "junção" com a informática após a digitalização ser incorporada totalmente a telecom, passou a ser cada vez mais uma vantagem competitiva. Comunicação instantânea, mobilidade, transferência de dados em alta velocidade, serviços multimídia e possibilidade de realizar teleconferências passaram a ser, dentre outros, recursos imprescindíveis para corporações de todos os portes. $\mathrm{O}$ avanço da internet só veio acentuar ainda mais a relevância das comunicações para a sociedade moderna.

No Brasil, como em grande parte dos países em desenvolvimento e com acentuada diferença social e econômica entre os cidadãos, a realidade dos consumidores é bastante distinta, o que exige um amplo leque de alternativas de serviços, desde os mais simples, de fácil utilização e custos módicos, para as famílias de baixa renda e para as micro-empresas, até os mais sofisticados, em altas velocidades e faixas largas, para os segmentos mais desenvolvidos da sociedade e para as empresas de maior porte.

De acordo com o Paste, os consumidores finais dos serviços de telecomunicações podem ser caracterizados como famílias urbanas, famílias rurais e empresas. As famílias urbanas são classificadas de acordo com sua renda e com o tipo de serviço que poderão consumir. Foram estabelecidas quatro classes, cujos serviços variam bastante, indo desde a necessidade de serviços coletivos de voz (públicos) da classe menos favorecida, até utilização de serviços avançados para transferência de dados pela classe mais abastada, passando, evidentemente, pelos serviços tradicionais de telefonia fixa e móvel, e utilização das facilidades da TV por assinatura das classes intermediárias. As famílias rurais, da mesma forma que as famílias urbanas, terão acesso a pelo menos uma modalidade de serviço de telecomunicações, priorizando os serviços públicos de telecomunicações, dependendo do local em que estejam localizadas.

Para o Paste, os consumidores empresariais também são classificados de acordo com seu porte. As pequenas e microempresas deverão ser atendidas, fundamentalmente, com os serviços de voz, com predominância para a telefonia fixa, e os de mensagem de voz, sendo parte atendida com o serviço de telefonia de uso público. 
Adicionalmente, estão previstos serviços de comunicação de dados, especialmente de baixa velocidade. As médias empresas deverão ser atendidas, em sua totalidade, com telefonia fixa, com uma parcela menor utilizando serviços de telefonia móvel celular e de mensagem de voz. Quanto à comunicação de dados, estas empresas estarão atendidas, em grande parte, com facilidades de baixa e média velocidades, além de atendimento menor de multimídia e serviços de vídeo.

As grandes empresas deverão ser atendidas com telefonia fixa, enquanto grande parte utilizará também o serviço de telefonia móvel. Todas terão acesso a serviços de comunicação de vídeo, texto e dados, em baixa, média e alta velocidades, e, de forma limitada, a multimídia e serviços de vídeo. As megaempresas deverão estar atendidas com telefonia fixa, telefonia móvel, serviços de comunicação de vídeo, texto e dados, com acessos de baixa, média e alta velocidades, redes corporativas, multimídia e serviços de vídeo. Os órgãos governamentais e as demais entidades deverão ter atendimento similar ao das empresas de mesmo porte.

Alguns estudos foram desenvolvidos com o intuito de analisar o tamanho e o potencial do mercado brasileiro. Os números, em sua grande maioria, foram superavaliados, ou seja, a demanda por serviços de comunicações foi grande nos primeiros anos após a privatização do sistema Telebrás, mas atualmente o que se vê é uma enorme diferença entre a oferta e a demanda. Esbarrou-se no limitador do mercado consumidor brasileiro: a renda e o poder aquisitivo do cidadão das classes mais baixas, que estão em maioria no país.

Dessa forma, as empresas operadoras de telefonia pública (fixa e móvel) precisam ter um amplo leque de opções de serviços para os consumidores, oferecendo variados serviços em termos de tecnologia, banda/capacidade, inovação e custo, entre outros. Ao mesmo tempo, elas necessitam competir pela venda dos seus serviços num mercado agora bastante competitivo.

\subsubsection{Operadores: Serviços e Redes}

Nesta classificação, dois tipos de empresas são identificadas: operadores de redes públicas de comunicação, são as tradicionais operadoras de serviços de telefonia 
(fixa ou móvel), e os operadores de serviços, ou seja, empresas que prestam serviços utilizando rede de comunicação, por exemplo, serviços ligados à internet, serviços de televisão, etc.

Com relação às operadoras de rede, como foi citado anteriormente, com a reestruturação do sistema de telefonia, tanto da fixa quanto da móvel, o território brasileiro foi dividido em regiões distintas para atuação das empresas operadoras. A divisão foi feita em três regiões para a telefonia fixa e uma região para a telefonia de longa distância (tabela 5.1). No serviço de telefonia móvel celular, dez foram as divisões (tabela 5.2).

Depois de consolidado todo o processo de privatização, existem dois tipos de empresas: a) as originadas do processo de privatização da Telebrás e das anteriormente existentes, que são as novas concessionárias de serviço público e tiveram obrigações com relação a metas de universalização e continuidade; e b) as operadoras com autorização para exploração de serviços (chamadas "autorizadas" ou “empresas-espelho"), selecionadas em processo licitatório após a privatização, que não são concessionárias de serviço público e, portanto, não têm obrigações em relação a metas de universalização nem de continuidade, devendo cumprir metas de expansão e atendimento por elas propostas por ocasião da licitação.

Sendo assim, as empresas-espelho de telefonia fixa no Brasil apresentam as seguintes características (PGT/USP, 2002):

- Não estão sujeitas às metas de universalização, continuidade, interconexão ou qualidade, tendo apenas que cumprir aquelas com que se comprometeram em suas propostas.

- Têm tarifas liberadas.

- Podem utilizar a tecnologia Wireless Local Loop (WLL), que é telefonia celular fixa e proporciona a vantagem de prescindir de redes cabeadas até a casa do 
usuário, o que acarreta menor tempo de implementação e menor custo de investimento ${ }^{17}$.

- Poderão revender serviços da concessionária.

Posteriormente, em 2001, a já complicada rede de telefonia fixa recebeu outros novos entrantes, as chamadas "empresas-espelhinhos". Elas foram idealizadas pela Anatel para atuar onde faltasse investimento depois do "boom" da privatização. Ou seja, essas empresas têm autorização para atuarem nos municípios fora dos grandes centros, que não foram priorizados pelas operadoras e suas espelhos (as primeiras). Assim como as espelhos, essas empresas não têm obrigação com metas de universalização nem com a instalação de telefones públicos.

Os planos das espelhinhos, porém, bateram de frente com a crise pela qual vem passando o setor de telecomunicações e as fontes de investimento secaram. Segundo a Anatel, até agosto de 2002, existiam três em operação (Jornal Estado de São Paulo, 25/08/2002): Nortelpa, em Paragominas (PA); Options, em Itapema (SC); e Apoio, em Marituba (PA). Isto de um total de autorizações para 482 municípios. O principal trunfo dessas empresas para a competição está na possibilidade de trabalharem com tarifas menores que as das concessionárias.

A tabela 5.1 mostra as áreas de atuação das empresas de telefonia fixa. São mostradas as concessionárias, as primeiras autorizadas (espelhos) e as autorizadas após período de definições (espelhinhos). Vale lembrar que as espelhinhos atuam em alguns municípios, portanto, apesar de estarem, na tabela, alocadas por região, elas não atuam na região toda. Para a maioria das espelhos isso também acontece.

Na telefonia celular, a divisão territorial do país aconteceu de forma semelhante à fixa. Foram determinadas dez áreas para atuação das empresas prestadoras de serviços. As prestadoras estatais foram privatizadas e as empresas compradoras passaram a atuar na chamada "Banda A". A Introdução da competição na telefonia celular deu-se com a licitação para as concessionárias da "Banda B", tendo sido

\footnotetext{
${ }^{17}$ Suas competidoras - as concessionárias - somente puderam utilizar a tecnologia WLL a partir de 2001, antes disso, só em cidades com menos de 50 mil habitantes ou naquelas que a empresa-espelho declare que não atenderá.
} 
criado para isso uma estrutura regulatória mínima (Lei Mínima das Telecomunicações - Lei 9.295, de 19.07.96), que desse aos investidores as garantias necessárias ao seu investimento e que permitisse o controle e o acompanhamento do setor pelas autoridades brasileiras ${ }^{18}$.

O aumento da concorrência com a entrada de diversas empresas no mercado da telefonia celular fez com que tecnologias de outras fontes, além das já instaladas, passassem a ser oferecidas, fragmentando ainda mais um mercado já excessivamente fragmentado pelos padrões internacionais. A existência de tantas tecnologias diversas já é um desvio das características existentes em praticamente todos os outros países em que a tecnologia está concentrada em uma ou duas fontes tecnológicas diferentes. Assim, se, por um lado, alguns argumentarão que a oferta de mais opções proporcionará uma maior concorrência, por outro lado, implicará na abdicação total da possibilidade de se obter escala, numa área em que economias de escala são fundamentais (PGT/USP, 2002).

A definição de novas tecnologias está entre as responsabilidades da Anatel, especialmente para telefonia celular. Atualmente, três são as tecnologias possíveis para o Serviço Móvel Celular (SMC) no Brasil: CDMA (Code Division Multiple Access), TDMA (Time Division Multiple Access) e GSM (Global System for Mobile Communications).

As Bandas A e B utilizam o padrão CDMA ou TDMA, a tabela 5.3 mostra as prestadoras do Serviço Móvel Celular que atuam nessas bandas e os padrões de tecnologia utilizados por cada elas. A Anatel abriu licitação para a Banda $\mathrm{C}$, mas até o final de 2002 não havia obtido êxito na venda da concessão.

Em 2001 houve licitação para concessão da Banda D e E, cuja tecnologia escolhida foi a GSM (Global System for Mobile Communications - Sistema Global para Comunicação Móvel), padrão primário digital wireless usado na Europa e Sudeste da Ásia, e que geralmente é referido como padrão digital Europeu.

\footnotetext{
${ }^{18}$ A Lei Mínima das Telecomunicações teve um caráter emergencial para permitir o estabelecimento de critérios para concessões de serviços, em sua maioria ainda não explorados pela iniciativa privada e que apresentavam elevada atratividade econômica, tais como o "serviço móvel celular", os "serviços limitados" (trunking), os "serviços via satélite" e os "serviços de valor adicionado" (paging e outros que possibilitam a constituição de redes corporativas)
} 
Para operar nas Bandas D e E entraram no mercado em 2002 duas novas empresas: a Oi, que pertence ao mesmo grupo controlador da Telemar, foi autorizada a operar na área de concessão desta operadora, que cobre 16 Estados da Federação e a TIM (Telecom Itália Mobile), que comprou direitos para operar em todo o território nacional.

Cada vez mais, os serviços relacionados à área de telecomunicações não se restringem apenas aos de acesso às redes de comunicações, tradicionalmente prestados por operadoras de telefonia fixa ou móvel. Ou seja, além das funções tradicionais de telefonia pública, o segmento de serviços em telecomunicações também é composto e dependente do oferecimento de outros produtos para atendimento do consumidor.

Os serviços de telecomunicações diversificaram-se bastante nos últimos tempos, influenciados principalmente por alguns fatores como a convergência das tecnologias de comunicação e computação, o fortalecimento da internet, o aumento da concorrência entre as empresas prestadoras e a exigência/necessidade de melhoria nos serviços prestados aos consumidores. 


\begin{tabular}{|c|c|c|c|c|c|c|c|}
\hline \multicolumn{8}{|c|}{ PRESTADORKS DO SMC } \\
\hline \multirow{3}{*}{$\begin{array}{c}\text { Ares } \\
\text { Concesuado }\end{array}$} & \multicolumn{5}{|c|}{ BAKDA A } & \multicolumn{2}{|c|}{ EUMDA $\mathrm{B}$} \\
\hline & \multicolumn{3}{|c|}{ Enpreaun Privaleradas } & \multirow[b]{2}{*}{ Gubas Frestadeses } & \multirow[b]{2}{*}{$\begin{array}{c}\text { Toescieais } \\
\text { Dlaitx }\end{array}$} & \multirow[b]{2}{*}{ Froblaess } & \multirow[b]{2}{*}{$\begin{array}{l}\text { Tesnaisue } \\
\text { digitai }\end{array}$} \\
\hline & Holeting & Prestaders & $\begin{array}{c}\text { Tespetagia } \\
\text { Digitai }\end{array}$ & & & & \\
\hline 1 & \multirow{3}{*}{ 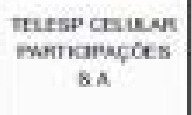 } & \multirow{3}{*}{ TELES cecuears A } & \multirow{3}{*}{ cowh } & & & Depsa & Treis \\
\hline 2 & & & & 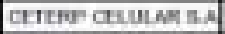 & cons & \multirow{2}{*}{ TESS 5.A } & \multirow{2}{*}{ Tous } \\
\hline & & & & CTEC CELULAA SA & TCEis & & \\
\hline 3 & 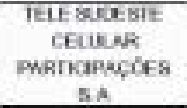 & $\begin{array}{l}\text { TEER CELUWR SA } \\
\text { MEST CHUEAR SA }\end{array}$ & coneh & & & $\begin{array}{l}\text { AIL NLQUR } \\
\text { TEIECONUESTE } \\
\text { SA A }\end{array}$ & TDEA \\
\hline 4 & 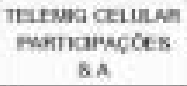 & TELMM CEULAR S.A & tones. & Crec CELULAH SA & now. & mevertis. & tows \\
\hline 5 & \multirow{2}{*}{ 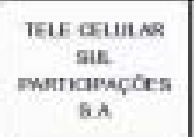 } & \multirow{2}{*}{ 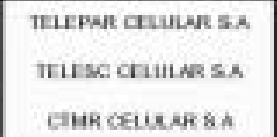 } & \multirow[t]{2}{*}{ tran } & $\begin{array}{c}\text { senoomin routan } \\
\text { S.A. }\end{array}$ & Trash & $\begin{array}{l}\text { Gionew reiroch } \\
\text { s.A }\end{array}$ & cresen \\
\hline 6 & & & & CELULAR B A CRK & Towax & TELET $8 h$ & IDAs \\
\hline$t$ & 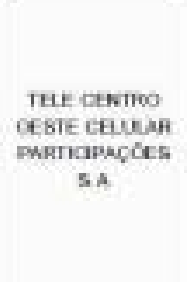 & 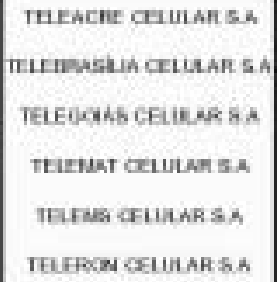 & Totis. & croc ceuens 8.A & Itosen. & Mut:knct S A & iDes: \\
\hline a & 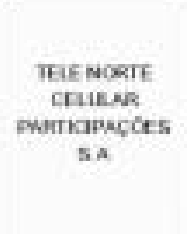 & 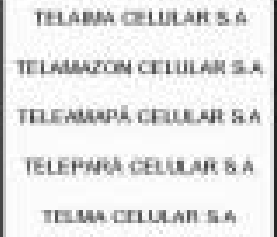 & Trous & & & 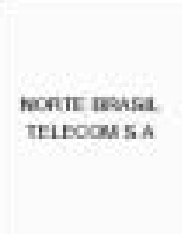 & Trus \\
\hline 9 & 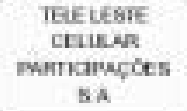 & 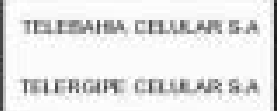 & crosh & & & MNDIE $8 A$ & Totis \\
\hline $\mathbf{m}$ & 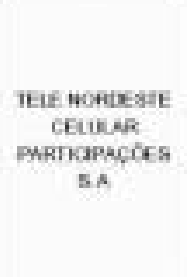 & 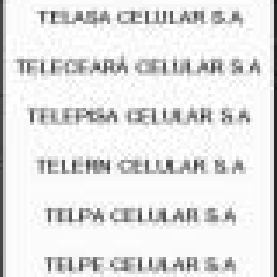 & Totis. & & & Bse 8 A & Tow. \\
\hline
\end{tabular}

Tabela 5.3 - Relação das Prestadoras do Serviço Móvel Celular das Bandas A e B (Fonte: Anatel, Março/2003)

Entram assim, neste mercado, os chamados operadores de serviços, que podem ser as próprias operadoras de telefonia, numa diversificação de suas atividades, ou empresas oriundas de outros setores, especialmente as provenientes da indústria de computação ou de entretenimento, que atuam principalmente com internet e TV por assinatura. Sendo assim, as operadoras de telefonia são fornecedores para os operadores de serviços, mas muitas vezes são também concorrentes deles. 
Apesar das operadoras de telefonia serem os grandes players do setor no que se refere a serviços, apresentando a maior receita do mercado $(81,52 \%$ no total, sendo $54,28 \%$ de participação das operadoras de telefonia fixa e $27,24 \%$ de telefonia celular) como pode ser observado na tabela 5.4, as outras empresas prestadoras de serviços também têm uma participação significativa e têm crescido muito nos últimos anos. Merece destaque os serviços corporativos com 6,98\% de participação, o avanço da internet, com $0,87 \%$ de participação. A expansão dos serviços em telecomunicações impulsiona o crescimento da indústria de equipamentos.

\begin{tabular}{|c|c|c|}
\hline Segmentos & Receita Líquida (US\$ milhões) & Participação (\%) \\
\hline Operadoras de Telefonia Fixa & $12.701 .252,50$ & 54,28 \\
\hline $\begin{array}{l}\text { Operadoras de Telefonia } \\
\text { Celular }\end{array}$ & $6.373 .782,70$ & 27,24 \\
\hline Corporativos & $1.633 .167,63$ & 6,98 \\
\hline Integração & $1.020 .334,96$ & 4,36 \\
\hline TV por Assinatura & $559.953,49$ & 2,39 \\
\hline Outros Serviços & $12.266,18$ & 0,05 \\
\hline Valor Agregado & $434.161,43$ & 1,86 \\
\hline Acesso à Internet & $203.448,67$ & 0,87 \\
\hline Consultoria e Projetos & $185.492,17$ & 0,79 \\
\hline Operadoras & & \\
\hline Radiocomunicação & $239.671,91$ & 1,02 \\
\hline Infra-estrutura de rede & $37.698,93$ & 0,16 \\
\hline TOTAL & 23.046.137,87 & 100 \\
\hline
\end{tabular}

Tabela 5.4 - Participação dos segmentos nas áreas de atividade em 2001 - Serviços (Fonte: Anuário Telecom, 2002)

\subsubsection{Fornecedores de Equipamentos}

A indústria de telequipamentos no Brasil praticamente inexistia até os anos 50. Os equipamentos de telecomunicações disponíveis no País eram importados e comercializado pelos escritórios dos principais fabricantes internacionais aqui instalados, em especial Ericsson e Siemens.

Com a política de substituições de importações implementada no segundo governo Vargas (1951-1954), as empresas estrangeiras passaram a sofrer pressões para iniciar 
a fabricação local dos equipamentos. No entanto as operações que se desenvolveram, nessa época, foram, basicamente, as de montagem de produtos desenvolvidos no exterior, a partir de componentes, em grande parte, ainda importados. Geralmente cabia à indústria no Brasil, as partes dos produtos com menos tecnologia agregada.

Com a aprovação do Código Brasileiro de Telecomunicações do início da década de 60, essa situação passou a mudar. Seu principal pilar era a unificação técnica da rede que, devido à heterogeneidade dos equipamentos, resultado do regime de concessões, prejudicava a interligação das diversas regiões do País.

Demonstrando a preocupação com a origem do capital que viesse a dominar a indústria local de telequipamentos, o Código estabeleceu que, para a operadora pública que seria responsável pelas ligações internacionais, seria dada preferência a empresas brasileiras e/ou que apresentassem maior índice de nacionalização. Esta estratégia, no entanto, não foi suficiente para estimular a entrada de capital privado nacional nessa indústria, dado que o regime de concessão para os serviços municipais e estaduais ainda vigorava.

Pode-se dizer que o governo praticou um tipo de política industrial alicerçada principalmente no seu poder de compra e que visou, basicamente, a consolidação no país de uma indústria produtora de equipamentos. Tal indústria revelou-se, ao fim do processo, constituída majoritariamente por empresas multinacionais, com participação menor de empresas de capital nacional, apesar da reserva de mercado aplicada ao setor, que na prática não permitia a compra de equipamentos de empresas que tivessem controle externo de seu capital (PGT/USP, 2002).

As escalas quase sempre expressivas das encomendas, aliadas à relativa homogeneidade tecnológica (plantas telefônicas compatíveis ou idênticas em estados ou regiões) e à exigência de cumprimento de elevados índices de nacionalização, levaram à fixação no país de plantas industrias em geral de grande, o que ajudou, em conjunto com a exigência do controle de capital por parte de nacionais, a desencorajar novos entrantes. Pode-se, pois, afirmar que se consolidou no Brasil uma indústria oligopolizada, com condições de pleno atendimento à demanda interna e 
que efetivamente nacionalizou boa parte de sua produção e desenvolveu expressivos recursos humanos.

Atualmente, o setor de equipamentos de telecomunicações no Brasil caracteriza-se como uma indústria com alto índice de concentração de fabricantes internacionais de equipamentos, enquanto que a parcela do capital nacional no setor, sempre foi pouco expressiva diante do porte da indústria internacional instalada no país. A presença de empresas locais, no modelo anterior, deveu-se em grande parte, à política de compras da Telebrás (durante o período de 1972 a 1998) e à capacitação tecnológica desenvolvida pelo $\mathrm{CPqD}$, necessária para entrar num mercado de alta tecnologia. Do contrário, não seria possível a criação de uma indústria local num setor caracterizado por investimentos significativos em P\&D, altamente concentrado em um baixo número de empresas mundiais (PGT/USP, 2002).

A indústria de equipamentos de telecomunicações no Brasil sempre esteve voltada para o atendimento do mercado interno. Apesar de o Brasil ser o único país na América Latina a desenvolver uma indústria local de equipamentos, iniciativas de exportação de tecnologia nacional para países da América Latina, durante o modelo anterior, nunca foi objetivo da política de desenvolvimento tecnológico do setor. Mesmo as filiais de multinacionais instaladas no país não foram utilizadas como plataforma de exportação para a América Latina. De acordo com a política industrial e tecnológica da Telebrás, o que se buscava para o país era o desenvolvimento de uma capacidade produtiva local para o atendimento exclusivamente da demanda interna e sob regras e decisões do MC quanto ao tipo de tecnologia que as matrizes de filiais deveriam transferir para o Brasil.

A representatividade das empresas locais no setor sempre foi minoritária. Estas começaram a surgir após alguns anos de implementação de programas de desenvolvimento de produtos pela Telebrás, já na década de 80 , com destaque para as centrais Trópico, cartão indutivo e fibras óticas. Como resultado destes programas e com a reserva de mercado garantida pela política de compras da Telebrás, foram surgindo algumas empresas locais, como Promon, Xtal, Daruma, Icatel, Autel/Autelcom, além de outras empresas atuantes em seguimentos muito específicos como a Digitel, Parks, AsGa e Elebra, no segmento de modens, e 
Intelbrás em terminais telefônicos. Ainda surgiram, a partir de desenvolvimento de tecnologia própria ou de parceiros estrangeiros, as empresas Batik, Zetax e Splice.

A presença da indústria local sempre esteve restrita a nichos específicos deste mercado, com exceção das centrais de comutação Trópico que "competiam" no principal segmento do setor, centrais de comutação. No segmento de comutação de menor porte tem-se as locais Monytel e Intelbrás, pois Batik e Zetax foram compradas pela Lucent Technologies, em 1999. Em transmissão tem-se Splice e Autel e em outros nichos tem-se Daruma, Icatel, Digitel, Parks e AsGa.

Mundialmente, a indústria de equipamentos para o setor de telecomunicações é dominada por poucas e grandes empresas transnacionais. Elas atuam com os principais nichos de produtos., tanto na telefonia fixa quanto na móvel. Atualmente, pode-se dizer que todos os grandes fabricantes mundiais de equipamentos estão presentes no mercado brasileiro: Ericsson, NEC, Siemems, Nortel, Alcatel, Motorola, Lucent, Nokia, Fujitsu, Uma importante empresa nacional atuando como concorrente dessas gigantes no segmento de telefonia é a Trópico S.A. A tabela 5.5 mostra os principais fornecedores de esquipamentos atuantes no mercado brasileiro.

\begin{tabular}{|c|l|l|l|l|}
\hline$*$ & Empresa & Origem & \multicolumn{1}{|c|}{ Prin ipais Produtos } & $\begin{array}{c}\text { Iní io no } \\
\text { Brasil }\end{array}$ \\
\hline 1 & Ericsson & Suécia & $\begin{array}{l}\text { Centrais Telefônicas; Estações } \\
\text { Rádio-Base }\end{array}$ & 1924 \\
\hline 2 & Nokia & Finlândia & Terminais celulares & 1997 \\
\hline 3 & Motorola & EUA & $\begin{array}{l}\text { Estações Rádio-Base; } \\
\text { Terminais celulares e fixos }\end{array}$ & 1992 \\
\hline 4 & Nortel & Canadá & Estação Rádio-Base & 1990 \\
\hline 5 & NEC & Japão & $\begin{array}{l}\text { Centrais Telefônicas; Estações } \\
\text { Rádio-Base }\end{array}$ & 1968 \\
\hline 6 & Lucent & EUA & $\begin{array}{l}\text { Centrais Telefônicas; Estações } \\
\text { Rádio-Base }\end{array}$ & 1996 \\
\hline 7 & Siemens & Alemanha & $\begin{array}{l}\text { Centrais Telefônicas; Estações } \\
\text { Rádio-Base }\end{array}$ & 1905 \\
\hline 8 & Alcatel & França & Centrais Telefônicas & 1989 \\
\hline$*$ Posição geral da empresa segundo ranking do setor de telecomuinicaç̃es (Anuário Telecom, 2001)
\end{tabular}

Tabela 5.5 - Principais fabricantes de equipamentos e sua posição no Brasil 
Como o enfoque desta pesquisa são esses players do setor, segue uma breve descrição das principais empresas fabricantes de equipamentos de telecomunicações instaladas no Brasil. Mais informações sobre as empresas que fazem parte da amostra dos casos estudados são apresentadas nos resultados deste trabalho e em anexo.

\section{Motorola:}

Em 1996, a Motorola decidiu implantar no Brasil a sua base industrial para a América do Sul. Os investimentos da Motorola no Brasil tiveram início em 1995, sendo que grande parte deles foi destinado à construção do Campus Industrial e Tecnológico de Jaguariúna (SP), que abriga todas as atuais operações fabris da empresa (celulares, rádios bidirecionais, Estações Rádio-Base (ERB) para rede celular e equipamentos iDEN). Também estão lá instalados um Centro de Pesquisa e Desenvolvimento de Terminais Celulares em hardware, software, mecânica e desenho industrial, um Centro de Tecnologia de Semicondutores, além de uma base da Motorola University, voltada ao treinamento de funcionários.

\section{Siemens:}

As primeiras atividades da empresa no país datam de 1867, com a instalação da linha telegráfica pioneira entre o Rio de Janeiro e o Rio Grande do Sul. Em 1895, no Rio de Janeiro, era aberto o primeiro escritório e, dez anos mais tarde (1905), ocorria a fundação da empresa no Brasil.

A Siemens é uma das empresas líderes do mercado eletroeletrônico brasileiro, com atividades nas áreas de Information e Communications, Automation and Control, Medical, Power, Transportation e Lighting. No Brasil, o grupo conta com treze unidades fabris, algumas ocupando destacada posição na organização mundial, como a fábrica de Manaus, um dos três centros de competência mundiais da Siemens para a fabricação dos telefones celulares GSM.

\section{Lucent Technologies:}

A Lucent iniciou suas operações no Brasil em 1996. Em 1999, comprou a Batik e a Zetax, duas empresas brasileiras de centrais de comutação. Em 2001, a Lucent 
investiu US\$ 50 milhões na construção de uma nova unidade em Campinas para a fabricação de cabos ópticos.

A Lucent do Brasil integra a divisão CALA (Caribe e América Latina) da empresa, respondendo por mais da metade dos negócios da corporação nessa região. Seus principais negócios no Brasil são com as operadoras de telecomunicações. Na área de telefonia celular, a Lucent fornece equipamentos para as operadoras.

\section{Nokia:}

Entrou no mercado brasileiro em 1997, através da constituição de uma aliança, do tipo joint-venture, com a brasileira Gradiente, resultando na criação da empresa NGI - NG Industrial Ltda, parceria que durou até 2001. A nova empresa iniciou suas operações em janeiro de 1998, em Manaus. O lucro desta aliança se dá na comercialização dos produtos, pois as marcas Gradiente e Nokia, fabricadas pela NGI, permaneceram independentes no mercado local e no Mercosul. A Nokia, detentora da tecnologia, é fornecedora de componentes para a Gradiente montar celulares, desde 1993. O Brasil é o sétimo maior mercado do mundo para a Nokia, atualmente presente no país por meio das seguintes unidades de negócios: Nokia Mobile Phones (divisão de aparelhos celulares), Nokia Networks (divisão para soluções de infra-estrutura), e a Nokia Internet Communications (atende empresas e provedores de serviços e aplicações de internet).

\section{Alcatel:}

A Alcatel está presente no Brasil desde 1989, quando iniciou suas atividades como parceira tecnológica de empresas brasileiras de telecomunicações. Através das aquisições da Elebra Telecom, SESA Rio, Multitel Teleinformática, Standard Elétrica e ABC Teletra, foi constituída em 5 de maio de 1992 a Alcatel Telecomunicações S.A. A Alcatel projeta, desenvolve e constrói redes de comunicações, tendo como clientes operadoras, provedores de serviço e empresas de conteúdo (voz, dados e multimídia).

\section{NEC:}


A japonesa NEC está presente no Brasil desde 1963, quando veio para trabalhar no tronco sul da Telebrás. Instalou sua unidade produtiva em 1968 com a fabricação de centrais telefônicas. Hoje, atua com equipamentos de infra-estrutura e se dedica à NGN. Sua fabricação é totalmente terceirizada para a Celestica, empresa CEM (Contract Electronics Manufacturers) $^{19}$. Possui no país uma unidade principal, localizada em Guarulhos na grande São Paulo, onde são desenvolvidas atividades administrativas, comerciais, de produção, engenharia e desenvolvimento de produtos.

\section{Ericsson:}

A Ericsson está instalada no Brasil desde 1924, sendo líder mundial em telecomunicações. Possui funcionários trabalhando na matriz em São Paulo, em sua área industrial em São José dos Campos, no Vale do Paraíba, em seu Centro de P\&D, em Indaiatuba, e em escritórios regionais. A Ericsson possui um dos maiores centros de pesquisas e desenvolvimento da América Latina, inaugurado em 2001 e localizado em Indaiatuba.

\section{Nortel:}

Empresa canadense, entrou no mercado brasileiro em 1990 através de uma parceria (joint-business) com a Promon, empresa que foi vital para o seu sucesso no Brasil. Em 1998, a empresa adquiriu as instalações da Promon em Campinas (SP), onde instalou sua fábrica. Com crescimento médio anual de 75\%, os negócios da Nortel ganharam impulso com a privatização da Banda B de telefonia celular, que trabalhou principalmente com a tecnologia TDMA, principal segmento da empresa no país. Apesar de $75 \%$ dos seus negócios estarem concentrados em redes wireless, a canadense definiu mais quatro linhas de negócios: comutação pública, sistemas de transmissão e centrais de trânsito, comutação privada e switches.

\section{Fujitsu:}

A japonesa Fujitsu está presente no Brasil desde 1972. Logo que chegou ao país, atuava na área de computação, hoje ela tem um departamento voltado para a área de telecomunicações, atuando com equipamentos de transmissão, comutação e acesso, tanto para telefonia fixa como para wireless. Em telecom, a empresa japonesa deu

\footnotetext{
${ }^{19}$ As CEM serão discutidas posteriormente neste mesmo capítulo.
} 
início às suas operações no mercado brasileiro através do fechamento de um contrato com a Teleamazon, operadora da holding Telemar.

\subsubsection{Universidades e Centros de Pesquisa}

Os Centros de Pesquisa, sejam eles vinculados ou não às universidades, são agentes fundamentalmente integrados aos demais players setor. Essa importância dos centros e universidades é em decorrência, principalmente, da característica da área, tão dependente do desenvolvimento tecnológico e da formação apropriada de profissionais técnicos.

No Brasil, alguns centros de pesquisa são considerados referência na área de telecomunicações. A começar pelo $\mathrm{CPqD}$, historicamente o mais importante centro do país, mas, como foi citado, após a privatização do Sistema Telebrás, o CPqD diferenciou sua atuação e não mais se destaca como desenvolvedor de tecnologia de ponta. No entanto, ainda mantém-se vinculado a projetos de pesquisa, geralmente em conjunto com empresas do setor.

Hoje, além do $\mathrm{CPqD}$, alguns outros centros de pesquisa ou departamentos/institutos em universidades são agentes importantes e estão envolvidos com o desenvolvimento científico e tecnológico em Telecomunicações no país, são eles os principais centros parceiros das empresas que recebem incentivos da lei de informática (MCT, 2003):

- INATEL - Instituto Nacional de Telecomunicações, em Santa Rita do Sapucaí.

- CESAR - Centro de Estudos e Sistemas Avançados do Recife, centro de pesquisa localizado no Recife.

- FITec - Fundação para Inovações Tecnológicas, com matriz no Recife e filiais em Minas Gerais e em São Paulo.

- CERTI - Fundação Centros de Referência em Tecnologias Inovadoras, ligado à Universidade Federal de Santa Catarina (UFSC)

- CITS - Centro Internacional de Tecnologia de Software, localizado no Paraná. 
- CPDIA - Centro de Pesquisa e Desenvolvimento de Informática e Automação, originalmente ligado à NEC, localiza-se em São Paulo e foi, em 2003, incorporado, em sua maioria, ao IPT (Instituto de Pesquisas Técnicas).

- INFORMAT - Instituto de Pesquisas em Informática e Automação, centro criado pela Ericsson, localiza-se em Indaiatuba.

- Instituto Eldorado - criado pela Motorola, localiza-se na região de Campinas.

- BRISA - Sociedade para o Desenvolvimento da Tecnologia da Informação, com duas unidades, uma localizada no Distrito Federal e outra em São Paulo

- LACTEC - Instituto de Tecnologia para o Desenvolvimento, é um centro de pesquisa científica e tecnológica criado a partir de uma parceria entre a UFPR (Universidade Federal do Paraná) e a COPEL (Companhia Paranaense de Energia)

Esses e outros centros, também importantes e que estabelecem relações de parcerias com empresas, serão mais detalhadamente analisados em capítulos posteriores. Além dos centros ou institutos formais, as universidades também têm cooperação com empresas de telecomunicações através de seus departamentos, na maioria das vezes de Computação e Engenharia Elétrica/Eletrônica: PUC, UNICAMP, USP, UFRGS, UFMG, CEFET, etc.

Analisando o trabalho de Prado e Porto (Prado e Porto, 2002a, 2002b), é possível verificar que existem diferenças entre os tipos de vínculos entre as empresas e cada um desses centros para a realização de pesquisas. Algumas empresas utilizam os centros como "extensão" de seus departamentos de P\&D, enquanto outras relações estabelecidas assemelham-se mais a vínculos de contratação de serviços. Até mesmo uma mesma empresa apresenta essas diferenças nos tipos de parcerias firmadas com dois centros / universidades distintos.

As cooperações formadas entre as companhias e as instituições de pesquisa são, em grande parte, estimuladas pelos incentivos fiscais oriundos da lei 10.176, antiga lei 8248, a chamada "Lei de Informática", que, entre as contrapartidas exigidas, 
estabelece que as empresas devem aplicar um percentual do faturamento em atividades de $\mathrm{P} \& \mathrm{D}$ realizadas cooperativamente com centros de pesquisa ou universidades. Na seção 5.4.3, a lei é discutida mais profundamente.

\subsubsection{Cadeia Produtiva do Setor de Telecomunicações}

Os players que compõem o setor, apresentados/discutidos nas seções anteriores, indicam o quão amplas são a abrangência e a complexidade das inter-relações existentes em telecomunicações. Essa composição do setor indica, de maneira ampla, quais são os agentes diretamente envolvidos na sua dinâmica e as influências que eles têm e que sofrem. No entanto, ela não mostra as relações existentes na cadeia produtiva do setor, portanto faz-se necessária a análise de uma configuração mais detalhada para o mapeamento industrial de telecomunicações.

Uma dessas configurações é o modelo em camadas, desenvolvido pelo Telecomvisions (2002), um grupo composto por consultores e analistas independentes oriundos da indústria ou da academia, que escrevem sobre vários aspectos das telecomunicações. Um colaborador importante é o fundador do projeto, Prof. Martin Fransman, da Universidade de Edinburgh. Tal modelo, mostrado na figura 5.2, considera a tecnologia de internet baseada na interface TCP/IP (Transmission Control Protocol / Internet Protocol) para criar as seis camadas que o compõem e, consequentemente, os níveis de atividades realizadas na cadeia de valores do setor.

Assim, além dos segmentos explícitos no modelo que mostra a composição do setor - fornecedores, operadoras e consumidores - ele também evidencia outros três níveis entre operadoras e clientes: serviços para conectividade (provedores de acesso) camada 3, serviços relacionados a navegação (permitem a utilização da internet) camada 4, e aplicações (criação e empacotamento de conteúdo ou informações) camada 5. Vale destacar que os consumidores podem ser clientes de serviços intermediários, não estando necessariamente apenas no final da cadeia.

Nesse modelo, os setores de telecomunicações e de computação praticamente se fundem no que é chamado "infocomunicações" ou infocommunications. As camadas 
3, 4 e 5 são praticamente compostas por empresas consideradas do segmento de computação, são as chamadas "ponto com”. A camada 5 já começa a se enquadrar em setores mais tradicionais da economia, apesar de ainda ser considerada da área de computação. As empresas desse nível são agências de informações, que não trabalham apenas no modelo tradicional, mas também utilizam as facilidades das tecnologias de comunicações para se destacarem nos segmentos em que atuam.

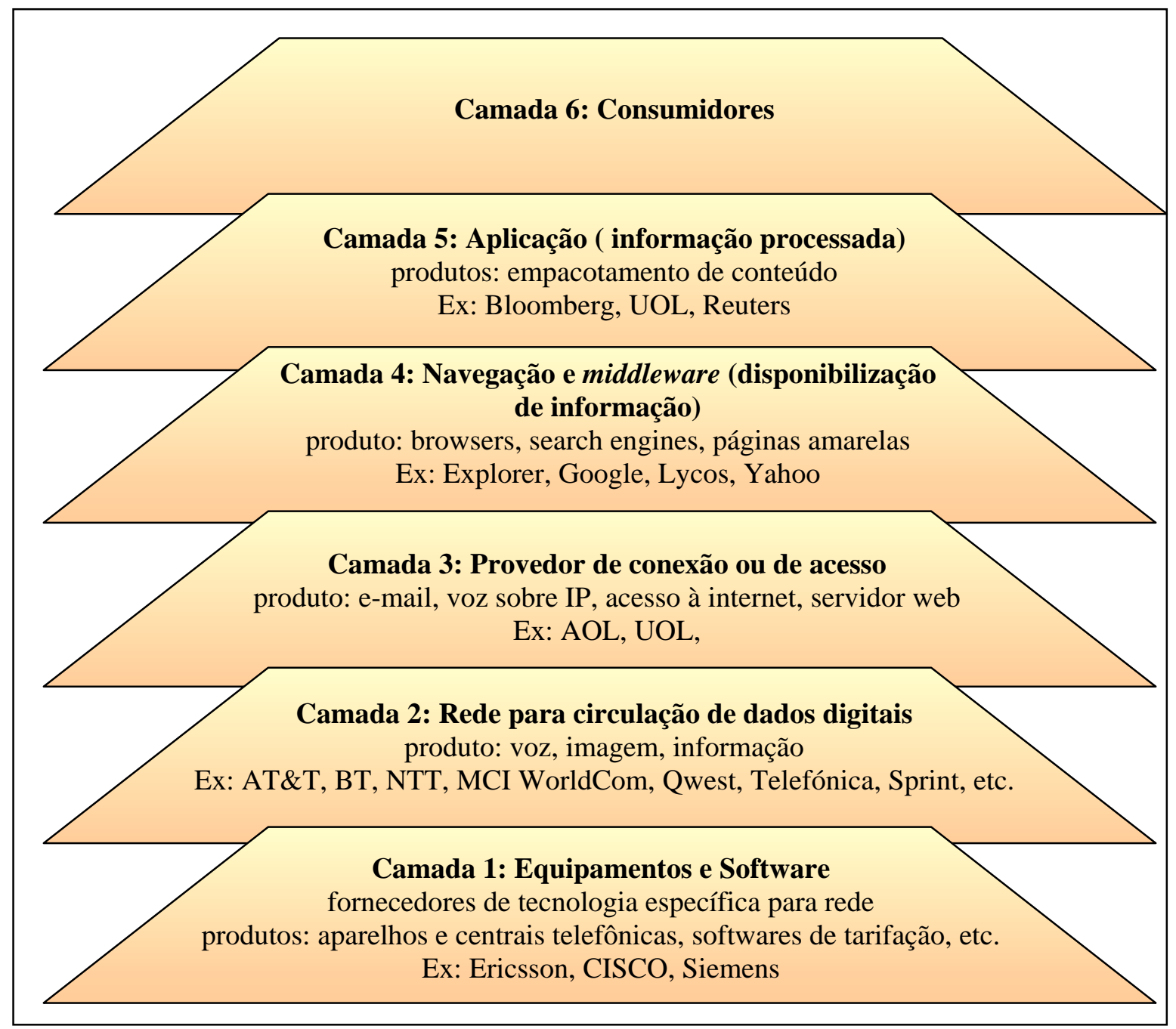

Figura 5.2 - Modelo em camadas para o Setor de telecomunicações (Fransman/Telecomvisions, 2002)

Uma outra representação da cadeia de valores do setor é a desenvolvida por Andrew Davies et alii (Davies et alii, 2001). Nesse modelo, as atividades da indústria de telecomunicações são divididas em dois grupos principais: produtos e serviços, que se complementam. Nesse modelo, as empresas do setor trabalham com quatro tipos de atividades: manufatura de componentes e sub-sistemas, integração de sistemas, 
operações e serviços, esses dois últimos bastante interligados. A figura 5.3 mostra esse modelo.

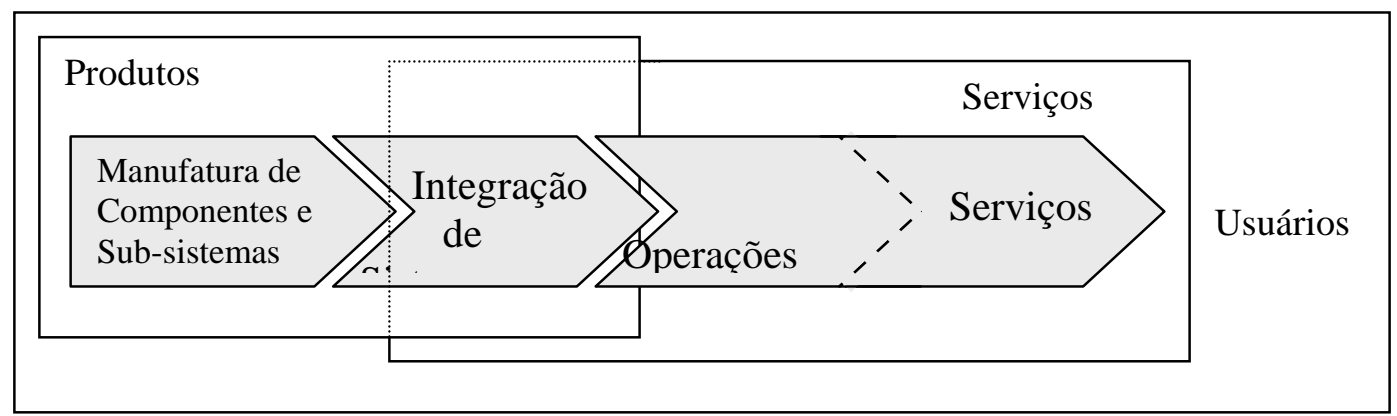

Figura 5.3 - Cadeia de valores do setor de telecomunicações (Davies et al., 2001)

\subsubsection{Proposta de uma nova estrutura para a cadeia de Telecomunicações}

Os modelos apresentados na seção anterior possuem alguns problemas e não representam completamente a cadeia produtiva do setor de telecomunicações. $\mathrm{O}$ modelo de Frasnman/Telecomvisions é pouco abrangente, desconsiderando segmentos importantes, enquanto que o modelo de Davies et alii, por ser muito amplo, não especifica claramente os players dos segmentos do setor.

A forte representação da ligação com a tecnologia utilizada na internet deixa o modelo proposto por Fransmam menos geral, uma vez que a internet, apesar de ser a forte tendência atual, não é a única das tecnologias utilizadas nas comunicações, esse pode ser um dos seus pontos fracos.

Uma outra limitação do modelo de Fransman é a falta de algumas categorias de empresas que compõem a cadeia de telecomunicações, como a de fabricantes de componentes para os fornecedores de equipamentos específicos de telecom. Esses fabricantes são geralmente mais fortemente atuantes em outras cadeias como a de eletrônica/computação (fabricantes de semicondutores, por exemplo) e a de elétrica (fábricas de baterias, fontes de energia, etc.). Talvez por isso é que eles são "descartados" na modelagem da cadeia de "infocomunicações", no entanto, eles exercem bastante influência na cadeia de telecomunicações, seja na fabricação ou no desenvolvimento tecnológico de produtos. Além disso, o modelo de Frasman considera outros players também muito ligados à cadeia e computação: camadas 3,4 e 5 . 
Uma outra "camada" não representada por esse modelo, é o das empresas atuantes na construção de infra-estrutura e na fabricação de equipamentos para isso. Por exemplo, entram nesse nível, companhias que produzem e/ou instalam fibras óticas e demais equipamentos de transmissão de dados, empresas também importantes para a cadeia como um todo, uma vez que influenciam e são influenciadas pelas estratégias do setor.

Analisando um nível mais "alto" na cadeia de telecomunicações, é possível verificar que várias empresas atuam com serviços de telefonia além das operadoras, não necessariamente utilizando a internet, como são os representados por Fransman em seu modelo. Tais empresas geralmente atuam como fornecedoras e/ou parceiras das operadoras de telefonia, desenvolvendo serviços para serem disponibilizados aos clientes finais (consumidores físicos ou jurídicos), contribuindo para a diferenciação e melhoria dos produtos das operadoras.

Sendo assim, propõe-se um novo modelo para a cadeia produtiva do setor, especialmente utilizado neste trabalho, que é mostrado na figura 5.4. Esse modelo abrange uma quantidade maior de agentes relacionados ao setor de telecom do que os compreendidos nos outros apresentados anteriormente. A figura representativa do modelo tenta mostrar a cadeia como uma rede interligada de players. As setas mostram uma relação de alimentação linear da cadeia, ou seja, os fornecedores de componentes atendem aos fabricantes de equipamentos para consumidores, para rede pública e para infra-estrutura, estes, por sua vez, têm como clientes os responsáveis pelos serviços de telecomunicações, sejam operadoras, provedores de conexão ou de conteúdo, que atendem aos consumidores.

Vale destacar que os consumidores também são atendidos diretamente pelos fornecedores de equipamentos para consumo final, especialmente aparelhos telefônicos. No caso dos aparelhos celulares, em geral, as operadoras de serviços de telefonia móvel são os clientes destes fornecedores e só então revendem os aparelhos para os consumidores (por isso a representação do agente "equipamentos consumidor final" ser feita por uma seta múltipla, indicando que, na cadeia, fornecem produtos tanto para "Serviços" quanto para "Consumidores"). 
É possível observar vínculos de um agente/player - representado pelas caixas - com vários outros agentes, seja a montante ou a jusante na cadeia produtiva, conforme figurado pela ordem da distribuição das caixas na figura 5.4 (da esquerda para a direita). No entanto, mesmo normalmente tendo uma relação linear entre eles, não significa que os players dispostos da esquerda para a direita sejam necessariamente fornecedores / clientes na seqüência apresentada. Por exemplo, os fabricantes de componentes fornecem para as empresas de montagem de equipamentos ou diretamente para os fornecedores de equipamentos (que realizam a montagem dos seus equipamentos).

No "início" da cadeia estão as empresas diretamente ligadas a produtos, ou seja, os fornecedores, sejam os de equipamentos para consumidor final ou para rede pública, os fabricantes de componentes elétricos / eletrônicos, os montadores de equipamentos, montagem de infra-estrutura e os fabricantes de equipamentos para infra-estrutura. Esses players trabalham em nichos distintos de produtos e são, em geral, compostos por empresas também distintas. No entanto, algumas companhias atuam em dois ou mais desses nichos, por exemplo, a Ericsson é fabricante de equipamentos para rede pública e também para consumidores, a Motorola, além de fabricante de equipamentos, também atua no desenvolvimento e na fabricação de alguns componentes eletrônicos específicos, e ambas atuam como provedoras de aplicações para rede.

As empresas fabricantes de equipamentos de infra-estrutura e os montadores de redes são as responsáveis pela estrutura física para as redes de comunicação. São elas as responsáveis pela fabricação e instalação de cabos, fibras, equipamentos para transmissão de sinal, etc. Elas podem trabalhar diretamente para as empresas operadoras de serviços (públicos ou não), o mais comum atualmente, ou para os governos de países, no intuito de construir a malha de interligação das redes.

Os fornecedores / fabricantes de equipamentos estão relacionados entre si e com os outros componentes da cadeia. Os fabricantes de equipamentos para rede, por exemplo, não são apenas fornecedores para as operadoras, mas também para os integradores de rede e para os desenvolvedores de aplicação. Essas empresas, aliás, desenvolvem atividades relacionadas mais a serviços do que a produtos. 
Alguns fornecedores de equipamentos também realizam atividades de integração de rede $^{20}$, como é o caso da Siemens e da Alcatel, as duas empresas que prestam serviços de manutenção da rede fixa da Telemar e, juntamente com a Nokia, de operação e manutenção da rede móvel GSM. Mas não são apenas os tradicionais fabricantes de equipamentos que atuam nesse nicho de negócios, existem algumas empresas especializadas em prover soluções de integração de rede, como a norteamericana SOTAS, Inc.

Essas empresas utilizam elementos - equipamentos, software, etc. - de múltiplos fornecedores para prover soluções para projeto, otimização, manutenção, monitoramento e gerenciamento de redes de comunicações. Elas atuam em parceria com os fornecedores de equipamentos para a prestação de serviços às operadoras. Há também uma delegação de serviços de gestão de redes das operadoras para as integradoras. Análises no comportamento do mercado mostram uma tendência bastante acentuada de terceirização desse tipo de serviço pelas operadoras (MouraFé, 2002). Essas mudanças ocorridas no comportamento das empresas são abordadas na próxima seção.

No caso dos desenvolvedores de aplicações para rede, que também estão no liminar entre produtos e serviços, eles atendem tanto operadoras quanto integradores de rede. Para as operadoras, as aplicações mais comuns são softwares para serviços específicos tanto para rede fixa quanto para a móvel, por exemplo, os para controle de chamadas a cobrar, secretária eletrônica, envio de mensagem, etc.

A parte da cadeia que é diretamente relacionada a serviços compreende as operadoras de acesso à rede pública, os provedores de conexão e os provedores de conteúdo / informação. Também para serviços, a justaposição dos players acontece, por exemplo, as operadoras atuam também como provedores de conexão, o que vem gerado grandes discussões, uma vez que isso pode estabelecer uma relação injusta, já que ela compete com seus clientes, os outros provedores de conexão.

\footnotetext{
${ }^{20}$ Há uma intensa alteração de papéis das empresas atuantes em telecomunicações, com movimento acentuado a jusante na cadeia produtiva, mudando seu core, o que será discutido na próxima seção.
} 


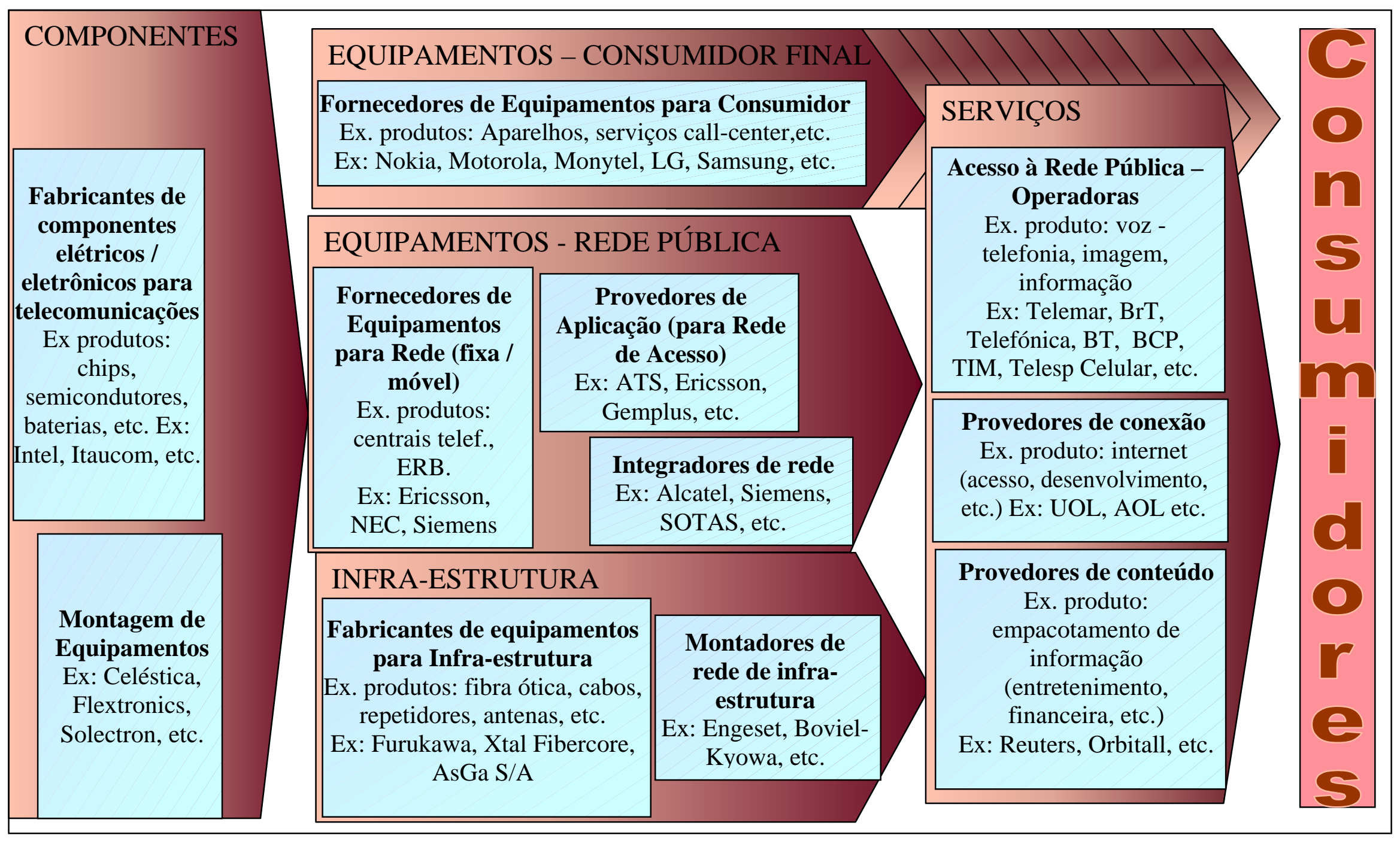

Figura 5.4 - Proposta para Cadeia Produtiva de Telecomunicações 


\subsubsection{Mudanças de papéis na cadeia}

O setor de telecomunicações passou e vem passando por uma grande reestruturação, seja em termos de tecnologias usadas (principalmente após a junção da computação e da telecom), de estrutura da cadeia (por exemplo, fim do monopólio estatal ), entrada e fortalecimento da internet, mudanças nos serviços oferecidos, etc. Dessa forma, algumas mudanças acontecem na sua organização industrial, com reconfiguração das atividades realizadas nas empresas, que passam a atuar em diferentes segmentos do setor. Ainda não é possível saber se os novos arranjos que começam a surgir serão por integração vertical (uma mesma empresa agrega atividades em diversos segmentos do setor) ou especialização vertical (uma empresa se especializa em um ou em poucos - segmentos do setor).

Pela semelhança entre os setores, especula-se que o comportamento do de telecomunicações será similar ao de computação (Telecomvisions, 2001). Nessa indústria, as empresas que dominavam o mercado na época dos computadores de grande porte, como IBM, Fujitsu e DEC, eram integradas verticalmente. Elas desempenhavam atividades de pesquisa, desenvolvimento e produção de seus próprios semicondutores, sistemas operacionais e programas aplicativos, além de também serem responsáveis pela montagem, marketing, vendas e distribuição dos seus produtos.

Com a entrada dos computadores pessoais (PC) e das redes computacionais, a organização industrial do setor mudou para especialização vertical ou horizontal (quando diferentes empresas se especializam em diferentes segmentos da indústria). Por exemplo, no segmento de semicondutores, a Intel se especializa nos microprocessadores e as companhias japonesas nas memórias para eles. A Microsoft se concentra no segmento de sistemas operacionais para PC, iniciado com o MSDOS, enquanto que Compaq e Dell dominam montagem e distribuição de equipamentos. E assim, várias outras empresas passam a atuar especificamente num segmento da indústria. 
Não se sabe ao certo se o comportamento da indústria de telecomunicações será semelhante ao da de computação, mas é possível apontar tendências através da análise do comportamento de algumas empresas. Certas companhias parecem se especializar em determinada camada da indústria, apresentando especialização. Assim se comportam empresas como Flextronics, Solectron e Celestica, que atuam na montagem de equipamentos eletrônicos e para telecomunicações, as chamadas CEM (Contract Electronics Manufacturers) ${ }^{21}$ e que estão cada vez mais especializadas nessas atividades. Essa característica é impulsionada também pela tendência dos fabricantes originais de equipamentos, conhecidos por Original Equipment Manufacturers (OEM), em abandonar as atividades de manufatura/montagem, como a Ericsson, a NEC, Nortel, e outras, que terceirizaram a fabricação dos aparelhos celulares, a montagem das ERBs, das centrais fixas, etc.

Essas empresas, que especializaram-se na manufatura / montagem de equipamentos eletrônicos, principalmente para as indústrias de computação e telecomunicações, têm se destacado pelo crescimento de suas atividades em outros países, que não o país sede e pela "prestação de serviços" para grandes companhias como Alcatel, Ericsson, Siemens, Sony, Cisco Systems, etc. (Andrade, 2001). A tabela 5.6 apresenta alguns dados das maiores empresas do segmento (Kador, 2001), que mostram a relevância atual do setor de telecomunicações para essas empresas. Vale destacar que, além de atuarem nos setores de telecomunicações e de computação, essas empresas também manufaturam equipamentos eletrônicos, industriais, médicos, domésticos, entre outros.

Dando continuidade à discussão sobre especialização no setor de telecomunicações, é importante analisar o segmento de software. Novas empresas especializadas em desenvolvimento de software entram para suprir a demanda por serviços ao cliente e especializam-se nesse segmento da indústria de telecom. Sem contar as operadoras de rede que, como citado anteriormente, em maioria absoluta estão concentrando-se mais na área de serviços, deixando segmentos como $\mathrm{P} \& \mathrm{D}$, que no passado foram fundamentais para seus negócios, para empresas que atuam num "nível mais baixo" na cadeia produtiva, conforme descrito na próxima seção deste trabalho.

${ }^{21}$ Também conhecidas por EMS (Electronics Manufacturing Services) 


\begin{tabular}{|c|c|c|c|c|c|c|c|}
\hline \multirow{2}{*}{ Empresa } & \multirow{2}{*}{$\begin{array}{l}\text { País de } \\
\text { origem }\end{array}$} & \multirow{2}{*}{$\begin{array}{c}\text { Faturam. } \\
(2000) \\
\text { (US\$ } \\
\text { bilhões) }\end{array}$} & \multicolumn{2}{|c|}{$\begin{array}{l}\text { Número de } \\
\text { Fábricas }\end{array}$} & \multirow{2}{*}{$\begin{array}{l}\text { Nro de } \\
\text { Funcio- } \\
\text { nários }\end{array}$} & \multicolumn{2}{|c|}{ Mix produtos (\%) } \\
\hline & & & $\begin{array}{l}\text { América } \\
\text { do Norte }\end{array}$ & $\begin{array}{l}\text { Outros } \\
\text { países }\end{array}$ & & Telecom & $\begin{array}{c}\text { Compu- } \\
\text { tação }\end{array}$ \\
\hline Solectron & EUA & 17,06 & 28 & 40 & 57.000 & $\mathrm{~N} / \mathrm{d}^{*}$ & $\mathrm{~N} / \mathrm{d}^{*}$ \\
\hline Flextronics & Singapura & 10,37 & 35 & 75 & 59.000 & 52 & 29 \\
\hline Celestica & Canadá & 9,75 & 20 & 16 & 31.000 & 34 & 66 \\
\hline SCI Systems & EUA & 9,15 & 27 & 18 & 31.700 & 32 & 32 \\
\hline Sanmina & EUA & 4,89 & 55 & 10 & 28.000 & 75 & 14 \\
\hline
\end{tabular}

Tabela 5.6 - Empresas de serviços de manufatura em telecomunicações

Embora existam indícios de que as empresas estão tornando-se mais especializadas, alguns casos ainda são claros de integração vertical, como a norte-americana Motorola, que desenvolve, principalmente para a telefonia celular, semicondutores, aparelhos telefônicos para usuário, equipamentos para rede, soluções em software. Sendo assim, não há comprovação de que a organização industrial de telecomunicações terá a mesma trajetória da apresentada pela indústria de computação, mas parece estar se orientando para especialização, pelo menos as companhias estudadas neste trabalho sinalizam para isso.

Um outro comportamento das empresas que pode ser percebido é a atual variação em seus ramos de atuação. Muitas sinalizam para a entrada em outros segmentos e até mesmo para a mudança de segmento de atuação. Parece existir uma tendência de encaminhamento a jusante na cadeia, ou seja, as empresas tendem a migrar para atividades de serviços.

Como citado anteriormente, vários são os exemplos de operadoras que deixaram de atuar no desenvolvimento de produtos para rede e começaram a concentrar-se mais nos serviços a serem disponibilizados aos clientes. Também fortalece, em todo o 
mundo, com reflexos no Brasil, a tendência das operadoras repassarem para terceiros as funções de manutenção e operação de suas redes (Moura-Fé, 2002).

Muitas empresas que atuam como fornecedoras de equipamentos estão deixando as atividades relacionadas a manufatura de componentes e até mesmo de alguns equipamentos de telecomunicações para concentrar-se na integração de sistemas (atuando como integradores de rede) e no fornecimento de soluções para operação e serviços.

Companhias como Ericsson e NEC terceirizaram suas operações de fabricação de aparelhos celulares movidas pelos baixos resultados conseguidos na e concentram-se no desenvolvimento e integração dos equipamentos para rede de comunicações. São grandes as discussões sobre as razões de cada empresa ao tomar essas atitudes, falase em erros nas estratégias de mercado e de design dos aparelhos, mas as mudanças têm ocorrido principalmente devido ao aumento da concorrência na área. Cerca de 60 empresas fabricam aparelhos celulares hoje. Esses produtos de consumo, cada vez mais, são utilizados como acessórios pelos consumidores e devem ser produzidos como tal, assim como ocorreu na indústria de eletro-eletrônico. São assim, fabricados em larga escala e a uma margem bastante pequena, o que a grande maioria das tradicionais empresas fornecedoras de equipamentos de telecom não está acostumada a fazer, ou seja, trabalhar com produto de consumo em massa. Vale destacar que a Ericsson não abandonou totalmente a área de aparelho celular, como comprova sua atual aliança com a japonesa Sony. Juntas, essas empresas desempenham atividades de desenvolvimento e marketing dos produtos.

É tão clara a mudança de enfoque, com uma tendência de atuação em serviços, que os tradicionais fabricantes de equipamentos estão, inclusive, alterando sua estrutura interna para melhor atendimento do mercado. É o caso da Motorola no Brsil, que, conforme mostrado por Moura-Fé (2002), desde dezembro de 2001 reestruturou suas áreas, seguindo um processo mundial, com realocação dos recursos internos, que atualmente conta com mais de 50\% dos funcionários na área de serviços.

Existem várias críticas a esse comportamento de a incursão dos fabricantes de equipamentos em integração, manutenção e gestão de redes, primeiramente por um 
motivo claro, "o fabricante vai focar no próprio equipamento; segundo, porque ele não vai adquirir capital intelectual da noite para o dia; e, terceiro, porque vai estar competindo com o seu próprio integrador, que conta com a vantagem de ter investido em capital intelectual desde o início" (Moura-Fé, 2002).

Por outro lado, embora a norte-americana Qualcomm tenha se desfeito da sua unidade para desenvolvimento e fabricação de aparelhos celulares e além disso, trabalha com o desenvolvimento de soluções para operadoras, essa empresa parece ter uma estratégia bastante diferente, que é passar de fornecedora de equipamentos, sem ainda ter abandonado essa atividade, para desenvolvedora de tecnologia de comunicação, garantindo a continuidade e a crescente utilização de sua tecnologia CDMA pelas operadoras, aliando-se a outros fornecedores. A terceira geração (3G) de celular (acesso a informações multimídia numa velocidade maior que a atual), cujo início das operações mundiais estava previsto para o ano de 2001, o que apenas foi feito no Japão, mas é constantemente adiado por vários fatores ${ }^{22}$, estará baseada nessa tecnologia (Kano, 2000).

\subsection{Desenvolvimento Tecnológico no Setor de Telecomunicações}

\subsubsection{Retrospectiva Histórica}

Até meados da década de 80 , mundialmente o setor era caracterizado pela monopolização nacional em serviços (operação de telefonia), mas a produção de equipamentos divergia em cada país, e surgiram tipos diferenciados de fornecedores (Fransman, 2001), influenciados principalmente pelas relações existentes entre as operadoras e a demanda por mercado local. No extremo dessas relações está o caso dos Estados Unidos, onde a integração vertical era total e a própria operadora (AT\&T) fabricava os equipamentos para infra-estrutura e para rede telefônica. No outro extremo estão os pequenos países desenvolvidos, com um mercado pouco significativo, e os países em desenvolvimento. Nesse caso, as operadoras nacionais

\footnotetext{
${ }^{22}$ Intensificados principalmente pelos problemas pelos quais as empresas do setor vêm passando.
} 
(monopólios) compravam seus equipamentos de fornecedores especializados, que competiam mundialmente.

No meio termo estão os países industrializados, como Japão, Reino Unido, França e Alemanha. Nesses países, com maior ou menor sucesso, os monopólios nacionais cooperavam com fornecedores locais, fortalecendo assim a indústria nacional. No caso do Japão, a operadora NTT (Nippon Telegraph and Telephone Corporation) relacionava-se com os fornecedores NEC, Fujitsu, Hitachi e Oki. No Reino Unido a relação de privilégio entre a operadora (Post Office, mais tarde British Telecom) e os fornecedores locais (GEC, Plessey, STC) não obteve tanto êxito quanto no Japão. Na França e na Alemanha, as relações entre as operadoras (France Telecom e Deutsche Telecom, respectivamente) e as empresas fornecedoras nacionais foram responsáveis pelo fortalecimento das gigantes Alcatel e Siemens. No Brasil, as pesquisas da Telebrás eram feitas no $\mathrm{CPqD}$ e os equipamentos fabricados nas empresas nacionais: Promon, Elebra, STC e SID. Também estavam presentes no mercado brasileiro como fabricantes: Ericsson, Siemens e NEC.

$\mathrm{Na}$ época dos monopólios, as operadoras detinham os centros de pesquisa responsáveis pelos desenvolvimentos tecnológicos do setor. Os laboratórios ligados a elas, como o Bell Lab da AT\&T, o CNET da France Telecom e o CPqD - um dos únicos casos de sucesso em países não desenvolvidos (Hobday, 1986) - eram responsáveis pela pesquisa inicial, pelo desenvolvimento e testes de protótipos, passando então para os fabricantes, que desenvolviam para fabricação. Mesmo sendo altamente inovativa, principalmente na área de equipamentos para comutação fixa (Gaffard e Krafft, 2000), embora outras áreas também tenham recebido grandes crescimentos tecnológicos, esse processo de inovação era lento, já que envolvia duas - ou mais - estruturas organizacionais (a operadora e o fabricante de equipamento) em etapas sequienciais (Fransman, 2001).

Essa estrutura de desenvolvimento tecnológico impunha barreiras ao processo de inovação, já que o acesso às redes de telecomunicações era restrito apenas às operadoras e seus parceiros na fabricação de equipamentos. Além disso, a base de conhecimento era fragmentada, uma vez que cada 'par' nacional tinha sua própria tecnologia (Fransman, 2001). 
Com o tempo, os fornecedores passaram a deter tecnologia e ter seus próprios centros de pesquisa. Além disso, eles passaram a ter acesso a mercados de países do terceiro mundo, onde as operadoras geralmente não tinham os parceiros fornecedores. A competição existente nesses mercados - e ausente nos países sede dessas empresas - foram fundamentais para estimular desenvolvimento tecnológico dos fabricantes (Fransman, 2001). Um exemplo é o caso da canadense Nortel (exsubsidiária da AT\&T), que, por causa do sua participação nos mercados em desenvolvimento, a partir dos anos 70, tornou-se um dos primeiros fabricantes a desenvolver as pequenas centrais telefônicas (Fransman, 1995), tecnologia que, de acordo com entrevistados da Lucent Technologies, só veio a existir na AT\&T, no final dos anos 90, com a aquisição das brasileiras Batik e Zetax pela Lucent (fabricante de equipamentos originária da fragmentação da AT\&T).

Essa estrutura industrial acaba a partir dos anos 90, com o fim dos monopólios nos principais países desenvolvidos - Japão, EUA e Reino Unido. Agora a indústria de telecomunicações não mais se restringe a operadoras e fornecedores de equipamentos, conforme observado nas seções anteriores, também fazem parte dela, empresas que detêm tecnologia em algumas áreas responsáveis pela evolução do setor, como as de semicondutores, software, internet e comércio eletrônico, e multimídia. Muitos dos novos players não têm competência específica em telecomunicações, então entram no mercado a partir de acordos de joint-ventures com operadoras, e, com o tempo, tornam-se também desenvolvedores de tecnologias para a indústria, contribuindo para o seu crescimento (Gaffard e Krafft, 2000).

As operadoras de telefonia passaram a transferir gradativamente a responsabilidade pela pesquisa e desenvolvimento de equipamentos de rede para os fabricantes e a negociar com quaisquer dos fornecedores disponíveis, desvinculando-se assim, do seu 'parceiro'. Os investimentos em P\&D passam então a ser mais intensos entre os fornecedores e deixam de existir nas operadoras. Uma comparação feita por Fransman (2001), mostra claramente isso, empresas como Ericsson, Nortel e Cisco investem um percentual bastante significativo de seu faturamento em desenvolvimento tecnológico (em torno de 15\%), comparado ao investimento feito pela indústria farmacêutica. Por outro lado, as operadoras que foram monopólio, 
como a NTT, British Telecom e AT\&T investem bem menos (cerca de 2\%) e as novas operadoras, que entraram após abertura dos mercados, não investem praticamente nada em P\&D. Ao invés, essas empresas preferem investir em inovações mercadológicas. A tabela 5.7 mostra os dados obtidos por Fransman (2001) para empresas da indústria de telecomunicação (fornecedores e operadoras) e em empresas de outros setores para comparação.

\begin{tabular}{|c|c|}
\hline EMPRESA & $\begin{array}{c}\text { Investimento P\&D } \\
(\% \text { Vendas })\end{array}$ \\
\hline NTT & $3.7 \%$ \\
\hline BT & $1.9 \%$ \\
\hline AT\&T & $1.6 \%$ \\
\hline Cisco & $18.7 \%$ \\
\hline Ericsson & $14.5 \%$ \\
\hline Nortel & $13.9 \%$ \\
\hline Lucent & $11.5 \%$ \\
\hline Nokia & $10.4 \%$ \\
\hline WorldCom & $\sim 0 \%$ \\
\hline Qwest & $\sim 0 \%$ \\
\hline Global Crossing & $\sim 0 \%$ \\
\hline Roche & $15.5 \%$ \\
\hline Glaxo Welcome & $14.4 \%$ \\
\hline Smithkline Beecham & $10.8 \%$ \\
\hline Indústria Automotiva & $4.2 \%$ \\
\hline Indústria Hoteleira & $3.2 \%$ \\
\hline Indústria de Construção Civil & $3.0 \%$ \\
\hline Indústria de Cervejaria & $2.3 \%$ \\
\hline
\end{tabular}

Tabela 5.7 - Investimento em P\&D - 1999 (Fransman, 2001)

Apesar do pouco investimento em desenvolvimento de produtos, as operadoras são parceiras dos fornecedores em muitas inovações tecnológicas. Essa integração é importante tanto para as operadoras, que podem acompanhar as evoluções da área e ter prioridade no uso de novos equipamentos, quanto para os fabricantes de equipamentos, que precisam de parceria para testes e análise de mercados. O estudo de caso do desenvolvimento do sistema R5A (Davies, 1997) é um exemplo da parceria entre a Ericsson e três operadoras, a sueca Telia (ex-monopólio), a britânica Vodafone e a alemã Mannesmann (ambas novas entrantes). 


\subsubsection{Características Atuais}

O desenvolvimento tecnológico, que sempre foi fundamental no setor de telecomunicações, é hoje, um dos principais sustentáculos da indústria. Dessa forma, as empresas estão alterando seus comportamentos e estratégias para tornarem-se cada vez mais competitivas, e isso, evidentemente, leva ao aprimoramento das atividades na área de pesquisa e desenvolvimento.

É fato a necessidade das empresas terem produtos competitivos em suas áreas de atuação, o caso da norte-americana Lucent pode ser um exemplo de erros estratégicos. A empresa não tem produtos competitivos em algumas áreas e não os vem desenvolvendo, isso a fez perder participação no mercado (Rosenbush e Borrus, 2001). Hoje a empresa está remodelando sua estrutura de P\&D com redução de unidades e de investimento.

Em geral, essas estruturas para P\&D, são cada vez mais globais. Geralmente, quanto mais complexo o desenvolvimento de um produto, maior é o envolvimento de outras unidades da companhia e de clientes localizados em várias partes do mundo. Um exemplo de desenvolvimento de produto complexo é o projeto CME R5A (Davies, 1997), desenvolvido pela Ericsson por um período de três anos e meio. O objetivo inicial era desenvolver uma estação rádio-base menor e mais barata, mas as alterações realizadas nesse equipamento influenciaram alterações em todos os equipamentos de rede da empresa. Foi um projeto que envolveu, em todos os estágios de projeto e produção, subsidiárias localizadas em 9 países europeus, além de das 3 clientes-chave, conforme citado anteriormente: Telia, Mannesmann e Vodafone.

Existe uma tendência das empresas em descentralizar o desenvolvimento de produtos. Todas as grandes empresas fornecedoras de equipamentos de telecom, listadas na tabela 5.5, possuem desenvolvimento global e realizam atividades cooperativamente com subsidiárias e clientes (Galina e Plonski, 2000). Os fatores que levam as companhias a envolver as subsidiárias são discutidos no capítulo 6, como parte dos resultados deste trabalho de doutorado. 
É também comum, encontrar integração entre os competidores para desenvolvimento de novas tecnologias. Por exemplo, a tecnologia CDMA, desenvolvida pela Qualcomm, deve muito do seu sucesso às parcerias realizadas com outros fornecedores de equipamentos, como a Ericsson. Hoje, variações dessa tecnologia são usadas em qualquer um dos três padrões (Japão, EUA, Europa) estabelecidos para a tecnologia celular de $3 \mathrm{G}$.

Uma outra característica comum às empresas do setor de telecomunicações é a determinação em localizar o desenvolvimento de alguns produtos (geralmente de tecnologia já dominada) em países em desenvolvimento. Assim, a unidade brasileira da Motorola está desenvolvendo, em parceria com a unidade chinesa, aparelhos de telefones (telefonia fixa), a brasileira fica responsável pelo design externo dos aparelhos, enquanto que os componentes internos são desenvolvidos na China (Galina, 2001b).

Também é comum entre os fornecedores, a realização de financiamento para os clientes (operadoras), principalmente para a incorporação de novas tecnologias, o que garante maior participação no mercado. Por exemplo, a tecnologia celular de terceira geração ainda não tem data para início fora da Ásia, mas estima-se que a Nokia terá garantia de 2 a 3\% do fornecimento mundial e a Ericsson mais de 10\%, ambas as empresas possuíam, em 2001, substanciais quantias financiadas para os clientes: US\$ 3.8 e US\$ 2 bilhões respectivamente (Reed et. al., 2001). Outras empresas também apresentam grandes montantes comprometidos com clientes, como é o caso da Motorola, Lucent, Nortel Networks e Qualcomm (Rosenbush et. al., 2001).

Pesquisa e Desenvolvimento em telecomunicações era baseado no desenvolvimento de hardware, após a intensificação da digitalização no setor, o desenvolvimento de software tornou-se também fundamental. Atualmente, grande parte do desenvolvimento de produtos está relacionada a softwares, que, segundo especialistas da área, permitem maior vantagem competitiva às empresas. Até mesmo no modelo em camadas do Telecomvisions (figura 5.2), o software aparece associado ao hardware em todas as camadas, conforme salienta Fransman (2001). Neste mesmo trabalho, Fransman cita que o aumento da importância do software para a indústria 
de telecom, associado ao custo relativamente baixo da sua produção, tem levado ao crescimento do número desenvolvedores em software na indústria de infocomunicação.

Não é difícil entender a importância do software para as empresas de telecomunicações hoje. Como discutido nas seções anteriores, há evidências de que as empresas desenvolvedoras de tecnologias no setor (fornecedores de equipamentos) estão caminhando a jusante na cadeia produtiva, portanto começando a direcionar suas atividades também para serviços. Atualmente, os serviços em telecom são, em maioria absoluta, definidos pelos softwares utilizados. Sendo assim, é natural que o desenvolvimento de software tenha papel importante para as empresas do setor.

O desenvolvimento de software segue passos similares ao do desenvolvimento tradicional de produtos, mas com algumas diferenças, que são oriundas principalmente da diferença intrínseca ao "produto" software. Por não ser fisicamente manipulável, ele tem algumas particularidades, por exemplo, a facilidade em internacionalizar o desenvolvimento é bastante grande, mas, também por isso, é necessário gestão e controle extremamente rigorosos para que o desenvolvimento seja eficaz. Para tanto, as empresas utilizam o Modelo de Maturidade de Capabilidade para Software, CMM (Capability Maturity Model for Software), um rigoroso modelo de aferição da capacidade e maturidade de uma organização de desenvolvimento de software estabelecido pelo SEI (Software Engineering Institute).

O CMM descreve os princípios e práticas relacionadas a maturidade do processo de software com o objetivo de auxiliar as empresas de software a melhorar a maturidade de seus processos de desenvolvimento, que evolui de um processo ad hoc, caótico para um processo maduro e disciplinado. Para isso, o CMM é organizado em cinco níveis, cada qual fornece uma gama de fundamentos para a melhoria contínua do processo:

1) Inicial - O processo de software é caracterizado como ad hoc e até mesmo, ocasionalmente, caótico. Poucos processos são definidos e o sucesso depende de esforço individual. 
2) Repetível - Os processos básicos de gestão de projeto são estabelecidos para acompanhar custo, cronograma e funcionalidade. A necessária disciplina do processo existe para repetir sucessos anteriores em projetos com aplicações similares.

3) Definido - O processo de software para as atividades de gestão e engenharia é documentado, padronizado e integrado em um processo de software padrão para a organização. Todos os projetos utilizam uma versão aprovada do processo de software padrão para desenvolvimento e manutenção de software.

4) Gerenciado - Medidas detalhadas do processo de software e da qualidade do produto são realizadas. O processo e os produtos de software são quantitativamente compreendidos e controlados.

5) Em Otimização - A melhoria contínua do processo é propiciada pelo feedback quantitativo do processo e pelas idéias e tecnologias inovadoras.

Essas são algumas das tendências para a área de desenvolvimento de produtos evidenciadas pelas empresas mundiais que atuam no setor. É bastante claro que as empresas estão, em geral, seguindo uma linha semelhante e apresentando ações estratégicas que as oriente para alguns pontos comuns, especialmente os relacionados a organização industrial e desenvolvimento tecnológico, que são tópicos de discussão de capítulos posteriores, relacionados aos resultados deste trabalho.

\subsubsection{Aspectos Propulsores do Desenvolvimento Tecnológico}

O desenvolvimento tecnológico no setor de telecomunicações está relacionado não apenas aos aspectos do desenvolvimento da tecnologia em si, mas também aos aspectos institucionais ou regulatórios do setor. Dessa forma, o papel das entidades / agências de regulamentação governamentais tem grande influência na orientação dos investimentos em P\&D das empresas. São influentes não apenas os reguladores regionais em cada país, mas também as entidades patronais e de classes, como ITU (International Telecommunications Union) e a ITS (International Telecommunications Society). 
Talvez este é um dos setores em que a regulação seja das mais influentes para a alocação de recursos no desenvolvimento tecnológico. Tanto na telefonia móvel, quanto na fixa, os órgãos reguladores estabelecem medidas regulamentares que regem o mercado, seja através da determinação de requisitos para a atuação das empresas, da estipulação sobre a utilização do spectrum, de definições referentes a segurança no uso de equipamentos ou para o meio ambiente, do estabelecimento de padrões tecnológicos a adotar, etc.

Para o desenvolvimento tecnológico, as empresas monitoram constantemente as determinações dos órgãos reguladoras ou as decisões de entidades, com interesse semelhante ao dedicado à análise da concorrência ou à busca por informações nos meios acadêmicos. Procuram assim, oportunidades de atuação ou de alinhamento das suas atividades de desenvolvimento de acordo com as regulamentações locais, regionais ou mundiais.

Por exemplo, no caso do Brasil, como foi apresentado nas seções anteriores, o Ministério das Comunicações determinou metas de universalização como uma medida de regulamentação para atuação no mercado local. Além disso, a Anatel, órgão que estabelece as características específicas para atuação das empresas, estabeleceu, por exemplo, os padrões tecnológicos a serem adotados para a telefonia móvel celular.

Apenas essas duas ações já foram suficientes para influenciar, de forma muito intensa, a alocação local do desenvolvimento de produtos nas empresas fornecedoras de equipamentos de telecomunicações. Empresas como Siemens e Nokia alocaram recursos locais (investimentos, mão-de-obra especializada, etc.) no desenvolvimento de produtos GSM (mesmo que apenas para adaptação dos produtos mundiais) quando do início, no Brasil, das atividades seguindo tal padrão.

Antes de 2001, quando as operadoras investiam maciçamente para aumentar a rede instalada, no intuito de cumprir as metas de expansão, houve um forte aquecimento do mercado, aumentando os investimentos locais em desenvolvimento de produtos. Esse aumento também ocorreu, em partes, pelos incentivos fiscais locais. 
No que se refere a incentivos fiscais para $\mathrm{P} \& \mathrm{D}$ no país, o setor de telecomunicações é beneficiado com a lei da Informática (antiga lei 8.248 de 23/10/1991, que deu origem às leis $\mathrm{n}^{\circ} 10.176$ de 11/01/2001, e, mais tarde, 10.664de 22/04/2003), que firmou o novo modelo de política de informática, pondo fim à reserva de mercado. Tal lei favorece as empresas que tenham como finalidade a produção de bens e serviços de informática, incluindo equipamentos de telecomunicações.

Os principais impactos no quadro institucional foram a concessão de incentivos, dos quais o mais importante é a isenção do IPI, e o cumprimento de contrapartidas a estes incentivos, dos quais os mais importantes são a realização do Processo Produtivo Básico (PPB) no país e a aplicação de 5\% da receita total da empresa em atividades de pesquisa e desenvolvimento. Os instrumentos legais pertinentes são os Decretos $783 / 93$ e 792/93 e as Portarias Interministeriais 272/93 e 273/93, que regulamentaram a Lei 8.248/91, conhecida por "Lei de Informática" e o Decreto 1.070, de 2 de março de 1994, que passou a regular o poder de compra de equipamentos e serviços por parte do governo (PGT, 2002).

Essa lei foi criada com o intuito de aumentar a produção de bens e serviços de informática e automação no País. Entre outros, a lei concedia às empresas produtoras isenção do Imposto sobre Produtos Industrializados - IPI até 31 de dezembro de 2000. Em contrapartida, as empresas beneficiadas devem atender às regras do Processo Produtivo Básico (PPB), que estabelece um critério mínimo de industrialização para cada classe de produto, em substituição ao conceito anterior de nacionalização, e investir no mínimo $5 \%$ do seu faturamento bruto do mercado interno em atividades de P\&D (2\% deveriam sem aplicados em projetos com centros de pesquisa ou universidades) a serem realizadas no país, conforme projetos elaborados pelas próprias empresas.

Após longas discussões no congresso nacional, a lei 8248 sofreu alterações por meio da lei 10.176 de 11 de janeiro de 2001. Entre as principais mudanças está a forma como deve ser distribuído o percentual do faturamento a ser investido em P\&D no Brasil. Continua havendo a obrigatoriedade de investimento de $5 \%$ do faturamento local em $P \& D$, entretanto a lei 10.176 exige que 2,3\% devem ser investidos em projetos de $\mathrm{P} \& \mathrm{D}$ desenvolvidos cooperativamente entre as empresas e universidades 
ou centros de pesquisas locais, sendo que, obrigatoriamente, $0,8 \%$ devem ser destinados para pesquisa em instituições localizadas no Norte, Nordeste ou Centro Oeste, $0,5 \%$ sob a forma de recursos financeiros depositados trimestralmente no Fundo Nacional de Desenvolvimento Científico e Tecnológico (FNDCT).

Essa obrigatoriedade apresenta a oportunidade para as universidades e centros de pesquisa de realizar projetos de $\mathrm{P} \& \mathrm{D}$ de interesse das empresas beneficiadas com os incentivos fiscais desta Lei, recebendo parte ou a totalidade dos recursos correspondentes aos $2,3 \%$ do faturamento das empresas com as quais venha a colaborar.

Com as alterações, a lei de informática se prorroga até 2009, porém os benefícios para as empresas referentes a redução de IPI (Imposto sobre Produtos Industrializados) serão diminuídos, passarão gradativamente de uma redução de $95 \%$ em 2001 para $70 \%$ em 31/12/2009, quando será extinto. As determinações prévias do PPB continuam valendo.

A fiscalização do cumprimento da lei é feita pelo Ministério de Ciência e Tecnologia (MCT) através de relatórios emitidos pelas empresas e verificam principalmente se a empresa investe os $2 \%$ do faturamento em $\mathrm{P} \& \mathrm{D}$ com as instituições de pesquisa brasileiras e sem fins lucrativos.

Como "Pesquisa e Desenvolvimento", a lei inclui também as seguintes atividades:

- Treinamento em C\&T (para os níveis médio e superior, incluindo especialização/aperfeiçoamento e pós graduação);

- Serviços Científicos e Tecnológicos (assessoria e consultoria, estudos prospectivos, ensaios,normalização, metrologia, qualidade, informação e documentação);

A tabela 5.8 mostra os percentuais de investimentos adicionais em $P \& D$, qualidade e produtividade, e treinamento sobre o total investido, pelas empresas da amostra analisada pela Fundação Dom Cabral em pesquisa encomendada pelo Ministério de ciência e tecnologia (MCT, 1997). 


\begin{tabular}{|l|c|c|c|c|}
\hline Investimentos Adicionais & 1994 & 1995 & 1996 & Total \\
\hline Pesquisa e Desenvolvimento & $64,4 \%$ & $57,4 \%$ & $52,6 \%$ & $57,1 \%$ \\
\hline Qualidade e Produtividade & $9,2 \%$ & $14,0 \%$ & $14,1 \%$ & $13,0 \%$ \\
\hline Treinamento & $5,9 \%$ & $14,0 \%$ & $28,0 \%$ & $16,7 \%$ \\
\hline
\end{tabular}

Tabela 5.8- percentuais de investimentos adicionais pelas empresas beneficiárias da Lei de Informática no período de 1994 a 1996. Fonte: Fundação Dom Cabral / MCT (MCT,1997) 


\section{RESULTADOS}

Os capítulos 6, 7 e 8 referem-se aos resultados deste trabalho. Em cada capítulo, procurou-se tratar das questões e hipóteses levantadas para esta tese e apresentadas no capítulo 2. Utilizou-se para isso, estudos de casos e análise de dados quantitativos conforme metodologia explicitada no capítulo 3.

Os estudos de casos com cada uma das empresas são apresentados em anexo para que os capítulos 6 e 7, que tratam especificamente da análise qualitativa deste trabalho, não ficassem estritamente descritivos. Ou seja, para que nesses capítulos não fossem incorporadas as descrições específicas das companhias, optou-se por mencionar apenas as análises conjuntas e os resultados gerais obtidos através da observação dos casos estudados.

Sendo assim, as informações específicas referentes a cada empresa encontram-se em anexo a este trabalho e devem ser consultadas, conforme necessário. Muitas vezes, nos capítulo 6, 7 e 8, faz-se referências específicas aos textos do anexo, a fim de ilustrar melhor os resultados apresentados e orientar o leitor a buscar informações pertinentes para o entendimento do texto e das discussões levantadas. 


\section{Capítulo 6}

\section{Atrativos para Atividades de Desenvolvimento Tecnológico no Brasil}

A partir dos estudos de campo realizados e da bibliografia consultada ${ }^{23}$, foram identificados alguns fatores como sendo importantes ou fundamentais para atraírem unidades de desenvolvimento de produtos para as subsidiárias. Devido aos interesses deste trabalho, os fatores citados são mais fortemente relacionados aos fatores que favorecem a participação das subsidiárias brasileiras do setor de telecomunicações, mas são também comuns a alguns outros setores, como o automobilístico citado por Dias e Galina (2000).

Os resultados obtidos nessa análise, apresentados neste capítulo, referem-se à questão 3 de tese, apresentada no capítulo 2: "Por que as subsidiárias brasileiras envolvem-se com DGP?". Trata-se do resultado de número 1, citado no mesmo capítulo 2.

\subsection{Fatores que atraem atividades de $P \& D$ para subsidiárias brasileiras}

Nos estudos de casos, as empresas informaram claramente alguns desses fatores, citando-os como definitivos para justificar a implantação ou a manutenção de atividades de DP localmente (Galina e Plonski, 2000). Outros fatores foram

\footnotetext{
${ }^{23}$ Para mais informações, consulte o capítulo 4, seção 4.1.3.
} 
identificados a partir da literatura consultada e confirmados como válidos para a realidade dos casos estudados.

Interesse no Mercado Brasileiro e Latino - A estratégia de atuação da subsidiária no mercado influencia a sua participação no DGP. Especificamente no setor de telecomunicações, no qual há padrões tecnológicos distintos, geralmente criados/ incentivados pelos grandes fabricantes mundiais. Ou seja, as instalações das unidades fabris são influenciadas pelos padrões locais/regionais de tecnologia determinadas pelo mercado. Assim, o mercado influencia na determinação das características e estratégias da subsidiária e consequentemente na sua relevância mundial. Para exemplificar, a Ericsson, empresa sueca instalada no Brasil, tem como estratégia atender toda a América Latina no segmento de telefonia celular, no padrão utilizado na região (CDMA/TDMA) e está se tornando um grande parceiro mundial no desenvolvimento tecnológico nessa área, com a transferência do centro de desenvolvimento CDMA de segunda geração de San Diego, EUA, para Campinas no interior do estado de São Paulo. Por trás dessa decisão está o interesse da transnacional em fazer com que a equipe norte-americana se dedique ao desenvolvimento da terceira geração da tecnologia em questão. Esse exemplo da subsidiária Ericsson será melhor apresentado e discutido em seções posteriores deste trabalho.

Competências Locais - Este é o fator mais facilmente detectado quando se espera estabelecer critérios que justifiquem a participação efetiva no desenvolvimento tecnológico. Está bastante claro que as organizações aproveitam as competências locais. No caso específico de Brasil e de Telecomunicações, o histórico determinou e hoje justifica a detenção de conhecimento em determinados segmentos. Isso faz com que as "unidades Brasil" das transnacionais tenham destaque mundial e tornem-se centros de excelência em algumas áreas ou alguns nichos de produtos. Isso é o que acontece em sistemas de tarifação para centrais telefônicas, caso por exemplo, da subsidiária brasileira da Ericsson, que tem um importante papel nessa área. Um outro exemplo é o desenvolvimento de centrais de pequeno porte, tecnologia brasileira desenvolvida pela Zetax - empresa nacional adquirida pela norte-americana Lucent 
em 1999, cujo desenvolvimento global está sendo feito pela unidade brasileira da companhia.

Vale destacar que a literatura afirma que as atividades de P\&D realizadas por TNCs nas subsidiárias parecem utilizar-se de talentos já disponíveis no país, ao invés de formar novos talentos ou conhecimento (Reddy, 1997). No entanto, nas empresas estudadas neste trabalho, isso é diferente, uma vez que a grande maioria das companhias locais possui algum tipo de treinamento para formação de mão-de-obra específica no Brasil. Esses projetos são estimulados através dos incentivos da lei de informática.

Custo de Desenvolvimento Local - Influencia de maneira considerável na determinação da participação do desenvolvimento de produtos, claro que sempre está aliado ao grau de competência. Como cita Reddy (Reddy, 1997), os custos de desenvolvimento em centros de pesquisa localizados em países em desenvolvimento (ex. Índia, Brasil e Israel) são geralmente menores que nos centros tradicionais. Nos casos estudados, esse fator foi citado com regularidade como sendo um dos importantes na determinação da participação brasileira no DGP. Seu principal componente é o custo da mão-de-obra qualificada (pesquisadores, cientistas, engenheiros, técnicos, etc.), que cai ainda mais no país com a desvalorização do Real frente ao Dólar ocorrida nos últimos anos.

No entanto, algumas empresas, como a Motorola, citam que a mão-de-obra no Brasil é mais cara do que em outros países em desenvolvimento, devido, principalmente, aos encargos trabalhistas. A mesma empresa também cita que o custo geral do DP no país é maior que em alguns outros paíse ${ }^{24}$, principalmente pela falta de políticas que estabeleçam critérios para importações de equipamentos utilizados para $P \& D$, que sejam dissociados dos de importações de equipamentos para comercialização ou fabricação. Segundo a empresa, isso encarece muito a realização de pesquisa local, prejudicando a escolha da unidade da TNC no Brasil, como destino de investimentos em P\&D.

\footnotetext{
${ }^{24}$ Até países desenvolvidos, como é o caso do Canadá.
} 
Autonomia da Subsidiária - O grau de autonomia da subsidiária estabelece seu grau de participação e influência no DP. Quanto maior a necessidade da subsidiária em estar seguindo regras estratégicas da matriz, menor será o desenvolvimento de novas competências (Gammelgaard, 1999).

Nos casos estudados, a autonomia das subsidiárias, em geral, é restrita. As estratégias locais seguem as estratégias globais da organização. É bom especificar que autonomia não significa independência da matriz, significa maior liberdade, por exemplo, na iniciativa para realização de $\mathrm{P} \& \mathrm{D}$ local, na determinação de processos, na escolha de fornecedores, na negociação com clientes e avaliação de suas necessidades. Quando a subsidiária possui autonomia, ela pode ter um melhor monitoramento do ambiente no qual está inserida, auxiliando na identificação de nichos para atuação. Além disso, a autonomia também pode implicar em mais recursos, sem necessidade de justificação à matriz, para apostar em inovações locais, correndo os riscos inerentes ao processo de inovação.

Quanto à liberdade recebida pelas subsidiárias estudadas especificamente no desenvolvimento de produtos, é bastante comum encontrar nenhuma ou pouquíssima autonomia nas suas etapas iniciais, como estudo de preferências e necessidades de consumidores locais, e alguma autonomia nas negociações com fornecedores locais, sempre tentando alinhar as negociações aos desejos das matrizes de escolha de fornecedores globais previamente estabelecidos.

Tipo de Produto - Quanto mais necessária for a receptividade local do produto, mais haverá participação da subsidiária no DP, gerada pelo conseqüente desenvolvimento local de competência. Em alguns casos estudados, a participação da subsidiária brasileira é mais efetiva nos produtos em cujo desenvolvimento ela tem que necessariamente participar (pela realidade local) e, portanto, adquiriu competência na área. A matriz "I-R" (Prahalad e Doz, 1987) apresentada na seção 4.1.3 deste trabalho é bastante condizente com a realidade do setor.

Além da receptividade local, se um produto exige adaptação local / regional, a subsidiária estará tendo a oportunidade de criar um segmento para o desenvolvimento de melhorias / alterações no produto, com necessidade, muitas 
vezes, de trabalhar em conjunto com os centros mundiais de desenvolvimento de produtos da TNC. Muitas das empresas estudadas apontam este como um dos principais fatores que contribuem para o desenvolvimento local de competências, culminando com a participação da subsidiária no DP devido à urgência em adaptar prontamente os produtos, a fim de atender aos clientes locais.

Nascimento (Nascimento, 1995) cita dois exemplos que ilustram bem esse fator e estabelece um vínculo para um outro fator que também deve influenciar a atração de desenvolvimento de produtos para a subsidiária local, as exigências governamentais para regulamentação. A Ericsson, no final dos anos 70 , realizou seu primeiro projeto de produto desde a concepção, o re-projeto do subsistema de tarifação das centrais cross-bar, que, por exigência do mercado brasileiro e por falta de interesse da matriz na tecnologia, foi integralmente feito na unidade local. Nos anos 80, algo parecido ocorreu, quando a TELEBRAS estabeleceu requisitos mínimos para centrais telefônicas digitais, o que exigia alterações nos produtos da empresa. Acordou-se que o trabalho seria feito no Brasil; o resultado disso foi a formação de uma equipe de 40 engenheiros com competência em centrais, particularmente nas áreas de tarifação e sinalização, exemplificando um outro fator, o histórico, tratado a seguir.

Aspectos Históricos / Herança Administrativa - O histórico das empresas é um fator importante para formação de competências locais. Além disso, a existência histórica de vínculos locais com DP pode influenciar fortemente as decisões de localização de unidades de $\mathrm{P} \& \mathrm{D}$, mesmo que ainda não existam competências numa área específica.

O exemplo da Ericsson, citado anteriormente e já comentado no fator "competência local" acima, é excelente para ilustrar a importância da herança administrativa como fator de atração de P\&D. Segundo Nascimento (Nascimento, 1995), após a formação do grupo para o projeto desenvolvido, nasceu a consciência da necessidade de encontrar novas tarefas para o grupo. A subsidiária começou a emprestar seus especialistas para trabalharem em projetos da TNC em outras unidades da empresa espalhadas pelo mundo. À medida que se ganhou experiência em trabalhos para essas outras unidades, passou-se a privilegiar os projetos realizados no Brasil e em 
algumas áreas, como tarifação. Hoje, como já foi dito, a unidade brasileira da Ericsson tem um importante papel no grupo em se tratando de tecnologia de tarifação para rede fixa.

Alguns outros exemplos podem ser dados para ilustrar esse fator. Várias empresas estudadas citaram a característica brasileira de, mesmo com poucos recursos, ter rapidez na execução de projetos de $\mathrm{DP}$, como a Siemens, que mostrou redução de $45 \%$ do tempo de projeto em relação aos objetivos da matriz alemã. Esse fator deve ter origem na história de desenvolvimento tecnológico em telecomunicações no país ter sido feito até recentemente por órgãos públicos e com poucos investimentos.

Como visto nesses exemplos, que mostram o fator histórico ligado ao fator de geração de competências locais, a história ou herança administrativa da subsidiária está geralmente relacionada ao desenvolvimento de outros fatores que atraem investimentos em $\mathrm{P} \& \mathrm{D}$.

Um outro exemplo de situação estabelecida através da história da subsidiária e que, muitas vezes, é fundamental para o desenvolvimento local, é o Relacionamento entre Matriz e Subsidiária, que se refere às relações pessoais entre os executivos da matriz e os da subsidiária. Se as pessoas envolvidas na tomada de decisões estratégicas na matriz tiverem boas relações com os executivos da subsidiária, as chances da unidade local ter um envolvimento significativo no desenvolvimento tecnológico são maiores. Birkinshaw e Hood (1998) afirmam que a alta qualidade do relacionamento entre matriz e subsidiária tem um impacto positivo para as subsidiárias "empreendedoras", ou seja, aquelas que trabalham desenvolvem competências localmente.

Aqui, os critérios considerados para o envolvimento da subsidiária são bastante subjetivos e difíceis de classificação, uma vez que dependem de ações individuais de empregados da empresa. Por exemplo, as relações entre matriz e subsidiária podem ser melhoradas através de funcionários expatriados ou pessoas que passam um tempo no escritório central da TNC, e que criam vínculos pessoais de relacionamento com a alta gerência da companhia (Birkinshaw e Hood, 1998). 
Nos estudos de casos feitos na indústria telecom, as empresas mais antigas no país, como Siemens e Ericsson, tiveram a chance de construir tais redes de relacionamentos através de funcionários da subsidiária e da matriz (ou dos centros de competências nos países desenvolvidos). O bom envolvimento da Siemens brasileira no DGP é, em grande parte, devido a esses relacionamentos criados entre as pessoas envolvidas com a tomada de decisão na matriz e os executivos ou os envolvidos com a unidade de P\&D no Brasil.

Um fator também relacionado com histórico e com mercado, é referente a Exigências Governamentais para Regulamentação. No setor de telecomunicações, as exigências de regulamentação são fortemente relacionadas às estratégias das companhias ao desenvolver tecnologia. Os padrões estabelecidos pelas agências governamentais influenciam consideravelmente o DP por causa da necessidade das empresas em adaptar seus produtos para atenderem ao mercado consumidor, isso leva as equipes locais a determinadas competências, e, por conseqüência, ao provável envolvimento com equipes mundiais de DP. Por exemplo, no Brasil, com a entrada do padrão GSM para telefonia móvel, apesar de ainda incipiente, as companhias fornecedoras dessa tecnologia começaram a criar equipes de engenharia no país para adaptação desses produtos para os clientes locais. Esses grupos tiveram que passar por treinamento nas matrizes e, alguns deles, ao começarem a desenvolver produtos específicos para o mercado brasileiro, acabavam colaborando com equipes mundiais para mudanças de produtos globais. É comum, mundialmente, as agências governamentais trabalham em conjunto com associações de classe e de companhias na área de telecom para definição de padrões e de regulamentações regionais.

Incentivos Fiscais - A presença de incentivos fiscais influencia fortemente na determinação de recursos das empresas para investimentos em pesquisa e desenvolvimento nas unidades locais.

Como já foi dito, o setor de telecomunicações é beneficiado com a lei de Informática (lei 10.176/01, em substituição à lei 8248/91). As empresas estudadas neste trabalho estão entre as maiores beneficiárias da Lei de Informática (MCT, 2003). Esse é um dos principais fatores, senão o principal, considerados pelas empresas quando investem em P\&D localmente. Apesar de terem diferentes justificativas, todas as 
companhias pesquisadas citaram este como o fator primordial na determinação de investimento no Brasil.

Isso pode ser também comprovado por uma pesquisa realizada pela Fundação Dom Cabral em 1997, intitulada "Estudos dos Impactos e Resultados dos Incentivos Fiscais de que tratam as Leis 8248/91 e 8661/93" (MCT, 2000). Os dados dessa pesquisa indicam que para 95\% das empresas estudadas, a extinção da Lei provocaria um impacto significativo ou muito significativo sobre sua atividade tecnológica. A pesquisa afirma ainda que $84 \%$ das empresas declararam ter alterado sua trajetória tecnológica pelo fato de ter sido beneficiada com incentivos fiscais da Lei de Informática. A alteração se deu em todos os âmbitos da lei: ampliação da produção local e desenvolvimento de novas linhas de produtos, ampliação e racionalização dos investimentos em $\mathrm{P} \& \mathrm{D}$, ampliação dos investimentos em treinamentos técnicos e engenheiros, ampliação dos investimentos em qualidade e produtividade, estabelecimento de parcerias e acordos de cooperação tecnológica com institutos de pesquisa e implantação de certificação ISO 9000.

Além disso, a mesma pesquisa comprova que no período 1994 a 1996, 67\% das empresas ampliaram seus gastos com $\mathrm{P} \& \mathrm{D}$ em função dos incentivos fiscais contemplados na Lei. As informações contidas na tabela 6.1 mostram os resultados da pesquisa em termos de indicadores de investimentos em atividades de P\&D nas empresas pesquisadas (MCT, 1997). No período 1994 - 1996, o investimento médio em P\&D foi da ordem e $6 \%$ do faturamento.

Segundo informações do Ministério de Ciência e Tecnologia (MCT,2000), no período de 1993 a 1998 as aplicações em pesquisa e desenvolvimento mais significativas (84\%) foram efetuadas em projetos de desenvolvimento de sistemas (27\%), desenvolvimento de software (21\%), desenvolvimento de hardware (15\%), treinamento (8\%), sistemas da qualidade $(8 \%)$ e em programas prioritários do MCT (5\%). A figura 6.1 mostra as áreas que mais receberam investimentos provenientes dos incentivos fiscais. 


\begin{tabular}{|l|c|c|c|c|}
\hline \multicolumn{1}{|c|}{ Indicador } & 1994 & 1995 & 1996 & Média \\
\hline Gastos correntes com P\&D/faturamento & $3,4 \%$ & $3,2 \%$ & $4,4 \%$ & $3,7 \%$ \\
\hline Gastos de capital com P\&D/faturamento & $4,7 \%$ & $5,4 \%$ & $4,9 \%$ & $5,0 \%$ \\
\hline Gastos totais com P\&D/faturamento & $5,9 \%$ & $5,7 \%$ & $6,0 \%$ & $5,9 \%$ \\
\hline
\end{tabular}

Tabela 6.1- Indicadores de investimentos em atividades de P\&D. Fonte: Fundação Dom Cabral, 1997 (MCT, 1997)

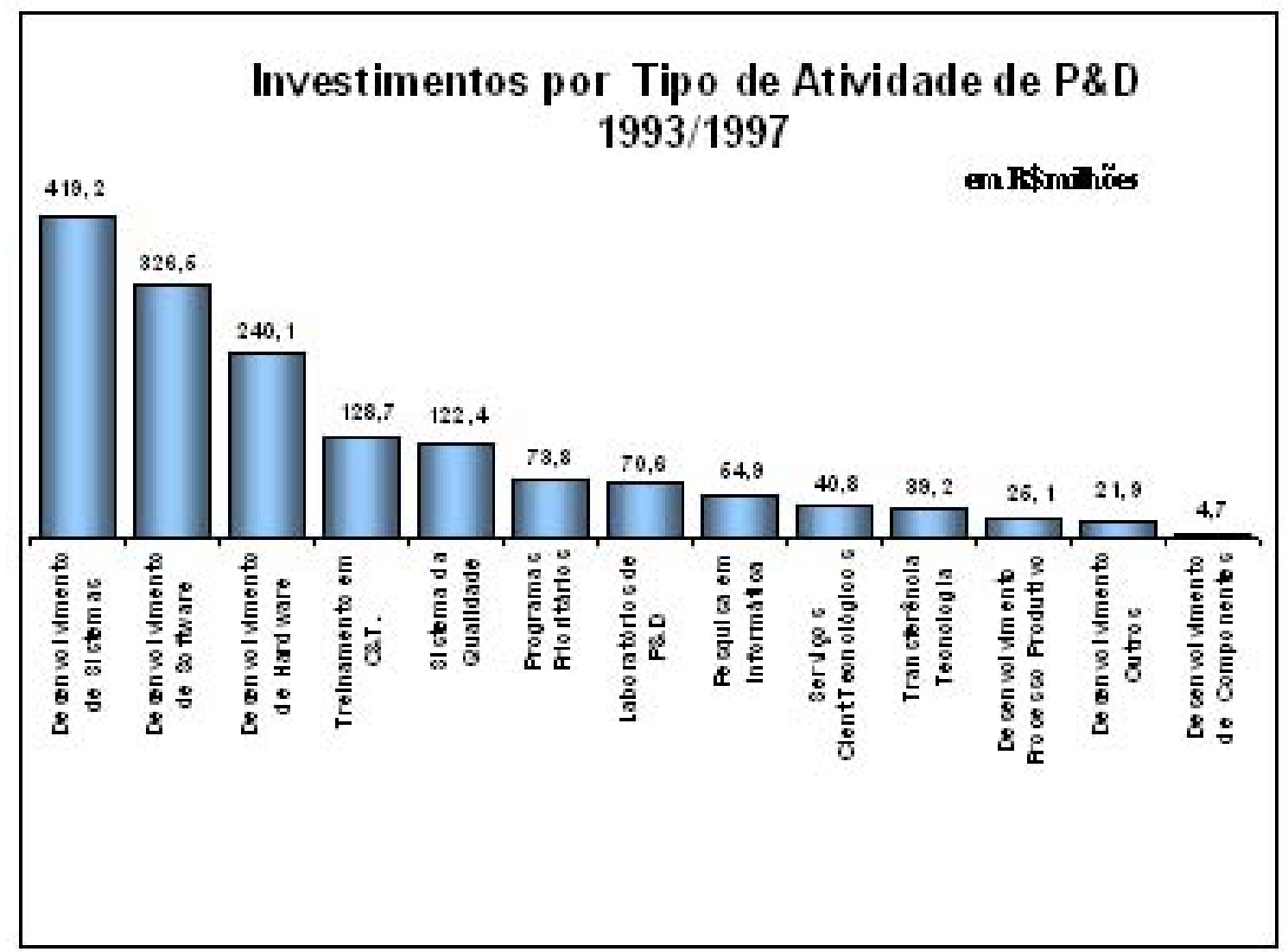

Figura 6.1- Investimento por Tipo de Atividade (1993 a 1997). Fonte: MCT (MCT, 2000)

Uma outra pesquisa mais recente do MCT (MCT, 2003) mostra a atualização desses dados, envolvendo o período entre os anos de 1993 e 2000, ou seja, englobando também a etapa pós-privatização do sistema Telebras. Vale a pena analisar os dados, especialmente porque houve, em 3 anos, uma ligeira mudança nos percentuais de investimento, apesar de manter as prioridades apresentadas anteriormente. 
No figura 6.2 é possível verificar que de 1993 a 2000, a participação das aplicações em projetos de desenvolvimento de sistemas foi de $28,4 \%$, ligeiramente superior ao percentual acumulado até 1997 (de 27\%). Para as atividades de desenvolvimento de software, o aumento foi mais significativo, passando de $21 \%$ no período anterior, para $28,4 \%$ com o acúmulo dos outros três anos. Houve uma diminuição clara em desenvolvimento de hardware, passando de $15 \%$ para $9 \%$ das atividades de $\mathrm{P} \& \mathrm{D}$, assim como em treinamento (de $8 \%$ para $6,8 \%$ ) e em sistemas da qualidade (de $8 \%$ para $6,9 \%)$, mas em menor escala.

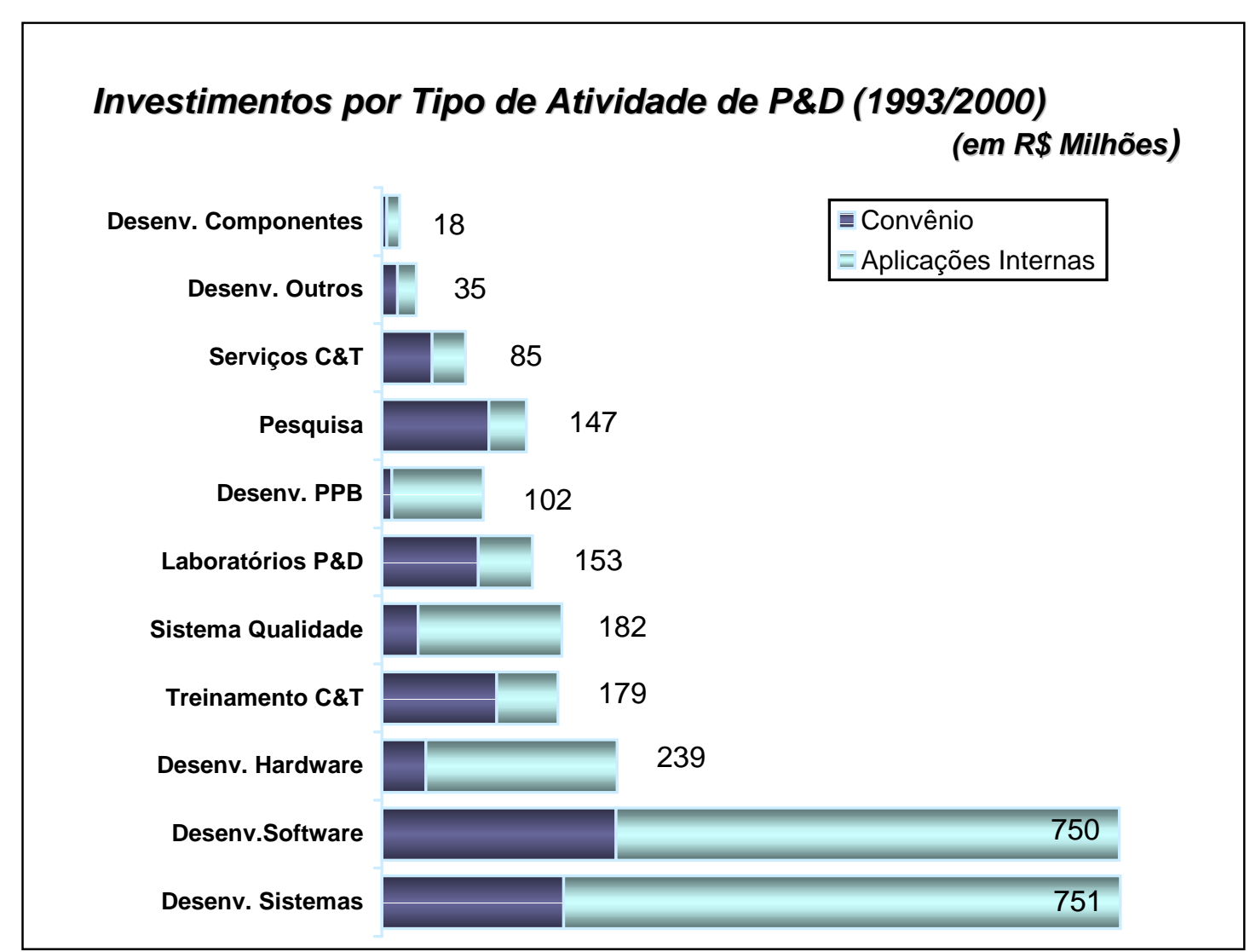

Figura 6.2- Investimento por Tipo de Atividade (1993 a 1997).

Fonte: MCT (MCT, 2003)

As informações disponibilizadas pelo Ministério de Ciência e Tecnologia, com o objetivo de avaliar os investimentos provenientes do incentivos garantidos pela lei, apesar de apresentarem dados até 1998, vão ao encontro das informações levantadas nos estudos de caso sendo realizados neste trabalho.

Como pode ser visto em Anexo, a Motorola citou a lei de informática como sendo fundamental, em alguns casos, para alavancar o desenvolvimento de produtos no 
Brasil, apesar de, por si só, não ser suficiente para sustentá-lo. A Ericsson, a NEC, a Nokia e a Siemens também se beneficiam com os incentivos da lei, indicando-a como importante. A Lucent cita a lei como sendo a principal influente em algumas áreas para que a matriz permitisse o desenvolvimento na unidade brasileira.

Das empresas estudadas, cinco estão entre as maiores fabricantes de bens de tecnologia da informação beneficiados com incentivos segundo o MCT. A tabela 6.2 mostra todas as empresas cujos principais segmentos de produtos são ligados a telefonia e sua posição no ranking de benefício proveniente da lei; as estudadas nesta pesquisa estão em destaque.

Portanto, a Lei de Informática tem papel relevante para atrair investimentos em P\&D para o país, no entanto é importante ressaltar a necessidade de uma política mais ampla para o crescimento do setor, o que será discutido nos capítulos seguintes. Isso é confirmado por Garcia e Roselino (2002), que analisaram e confirmaram a importância da lei para a cadeia produtiva do complexo eletrônico brasileiro, afirmaram porém, que "do ponto de vista de uma política mais ambiciosa de desenvolvimento do complexo eletrônico no Brasil, a Lei da Informática tem sido insuficiente para a formação de capacitações no setor" (Garcia e Roselino, 2002, p. 21).

Além desses fatores, outros são esporadicamente manifestados nos estudos de caso realizados, entre eles, a origem do capital e conseqüente cultura organizacional da TNC (aspectos culturais). Por exemplo, as empresas de origem européia, especialmente a Ericsson, possuem maior abertura para a internacionalização do desenvolvimento de produtos do que japonesas (no caso, a NEC) ou americanas. Isso se justifica pela necessidade de busca, fora dos seus países de origem - geralmente pequenos - por maior quantidade de mão-de-obra qualificada e por novas tecnologias.

Um fator importante, mas que não influencia diretamente o desenvolvimento de produtos, e sim o desenvolvimento de processos, é o grau de inovação dos produtos fabricados localmente. Geralmente, se a tecnologia é recente, há maior integração entre subsidiária brasileira e unidade central detentora de conhecimento 
do produto (matriz ou outro centro de excelência), conhecido como produt owner. No caso das tecnologias já estabelecidas, é comum a padronização de processos para todas as unidades fabris.

\begin{tabular}{|c|c|c|}
\hline Empresa & Posição & Segmento / Produtos \\
\hline Equitel & 02 & $\begin{array}{l}\text { Centrais telefônicas públicas e privadas, Rádios } \\
\text { Digitais }\end{array}$ \\
\hline Ericsson Telecomunicações S/A & 03 & $\begin{array}{l}\text { Telefonia celular, Centrais telefônicas públicas e } \\
\text { privadas, Rádios Digitais }\end{array}$ \\
\hline NEC do Brasil & 04 & $\begin{array}{l}\text { Telefonia celular, Centrais telefônicas públicas e } \\
\text { privadas, Rádios Digitais }\end{array}$ \\
\hline Alcatel Telecomunicações S/A & 06 & $\begin{array}{l}\text { Centrais telefônicas públicas e privadas, Rádios } \\
\text { Digitais }\end{array}$ \\
\hline $\begin{array}{l}\text { STC Sistemas } \\
\text { telecomunicações Ltda. }\end{array}$ & 10 & Centrais telefônicas (linha Trópico) \\
\hline $\begin{array}{l}\text { Lucent Tech Network Systems } \\
\text { do Brasil }\end{array}$ & 11 & Telefonia celular \\
\hline Motorola Industrial Ltda. & 15 & Telefonia celular, pager e trunking \\
\hline $\begin{array}{l}\text { Matel Tecnologia de } \\
\text { Teleinformática }\end{array}$ & 18 & Centrais telefônicas públicas e privadas, \\
\hline Batik Equipamentos S/A * & 20 & $\begin{array}{l}\text { Telefonia celular, Centrais telefônicas públicas e } \\
\text { privadas }\end{array}$ \\
\hline $\begin{array}{l}\text { Zetax Tecnologia, eng. Ind. e } \\
\text { Com. S/A* }\end{array}$ & 27 & Centrais telefônicas públicas e privadas \\
\hline $\begin{array}{l}\text { Northen Telecom do Brasil Ind. } \\
\text { e Com. Ltda. (Nortel) }\end{array}$ & 45 & Telefonia Celular \\
\hline $\begin{array}{l}\text { Intelbrás S/A Ind. Telecom. Elet. } \\
\text { Brasil }\end{array}$ & 49 & Centrais telefônicas públicas e privadas \\
\hline
\end{tabular}

Tabela 6.2-Maiores Fabricantes beneficiados com incentivos da lei 8248. Fonte: MCT, 1997.

Sendo assim, esses outros fatores influenciam também a aproximação das subsidiárias brasileiras do desenvolvimento tecnológico. No entanto, por serem 
fatores extremamente genéricos e subjetivos e por manifestarem-se em menor intensidade, não serão considerados nos modelos/classificações propostos neste trabalho e apresentados na próxima seção.

\subsection{Classificações para os fatores de atração de atividades tecnológicas para o} Brasil

Com o intuito de deixar mais claro o papel dos fatores de atração de atividades tecnológicas descritos na seção anterior, vale criar uma classificação para que eles sejam, de alguma forma, padronizados e mais facilmente analisados / utilizados. Chiesa (1995) afirma que fatores ligados à demanda e à tecnologia são as duas principais razões para a internacionalização de $\mathrm{P} \& \mathrm{D}$.

No mesmo trabalho, esse autor também cita que a escolha pela localização correta é vital e que os fatores considerados para isso são basicamente dois, os relacionados a $\mathrm{P} \& \mathrm{D}$ (custos de transferência de tecnologia/conhecimento, qualidade da matériaprima, etc.) e os não relacionados a P\&D (localização das unidades de negócios, infra-estrutura local e cultura organizacional).

Sendo assim, tentou-se, neste trabalho, estabelecer algumas relações gerais entre os fatores de atração de desenvolvimento para o país e as ações das companhias que os apontaram como relevantes nas suas decisões, o modelo desenvolvido para isso é mostrado na seção subseqüente. Além disso, vale analisar quais são os agentes relacionados a cada um desses fatores, seja para motivação ou para conhecer suas origens, o que é mostrado na seção seguinte à próxima.

\subsubsection{Modelo Causa X Efeito}

A identificação dos fatores através dos estudos de casos orientou o desenvolvimento de um modelo que retrata a influência na participação brasileira. Optou-se por criar um modelo de causa e efeito, ou seja, foram identificadas algumas causas relacionadas aos fatores citados, que levam aos efeitos medidos através da 
probabilidade das empresas envolverem ou não as subsidiárias no desenvolvimento de produtos (DP).

Como causas, foram listadas as características gerais de empresas que tenham desenvolvimento global de produtos frente a alguns fatores que foram identificados como influentes na escolha do local para instalar as unidades de DP, especialmente no caso da subsidiária brasileira. A partir deles, é possível verificar o comportamento da TNC, ou seja, os efeitos na empresa, que basicamente levam a uma probabilidade alta ou baixa de participação.

Sendo assim, o modelo contribui para o entendimento da participação da subsidiária brasileira no DGP, permitindo ainda, verificar que papéis têm tais unidades locais no que se refere à classificação de distribuição de atividades, como defendido por Bartlett e Ghoshal, e Ferdows (Bartlett e Ghoshal, 1992 e Ferdows, 1997), e mais especificamente a distribuição de unidades de P\&D como o defendido por Ronstad (Ronstadt, 1984).

As classificações desses autores mostram as prováveis diferenças entre as subsidiárias de uma TNC e a relevância das mesmas em diferentes aspectos de suas atividades. Quanto maior as atividades de P\&D presentes nas unidades distribuídas globalmente, mais importância têm essas unidades para o grupo como um todo.

É bom salientar que a presença isolada de um dos fatores não deve caracterizar um efeito específico no modelo, o conjunto de vários fatores é que pode determinar uma causa para localização das unidades da TNC. A tabela 6.3 mostra um resumo do modelo proposto para causas $\mathrm{X}$ efeitos para a participação das subsidiárias brasileiras no desenvolvimento tecnológico.

Na causa relacionada ao interesse no mercado local/regional por parte da empresas, se ele é alto, a probabilidade de participação da subsidiária é também alta, e se ela é baixa, ou seja, estrategicamente a empresa não tem interesse em ampliar sua participação no mercado local, a probabilidade da subsidiária local possuir uma unidade de P\&D é baixa. 


\begin{tabular}{|c|c|}
\hline CAUSAS (Fatores Influentes) & EFEITOS (P/NP) \\
\hline \hline Interesse no Mercado Brasileiro e Latino & $\begin{array}{c}\text { Alto - P } \\
\text { Baixo - NP }\end{array}$ \\
\hline \hline Competências Locais & $\begin{array}{c}\text { Existe - P } \\
\text { Não Existe - NP }\end{array}$ \\
\hline \hline Custo de Desenvolvimento Local & $\begin{array}{l}\text { Baixo - P } \\
\text { Alto - NP }\end{array}$ \\
\hline \hline Autonomia da Subsidiária & $\begin{array}{c}\text { Existe - P } \\
\text { Não Existe - NP }\end{array}$ \\
\hline \hline Incentivos Fiscais & $\begin{array}{c}\text { Existe - P } \\
\text { Não Existe - NP }\end{array}$ \\
\hline \hline Tipo de Produto & $\begin{array}{l}\text { Estratégico localmente- P } \\
\text { Não Estratégico localm/.- NP }\end{array}$ \\
\hline \hline Aspectos Históricos & $\begin{array}{l}\text { Favorável a DP - P } \\
\text { Não favorável a DP- NP }\end{array}$ \\
\hline \hline Efeitos para a Subsidiária: & $\begin{array}{l}\text { P - Alta probabilidade de participar do DP } \\
\text { NP - Baixa probabilidade de participar do DP }\end{array}$ \\
\hline
\end{tabular}

Tabela 6.3: Modelo Causas X Efeitos da Participação das Subsidiárias no DP (Galina e Plonski, 2000)

Quanto às competências locais, a existência delas, obviamente, favorece a participação no desenvolvimento tecnológico, ocorrendo o oposto caso não exista competência específica em áreas de interesse das empresas. Algo semelhante acontece com a autonomia da subsidiária local, se ela possui uma liberdade maior principalmente financeira - de monitorar o ambiente e de investir em desenvolvimento local por conta própria, as probabilidades de estar criando unidades de desenvolvimento são muito maiores.

Também se assemelham a esses dois fatores, a existência ou não de incentivos fiscais, que influenciam diretamente em maior ou menor probabilidade de participação no desenvolvimento. Um outro fator importante, também considerado como causa da atração de atividades tecnológicas para as unidades locais das TNCs, 
é o relacionado a custos do desenvolvimento, que, se forem menores quando comparados a outras unidades que se assemelham às brasileiras, mais chances terão as subsidiárias locais de atrair investimento.

O tipo de produto é um dos fatores influentes mais complexos para análise porque ele pode ser "enquadrado" em outros fatores como interesse no mercado e aspectos históricos, como foi comentado anteriormente. No entanto, em linhas gerais, se o tipo de produto fabricado localmente for estratégico para a TNC, para o mercado interno - e até para o mercado mundial, a probabilidade de ter seu desenvolvimento na subsidiária local é maior do que se for um produto menos relevante para a companhia.

Os aspectos históricos, ou seja, a herança que a companhia local vai formando ao longo de sua existência no país, são extremamente importantes, mas são muito relacionados aos outros fatores/causas já citados. Em termos gerais, é possível afirmar que se a subsidiária possui um histórico favorável ao seu envolvimento em atividades de desenvolvimento tecnológico (com formação de competências, custos competitivos, etc.), e se essa capacidade já foi demonstrada para a TNC como um todo, suas chances de localizar atividades de P\&D são extremamente fortalecidas. E finalmente, as exigências governamentais para regulamentação, que, caso existam, mostram-se relevantes para atrair atividades de adaptação de produtos pelas companhias transnacionais.

Mais uma vez, vale salientar que todos esses fatores devem ser avaliados e são relevantes na determinação de uma unidade de desenvolvimento tecnológico para as TNCs. A presença isolada de um ou outro, não estabelece o sucesso da subsidiária na atração de atividades de P\&D para o país em que ela se encontra.

\subsubsection{Modelo para Generalização dos Fatores}

Os fatores que estimulam a atração de atividades de desenvolvimento tecnológico para o Brasil, apresentados anteriormente, são motivados por alguns interesses comuns relacionados a aspectos econômicos / financeiros, mercadológicos e 
tecnológicos. Ou seja, com as atividades de P\&D realizadas localmente, as empresas transnacionais buscam, em geral, diminuição dos custos de desenvolvimento, melhoria / aumento de participação no mercado local / regional, e tecnologia diferenciada.

Assim como os fatores de atração são motivados por esses interesses, são influenciados, direta ou indiretamente, não apenas pelas estratégias da própria corporação, mas também pela característica do ambiente local, especialmente relacionado a infra-estrutura para desenvolvimento tecnológico, e pelas políticas públicas / ações governamentais estabelecidas no país.

Considerando essas principais características, que generalizam, de alguma forma, os fatores de atração de P\&D para o Brasil, foi desenvolvida uma matriz para classificálos, mostrada na tabela 6.4. Na primeira coluna, os fatores identificados nos casos realizados e apresentados anteriormente são listados. Na segunda e na terceira colunas, observamos, respectivamente, os três aspectos gerais para motivação desses fatores e sua origem.

O primeiro fator mencionado refere-se ao interesse no mercado local / regional, que é motivado principalmente por aspectos mercadológicos, apesar de ser, obviamente, também motivado por interesses econômicos da empresa com a expansão de demanda. Esse é um fator que depende principalmente das estratégias da companhia, no entanto, o ambiente pode, indiretamente, também influenciar. Por exemplo, no caso do Brasil, a Anatel regulamenta o tipo de tecnologia utilizada na telefonia móvel, sendo que recentemente ela estabeleceu GSM como sendo o padrão para as bandas $\mathrm{D}$ e E, o que levou as empresas que dominam essa tecnologia (Siemens, Nokia, Ericsson e Alcatel, principalmente) a se voltarem para um novo mercado que se estabelecia a partir de 2002, com a entrada das novas operadoras de telefonia.

No entanto, esse exemplo está mais relacionado ao fator de regulamentação pública, mostrando, mais uma vez, que esses fatores de atração apresentam-se integrados e interdependentes. As exigências de regulamentação são ligadas principalmente a mercado ou tecnologia. 
Quando a causa de atração é a presença de competências específicas, seja na subsidiária ou no país/região onde ela se encontra, o fator motivacional é estritamente tecnológico. Esse fator depende não apenas da corporação, no sentido em que estabelece a rede de competências em cada segmento de tecnologia em que está envolvida mundialmente, mas principalmente do ambiente da subsidiária, seja com a existência de centros de formação e capacitação para profissionais qualificados ou de centros de pesquisa que detêm conhecimento na área de interesse da TNC. É evidente que a formação local de competências está também diretamente ligada a políticas públicas.

No caso dos custos baixos para o desenvolvimento serem atrativos para a localização de unidades de $\mathrm{P} \& \mathrm{D}$, está clara que sua relação é econômica. Isso depende do ambiente, que indiretamente tem origem em políticas públicas. Sua origem também poderia ser indiretamente ligada à corporação, uma vez que a subsidiária possa ter desenvolvido mecanismos para ter esses custos reduzidos, no entanto, essa origem não é tão atada quanto as duas outras.

Autonomia da subsidiária é um fator que está ligado basicamente a aspectos econômicos/financeiros e, com menor intensidade no caso do Brasil, a aspectos tecnológicos e basicamente depende das estratégias da corporação. Os incentivos fiscais, por sua vez, são motivados por fatores econômicos e dependem de ações governamentais.

O tipo de produto é um fator cuja motivação está baseada no aspecto mercadológico, por depender diretamente do mercado local/regional, e, menos diretamente, no aspectos tecnológico, já que a orientação (tecnológica) da subsidiária determina, por muitas vezes, sua participação no desenvolvimento de alguns nichos de produtos, no entanto, o item tecnológico está mais relacionado a outros fatores de atração. Um deles é o referente ao histórico da companhia no Brasil, que também é motivado, mesmo que indiretamente, por aspectos mercadológicos. Esse fator é mais fortemente influenciado pelas estratégias da corporação e menos pelo ambiente externo. 


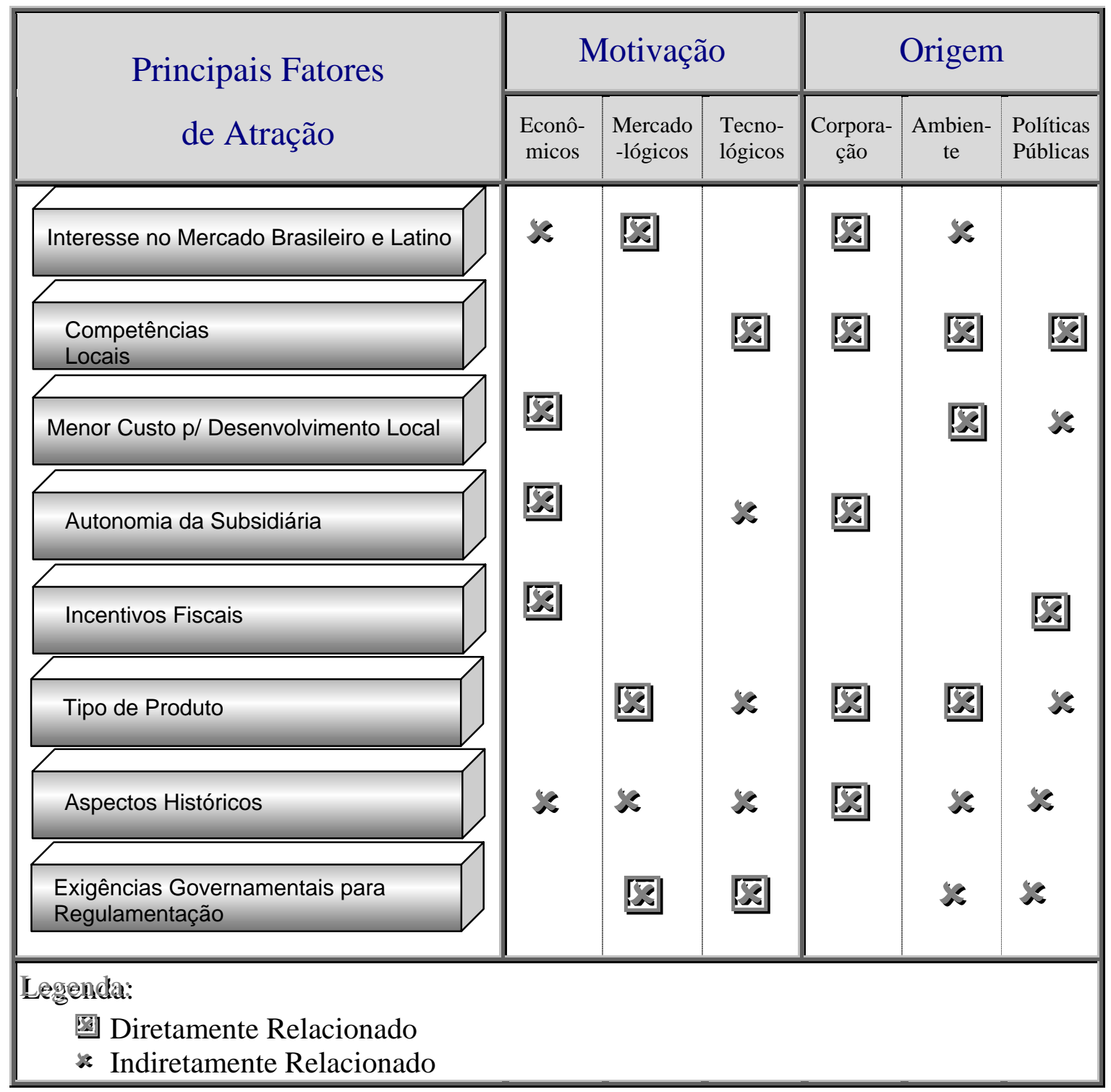

Tabela 6.4 - Principais fatores de atração para o desenvolvimento tecnológico na subsidiária brasileira das TNCs. 


\section{Capítulo 7}

\section{Envolvimento das Equipes Brasileiras no DGP}

A questão "Como se dá o Desenvolvimento Global de Produtos em empresas que tenham equipes distribuídas mundialmente?" (questão 6 - Q6 - desta tese, apresentada na figura 2.2, capítulo 2) foi trabalhada parcialmente no capítulo $4^{25}$, como parte da revisão bibliográfica deste trabalho de tese. A mesma questão é retomada aqui para que os resultados dos estudos de caso sejam apresentados, através da discussão dos modelos existentes na bibliografia.

Propõe-se responder essa questão de tese sob o aspecto perspectivo da situação, sempre com o enfoque no desenvolvimento global de produtos no setor e, mais especificamente, no envolvimento das subsidiárias brasileiras nesse desenvolvimento. Isso será feito através de análise dos estudos de casos com empresas. A partir dessa análise, é possível avaliar o que está acontecendo na indústria de telecomunicações no que se refere ao desenvolvimento tecnológico feito no Brasil, procurando levantar algumas tendências para a área, no intuito de estimular a participação das subsidiárias locais no DGP.

A questão 6 está relacionada às questões 4 (Q4 - "Por que as equipes locais estão envolvidas no desenvolvimento de alguns "nichos" específicos de produtos?") e 5 (Q5 - “Em quais fases do DP as subsidiárias estão envolvidas e por que?”) deste

\footnotetext{
${ }^{25}$ Seção 4.2 .3
} 
trabalho. Portanto, este capítulo também trata das hipóteses ${ }^{26}$ e resultados referentes a tais questionamentos levantados.

Ainda é apresentado neste capítulo, o resultado referente ao estudo das relações de cooperação entre empresa e universidades/institutos de pesquisa (CEU), no intuito de estabelecer discussão sobre a hipótese 5 (H5) desta tese (figura 2.2): "Para o desenvolvimento local de produtos, há pouco envolvimento com centros de pesquisa".

\subsection{Desenvolvimento de Produtos nas Subsidiárias Brasileiras - estudos de Casos}

Como pode ser observado no capítulo 3 , que trata da metodologia da pesquisa, as empresas estudadas neste trabalho são os principais fabricantes mundiais de equipamentos para telecomunicações, cuja presença no Brasil é forte. Trata-se das maiores empresas do segmento que atuam no país (Anuário Telecom, 2002).

Sendo assim, com base nos estudos de casos feitos, é possível levantar alguns resultados relevantes para esta pesquisa. Para tal, foi criado um quadro-resumo (Tabela 7.1) com os dados obtidos nos estudos com as empresas, permitindo uma comparação entre as companhias analisadas. Em anexo, encontram-se mais informações sobre as empresas estudadas, que deve ser consultado para melhor atendimento dos resultados discutidos neste capítulo.

Procurou-se listar os assuntos mais importantes relacionados ao desenvolvimento de produtos: principais produtos ou segmentos com fabricação local e a relação dela com o DP, principais áreas e/ou produtos cuja pesquisa e desenvolvimento é realizada no Brasil, fatores que atraem atividades P\&D para o país (cuja análise foi mostrada no capítulo 6), dificuldades levantadas pelas empresas quando realizam P\&D localmente, aquisição de tecnologia da matriz, e autonomia da subsidiária brasileira no desenvolvimento tecnológico. Esses itens foram levantados através de

\footnotetext{
${ }^{26}$ As hipóteses levantadas são: H6 - “As equipes estão envolvidas no desenvolvimento de alguns "nichos" de produtos por causa da competência de suas subsidiárias ou dos países onde elas estão localizadas" e H7 - "As subsidiárias estão envolvidas nas fases posteriores (menos dependentes de conhecimentos tecnológicos) do DGP”
} 
entrevistas $^{27}$ em vários setores das empresas, mais especificamente na área de pesquisa e desenvolvimento das companhias, conforme citado na metodologia deste trabalho $^{28}$.

\subsubsection{Fabricação}

Com relação à fabricação local, vários pontos em comum foram encontrados entre as empresas estudadas. O primeiro deles é que as companhias estão, cada vez mais, atuando a jusante na cadeia produtiva do setor de telecomunicações, portanto, é tendência entre as empresas que a fabricação de produtos local - e mundial - fique a cargo de companhias que atuam especificamente na montagem de produtos eletrônicos, as chamadas CEM (Contract Electronics Manufacturers). A Ericsson tem a fabricação de seus produtos feita majoritariamente pela Flextronics, que mundialmente é a principal fornecedora da companhia. No Brasil, ela também terceirizou parte da fabricação para a Solectron, que tem planta localizada em São José dos Campos. A NEC tem sua fabricação terceirizada para Celestica desde julho de 2000, ocasião em que toda a fábrica da NEC foi vendida para a Celestica, que também incorporou os então 600 funcionários e desde essa época tem exclusividade de fabricação dos produtos NEC no país.

A Motorola fabrica seus produtos, mas se a demanda é grande, a ponto da unidade fabril local da companhia não ser capaz de conseguir atender aos pedidos, parte da produção é repassada à Celestica, outra das grandes empresas que atuam como CEM.

Um outro ponto em comum entre as empresas é o direcionamento dos produtos fabricados localmente, a grande maioria é destinada ao mercado Brasileiro e alguns ao latino-americano. No entanto, há indícios de que a exportação está crescendo nessas empresas, principalmente após a dificuldade enfrentada pelo setor 2001, quando o mercado interno deu sinais de estagnação. As duas principais companhias que fabricam, ou seja, que não terceirizaram para uma CEM, Motorola e Nokia, mostram dados que comprovam aumento de exportação nos últimos 2 anos.

\footnotetext{
${ }^{27}$ Cujo questionário encontra-se no apêndice

${ }^{28}$ Capítulo 3
} 
Entre as primeiras entrevistas com as empresas, ocorridas em 2000, e as últimas, ocorridas em 2002, observa-se uma mudança nos principais tipos de produtos considerados importantes localmente pelas companhias; isso em decorrência, também, da crise do setor em 2001, mas principalmente pela mudança do mercado após o final do boom oriundo da privatização do Sistema Telebrás, quando as operadoras de telefonia estavam recriando as malhas de comunicação e a demanda era alta por produtos de rede. Em 2000, fabricava-se principalmente centrais para telefonia fixa e Estações Rádio Base, hoje, a fabricação de centrais fixas é ínfima. $\mathrm{Na}$ Motorola e na Nokia, a fabricação de aparelhos celulares cresceu até 70\% em 2 anos, movidas também pelo aumento da exportação desses produtos.

\subsubsection{Pesquisa e Desenvolvimento}

Fazem parte da amostra estudada, empresas extremamente inovadoras, que investem valores consideráveis em P\&D. São companhias que faturam anualmente valores em torno dos US\$ 30 bilhões e destinam, em geral, investimentos em P\&D da ordem de 10-15\% do faturamento, valores comparáveis aos da indústria farmacêutica.

Em geral, as empresas estudadas distinguem perfeitamente a pesquisa do desenvolvimento de produtos. Normalmente, a pesquisa pura é feita em centros de pesquisa da própria empresa ou por universidades ou institutos externos. Os projetos core, ou seja, os estratégicos para a companhia, são mantidos internamente (seja na matriz ou em centros de pesquisa da companhia em outros países, em geral os desenvolvidos)

Na Motorola, por exemplo, a pesquisa é claramente distinta do desenvolvimento. A pesquisa é feita especialmente nos Motorola Labs (localizado em alguns países da Ásia e Europa, além dos EUA), que norteiam as subsidiárias em termos de desenvolvimento tecnológico, e nas universidades parceiras (em projetos de interesse da e financiados pela empresa).

Na Nokia, os centros de pesquisa, cada qual com sua especialidade, propõem a tecnologia para os novos produtos que serão desenvolvidos na matriz ou mundialmente. Na Ericsson, a pesquisa fica a cargo da Ericsson Research, que tem 
como foco a realização de pesquisa de ponta para desenvolvimentos futuros ${ }^{29}$, enquanto que as Core Units (CU s) ficam com o desenvolvimento de produtos para as diferentes linhas de negócios da companhia para um "futuro próximo". As áreas estudadas atualmente pela Ericsson Research são: Redes IP, tecnologias de acesso, tecnologias multimídia, tecnologias óticas, rede de acesso sem fio (wireless), segurança e saúde.

A Lucent Technologies também tem clara a divisão entre pesquisa e desenvolvimento. A companhia possui um dos mais tradicionais institutos de pesquisa, o Bell Labs, que é responsável por várias descobertas na área de telecomunicações e em outras áreas. O desenvolvimento de produtos da companhia segue as linhas traçadas pelo Bell Labs e depende dele para aprovação de projetos de desenvolvimento.

No Brasil, as atividades de P\&D nas empresas estudadas limitam-se a desenvolvimento de produtos (o "D”). A parte de pesquisa é irrisória e, em geral, quando acontece, é feita em universidades ou institutos de pesquisa locais, que realizam alguns projetos com as empresas. São projetos esporádicos, que, eventualmente, envolvem equipes do líder mundial da tecnologia desenvolvida pela companhia (normalmente o centro de excelência da empresa, esteja ele localizado na matriz ou em alguma subsidiária).

\section{$\underline{\text { Tipos de produtos desenvolvidos localmente }}$}

O desenvolvimento de produtos no Brasil acontece, em grande maioria, em software. No entanto, algumas empresas também têm equipes de desenvolvimento de hardware. A Lucent, que no Brasil foca suas atividades de P\&D especialmente em produtos desenvolvidos pela Batik e Zetax, empresas brasileiras adquiridas pela companhia norte-americana, desenvolve tanto hardware quanto software localmente. Trata-se de centrais telefônicas de pequeno porte e compactas, conhecidas por família BZ, que vieram a se tornar produtos mundiais da companhia. Para os demais

\footnotetext{
${ }^{29}$ Algns projetos desenvolvidos atualmente são: sistemas móveis de quarta geração, que pode ser utilizado em 10 anos ou mais ou jamais serem comercializados, e os efeitos de radiação no corpo humano
} 
produtos da empresa, o desenvolvimento realizado pela no Brasil limita-se a adaptações de softwares.

A Motorola possui no Brasil dois segmentos para o desenvolvimento de seus produtos, uma ligada a soluções para comunicações (CE - Communication Enterprise), outra para o desenvolvimento de semicondutores (SPS - Semiconductor Products Sector). A área de comunicações (CE) tem várias subdivisões dependendo do produto criado, no Brasil, há presença de duas delas: para consumidor final (Personal Communications Sector - PCS) e para infra-estrutura de telefonia (Global Telecom Solutions Sector - GTSS).

Para PCS, há desenvolvimento de hardware, mas é irrisório e limita-se a pequenas adaptações ao mercado local. O principal foco do desenvolvimento dá-se em software, área em que a equipe brasileira tem posição considerável para a companhia mundial. Na área de GTSS, o envolvimento brasileiro limita-se a adaptações. No entanto, em semicondutores, apesar de não fabricar tais componentes no país, a subsidiária local mantém equipe que participa da rede de desenvolvimento de produtos globais na área, portanto, desenvolve hardware.

A NEC possui desenvolvimento de hardware de Equipamentos para Acesso a Rede (família dos FAs). Nos demais produtos, o desenvolvimento é principalmente para adaptação local e baseia-se em Software. Na Siemens, os entrevistados afirmam que desenvolvem tanto software quanto hardware, mas garantem que o desenvolvimento de software é muito maior no país do que de hardware, informando que, dos produtos desenvolvidos no Brasil para o mercado mundial, em linhas gerais, 14\% são equipamentos (hardware) e $86 \%$ software. Mais uma vez se confirma a tendência de, no Brasil, ser mais forte o desenvolvimento de software.

Vale destacar que os parceiros locais da Siemens para o DP já possuem papéis definidos de acordo com as estratégias da companhia no que se refere às suas atribuições, por exemplo, o CEFET-PR colabora principalmente com desenvolvimento de hardware, enquanto que a PUC-PR participa ativamente do desenvolvimento de software. 
Aliás, segundo as empresas estudadas, a competência em desenvolvimento de software é provada mundialmente de maneira bastante difícil. Geralmente, as subsidiárias mostraram-se capazes de desenvolver a partir de alguns projetos, que conseguiram apresentar à TNC, cumprindo prazo, custos e padrões de qualidade, superando, muitas vezes, equipes já reconhecidas pela companhia. No entanto, mesmo provando-se excelentes parceiras para desenvolvimento global, as empresas competem com outras unidades mundiais da TNC a cada novo projeto a ser trabalhado.

As maneiras como as afiliadas do grupo são "escolhidas" para participar dos projetos, depende da empresa. Em algumas, a decisão é tomada pela matriz ou pela unidade que coordena o projeto a partir de um conjunto de possíveis subsidiárias. Por exemplo, na Motorola, no caso de software para celular, a decisão de onde ele será desenvolvido é tomada por uma unidade norte-americana (não é a matriz), baseada em características / competências de cada subsidiária mundial. Essa unidade é a controladora do desenvolvimento global de produtos para terminais de telefonia móvel. É claro que um outro fator que influencia na escolha é o mercado local de cada subsidiária, mas não é ele que determina o tipo de produto que será desenvolvido localmente, uma vez que os produtos são globais e há pouquíssimas adaptações locais. Muitas vezes os produtos são desenvolvidos no Brasil e nem são fabricados ou comercializados no país.

Há uma outra forma de determinar os parceiros para desenvolvimento, quando as oportunidades para participação em novos projetos de desenvolvimento de produtos passam por divulgação interna na companhia, geralmente na intranet do grupo. Os grupos das subsidiárias interessadas apresentam suas propostas e colocam-se como candidatos a colaboradores. Faz-se então um processo de seleção para determinar quem estará envolvido no projeto. Comportam-se assim, empresas como Ericsson e Motorola e Siemens.

É interessante destacar que, salvo algumas exceções, na grande maioria dos casos, as subsidiárias brasileiras estão envolvidas no desenvolvimento de software, mas não são coordenadoras dos projetos. Esse papel de gestor ou coordenador no desenvolvimento de software é importante porque é quem detém o conhecimento do 
processo de desenvolvimento como um todo. É ele quem determina metodologias, padrões, processos a seguir; também cabe a ele especificar requisitos e definir objetivos / escopos dos produtos; é também tarefa sua, estabelecer integração dos vários subsistemas desenvolvidos globalmente. Isso agrega um tipo de conhecimento a esse player, que o coloca em vantagem em relação aos demais, que correm o risco de tornarem-se meras fábricas de software.

Fazendo uma analogia simplificada entre desenvolvimento de software e desenvolvimento/fabricação de produtos industriais tradicionais, pode-se ter a seguinte relação: a avaliação de requisitos do software, a coordenação do projeto e a programação dos módulos do sistema no processo de desenvolvimento de software estão respectivamente para concepção de produtos, definição de estratégias/detenção de conhecimento e fabricação no desenvolvimento de produtos tradicionais.

Com relação ao tipo de produto (especificamente software) desenvolvido com a participação das subsidiárias brasileiras, há algumas semelhanças. Por exemplo, na área de centrais telefônicas, a maioria das empresas desenvolve software para adaptação de produtos ao mercado brasileiro ou seja, as equipes no Brasil não estão envolvidas no desenvolvimento de produtos globais.

No entanto, existem alguns segmentos específicos nos quais a unidade local está envolvida. É o caso por exemplo, da Ericsson, que entre os softwares para telefonia fixa desenvolvidos pela empresa no Brasil, os de Tarifação / Billing são os principais produtos em cujos desenvolvimentos o Brasil está envolvido. Para o desenvolvimento de software para Tarifação e Billing, a unidade brasileira é considerada centro de excelência no desenvolvimento global nesse segmento.

É evidente que esse envolvimento significativo na área coloca a afiliada local numa posição confortável de dependência da TNC para com ela, possibilitando trabalhar continuamente na evolução tecnológica do segmento de produtos referido. Isso é especialmente importante agora, devido à mudança pela qual está passando a área de centrais telefônicas, com a entrada da nova geração de produtos (NGN), que utilizam a tecnologia IP para transferência de dados, inclusive voz. 
Mas, vale lembrar que essa é uma exceção, o que se observou nos casos estudados é que as empresas não têm envolvimento global no desenvolvimento de centrais telefônicas. Isso pode parecer estranho porque o Brasil criou sua história em telefonia, tendo este tipo de produto entre os mais importantes do país ${ }^{30}$. No entanto, por ser tecnologia antiga e completamente dominada e não ter grandes inovações, as companhias preferem - por razões como custo - manter o desenvolvimento centralizado, distribuindo apenas a adaptação de softwares para serviços, ligados diretamente às operadoras de telefonia.

Entretanto, apesar de não participarem ativamente do DGP na área de centrais, as empresas estudadas estão se destacando em alguns segmentos para o desenvolvimento de produtos para acesso às redes de comunicações, especialmente da nova geração em telefonia fixa (NGN). Isso pode ser explicado porque o Brasil se destaca em desenvolvimento de software e os produtos da NGN são muito dependentes de software.

É o caso da Siemens, cuja unidade brasileira é Centro de Competência para um módulo do equipamento que faz comutação em NGN. Trata-se do módulo para conexão do assinante à central telefônica. Na NEC, o envolvimento brasileiro no DNP ocorreu especialmente para os equipamentos de acesso à rede (família de produtos conhecida na empresa por "FA"). Os recursos para novos projetos são destinados principalmente a melhoria de versões dos equipamentos para diminuição de custos e mudanças incrementais nas características dos produtos. Nesses equipamentos, a equipe brasileira é líder mundial dessa tecnologia, mas isso não garantiu que a equipe local ficasse responsável pela continuidade tecnológica do produto, especialmente para a tecnologia de nova geração (NGN), utilizando IP. Essa tarefa foi repassada à matriz. À unidade brasileira cabe, esporadicamente, o desenvolvimento de alguns projetos específicos na área. A equipe local de desenvolvimento de produtos na NEC está se extinguindo ${ }^{31}$ e, está claro, que a forte dependência do desenvolvimento de produtos às adaptações locais, ou melhor, o não

\footnotetext{
${ }^{30}$ Basta considerar que a família de centrais digitais Trópico foi o principal produto desenvolvido pelo CPqD em cooperação com as empresas do Sistema Telebrás.

${ }^{31}$ Mais informações nos Anexos.
} 
envolvimento efetivo da unidade brasileira no DGP, levou a área de P\&D da companhia a essa situação.

A participação brasileira é semelhante quando se trata de desenvolvimento de software para Estações Rádio-Base, ou seja, nesse nicho de produtos, as equipes brasileiras trabalham basicamente com desenvolvimento de software e estão envolvidas com adaptações de produtos ao mercado local. Vale destacar que na primeira rodada de entrevistas (em 2000), esse segmento de produtos estava entre os principais nas companhias devido à necessidade de aumento de infra-estrutura de rede pós-privatização, no entanto, na segunda rodada (em 2002), esses produtos tinham pouca participação no faturamento das empresas, exceto por aquelas que estavam envolvidas com a criação de infra-estrutura para GSM. Mostrando, mais uma vez, que o mercado influencia diretamente no desenvolvimento tecnológico, conforme mostrado no capítulo 6.

Para desenvolvimento de aparelhos celulares, a participação brasileira também é esporádica e, quando acontece, é bastante concentrada em adaptação e desenvolvimento de software específico para um determinado serviço de uma operadora cliente. A Motorola, por exemplo, é a empresa estudada com maior participação da unidade brasileira no DP na área de aparelhos, e, ainda assim, a maioria do desenvolvimento de produtos é relacionada a mudanças incrementais, pouca inovação acontece localmente e, quando existe, é relacionada a design ou a interface dos aparelhos. Apesar de existir, pouco do desenvolvimento local refere-se a mudanças na plataforma dos produtos. No caso dos aparelhos celulares, nem mesmo o Sistema Operacional ou os softwares para conexão com as operadoras foram ou são desenvolvidos no Brasil, dois segmentos de sub-produtos globais.

Sendo assim, no pouco envolvimento que as equipes das subsidiárias brasileiras tem com desenvolvimento global de produtos, ele acontece principalmente em software e em alguns nichos específicos de desenvolvimento de software, comprovanto a hipótese 6 (H6). No entanto, essa limitação não precisa ser vista negativamente, uma vez que já é realidade e a tendência do setor evidencia fortalecimento do software nos produtos de telecomunicações. 
Uma outra área em que a participação das subsidiárias brasileiras vem crescendo é a de serviços, especialmente de integração de rede. É tendência entre as empresas fornecedoras de equipamentos para telecomunicações, caminhar à jusante na cadeia produtiva do setor, conforme discutido no capítulo 5. Mundialmente, essa tendência é fato, e no Brasil, em particular, isso se mostra bastante crescente nas empresas estudadas. Todas elas confirmam que atuam nesse segmento e que essa participação deve aumentar, inclusive com prestação de serviços para outras unidades da companhia mundial.

A área de serviços na Ericsson, principalmente ligada às atividades de integração de redes, destaca-se cada vez mais. No Brasil, segundo informações da companhia, existe um "centro de competência mundial" em serviço de design de rede para sistemas indoor. Esse centro faz parte da business unit "Serviços Globais" 32 e presta serviço para várias subsidiárias da Ericsson espalhadas mundialmente.

Na Lucent mundial, no ano de 2001, os principais segmentos de atuação da TNC foram o de equipamentos para redes, com $26 \%$ das vendas, e o de serviços de integração, com 19\% (GEEIN, 2002b). No Brasil, a empresa também desempenha atividades no segmento de integração e mostra interesse em aumentar sua atuação nele.

\section{$\underline{\text { Processo de Desenvolvimento de Produtos }}$}

O processo de desenvolvimento de produtos é bastante similar em todas as empresas estudadas. Seguem o modelo tradicional, com etapas claramente definidas e possuem, normalmente, um plano de negócio com aspectos econômicos, de mercado e de tecnologia. As etapas, em geral, são: concepção, estudo de viabilidade, desenvolvimento técnico, prototipação, testes, fabricação.

A etapa de concepção envolve a definição do conceito do produto, devendo relacionar áreas de pesquisa, de desenvolvimento e de marketing. O estudo de viabilidade refere-se tanto a aspectos técnicos quanto financeiros e mercadológicos. O DP segue então para a fase de desenvolvimento e criação de protótipos, passando

\footnotetext{
${ }^{32}$ Mais informações em Anexo.
} 
finalmente para testes e finalmente fabricação em ampla escala. A etapa de testes está relacionada a testes de produto (separadamente), de sistema (quando o produto é parte de um sistema completo - hardware e software), de integração (os vários produtos e sistemas) e de campo (no cliente).

Geralmente, a etapa de concepção do produto está ligada diretamente à matriz (ou subsidiária líder na tecnologia específica do produto considerado), especialmente quando trata-se do desenvolvimento de produtos globais. Quando a subsidiária faz concepção de produtos, ela o faz para o mercado local, e segue, na maioria das vezes, estratégias estabelecidas globalmente pela companhia em termos de tecnologia a ser usada, novos produtos, segmentos novos ou a serem continuados.

Por exemplo, na unidade brasileira da Motorola, seguindo as estratégias da matriz, o setor de marketing (Product Marketing) verifica preferências e necessidades dos consumidores locais. O Business Case ${ }^{33}$ é preparado para, só então, após aprovação muitas vezes com envolvimento de equipes globais - ser encaminhado ao desenvolvimento.

Segundo entrevistas com executivos da Motorola Brasil, a equipe brasileira está envolvida em todas as etapas do DP, mas o grau de participação é decrescente quanto mais no início estiver o desenvolvimento. Segundo informações da empresa, isso vem mudando e a participação está crescendo com a maturidade das equipes de desenvolvimento

Na Nokia, a concepção geral dos produtos é feita na matriz, mas os centros de pesquisa, cada qual com sua especialidade, propõem a tecnologia para os novos produtos. Sendo assim, a primeira fase de DP acontece nos centros de pesquisa, que de fato pode ser considerada de desenvolvimento tecnológico e pode ter como resultado um produto inovador. Esses centros de pesquisa estão localizados em países desenvolvidos, com exceção de China, Hungria e Malásia ${ }^{34}$.

$\mathrm{Na}$ Ericsson, as fases realizadas no Brasil englobam engenharia ou detalhamento de requisitos do produto, estudo de viabilidade, execução do projeto de

\footnotetext{
${ }^{33}$ Estudo de viabilidade.

${ }^{34} \mathrm{Em}$ anexo, todos esses países são mencionados.
} 
desenvolvimento e teste funcional do produto, as demais, especificamente concepção e teste sistêmico, dificilmente são feitas pela subsidiária local.

A Lucent, uma vez que direciona suas atividades de P\&D para produtos originalmente brasileiros, as centrais telefônicas da família BZ, obviamente realiza, para tais produtos, todas as fases de desenvolvimento. È evidente que a tecnologia desses produtos já é dominada e que a necessidade de desenvolvimento atual é focada a adaptações para atendimento aos diversos clientes. No entanto, a empresa continua com mudanças incrementais nos produtos, incorporando, por exemplo, tecnologia IP para transferência de dados e voz.

No desenvolvimento global de produtos, as subsidiárias trabalham, geralmente, de maneira integrada à rede mundial e suas atividades são controladas/coordenadas globalmente. Para integração e coordenação do processo de DP, as empresas utilizam metodologias e sistemas de gestão específicos. Algumas são mais "organizadas" que outras nesse aspecto. A Ericsson, por exemplo, utiliza um software para gestão e integração mundial do processo de DP chamado Rational, que utiliza-se de ferramentas específicas para o desenvolvimento.

Em geral, as estruturas para P\&D são, cada vez mais, globais. Geralmente, quanto mais complexo o desenvolvimento de um produto, maior é o envolvimento de outras unidades da companhia e de clientes localizados em várias partes do mundo. Um exemplo de desenvolvimento de produto complexo é o projeto CME R5A (Davies, 1997), desenvolvido pela Ericsson por um período de três anos e meio. O objetivo inicial era desenvolver uma estação rádio-base menor e mais barata, mas as alterações realizadas nesse equipamento influenciaram alterações em todos os equipamentos de rede da empresa. Foi um projeto que envolveu, em todos os estágios de projeto e produção, subsidiárias localizadas em 9 países europeus, além de 3 clientes chave: Telia, Mannesmann e Vodafone.

Aliás, a integração entre clientes para o DP - geralmente as operadoras - e fornecedores de equipamentos para telecom, diferentemente do que era fato há duas décadas, não acontece com tanta freqüência, ela é mais comum nos processos de 
adaptações locais de produtos. Para o desenvolvimento de novos produtos, a relação entre elas acontece em menor proporção, mas não deixa de existir.

A internacionalização das empresas operadoras de telefonia, que atualmente possuem atuação mundial, implica em desenvolvimento global de produtos com os fabricantes, tornando as unidades externas de DP dos fornecedores de equipamentos ainda mais competitivas e levando-as ao desenvolvimento de soluções para o mercado mundial.

\section{Dificuldades para realização de P\&D no país}

Entre as dificuldades apontadas pelas companhias estudadas no desenvolvimento realizado no Brasil, a principal está relacionada aos riscos decorrentes da localização dessas atividades no país. Riscos que se traduzem sob vários aspectos, inclusive sob as políticas públicas existentes no país, que, de acordo com as empresas, são instáveis, incipientes e desarticuladas. A Lei de informática, principal mecanismo de incentivo público utilizado pelas empresas estudadas, por exemplo, é simplesmente uma lei para estimular a realização de $\mathrm{P} \& \mathrm{D}$ no Brasil, mas ela não agrega os diversos segmentos do governo que poderiam se beneficiar com os recursos provenientes dela.

A subsidiária da Siemens, por exemplo, afirma que um problema para o desenvolvimento local é a falta de uma política industrial efetiva, de longo prazo e que estimule fortemente o setor a investir em P\&D local. Essa crítica da empresa vai muito além de incentivo fiscal, segundo os executivos entrevistados, apenas o incentivo não atrai desenvolvimento tecnológico para o país, é preciso uma reestruturação com diretrizes mais amplas que apenas isenção fiscal.

A Motorola citou que a falta de política efetiva prejudica a realização de $\mathrm{P} \& \mathrm{D}$ no Brasil, afirmando que a não integração de diversos órgãos e unidades governamentais para estimular as atividades é extremamente negativa e que começa, por exemplo, na importação de um equipamento para pesquisa, no qual incide impostos regulares de importação, sem diferenciar as máquinas utilizadas em $\mathrm{P} \& \mathrm{D}$ das de produção / fabricação. Ela cita que a subsidiária local já perdeu projetos para 
outra subsidiária porque o custo para a matriz enviar os equipamentos necessários para o Brasil seria, por causa dos impostos, muito superior ao valor do envio para uma unidade localizada em outro país.

Um outro fator negativo para o desenvolvimento de produtos no Brasil citado pelas empresas, refere-se à mão-de-obra especializada, mas as principais ressalvas não são em relação à qualidade de formação, e sim à quantidade de pessoal disponível no mercado, isso antes da crise de 2001, ou seja, foi citado nas primeiras entrevistas com as empresas (em 1999/2000). É evidente que a situação inverteu-se na época das segundas entrevistas (2002), quando a crise do setor já havia determinado redução do quadro de funcionários na maioria absoluta das empresas.

Quanto à formação em si, duas foram as empresas que levantaram problemas. A Ericsson citou a falta de fluência no idioma inglês como falha na formação dos especialistas na área e isso foi comprovado pelas outras companhias num questionamento indutivo da resposta à pergunta. A Motorola citou que formação em gestão dos funcionários técnicos é muito falha, ou seja, eles têm problemas para gerir os processos de desenvolvimento, apesar da excelente formação técnica. Aliás, vale citar que a maioria absoluta das companhias citou a relação entre o êxito das equipes brasileiras de desenvolvimento e a boa formação técnica dos funcionários, que é, em geral, mais ampla e sólida que as de empregados de afiliadas em outros países.

Algumas subsidiárias citaram também a relação com as matrizes como ponto dificultador no desenvolvimento de produtos realizado por elas. Esse fator foi apontado pela Nokia e pelas duas companhias norte-americanas, Motorola e Lucent, que não apoiam naturalmente a realização do desenvolvimento no Brasil. Apesar de uma das empresas européias estudadas - Nokia - está entre as críticas desse fator "relação matriz-subsidiária", 100\% das empresas norte-americanas estudadas (Motorola e Nokia) citaram o problema interno da companhia e isso vale uma ressalva para algumas elucubrações. Há duas idéias alternativas para justificar isso, a primeira é que companhias norte-americanas são muito mais ligadas a comprovação de resultados do que as européias, por exemplo, e forçam as subsidiárias a comprovações numéricas extremamente desgastantes para justificarem investimentos locais. A segunda idéia está relacionada a uma observação feita neste trabalho, de 
que a internacionalização do DP nas TNC depende da origem da companhia. Todas as empresas estudadas possuem DGP, mas umas utilizam uma estratégia de maior internacionalização das atividades que outras. As Européias (Ericsson, Siemens, Nokia e Alcatel) apresentam maior cooperação internacional das equipes do que as japonesas ou as norte-americanas. O mais provável é que essas duas idéias sejam os fatores que influenciam as relações intempestivas entre matrizes e subsidiárias das companhias citadas.

Um outro exemplo de diferenciadas estratégias para centralização x descentralização de DP, a japonesa NEC, na década de 80, considerou mudanças no tipo de coordenação porque os custos da centralização estavam excedendo os benefícios (Bartlett e Ghoshal, 1992). Hoje, apesar de parecer ainda bastante centralizadora, a TNC tem adotado uma política de descentralização de desenvolvimento tecnológico, a matriz procura incentivar / forçar o desenvolvimento local. Segundo informações da empresa, segue-se essa estratégia com o objetivo principal de atender as exigências regionais (mercado e legislação) e tirar proveito do talento local. Um outro fator que interferiu na adoção da estratégia descentralizadora foi a necessidade de maior dinamismo no atendimento a clientes para a conquista de mercado.

Um outro fator citado pelas subsidiárias como desmotivador para participação no DGP refere-se às relações com as universidades e instituições de pesquisa para realização cooperativa de $\mathrm{P} \& \mathrm{D}$, apesar de todas as companhias afirmarem que essas relações melhoraram nos últimos anos. As principais críticas às universidades e instituições referem-se à falta de alinhamento dos tipos de pesquisa realizados pelas empresas e pelas instituições e à falta de profissionalização das instituições para criação das parcerias. As principais críticas foram NEC, Ericsson e Nokia.

Há ainda alguns outros aspectos de influência negativa no desenvolvimento realizado no Brasil também citados pelas companhias estudadas, mas são pontuais e não foram confirmadas por outras companhias, portanto não podem ser generalizados para resultados. Um deles é o custo local para desenvolvimento, apresentado pela Motorola apenas como um fator negativo, se comparado com outras subsidiárias do grupo. 


\section{$\underline{\text { Autonomia da Subsidiária }}$}

Conforme citado no capítulo 6 , nos casos estudados, a autonomia das subsidiárias para atividades relacionadas a P\&D, em geral, é restrita e seguem as estratégias globais da organização, estabelecidas pela matriz ou pelas unidades centrais de tecnologia específicas (os product owner).

A autonomia é maior na definição de processos do que de produtos, o que foi evidenciado na grande maioria das companhias: Motorola, Ericsson (evidenciado antes da terceirização para uma CEM), Nokia, Siemens e Lucent. Quanto à relação com fornecedores, há alguma autonomia nas negociações com fornecedores locais, sempre tentando alinhar as negociações aos desejos das headquarters de escolha de fornecedores globais previamente estabelecidos.

No desenvolvimento de novos produtos (DNP), é mais difícil encontrar autonomia nas subsidiárias, especialmente nas fases iniciais do desenvolvimento, como concepção de produtos através de estudo de preferências e necessidades de consumidores locais. Algumas empresas têm um grau maior de autonomia para o DNP (Siemens e Lucent), sempre em alguns nichos específicos e principalmente para adaptação de produtos e não para concepção / proposta de novos produtos globais, enquanto outras têm pouquíssima liberdade para inovar localmente, como Nokia, por exemplo.

$\mathrm{Na}$ adaptação dos produtos, as companhias possuem relativa autonomia para a análise de necessidades dos consumidores, mas os projetos para customizações são, na grande maioria das vezes, avaliados mundialmente. É o caso da Siemens, que pode fazer análise de mercado e desenvolver projetos referentes a alterações nos produtos para atendê-lo, no entanto, para executar tais mudanças, é necessário submeter tais projetos à matriz. A Nokia tem um comportamento semelhante, mas ligado especificamente a adaptações de software. Na Ericsson, a customização de produtos deve seguir padrões previamente estabelecidos. Vale ressaltar que esse processo de adaptação ocorre especialmente para produtos de infra-estrutura de rede, que tem uma necessidade maior de customização local. Quanto aos produtos orientados para o consumidor final, a grande maioria das companhias não tem 
autonomia para alterações, nem mesmo para análise de preferências de consumidores.

\subsection{Estruturas de Interações de equipes no DGP}

Nos casos estudados, foi possível identificar algumas características das empresas, que permitem não apenas classificá-las para melhor analisá-las, mas também orientar um estudo mais aprofundado na dinâmica da internacionalização do DP e não apenas na estratégia da empresa ao internacionalizar suas atividades de P\&D.

As diferenças entre as empresas começam pelas estratégias das companhias em descentralizar P\&D. Como foi citado na seção 7.1, algumas empresas estudadas têm uma estratégia mais descentralizada que outras para realização do desenvolvimento tecnológico - apesar de todas elas terem desenvolvimento fora de seus países de origem - e isso influencia a maneira com que organizam suas equipes distribuídas geograficamente.

A dinâmica da internacionalização pode ser observada através de diferentes aspectos, entre eles, um dos principais é a composição / formação das equipes globais envolvidas no desenvolvimento de produtos realizado mundialmente e a organização delas para o trabalho.

No capítulo 4, foram apresentados modelos estruturais para organização de atividades internacionais de P\&D encontrados na literatura (Chiesa e Manzini, 1996; Chiesa, 2000; Gassmann e von Zedtwitz, 1999). Esses modelos são semelhantes e complementares. De modo geral, os tipos de estruturas organizacionais estabelecidas podem ser classificados pelo estilo de divisão de tarefas:

- centralização do desenvolvimento, na qual o desenvolvimento de produtos e processos é feito por unidades centrais (geralmente, centros de excelência), com ou sem a participação de subsidiárias da companhia para o monitoramento local de mercado e tecnologia. 
- integração para o desenvolvimento de produtos e processos, com maior ou menor conexão entre as subsidiárias localizadas em diferentes países/regiões.

Essa classificação comum para os dois modelos distintos apresentados é possível, especialmente porque Gassmann e von Zedtwitz (1999) afirmam que o modelo Policêntrico (figura 4.11) está caindo em desuso e não é mais utilizado pelas TNCs. Se esse modelo fosse ainda considerado, teríamos, além da centralização e da integração para o desenvolvimento, a descentralização total das atividades de $\mathrm{P} \& \mathrm{D}$, sem que seja feito controle algum desses desenvolvimentos pelas companhias.

Sendo assim, as estruturas organizacionais para P\&D internacional desenvolvidas por Chiesa (2000) - também em conjunto com Manzini (Chiesa e Manzini, 1996) - e por Gassmann e von Zedtwitz (1999) são semelhantes, mas, como possuem características próprias, vale uma discussão sobre as diferenças, salientando vantagens e desvantagens entre elas.

Em termos gerais, a classificação de Gassmann e von Zedtwitz está mais baseada no contraponto entre matriz e subsidiária do que a de Chiesa, que isenta seu modelo da localização específica da unidade (matriz ou subsidiária). Essa característica do modelo de Chiesa é mais representativo dos modelos utilizados pelas empresas de telecom estudadas neste trabalho. Isso porque as subsidiárias das TNCs compõem as companhias e, ao participarem do desenvolvimento global de produtos, podem ocupar papéis que, no modelo de Gassmann e von Zedtwitz, são exclusivos das matrizes. Nos estudos de casos desenvolvidos, foi observado que algumas subsidiárias podem ocupar posições de liderança nos projetos internacionais de DP.

Essa é a principal diferença entre as características dos dois modelos (de Chiesa e Gassman e von Zedtwitz). Por exemplo, a "Estrutura de Especialização Isolada" do modelo de Chiesa é semelhante à "Estrutura Etnocêntrica" de Gassman e von Zedtwitz, uma vez que compreendem estratégias de empresas que procuram centralizar P\&D em centros de competências. No entanto, essas duas estruturas possuem uma diferença importante: na Especialização Isolada, vários podem ser os centros de excelência (dependendo da tecnologia, produto ou área na empresa), 
enquanto que o modelo Etnocêntrico considera que "todas as atividades de P\&D são concentradas na matriz" (Gassman e von Zedtwitz , 1999, p. 236).

Sendo assim, pelas características das empresas de telecomunicações estudadas neste trabalho, a classificação de Chiesa é mais apropriada ${ }^{35}$, porque, quando ocorre a centralização de atividades de $P \& D$, ela é geralmente feita em alguns centros de competência da empresa, localizados na matriz ou em outros países ${ }^{36}$, que seguem estratégias estabelecidas pela matriz, como na estrutura de Especialização Isolada. Ou seja, em empresas de grande porte, como as estudadas, não há apenas um centro de excelência na matriz concentrando as atividades de P\&D, como defendem Gassman e von Zedtwitz; essas empresas, em geral, possuem diferentes centros de excelência para as suas diferentes tecnologias.

A Ericsson, por exemplo, localiza nos EUA seu centro de excelência da tecnologia CDMA. Tal centro é responsável pela coordenação mundial das atividades de desenvolvimento realizadas por outras unidades da companhia. No entanto, o desenvolvimento tecnológico para GSM é coordenado por centros de pesquisa localizados na Europa, especialmente na Suécia (matriz) e no Reino Unido.

No entanto, de modo geral, apesar da boa adaptação do modelo de Chiesa aos estudos de caso feitos neste trabalho, vale salientar, que para segmentos em algumas empresas estudadas, o modelo de Gassman e von Zedtwitz é apropriado, tendo, inclusive, exemplos da estrutura Policêntrica desses autores (como a Nokia, cujo exemplo é citado a seguir neste capítulo). No entanto, o modelo de Chiesa será mais referenciado porque é mais característico das empresas estudadas aqui.

$\mathrm{Na}$ verdade, essa dificuldade de classificar as empresas de acordo com um modelo próprio e único ocorre porque as companhias estudadas possuem comportamentos diferenciados até mesmo internamente, ou seja, foi observado que uma mesma empresa tem diferentes tipos de unidades internacionais e de relações entre elas, isso

\footnotetext{
${ }^{35}$ A estrutura de Especialização Isolada parece ser também mais apropriada para empresas de grande porte em geral, não apenas as de telecomunicações, isso porque elas possuem diversas áreas tecnológicas e, geralmente, dividem o desenvolvimento em centros de competências específicos.

${ }^{36}$ Em sua maioria, os países desenvolvidos.
} 
é, possuem estruturas de P\&D diferenciadas dependendo da área / segmento / nicho de produto considerado.

Por exemplo, a equipe brasileira de DP da NEC, de modo geral, sempre esteve mais ligada ao monitoramento do mercado, atendimento do cliente e adaptação de produto, o que leva a participação da subsidiária brasileira a ser enquadrada no modelo de "Estrutura de Especialização Suportada", uma vez que as atividades de desenvolvimento local (de monitoramento) são controladas por um centro de excelência, que na NEC, geralmente ${ }^{37}$, é na matriz.

No entanto, para o desenvolvimento da tecnologia para equipamentos de acesso a rede $^{38}$, a estrutura passou, com o tempo, a ser parte da estratégia mundial da companhia e ser organizada por um centro mundial integrador de $\mathrm{P} \& \mathrm{D}$, mostrando que a empresa mudou, nesse nicho de produtos, seu modelo de desenvolvimento internacional para "Estrutura de Contribuidores Especializados".

A Motorola é um outro caso interessante, uma vez que possui diferentes estratégias para interações globais no DP, dependendo do nicho de produto considerado. Para a área de comunicações (CE), por exemplo, os dois segmentos distintos presentes no Brasil, o PCS - para comunicação pessoal - e o GTSS - para infra-estrutura de rede - têm diferentes estratégias e utilizam modelos também diferenciados para organização de suas equipes mundiais. Já a área de semicondutores (SPS), possui ainda outra formação distinta.

Para GTSS, as equipes são organizadas em "Estrutura de Especialização Suportada", uma vez que as subsidiárias são utilizadas para monitorar os ambientes locais e adaptar apropriadamente os produtos globais desenvolvidos por um centro de excelência. É também comum encontrar nesta área da empresa, alguns produtos globais que são diretamente instalados e a equipe local apenas recebe treinamento (do centro de excelência que detém a tecnologia do produto em questão) para fabricação e suporte técnico local, numa estrutura similar à "Estrutura de Especialização Isolada".

\footnotetext{
${ }^{37}$ Dependendo do nicho de produto.

${ }^{38}$ Principal nicho de produto desenvolvido no Brasil, que foi criado para atendimento local a cliente e que tornou-se produto global da companhia
} 
Já na área de PCS, a subsidiária brasileira coopera de duas maneiras distintas com a rede mundial de P\&D. Uma delas é similar à "Estrutura de Contribuidores Especializados", uma vez que a equipe local contribui com o desenvolvimento global, cujos projetos são integrados por um centro mundial. $\mathrm{O}$ outro modelo utilizado na área PCS da companhia é o "de Laboratórios Integrados" ou "de Rede", já que a unidade brasileira desenvolve certos projetos cooperando diretamente com outras subsidiárias que compõem a rede global em projetos supervisionados - mas não integrados - por uma unidade da TNC. Isso acontece, por exemplo, em alguns projetos feitos entre a subsidiária brasileira e a subsidiária chinesa para desenvolvimento de produtos para um segmento de mercado ${ }^{39}$, conforme citado no Anexo.

No segmento de semicondutores (SPS), a unidade brasileira da Motorola possui o BSTC (Brazil Semiconductor Technology Center), centro para desenvolvimento de projetos de circuitos integrados, que possui atividades de desenvolvimento de novos produtos em alguns nichos específicos do segmento SPS. Nesse caso, o centro brasileiro tem certa autonomia para desenvolver novos projetos, que são supervisionados pela unidade central da referida tecnologia, portanto, comportam-se de acordo com a "Estrutura de Laboratórios Integrados" ou "Estrutura de Rede". No entanto, os projetos realizados no Brasil têm uma certa coordenação da matriz, apesar da liberdade da subsidiária local em desenvolver. Isso acontece porque os projetos locais fazem parte de projetos mundiais da companhia, geralmente são componentes de produtos mais amplos e de sistemas complexos. Portanto, o que acontece é que em segmentos específicos de semicondutores, a unidade local tem certa autonomia para desenvolver, assemelhando-se à estrutura de "Rede", no entanto, como são desenvolvidas partes que compõem produtos / sistemas, é preciso uma coordenação de projetos mais eficaz que a descrita por Chiesa (2000) ao definir a "Estrutura de Rede". Isso será discutido mais adiante nesta mesma seção.

A Ericsson por sua vez, também tem comportamento semelhante, em alguns segmentos ela tem comportamento condizente com um tipo de estrutura, em outras

\footnotetext{
${ }^{39}$ Por exemplo, foi desenvolvido em parceria com a unidade chinesa da companhia, no segmento de produtos para consumidor final, um aparelho de telefone fixo, projeto no qual a subsidiária brasileira ficou responsável pelo design e a chinesa pelos componentes eletrônicos.
} 
áreas ela pode ser enquadrada em uma outra estrutura. A maioria das áreas da empresa atuam de acordo com a "Estrutura de Contribuidores Especializados", uma vez que a subsidiária local faz parte de equipes integradas mundialmente em determinados nichos de produtos.

Nas tecnologias em que ela é líder ${ }^{40}$, o comportamento da companhia pode ser classificado em duas estruturas. Para os sistemas de Billing, que fazem parte de um sistema amplo dos produtos globais da empresa, a subsidiária também compõe uma estrutura de "Contribuidores Especializados". Para determinados segmentos de produtos de segunda geração de CDMA, há uma certa independência para realização de alguns projetos, ou seja, é possível colocar a subsidiária local em uma posição na "Estrutura de Rede".

A subsidiária brasileira da Nokia comporta-se majoritariamente como adaptadora de produtos globais, ou seja, compondo uma "Estrutura de Especialização Suportada". Isso acontece principalmente para os aparelhos celulares, em que há necessidade de "tropicalização" de alguns produtos, especialmente software para atender às necessidades dos clientes locais, em geral, serviços específicos das operadoras no Brasil, como por exemplo, o sistema pré-pago ${ }^{41}$.

Eventualmente, a Nokia no Brasil apenas recebe a tecnologia de um centro de excelência da companhia quer seja para fabricação local ou para revenda/instalação no país de equipamentos feitos no exterior. Isso pode acontecer tanto para infraestrutura de rede, quanto para aparelhos a consumidores finais. Nesse caso, a companhia possui papel numa "Estrutura de Especialização Isolada".

Uma outra característica da Nokia é que, principalmente devido aos recursos da Lei de Informática, a unidade local da companhia realiza certos projetos que não são globais, utilizando-se de uma estrutura semelhante à Policêntrica desenvolida por Gassmann e von Zedtwitz (1999). Por exemplo, o produto desenvolvido em conjunto com um centro de pesquisa local para teste de queda de aparelho móvel ${ }^{42}$. Este

\footnotetext{
${ }^{40}$ Citadas anteriormente neste capítulo e no Anexo.

${ }^{41}$ O sistema "Pré-pago" é um serviço da telefonia móvel em que as operadoras recebem um tipo de depósito do cliente e prestam serviço a este, mediante tal adiantamento.

${ }^{42}$ No Anexo I são apresentadas mais informações do caso.
} 
aparelho, segundo os executivos entrevistados, é o mais completo na TNC, mas, embora tenha tido certo esforço por parte dos funcionários locais para que seja utilizado em outras subsidiárias da Nokia, não há previsão de "exportação" dessa tecnologia para a companhia global.

A Siemens, no que se refere a estrutura interna para desenvolvimento internacional, também tem comportamentos diferenciados dependendo do segmento de produtos. $\mathrm{O}$ Centro de Competência em comutação têm autonomia total ${ }^{43}$, uma vez que é responsável mundialmente pela gestão do desenvolvimento da linha de produtos em questão. Isso coloca a equipe local numa estrutura mundial de "Contribuidores Especializados", já que as atividades realizadas localmente são parte de um projeto mais amplo da companhia, mas a organização mundial para realização desses projetos também assemelha-se à "Estrutura de Rede", pela relativa autonomia da qual a subsidiária dispõe ao realizar P\&D local.

$\mathrm{Na}$ verdade, essa situação é semelhante à da Motorola, descrita anteriormente. As subsidiárias das companhias têm certa liberdade para desenvolver localmente num determinado nicho de produtos, mas como os produtos criados a partir desses desenvolvimentos são parte de sistemas mundiais complexos, há necessidade de maior controle / coordenação para integração de projetos.

Em desenvolvimento de software, isso é ainda mais nítido. As equipes mundiais desenvolvem partes específicas de sistemas computacionais amplos e complexos, que são coordenados por uma unidade central. Mas cada afiliada pode estar desenvolvendo métodos para melhorias incrementais nos programas desenvolvidos por elas, sem, obviamente, perder a característica de integração sistêmica, fundamental nesses projetos. No Brasil, por exemplo, algumas subsidiárias estudadas desenvolvem projetos em parceria com universidades e/ou centros de pesquisa no intuito de buscar melhorias em áreas específicas de desenvolvimento de sistemas e de programação como metodologias de desenvolvimento, redutibilidade de problemas, medidas de complexidade, etc.

\footnotetext{
${ }^{43}$ Melhor observado no Anexo.
} 
Sendo assim, verificou-se nos casos estudados, que apesar das empresas poderem ser, na grande maioria das vezes, enquadradas de acordo com uma das estruturas de Chiesa, há algumas exceções, portanto, a classificação desse autor merece alguns ajustes para atender melhor aos casos do setor de telecomunicações.

A primeira delas é com relação à existência de um maior controle / coordenação dos projetos realizados pelas unidades globais de $P \& D$ para que não haja duplicação de esforços. Além disso, os desenvolvimentos ocorridos nas unidades da companhia podem ser partes de um projeto maior. Ou seja, há necessidade de mesclar características da "Estrutura de Contribuidores Especializados" e da "Estrutura de Rede". Propõe-se, portanto, uma alteração nessas estruturas para que a de "Rede" passe a ser coordenada por unidade central e não apenas supervisionada, e para que a de "Contribuidores Especializados" apresente claramente uma integração entre os centros contribuidores, o que levaria também à utilização de nomenclatura mais apropriada, propõe-se o nome de "Estrutura de Contribuidores Especializados Integrados".

Uma outra alteração interessante no modelo de Chiesa é na "Estrutura de Especialização Isolada" ou "Estrutura de Centro de Excelência", para que seja apresentada a relação entre o centro de excelência e as demais afiliadas das empresas, que recebem o conhecimento dessa unidade para revenda ou fabricação local, assemelhando-se à estrutura Etnocêntrica do modelo de Gassmann e von Zedtwitz (1999). Dessa forma, as mudanças propostas geraram um novo modelo representativo das estruturas de $\mathrm{P} \& \mathrm{D}$ Internacional para a participação brasileira no DGP de empresas fornecedoras de equipamentos de telecomunicações, que pode ser visualizado na figura 7.1. 


\section{Estrutura de Centro de Excelência}

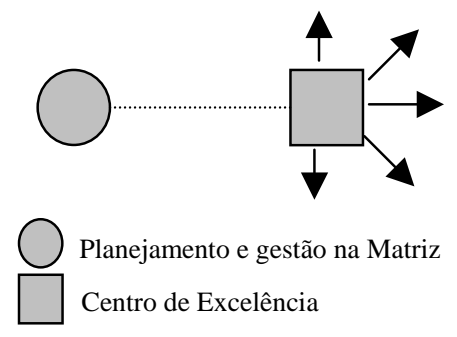

\section{Características:}

- Centro responsável pelo desenvolvimento de certo(a) tecnologia/produto globais

- Transferência de conhecimento do centro de excelência para as subsidiárias

- Não há monitoramento de mercados e tecnologia locais

\section{Estrutura de Especialização Suportada}

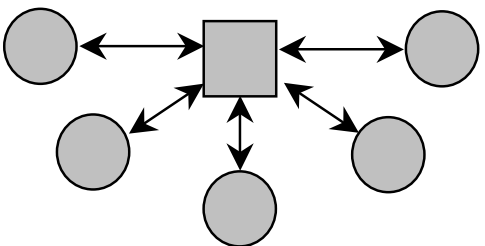

Características:

Unidades de Monitoramento ou de Adaptação Local

Centro de Excelência

\section{Estrutura de Contribuidores Especializados Integrados}

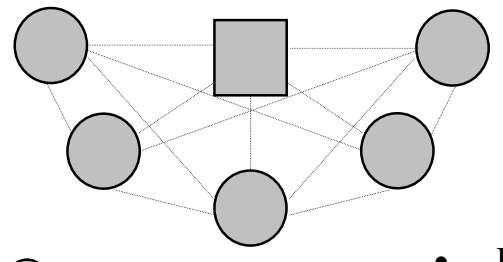

\section{Características:}

- Divisão de tarefas entre as unidades

- Atribui a cada subsidiária, atividades individuais

- Coordenação central de P\&D

- Há interações controladas entre as unidades,

- Definição e de desenvolvimento realizadas pelas unidades

Centro Integrador Global

- Exploração de forças locais

\section{Estrutura de Rede Associada}

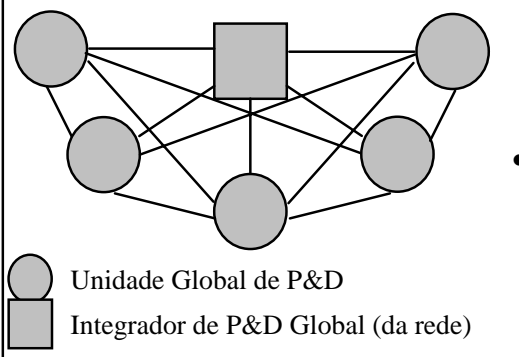

\section{Características:}

- $\quad$ Atividades de P\&D são internacionalizadas

- Liberdade aos laboratórios estrangeiros para inovação

- Coordenação das atividades globais

- Exploração e refinamento de forças locais

Figura 7.1 - Modelo Representativo das Estruturas de P\&D Internacional mais usadas pelos casos estudados

Vale citar que, como as empresas têm diferentes organizações estruturais para o desenvolvimento dependendo do segmento de produto a ser trabalhado e todas são empresas estrangeiras, a grande maioria delas - senão todas - apresenta produtos que são apenas revendidos no mercado brasileiro ou fabricados no Brasil e revendidos 
interna e externamente, sem necessidade de adaptação. Ou seja, essas companhias, para alguns nichos, enquadram-se na "Estrutura de Especialização Isolada", apenas recebendo treinamento para fabricação ou suporte à tecnologia repassada pelo centro de excelência da TNC. No entanto, ao adotar essa estrutura, a empresa ou a área na empresa não tem integração com o desenvolvimento global de produtos, portanto, nos casos feitos, não foram citados muitos exemplos de utilização dessa estrutura.

Observou-se que as empresas estudadas podem ser classificadas em todas as estruturas de organização das equipes internacionais de desenvolvimento, mas as principais estruturas nas quais as subsidiárias no Brasil possuem equipes envolvidas são a "Estrutura de Especialização Suportada" e a "Estrutura de Contribuidores Especializados Integrados”. Em ambas, há uma integração com as equipes de desenvolvimento mundial da companhia como um todo, mas de maneiras diferentes. Na primeira estrutura, as subsidiárias são utilizadas para adaptações locais ou para monitoramento do ambiente, enquanto que na segunda, são parte de uma organização global de desenvolvimento, com papéis claros/definidos e com pouca autonomia.

Em ambas as estruturas mais comuns às empresas estudadas, a característica de centralização de coordenação do DP está presente. Isso confirma um estudo feito por Camargos e Sbragia (2002), no qual afirmam que as empresas localizadas no Brasil, utilizadas para tal estudo, apresentam tendência centralizadora, afirmando que “chama a atenção, a manutenção da coordenação central até mesmo naquelas estruturas de P\&D mais descentralizadas" (Camargos e Sbragia, 2002, p. 102).

\subsection{Estrutura Organizacional para P\&D Internacionalizada}

Como mencionado na seção 4.2.3.2., além das estruturas internacionais para integração de equipes de $\mathrm{P} \& \mathrm{D}$, são analisadas também a organização hierárquica dessas unidades. Entre as várias formas adotadas pelas empresas para organizá-las, estão a funcional, a divisional e a matricial (De Meyer e Mizushima,1989). Nos estudos de caso realizados neste trabalho, observou-se que existem companhias com características em cada uma delas, mas a maioria delas possui estrutura divisional ou 
matricial. Isso porque a divisão entre segmentos de produtos no setor de telecomunicações é muito forte, fazendo-se necessário especificidades. Em anexo, é possível verificar o comportamento das companhias estudadas sob este aspecto.

Além dessas três estruturas distintas, foi mostrado no capítulo 4, que algumas TNCs estabelecem, periodicamente, times para "forças-tarefas", ou seja, montam equipes multifuncionais e inter-disciplinares com um tempo de vida limitado para projetos específicos (Reger, 1999). Isso foi evidenciado na Nokia, por exemplo, que mostrou uma maneira diferente das outras empresas analisadas. Para o desenvolvimento de aparelhos celulares CDMA, existe uma equipe de funcionários estabelecidos na subsidiária norte-americana da companhia, localizada em San Diego (que detém a tecnologia CDMA), que trabalham temporariamente no Brasil de maneira esporádica. São funcionários de origem brasileira, mas alocados nos EUA, de onde são direcionados para projetos específicos em alguns países, entre eles o Brasil.

Nessa equipe de trabalho existem funcionários de diversas nacionalidades, que têm diferentes países como clientes. No entanto, geralmente, os indivíduos são destinados a trabalhos em seus países de origem, portanto os indianos trabalham de maneira muito próxima da subsidiária da Nokia localizada na Índia, o acontece mesmo com os chineses, brasileiros, etc. É evidente que o trabalho dessas equipes nos vários países em que são temporariamente estabelecidos, é, em sua maioria, de adaptação de produtos desenvolvidos pela unidade central detentora da tecnologia (subsidiária norte-americana).

Uma outra característica é que, nas empresas estudadas, há evidências de que as unidades de P\&D das subsidiárias brasileiras que sejam subordinadas à própria diretoria da empresa local - especialmente para direcionamento de investimentos em desenvolvimento interno - possuem mais autonomia para a realização de suas atividades. Na literatura isso é evidenciado pelo trabalho de Hakanson e Zander (1986), que afirmam que a responsabilidade pela alocação de fundos para P\&D deveria ser da subsidiária, apenas dessa forma, os processos decisórios seriam flexíveis o bastante para permitir agilidade na exploração de novas oportunidades locais/regionais de negócios. 
É preciso deixar claro que essa subordinação à unidade local não significa que as atividades de desenvolvimento global não sejam coordenadas por uma unidade central, seja ela responsável pela $\mathrm{P} \& \mathrm{D}$ de uma divisão ou da companhia como um todo. Na verdade, o departamento de $\mathrm{P} \& \mathrm{D}$ local responderia tanto para a subsidiária quanto para a unidade de controle global de $\mathrm{P} \& \mathrm{D}$, caracterizando a estrutura matricial de De Meyer e Mizushima (1989).

Como foi discutido no capítulo 6, a autonomia da subsidiária é um dos fatores que possibilitam o envolvimento da unidade local no desenvolvimento de produtos e o desenvolvimento de competências para atuação no DGP, portanto seria interessante que as afiliadas brasileiras das TNCs atuassem de maneira mais autônoma. Considerando que uma estrutura organizacional em que a unidade de P\&D é diretamente subordinada à subsidiária local tem mais chances de trabalhar autonomamente, é lícito afirmar que quanto mais ligada à unidade local e menos desvinculada na unidade global, especialmente na determinação de alocação de investimentos em $\mathrm{P} \& \mathrm{D}$, mais competências a afiliada local teria, consequentemente, mais envolvida no DGP ela poderia estar.

\subsection{Análise da Cooperação entre Empresas e Universidades / Centros de Pesquisa no Setor de Telecomunicações}

As relações de cooperação entre as companhias estudadas e centros de pesquisa ou universidades no Brasil existem e se intensificaram principalmente por causa dos requisitos da Lei de Informática, que obriga as empresas a realizarem projetos cooperativos com essas entidades.

Mundialmente, por serem de uma área que trabalha com tecnologia de ponta, as empresas de telecomunicações têm cultura de parceria com institutos de pesquisa. A Lucent Technologies Inc., por exemplo, é uma empresa que foi criada em 1996 a partir da separação da AT\&T, que passou a dedicar-se unicamente à operação de telefonia. A Lucent passa então a ser a empresa do grupo no segmento de fabricação de equipamentos. O Bell Labs, tradicional laboratório de pesquisa, é o braço de P\&D 
da Lucent, e possui vínculos com várias universidades dos EUA para realização de pesquisa de ponta na área de comunicações.

Além da obrigação da Lei de Informática, como citado anteriormente, os motivos que levam as empresas no Brasil a buscarem cooperação com universidades e centros de pesquisa são variados. A falta de mão-de-obra interna, tanto em quantidade quanto em especialização dos funcionários, leva à Cooperação EmpresaUniversidade (CEU). Isso porque a falta de pessoal qualificado internamente limita a realização de P\&D local.

$\mathrm{Na}$ época do boom do setor de telecomunicações, a falta de mão-de-obra especializada era geral do mercado, hoje essa falta acontece porque as empresas estão desintegrando suas equipes para redução de custos, consequentemente, há necessidade de repassar eventuais atividades tecnológicas para as parceiras.

Um outro motivo apresentado pelas empresas é a oportunidade de descobrir competências locais, utilizá-las e expô-las externamente para a companhia como um todo. Algumas empresas (Ericsson, Motorola, Siemens) citaram exemplos de produtos desenvolvidos em CEU no Brasil que repercutiram internacionalmente nas TNCs. A utilização de equipamentos dos institutos também foi indicado como fator importante para criar parcerias.

Além disso, o custo do desenvolvimento com o parceiro da academia é menor e torna-se um outro fator motivador da CEU. A Ericsson, por exemplo, alega que é mais barato desenvolver em universidades/centros de pesquisa do que internamente, especialmente se existe a necessidade de montar equipes internas para trabalharem com determinados segmentos.

A necessidade de formação profissional também foi citada como importante no estabelecimento de parcerias. A Alcatel criou uma rede de laboratórios, chamada Lab Com que, entre outros, "procura apoiar a formação e o aprimoramento profissional pelo estudo prático de princípios e aplicações tecnológicas" (Alcatel, 2002). 
A coordenação das atividades feitas em parceria geralmente ficam sob responsabilidade das empresas, que também estabelecem critérios para propriedade intelectual e divulgação do conhecimento em contrato.

As atividades realizadas em parceria com as universidades ou centros de pesquisa são variadas. Algumas empresas têm projetos ligados ao treinamento e qualificação profissional de alunos, atividades previstas e aceitas para comprovação da Lei de Informática. Entre as atividades relacionadas especificamente com o desenvolvimento de produtos, há algumas diferenças de empresa para empresa.

No entanto, a maioria delas procura desenvolver fora de suas unidades internas de $\mathrm{P} \& \mathrm{D}$, o que não é core para a companhia. Dessa forma, geralmente, elas encaminham para os parceiros, atividades de pesquisa ou, se de desenvolvimento, atividades que não dependam de informações estratégicas, especialmente mundiais. Normalmente, as empresas financiam o projeto cooperativo e providencia suporte técnico ao pesquisador, seja com bolsas de pesquisa, viagens, aquisição de equipamentos, etc. Além disso, é comum encontrar investimentos feitos para equipar os centros de pesquisa.

Dentre as dificuldades mais relevantes apresentadas pelas empresas, foram destacados problemas na negociação, principalmente com as universidades, geralmente porque estas têm sido avaliadas como muito burocráticas. Dessa forma, quando a empresa deseja gerar inovações, decide por buscar associação com as fundações ou institutos de pesquisa em razão destes apresentarem um comportamento mais ágil (Prado e Porto, 2002).

Um outro fator mencionado pelas empresas foi $\mathrm{o}$ referente à característica demasiadamente acadêmica das instituições cooperadas, ou seja, falta experiência para trabalhar com empresas, que são dinâmicas e precisam que os acordos de parceria e os projetos sejam executados no mais rápido prazo possível. Segundo as empresas, o cumprimento dos prazos, muitas vezes, não é cumprido nos projetos de cooperação. 
Além disso, outra barreira apresentada pelas companhias é o tipo de pesquisa realizado nas instituições, que é pouco prática e está, em várias situações, longe da pesquisa realizada pela empresa. Portanto, as reclamações de que as instituições são extremamente acadêmicas, são referentes tanto a burocracia e prazos, quanto ao tipo de pesquisas realizadas. Quando reclamam desses problemas, os entrevistados procuram dizer que eles já vem sendo sanados e as parcerias estão cada vez melhores.

Uma característica também comum entre as empresas, é a criação de seus próprios centros ou fundações de pesquisa, que, por mais que as empresas neguem, servem, de alguma forma, para "externalizar" a pesquisa que seria realizada internamente e, com isso, prestar contas dos recursos exigidos pela Lei de Informática para pesquisas fora dos muros das companhias. Além disso, a Lei de Informática exige que parte do investimento externo seja direcionado para instituições do norte, nordeste ou centrooeste do país.

Entre os principais centros de pesquisa e universidades que cooperam com as empresas estudadas, estão: Instituto Eldorado (criado pela Motorola), CPDIA (criado pela NEC e adquirido recentemente pelo IPT), Fundação Nokia de Tecnologia, Fundação Informat (criada pela Ericsson), FITec (criada pela Lucent).

Além desses institutos "próprios", alguns institutos e universidades destacam-se na área de telecomunicações. Entre as principais entidades envolvidas no desenvolvimento cooperativo com as empresas estudadas estão: CPqD, CITS (Centro Internacional de Tecnologia de Software), C.E.S.A.R. Inatel, PTC/USP (Departamento de Engenharia de Telecomunicações e Controle, Escola Politécnica / Universidade de São Paulo), PUC-PR, UFPE e UNB, entre outras.

A figura 7.2 mostra os principais centros de pesquisa beneficiados pela Lei de Informática de acordo com informações da SEPIN/MCT (MCT, 2003). Destaca-se o papel dos centros de pesquisa / fundações criados pelas empresas de telecom, conforme citado anteriormente. Informat, Eldorado e CPDIA ocupam a primeira, segunda e quarta posições, respectivamente, entre os maiores receptores de investimentos dos recursos provenientes da Lei de Informática. 


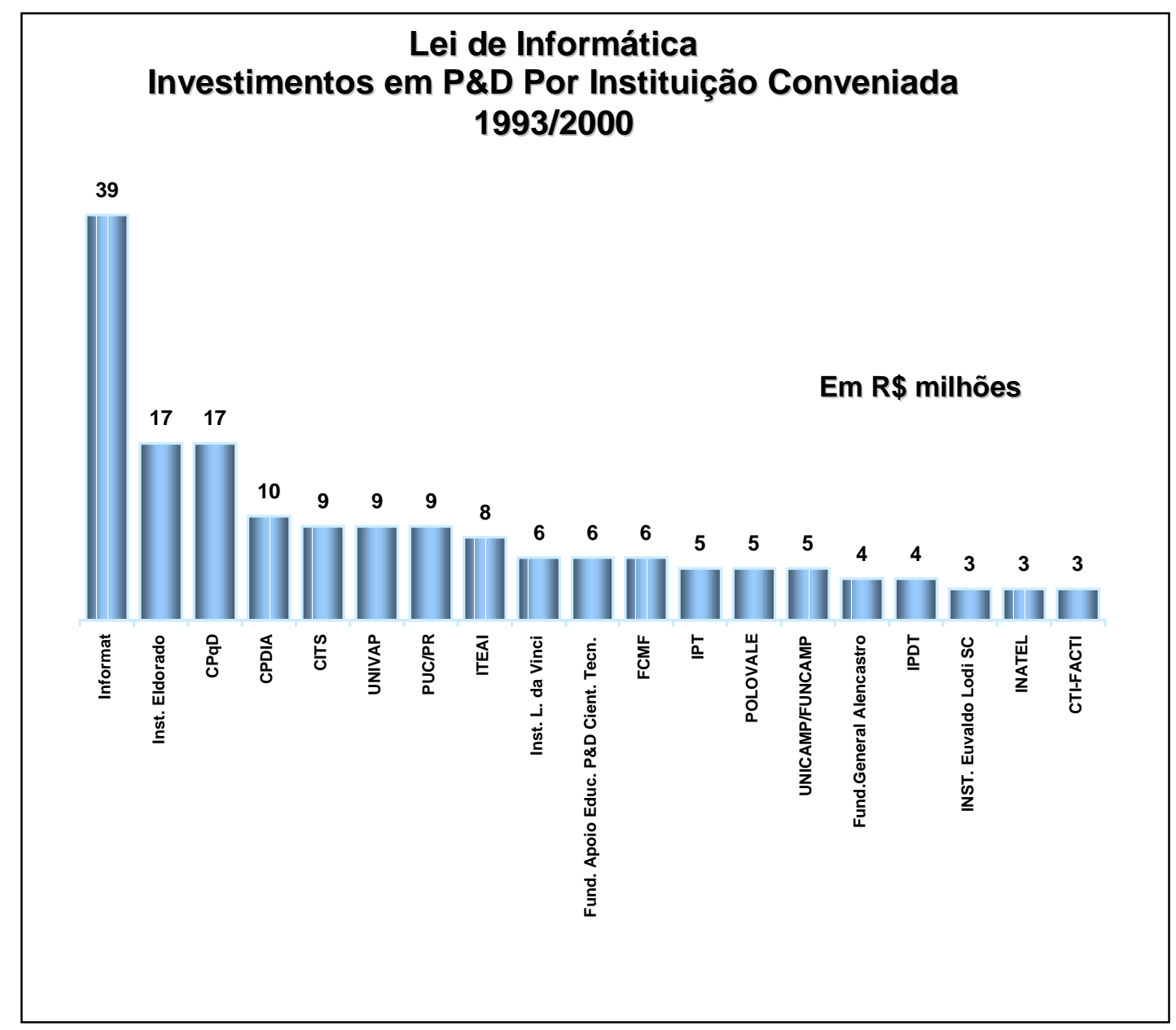

Figura 7.2 - Investimentos provenientes da Lei de Informática nos centros de pesquisa (MCT, 2003)

Um dos centros visitados nesta pesquisa foi o Departamento de Engenharia de Telecomunicações e Controle (PTC), da Escola Politécnica da Universidade de São Paulo. O PTC é formado por 3 laboratórios de pesquisa: LAC - Laboratório de Automação e Controle, LCS - Laboratório de Comunicações e Sinais, e LEB Laboratório de Engenharia Biomédica.

Nos Laboratórios do PTC são desenvolvidas pesquisas, tanto básicas como aplicadas. No LAC há pesquisas em sistemas de controle e automação, teorias de controle avançado, controle de processos industriais, robótica e automação da manufatura, e modelos matemáticos aplicados a finanças, biologia, e outras áreas. O LCS desenvolve pesquisas em comunicações em banda larga, comunicações por spread spectrum, comunicações móveis, eletromagnetismo aplicado, redes de alta 
velocidade, comunicações ópticas, aplicações de redes neurais artificiais, processamento digital de sinais, filtragem adaptativa e equalização, processamento de sinais de voz, entre outras. O LEB desenvolve pesquisas em processamento de sinais para diagnósticos neurológico e cardiológico, estudo do sistema nervoso por modelos matemáticos e experimentos, desenvolvimento e ensaios de equipamentos médicos, próteses eletrônicas para deficientes, modelagem do sistema respiratório e locomotor, entre outras.

O PTC possui alguns convênios com empresas do setor estudado, esses convênios têm incentivo da lei de informática (8248). Os principais convênios são com as transnacionais Motorola e Ericsson e com a brasileira GMK. É clara a diferença existente entre os projetos realizados com cada uma dessas empresas.

Com a Motorola, as atividades conjuntas estão ligadas a formação de alunos de graduação. O projeto de capacitação tecnológica (P.C.T.) objetiva a formação de profissionais para a área de telecomunicações. Os alunos escolhidos num processo de seleção recebem bolsas para estudarem assuntos específicos de interesse da empresa, definidos e elaborados previamente com o departamento. A Motorola possui contrato parecido com outras instituições de ensino.

O projeto realizado com a GMK, empresa brasileira que atua no segmento de serviços de telecom para consumidor final (ex: call center), é mais fortemente relacionado a geração de conhecimento e desenvolvimento tecnológico do que o projeto da Motorola. O convênio com essa empresa tem a participação da FDTE (Fundação para o Desenvolvimento Tecnológico da Engenharia), que auxilia o PTC, principalmente, nos assuntos administrativos.

O trabalho cooperativo com a GMK era relacionado com reconhecimento de voz. Foi desenvolvido um projeto de pesquisa para reconhecimento discreto de voz, mas a tendência do mercado estava para reconhecimento contínuo, assim, a GMK resolveu encerrar tal pesquisa, adquirindo tecnologia estrangeira para reconhecimento contínuo e adaptando para seus produtos. Isso mostra que uma pesquisa tecnicamente viável e reconhecida pela comunidade científica (Martinez, 1995; Jeszensky, 1996) 
pode ser descontinuada se os pesquisadores não alinharem seus projetos com os interesses da indústria / do mercado.

Apesar desse exemplo não ser concernente com os fatores considerados na escolha das entidades de pesquisa a serem estudas, uma vez que não foi feito estudo de caso com a GMK, vale a pena citá-lo porque é um caso típico de falta de alinhamento entre as pesquisas realizadas na universidade e as feitas na indústria. Mostra que, cada vez mais, é importante ter integração empresa-universidade, e isso a lei 8248 vem incentivando de maneira ímpar.

E, finalmente, o convênio com a Ericsson, que, dos três, é o mais pertinente se pensarmos em geração de conhecimento tecnológico. O projeto desenvolvido em conjunto com empresa também é intermediado pela FDTE, e envolve 10 professores do PTC e do Departamento de Engenharia de Computação e Sistemas Digitais (PCS) da Escola Politécnica da USP, bem como seus orientados. Ao todo são oito projetos, que serão desenvolvidos em 24 meses, nos quais serão investidos cerca de US\$ 2 milhões.

Esses projetos foram definidos conjuntamente com a empresa, que, antes de estabelecê-los, procurou identificar as áreas em que o PTC tem interesse e atua com competência. As atividades de pesquisa serão realizadas com o patrocínio e envolvimento da Ericsson Research na Suécia, tecnicamente os projetos são subordinados à equipe estrangeira. Convênios similares estão sendo desenvolvidos com outros centros de pesquisa / universidades. 
Tabela 7.1 - Quadro-Resumo comparativo entre as empresas estudadas

\begin{tabular}{|c|c|c|c|c|c|c|}
\hline Empresa & $\begin{array}{l}\text { Fabricação } \\
\text { Local }^{\#}\end{array}$ & P\&D no Brasil & $\begin{array}{c}\text { Fatores que } \\
\text { atraem P\&D }\end{array}$ & $\begin{array}{c}\text { Dificuldades para } \\
\text { P\&D local }\end{array}$ & $\begin{array}{c}\text { Aquisição de } \\
\text { tecnologia }\end{array}$ & Autonomia da subsidiária \\
\hline Motorola & $\begin{array}{l}\text { - } \quad \text { Terminais } \\
\text { celulares; } \\
\text { - } \quad \text { ERB; } \\
\text { - } \quad \text { Trunking. }\end{array}$ & $\begin{array}{l}\text { DNP: } \\
\text { Semicondutores; } \\
\text { DNP/Adaptação: } \\
\text { terminais pessoais; } \\
\text { Adaptação: ERB }\end{array}$ & $\begin{array}{l}\text { - Proximidade do } \\
\text { mercado consumidor; } \\
\text { incentivo fiscal (lei de } \\
\text { informática); } \\
\text { - Competências } \\
\text { decorrentes de fatores } \\
\text { históricos; } \\
\text { - Relação custo- } \\
\text { benefício favorável }\end{array}$ & $\begin{array}{l}\text { - Problemas políticos } \\
\text { da empresa (relação } \\
\text { matriz-subsidiárias); } \\
\text { - Quantidade de mão- } \\
\text { de-obra (primeira fase } \\
\text { das entrevistas - antes } \\
\text { da crise do setor) } \\
\text { - Falta de política } \\
\text { pública para estimular } \\
\text { desenvolvimento local }\end{array}$ & $\begin{array}{l}\text { - Subsidiária não } \\
\text { paga royalties para a } \\
\text { matriz; } \\
\text { - tecnologia é } \\
\text { passada por meio de } \\
\text { documentação e } \\
\text { treinamento ( } 25 \% \text { na } \\
\text { matriz) }\end{array}$ & $\begin{array}{l}\text { Grande: definição de } \\
\text { processos; } \\
\text { Média: negociação com } \\
\text { fornecedores locais e mundiais; } \\
\text { Pequena: definição de produtos }\end{array}$ \\
\hline NEC & $\begin{array}{l}\text { Terceirizada para } \\
\text { Celestica } \\
\text { - Centrais } \\
\text { telefônicas fixas de } \\
\text { comutação; } \\
\text { - Rádios ponto-a- } \\
\text { ponto; } \\
\text { - Equipamentos } \\
\text { de acesso a rede } \\
(F A) ; \\
\text { - ERB }\end{array}$ & $\begin{array}{l}\text { DNP: } \\
\text { equipamentos de } \\
\text { acesso a rede } \\
(F A) \text {; } \\
\text { DNP/Adaptação: } \\
\text { ERB; rádios } \\
\text { ponto-a-ponto } \\
\text { Adaptação: } \\
\text { centrais } \\
\text { telefônicas fixas }\end{array}$ & $\begin{array}{l}\text { Proximidade do } \\
\text { mercado } \\
\text { consumidor; } \\
\text { incentivo fiscal (lei } \\
\text { de informática); } \\
\text { aproveitamento de } \\
\text { competências } \\
\text { locais; baixo custo } \\
\text { de desenvolvimento }\end{array}$ & $\begin{array}{l}\text { - Relação com } \\
\text { fornecedores; } \\
\text { - Parcerias com } \\
\text { instituições de pesquisa } \\
\text { (tem melhorado) }\end{array}$ & $\begin{array}{l}\text { Compra tecnologia } \\
\text { da matriz ou de } \\
\text { outras subsidiárias; } \\
\text { treinamento } \\
\text { geralmente é feito } \\
\text { na matriz e } \\
\text { repassado para } \\
\text { outros funcionários }\end{array}$ & $\begin{array}{l}\text { Grande: estudos de } \\
\text { preferências de consumidores } \\
\text { locais, alterações de matérias- } \\
\text { primas, e negociação com } \\
\text { fornecedores locais e mundiais; } \\
\text { Média: definição/ alteração de } \\
\text { produtos e processos }\end{array}$ \\
\hline
\end{tabular}




\begin{tabular}{|c|c|c|c|c|c|c|}
\hline Siemens & $\begin{array}{l}\text { - Comutação } \\
\text { (DLU Shelter); } \\
\text { - Centrais } \\
\text { telefônicas fixas de } \\
\text { comutação } \\
(E W S D) ; \\
\text { - centrais de } \\
\text { médio e pequeno } \\
\text { porte (PABX); } \\
\text { - terminais fixos }\end{array}$ & $\begin{array}{l}\text { DNP/Adaptação: } \\
\text { Comutação }(D L U \\
\text { Shelter); terminais } \\
\text { fixos; centrais } \\
\text { fixas }(E W S D) \\
\text { Adaptação: } \\
\text { centrais de médio } \\
\text { e pequeno porte } \\
\text { (PABX) }\end{array}$ & $\begin{array}{l}\text { Proximidade do } \\
\text { mercado } \\
\text { consumidor; } \\
\text { aproveitamento de } \\
\text { competências } \\
\text { locais; incentivo } \\
\text { fiscal (lei de } \\
\text { informática) }\end{array}$ & $\begin{array}{l}\text { - Falta de política } \\
\text { industrial; } \\
\text { • quantidade de mão } \\
\text { de obra (antes do } \\
\text { boom); }\end{array}$ & $\begin{array}{l}\text { Características dos } \\
\text { produtos fabricados } \\
\text { localmente são } \\
\text { repassados através } \\
\text { de documentação } \\
\text { específica e } \\
\text { treinamento feito na } \\
\text { matriz }\end{array}$ & $\begin{array}{l}\text { Grande: para análise de } \\
\text { mercado e decidir sobre o DNP } \\
\text { (submetendo projeto à matriz) } \\
\text { Média: alteração de produtos; } \\
\text { negociações c/ fornecedores } \\
\text { locais } \\
\text { Baixa: negociações c/ } \\
\text { fornecedores mundiais }\end{array}$ \\
\hline Ericsson & $\begin{array}{l}\text { Terceirizada para } \\
\text { Flextronics } \\
\text { - Centrais } \\
\text { telefônicas de } \\
\text { comutação }(A X E) \text {; } \\
\text { - ERB; } \\
\text { - Terminais } \\
\text { celulares }\end{array}$ & $\begin{array}{l}\text { DNP: centrais } \\
\text { telefônicas (líder } \\
\text { mundial da } \\
\text { tecnologia de } \\
\text { tarifação das } \\
\text { centrais AXE) } \\
\text { DNP/Adaptação: } \\
\text { centrais } \\
\text { telefônicas; } \\
\text { terminais } \\
\text { celulares; ERB }\end{array}$ & $\begin{array}{l}\text { Proximidade do } \\
\text { mercado } \\
\text { consumidor; } \\
\text { competências locais } \\
\text { decorrentes de } \\
\text { fatores históricos; } \\
\text { baixo custo de } \\
\text { desenvolvimento; } \\
\text { proximidade da } \\
\text { fábrica local devido } \\
\text { à sua relevância } \\
\text { para a TNC; } \\
\text { incentivo fiscal (lei } \\
\text { de informática) }\end{array}$ & $\begin{array}{l}\text { - Parcerias com } \\
\text { instituições de pesquisa } \\
\text { (tem melhorado); } \\
\text { - falta de fluência no } \\
\text { idioma inglês dos } \\
\text { funcionários; } \\
\text { - indefinições nos } \\
\text { incentivos fiscais }{ }^{2} \mathrm{e} \\
\text { instabilidade em } \\
\text { políticas públicas. }\end{array}$ & $\begin{array}{l}\text { Maior parte dos } \\
\text { processos são } \\
\text { desenvolvidos em } \\
\text { parceria com a } \\
\text { matriz, quase nada é } \\
\text { desenvolvido } \\
\text { apenas no Brasil; } \\
\text { Quanto mais recente } \\
\text { a tecnologia, maior } \\
\text { é integração c/ a } \\
\text { matriz; maior parte } \\
\text { do treinamento } \\
\text { ocorre no product } \\
\text { owner, com } \\
\text { posterior dissemina- } \\
\text { ção na unidade local }\end{array}$ & $\begin{array}{l}\text { Grande: para customizações de } \\
\text { produtos/processos (sempre } \\
\text { seguindo padronização global) } \\
\text { Média: definições de } \\
\text { processos; negociação com } \\
\text { fornecedores locais ou } \\
\text { mundiais; definições/alterações } \\
\text { matérias-primas } \\
\text { Baixa: Estudos de preferências } \\
\text { consumidores; decisões sobre } \\
\text { DNP }\end{array}$ \\
\hline
\end{tabular}




\begin{tabular}{|c|c|c|c|c|c|c|}
\hline Lucent & $\begin{array}{l}\text { - Centrais } \\
\text { telefônicas de } \\
\text { pequeno porte } \\
(B Z 500)^{3} ; \\
\text { - ERB; } \\
\text { - Central } \\
\text { telefônica de } \\
\text { comutação }\end{array}$ & $\begin{array}{l}\text { DNP: Centrais } \\
\text { telefônicas de } \\
\text { pequeno porte } \\
\text { (líder mundial da } \\
\text { tecnologia) } \\
\begin{array}{l}\text { Adaptação: } \\
\text { centrais } \\
\text { telefônicas; ERB }\end{array}\end{array}$ & $\begin{array}{l}\text { Proximidade do } \\
\text { mercado } \\
\text { consumidor } \\
\text { (redução de custos e } \\
\text { agilidade para } \\
\text { atendimento); } \\
\text { competências locais } \\
\text { (especialmente em } \\
\text { software); incentivo } \\
\text { fiscal (lei de } \\
\text { informática); baixo } \\
\text { custo de mão-obra } \\
\text { p/ desenvolvimento; } \\
\text { tecnologia nacional } \\
\text { adquirida na compra } \\
\text { de empresas } \\
\text { brasileiras não era } \\
\text { dominada pela TNC }\end{array}$ & $\begin{array}{l}\text { - Relação com a } \\
\text { matriz é difícil pela } \\
\text { dependência da } \\
\text { subsidiária, que tem } \\
\text { sempre que provar } \\
\text { retorno financeiro, o } \\
\text { que limita a liberdade } \\
\text { para ações de P\&D, } \\
\text { que são sujeitas a riscos }\end{array}$ & $\begin{array}{l}\text { Aproximadamente } \\
\text { metade dos } \\
\text { processos } \\
\text { produtivos são } \\
\text { desenvolvidos em } \\
\text { conjunto com a } \\
\text { equipe que detêm a } \\
\text { tecnologia do } \\
\text { produto, pouco } \\
\text { menos da metade é } \\
\text { desenvolvido no } \\
\text { Brasil e } \\
\text { pouquíssimo vem } \\
\text { completamente } \\
\text { definido de fora; } \\
\text { maioria dos } \\
\text { funcionários são } \\
\text { treinados na matriz }\end{array}$ & $\begin{array}{l}\text { Grande: DNP para tecnologia } \\
\text { da subsidiária (produto da } \\
\text { família BZ); para definição de } \\
\text { processos (sempre seguindo } \\
\text { padronização global); } \\
\text { negociação com fornecedores } \\
\text { (mundiais ou locais) } \\
\text { Média: DNP para tecnologias } \\
\text { direcionadas a países em } \\
\text { desenvolvimento } \\
\text { Baixa: Definições/alterações de } \\
\text { matérias-primas; alterações de } \\
\text { produtos (feitos no exterior) }\end{array}$ \\
\hline Alcatel & $\begin{array}{l}\text { Terceirizada para } \\
\text { Sanmina-SCI } \\
\text { - Telefonia Fixa: } \\
\text { Centrais, } \\
\text { equipamentos para } \\
\text { transmissão } \\
\text { - Iniciando } \\
\text { atividades com } \\
\text { tecnologia GSM }\end{array}$ & $\begin{array}{l}\text { A empresa } \\
\text { trabalha apenas } \\
\text { com algumas } \\
\text { poucas adaptações } \\
\text { para mercado } \\
\text { local. }\end{array}$ & $\begin{array}{l}\text { Mercado } \\
\text { Lei de Informática }\end{array}$ & $\begin{array}{l}\text { - Falta de política } \\
\text { industrial foi citado } \\
\text { como principal fator de } \\
\text { empecilho. }\end{array}$ & $\begin{array}{l}\text { A subsidiária paga } \\
\text { royalties a outra } \\
\text { unidade da TNC } \\
\text { caso fabrique } \\
\text { equipamentos } \\
\text { desenvolvidos por } \\
\text { outras unidades da } \\
\text { companhia. }\end{array}$ & $\begin{array}{l}\text { Média: Para adaptação de } \\
\text { produtos ao mercado local } \\
\text { (sempre seguindo } \\
\text { recomendações da TNC) } \\
\text { Inexistente: para } \\
\text { desenvolvimento de novos } \\
\text { produtos. }\end{array}$ \\
\hline
\end{tabular}




\begin{tabular}{|c|c|c|c|c|c|c|}
\hline Nokia & $\begin{array}{l}\text { - Telefonia } \\
\text { Móvel: aparelhos } \\
\text { celulares; ERB }\end{array}$ & $\begin{array}{l}\text { DNP: softwares } \\
\text { para serviços } \\
\text { específicos do } \\
\text { mercado local } \\
\text { (especialmente } \\
\text { serviços pré-pagos) } \\
\text { Adaptação: ERB, } \\
\text { aparelhos }\end{array}$ & $\begin{array}{l}\text { Tamanho do mercado } \\
\text { consumidor; abertura } \\
\text { do mercado, com } \\
\text { entrada de grandes } \\
\text { competidores } \\
\text { mundiais; incentivo } \\
\text { fiscal (lei de } \\
\text { informática). }\end{array}$ & $\begin{array}{l}\text { - A relação com a } \\
\text { matriz dificulta um } \\
\text { pouco, a matriz é } \\
\text { "centralizadora"; } \\
\text { - as parcerias com } \\
\text { universidades não } \\
\text { são "naturais"; } \\
\text { - falta definição de } \\
\text { políticas públicas } \\
\text { claras e mais amplas. }\end{array}$ & $\begin{array}{l}\text { A empresa não paga } \\
\text { Royalties para a } \\
\text { matriz; o treinamento } \\
\text { de funcionários tanto } \\
\text { para tecnologia de } \\
\text { produtos quanto de } \\
\text { processos é, } \\
\text { geralmente, feito na } \\
\text { matriz ou em } \\
\text { subsidiária que } \\
\text { detenha conhecimento } \\
\text { e replicado para } \\
\text { funcionários da } \\
\text { subsidiária local. }\end{array}$ & $\begin{array}{l}\text { Grande: Para adaptação de } \\
\text { produtos ao mercado local } \\
\text { (especialmente desenvolvimento } \\
\text { de software), mas com a } \\
\text { supervisão da matriz. } \\
\text { Média: para desenvolvimento / } \\
\text { alteração de processos produtivos. } \\
\text { Pequena: para verificação de } \\
\text { necessidades de consumidores, } \\
\text { para concepção de produtos, etc. }\end{array}$ \\
\hline
\end{tabular}

Legenda: ERB: Estação Rádio-Base; DNP: Desenvolvimento de Novos Produtos; Trunking: sistema de rádio transmissão empresarial;

\# Dados levantados em 2000-2001

1- A partir de 2001, fabricação terceirizada para Flextronics

2- Refere-se principalmente à demora para aprovação e regulamentação da prorrogação da lei de informática

3- Produto de tecnologia brasileira desenvolvido por empresa nacional adquirida pela Lucent em 1998 (Batik) 


\section{Capítulo 8}

\section{Pesquisa Quantitativa com indicadores de C\&T}

O objetivo deste capítulo é mostrar alguns dados quantitativos que possam contribuir com a análise dos resultados das atividades de P\&D desenvolvidas pelas empresas transnacionais estudadas. Isso levaria a respostas para a questão 7 desta tese: "Quais são os resultados da P\&D feita pelas subsidiárias locais?"44.

O intuito é avaliar a relevância dessas atividades de acordo com os resultados que elas geraram em termos de alguns indicadores de Ciência e Tecnologia (C\&T). Para tanto, foram coletados e analisados, para cada empresa estudada, dados de patentes nacionais e internacionais - e dados bibliométricos. Esses estudos quantitativos, assim como os estudos de casos (análises qualitativas), foram feitos com empresas transnacionais estrangeiras fornecedoras de produtos e serviços para o setor de telecomunicações com subsidiárias instaladas no Brasil.

Considerando a fragilidade dos resultados quando se estabelecem apenas análises estatísticas com patentes, já que tais estudos podem ser indicadores imperfeitos se utilizados sozinhos (Pavitt, 1988), é necessário e prudente combiná-los com outros indicadores de C\&T, portanto, além do estudo com dados bibliométricos, neste capítulo também é mostrada uma análise com dados secundários, desenvolvida através de alguns estudos relevantes em C\&T disponibilizados por instituições de renome. Foram avaliados dados dos seguintes trabalhos:

\footnotetext{
${ }^{44}$ Conforme apresentado no capítulo 2.
} 
- PINTEC - Pesquisa Industrial: Inovação Tecnológica 2000 (PINTEC / IBGE, 2002), desenvolvida sob a coordenação do IBGE (Instituto Brasileiro de Geografia e Estatística) e apoio da FINEP (Financiadora de Estudos e Projetos).

- Pesquisa realizada pela ANPEI (Associação Nacional de Pesquisa, Desenvolvimento e Engenharia das Empresas Inovadoras) (ANPEI, 1999), que se refere ao levantamento das características da inovação tecnológica das empresas.

\subsection{Patentes}

Estudos de várias naturezas podem ser feitos com patentes e as conclusões são as mais diversas possíveis. Os usos mais comuns para os dados estatísticos de patentes são para análises realísticas de setores, países, empresas ou para levantamento de questões e hipóteses para estudos exploratórios futuros. Dessa forma, trata-se de indicadores de C\&T importantes e amplamente utilizados em estudos relacionados à gestão tecnológica.

Alguns estudos feitos com patentes são importantes para esse trabalho e ajudaram a analisar melhor os dados obtidos aqui. Um deles foi feito por Albuquerque (2000), e compara dados sobre patentes concedidas nacionalmente e internacionalmente a empresas instaladas no Brasil. Tal trabalho concluiu que países em desenvolvimento têm atividades tecnológicas importantes localmente, mas não são significativas mundialmente.

Essas atividades são, por exemplo, relacionadas a adaptações de inovações estrangeiras, o que, não necessariamente, garante o crescimento tecnológico do país. Isso se confirma no setor de telecomunicações, cujo envolvimento das subsidiárias locais é mais intenso na regionalização de produtos, apesar de também acontecer envolvimento global no desenvolvimento de alguns nichos de produtos.

Um trabalho realizado especificamente no setor de telecomunicações foi feito por 
Schmoch (1996) entre os anos de 1987 a 1989, e mostra que os fluxos de patentes solicitação de patentes a países estrangeiros - refletem nos fluxos de tecnologia. Ele fez uma análise das diferentes estratégias de internacionalização de patentes de várias companhias, entre elas, as sete estudadas neste trabalho, lembrando que, na época, a Lucent ainda não havia sido desmembrada da AT\&T, isso só aconteceu em 1996.

Segundo tal pesquisa (Schmoch, 1996), os EUA ficam entre os países estrangeiros que mais recebem pedidos de concessão de patentes, principalmente para NEC e Ericsson. O Japão também se mostra importante, especialmente para as companhias americanas, AT\&T (Lucent) e Motorola. As empresas européias concentram suas solicitações na própria Comunidade Européia, especialmente para Grã Bretanha, Alemanha e França. No entanto, o mesmo estudo mostra que a maior parte das patentes requeridas pelas companhias é mesmo realizada no país de origem/ quebrando essa regra, destaca-se a Alcatel, que tem como principal país de depósito, a Alemanha.

Sendo assim, neste trabalho de pesquisa, para o levantamento de dados de patentes, a metodologia utilizada, já apresentada no capítulo 3, levou em consideração duas bases de dados, uma nacional, a do INPI (Instituto Nacional de Propriedade Intelectual) e outra internacional, a norte-americana USPTO (United States Patent and Trademark Office), em virtude da relevância dos EUA como destino de solicitações de patentes internacionais pelas companhias estudadas (Schmoch, 1996). A essas duas bases, foram feitas consultas sobre dados de depósito ou de concessão de patentes para as empresas fornecedoras de equipamentos de telecomunicações, que têm presença no Brasil.

As patentes das empresas selecionadas na área de telecomunicações são requeridas principalmente na seção de eletricidade, a seção $\mathrm{H}$, de acordo com a classificação internacional de patentes (IPC - International Patents Classification). O INPI utiliza esse sistema de classificação, enquanto o USPTO utiliza o sistema norte-americano, mas faz analogia entre suas classes e as da IPC, possibilitando assim, consultas através da classificação internacional. A classe 04 da seção H (Técnicas de Comunicação) é a mais relacionada a telecomunicações e, consequentemente, a que recebe o maior número de registro de patentes das empresas estudadas; em algumas 
delas (NEC e Nokia), 95\% das patentes regionais - solicitadas ao INPI - são classificadas na seção H04.

Essa classificação somente foi utilizada nas consultas gerais, nas buscas específicas com empresas, a menos que indicado, não foi utilizada, isso porque as companhias selecionadas para o estudo têm como principal - senão única - atividade, o fornecimento de equipamentos e sistemas para o setor de telecomunicações. A Siemens foi tratada em alguns momentos como exceção, já que é a empresa mais diversificada de todas as estudadas, atuando em diferentes segmentos além do de telecom.

É importante considerar que é mais comum o registro de copyright do que o registro de patentes para software, um dos principais nichos de produtos, do qual as subsidiárias brasileiras participam do desenvolvimento. Entretanto, no setor de telecomunicações, especialmente telefonia, é comum que eles sejam registrados como patentes porque são bastante relacionados às melhorias de hardware (Schmoch, 1996).

\subsubsection{Patentes Internacionais}

A consulta aos dados de patentes concedidas pelo USPTO foi feita nos dois períodos mencionados anteriormente: entre 1991 e 1995 e entre 1996 e 2000 . A flexibilidade na combinação de diferentes consultas possibilitou encontrar informações diversificadas e importantes para as análises.

Para mostrar a situação geral do Brasil na seção que engloba telecomunicações (seção $\mathrm{H}$ ), sem se preocupar com as empresas estudadas, verificou-se o número de patentes concedidas a ele como país inventor ou como país da empresa solicitante da patente. Os resultados, apresentados na tabela 8.1, não são animadores. Mostram que a participação do país, tanto como residência do inventor como local da empresa não é significativo. O número de patentes concedidas a empresas localizadas no país diminuiu $44 \%$ de um período para o outro, isso provavelmente foi influenciado pela privatização do sistema Telebrás. Por outro lado, houve um aumento de $65 \%$ no 
número de patentes que tenham pelo menos um inventor residente no Brasil.

\begin{tabular}{ccc}
\cline { 2 - 3 } & $1991-1995$ & $1996-2000$ \\
\hline Brasil & & \\
Empresa & 16 & 9 \\
Inventor & 26 & 43 \\
\hline Índia & & \\
Empresa & 1 & 11 \\
Inventor & 22 & 74 \\
\hline Israel & & \\
Empresa & 150 & 394 \\
Inventor & 331 & $\mathbf{8 1 0}$ \\
\hline China & & \\
Empresa & 31 & 39 \\
Inventor & 61 & 117 \\
\hline
\end{tabular}

Tabela 8.1 - Patentes concedidas a empresas e inventores residentes em cada país - Seção H. (Fonte: USPTO)

Em números absolutos a quantidade de patentes é extremamente pequena, e a situação se agrava quando comparado com os outros países em desenvolvimento como Índia, Israel e China. Se comparado com a Índia, o Brasil tinha uma posição ligeiramente melhor no primeiro período, mas no segundo, aquele país teve um aumento bastante significativo tanto para empresas como para inventores, o que aconteceu também com os outros dois países.

A situação privilegiada fica com Israel, que tem um número de patentes registradas muito mais expressivo do que os outros. No entanto, está claro que tal país tem uma situação privilegiada (em relação aos demais países considerados) pela sua própria história e pelas suas relações com os EUA. De qualquer forma, para os três países, os números apresentados são muito pequenos para representar uma seção inteira. Qualquer uma das empresas estudadas supera o número apresentado por esses países, especialmente no segundo período (tabela 8.2).

É importante diferenciar a participação do inventor ou da subsidiária no desenvolvimento que originou a patente. Se houver participação de inventor local e a patente não for requerida pela sua respectiva unidade, isso pode significar que o 
grupo de pesquisa da subsidiária não está envolvido com a pesquisa, ou seja, a pesquisa provavelmente foi desenvolvida fora dela. Uma outra possibilidade a ser considerada quando isso acontece é que a subsidiária pode não ter autonomia ou 'poder' para confrontar a matriz e solicitar a patente internacional. Portanto, quando possível, vale a pena separar os dados entre subsidiária e inventor.

Uma consulta mais específica foi feita à base do USPTO através do nome de cada uma das empresas e dos seus países. Assim, qualquer pedido que foi solicitado pela subsidiária e não pela matriz é prontamente encontrado. O resultado é apresentado na tabela 8.2 e mostra claramente que as subsidiárias dos países estudados, talvez por algum dos motivos citados anteriormente, não apresentam patentes registradas no USPTO em seus nomes, com exceção da subsidiária indiana da NEC, que possui uma patente registrada. Mais uma vez, os resultados se repetem. Israel se destaca e o Brasil tem a pior atuação dentre eles. Apenas duas patentes concedidas tiveram participação de inventores brasileiros, uma da Ericsson e outra da Lucent.

Israel tem o resultado mais expressivo, mas apenas nas patentes em conjunto com as norte-americanas Lucent e Motorola, além disso, as unidades localizadas naquele país não tiveram nenhuma das patentes requerida em seus nomes. Por outro lado, 2,0\% das patentes concedidas à Motorola no segundo período tiveram a participação de pesquisadores de Israel e esse número é bastante significativo.

Para mostrar que os resultados apresentados para cada um dos países listados na tabela 8.1 são realmente baixos, uma outra análise foi feita para outras subsidiárias e para as matrizes. Uma limitação para essa busca é a impossibilidade de procurar EUA como país na base do USPTO. Assim, para as duas empresas norte americanas não foram encontrados dados e o mesmo acontece para as subsidiárias das outras empresas localizadas nos EUA.

Seriam informações úteis, já que as subsidiárias americanas estão entre as que mais desenvolvem produtos para todas as empresas estudadas, mas para o propósito de comparar com os países acima listados, os resultados mostrados, que compreendem o período de 1996 a 2000, são suficientes. A tabela 8.3 mostra a porcentagem de patentes concedidas à matriz e a algumas das subsidiárias com maior participação. 


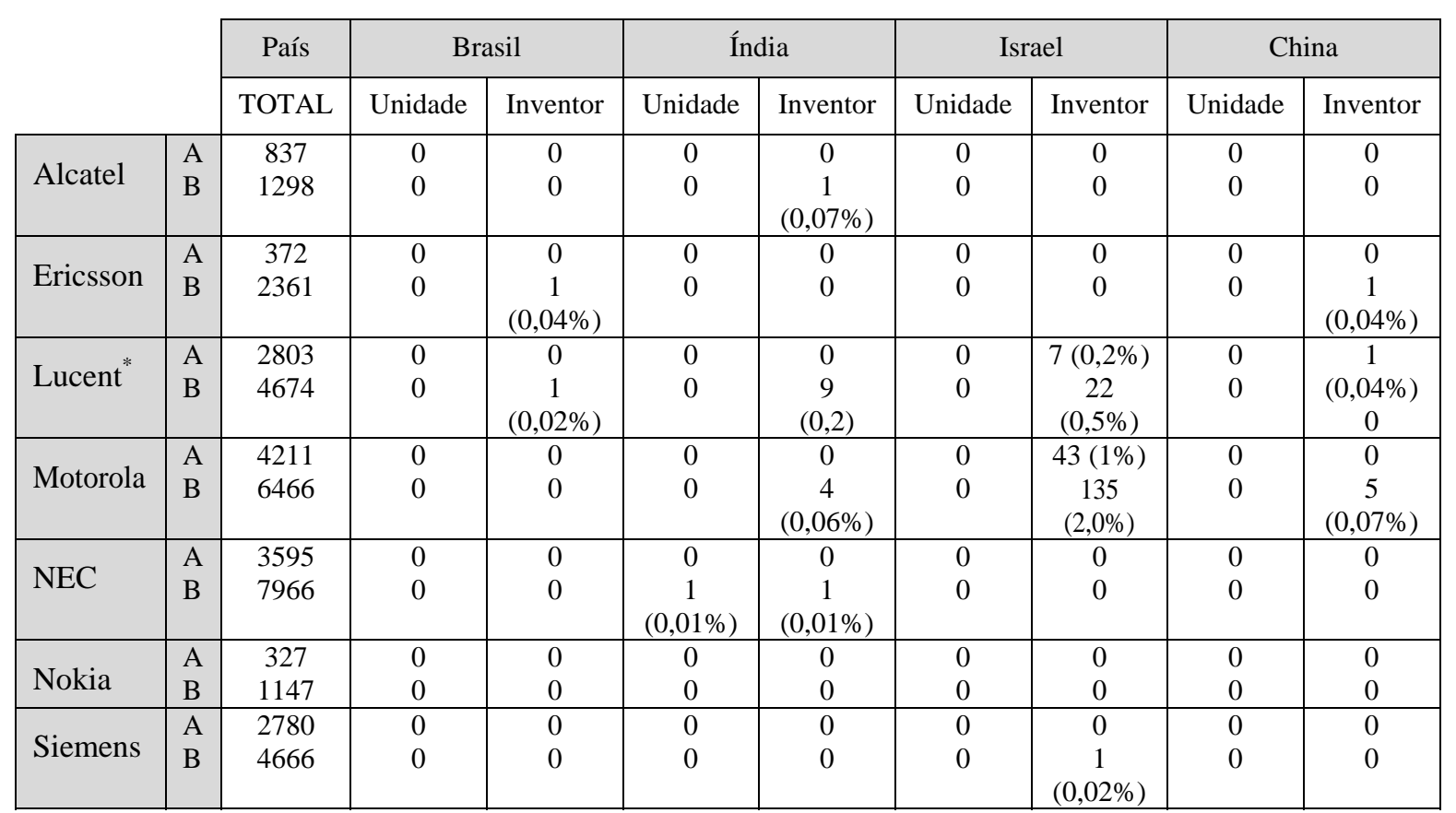

A - 1991 a 1995; B - 1996 a 2000

* AT\&T no primeiro período (A)

Tabela 8.2 - Patentes concedidas às empresas estudadas - participação dos países selecionados através do número de patentes por subsidiárias (unidades) e por inventores (Fonte: USPTO)

\begin{tabular}{|l|c|c|c|c|}
\hline \multicolumn{1}{|c|}{ Empresa } & Matriz & Alemanha & Suíça & Outras \\
\hline Alcatel & $53 \%$ & $4 \%$ & $0,4 \%$ & Holanda: $22 \%$ \\
\hline Ericsson & $57 \%$ & $0,04 \%$ & $0,03 \%$ & Japão: 0,04\% \\
\hline NEC & $97 \%$ & $0 \%$ & $0 \%$ & França: $0,06 \%$ \\
\hline Nokia & $94 \%$ & $4 \%$ & $0,2 \%$ & Japão: $0,2 \%$ \\
\hline Siemens & $73 \%$ & - & $0,2 \%$ & Suécia: $2,1 \%$ \\
\hline
\end{tabular}

Tabela 8.3 - Patentes concedidas à matriz e a algumas subsidiárias no período de 1996 a 2000 (Fonte: USPTO)

A maioria absoluta das requisições de patentes em todas as empresas é em nome da matriz. Em algumas delas quase a totalidade das patentes é garantida à matriz, é o caso da NEC, seguida pela Nokia, cujas matrizes possuem respectivamente $97 \%$ e 94\% de todas as patentes solicitadas pelas empresas ao USPTO.

Das patentes solicitadas pela Nokia, a Alemanha possui a maior participação, fica com $4 \%$ do total, o que representa $70 \%$ das patentes concedidas às subsidiárias da empresa. É bastante provável que exista uma participação expressiva das subsidiárias 
norte americanas, pelo menos nos estudos de casos com a empresa, fica claro que as unidades dos EUA participam ativamente de várias pesquisas importantes para a companhia.

A participação das unidades norte americanas deve ser mais intensa ainda na NEC. Um indício para esse fato, é que a subsidiária americana da companhia tem patentes requeridas em seu nome no Brasil, como pode ser visto na próxima seção deste capítulo.

Ainda segundo os dados apresentados na tabela 8.3, a Alemanha participa ativamente em duas empresas especificamente: Alcatel e Nokia. Em compensação, a alemã Siemens possui razoável participação das subsidiárias suecas. Um dado bastante surpreendente é a participação de $22 \%$ das subsidiárias holandesas da Alcatel. Esse número é muito significativo e mostra que $47 \%$ das patentes concedidas às subsidiárias da empresa são da Holanda.

Comparando então os números dessas subsidiárias com os das unidades instaladas no Brasil, Índia, Israel e China, temos um quadro muito pessimista. Como dito, a única subsidiária desses quatro países a ter patente em seu nome é a indiana da NEC, e isso representa apenas $0,01 \%$ das patentes dessa empresa.

Para ficar mais clara a comparação entre as subsidiárias dos países em desenvolvimento escolhidos e as dos países desenvolvidos (fora EUA) que participam mais ativamente da requisição de patentes ao USPTO, vale analisar a tabela 8.4, que mostra o percentual de participação dos inventores dessas unidades.

\begin{tabular}{|l|c|c|c|c|}
\hline \multicolumn{1}{|c|}{ Empresa } & Matriz & Alemanha & Suíça & Outras \\
\hline Alcatel & $44 \%$ & $22 \%$ & $0,8 \%$ & $\begin{array}{c}\text { Holanda: } 0,6 \% \\
\text { Bélgica: } 8 \%\end{array}$ \\
\hline Ericsson & $52 \%$ & $2 \%$ & $0,2 \%$ & Japão: $0,4 \%$ \\
\hline NEC & $97 \%$ & $0,03 \%$ & $0,01 \%$ & França: 0 \\
\hline Nokia & $71 \%$ & $4 \%$ & $0,03 \%$ & Japão: $0,7 \%$ \\
\hline Siemens & $68 \%$ & - & $0,6 \%$ & Suécia: $2,1 \%$ \\
\hline
\end{tabular}

Tabela 8.4 - Participação de inventores das patentes concedidas à matriz e a algumas subsidiárias no período de 1996 a 2000 (Fonte: USPTO)

Esses dados mostram que a participação dos inventores das matrizes é inferior ao 
número de patentes registradas em nome delas. A maior diferença fica com a Nokia cuja matriz registra $94 \%$ das patentes, mas apenas $71 \%$ das patentes têm inventores residentes na Finlândia.

Sendo assim, está claro que as subsidiárias participam mais como 'inventores' do que como 'detentores' das patentes. Um dado curioso é a subsidiária holandesa da Alcatel, que com apenas $0,6 \%$ de participação de inventores locais, registra $22 \%$ das patentes da companhia. A subsidiária na Bélgica da mesma empresa está entre as que mais colaboram com inventores $(8 \%)$, mas detém apenas uma patente.

\subsubsection{Patentes Domésticas}

As consultas regionais à base de dados do INPI também compreendem dois períodos, mas se limitam aos intervalos de 1992 a 1995 e de 1996 a 2000, porque os dados disponibilizados online pelo INPI começam em 1992.

No entanto, isso não interfere nos resultados porque independentemente de se comparar períodos de 4 ou 5 anos, o aumento no número de requisições de patentes no segundo período foi muito significativo (tabela 8.5), isso porque, após a privatização da Telebrás, o setor teve crescimento acentuado e novas tecnologias começaram a ser comercializadas no país.

\begin{tabular}{ccc}
\cline { 2 - 3 } & $\mathbf{1 9 9 2 - \mathbf { 1 9 9 5 }}$ & $\mathbf{1 9 9 6 - \mathbf { 2 0 0 0 }}$ \\
\hline Alcatel & 24 & 102 \\
Ericsson & 144 & 1275 \\
Lucent $^{*}$ & 30 & 308 \\
Motorola & 305 & 798 \\
NEC & 39 & 158 \\
Nokia & 17 & 221 \\
Siemens & 289 & 568 \\
\hline * AT\&T no período de 1992 a 1995 \\
\hline
\end{tabular}

Tabela 8.5 - Solicitação de patentes regionais pelas empresas estudadas (Fonte: INPI)

Em ambos os períodos, o número de patentes solicitadas pelas empresas estudadas 
varia bastante entre elas. Há diferenças enormes de um período para outro. Vale destacar que participaram da consulta tanto as patentes requeridas quanto as patentes concedidas pelo INPI nos respectivos períodos.

A flexibilidade de busca nessa base (INPI) é menor se comparada à da USPTO, mas isso não prejudica o trabalho e a análise dos resultados. Uma das limitações de consulta é com relação ao endereço do inventor ou das empresas solicitantes de patentes. Não é possível fazer esse tipo de busca na base do INPI, para esses campos há apenas a possibilidade de consulta pelo nome. Dessa forma, como é praticamente impossível associar os nomes dos inventores de cada produto em cada empresa aos seus respectivos países, não se conhece a participação dos inventores brasileiros, ou de qualquer outro país com patente registrada pelo instituto.

Essa dificuldade é menor quando se trata da consulta à localização das empresas porque é mais fácil encontrar os nomes das subsiárias locais. Assim, buscou-se, para cada empresa, a participação de cada uma das suas subsidiárias brasileiras.

A tabela 8.6 mostra os resultados da participação das unidades brasileiras. Como o número de patentes na base regional é bastante superior ao número na USPTO, mostra-se aqui apenas os percentuais de participação. A partir desses dados é possível verificar que o número de patentes solicitadas em nome das subsidiárias brasileiras é, claro, maior do que na base do USPTO, mas ainda assim, é pouco expressivo.

Muitas outras subsidiárias das companhias superam a participação das unidades nacionais, por exemplo, a subsidiária norte-americana da Ericsson possui 9,7\% de participação no primeiro período (A), e a unidade Brasil tem 3,5\%. No período B os resultados são piores, o número da unidade local caiu para $0,6 \%$ e da norteamericana subiu para 33\%. É provável que esse aumento muito acentuado dos EUA seja em função dos produtos relacionados à tecnologia utilizada em telefonia digital no país (Banda A) que, na Ericsson, fica sob responsabilidade das unidades nos EUA (Dias e Galina, 2000).

Um outro dado interessante sobre a base de dados do INPI é relacionado ao país 
prioridade da patente requerida, ou seja, em que país a patente foi pedida primeiramente. Na seção H, 4480 patentes dão prioridade aos Estados Unidos. Isso é um indício de que as patentes requeridas regionalmente para tal seção são provavelmente patentes de produtos para o mercado mundial.

\begin{tabular}{|c|c|c|c|c|}
\hline & & Matriz & Brasil & Outras \\
\hline Alcatel & $\begin{array}{l}\mathbf{A} \\
\mathbf{B}\end{array}$ & $\begin{array}{l}96 \% \\
95 \%\end{array}$ & $\begin{array}{l}4 \% \\
0 \%\end{array}$ & $\begin{array}{c}- \\
\text { EUA: } 5 \%\end{array}$ \\
\hline Ericsson & $\begin{array}{l}\mathbf{A} \\
\mathbf{B}\end{array}$ & $\begin{array}{l}83 \% \\
65 \%\end{array}$ & $\begin{array}{l}3,5 \% \\
0,4 \%\end{array}$ & $\begin{array}{l}\text { EUA: } 9,7 \% \\
\text { EUA: } 33 \%\end{array}$ \\
\hline Lucent $^{*}$ & $\begin{array}{l}\mathbf{A} \\
\mathbf{B}\end{array}$ & $\begin{array}{l}100 \% \\
100 \%\end{array}$ & $\begin{array}{l}0 \% \\
0 \%\end{array}$ & $\begin{array}{l}- \\
-\end{array}$ \\
\hline Motorola & $\begin{array}{l}\text { A } \\
\text { B }\end{array}$ & $\begin{array}{l}99,3 \% \\
98,6 \%\end{array}$ & $\begin{array}{l}0 \% \\
0 \%\end{array}$ & $\begin{array}{c}\text { Reino Unido: } \\
0,7 \% \\
\text { Reino Unido: } 1 \% \\
\text { Israel: } 0,4 \%\end{array}$ \\
\hline NEC & $\begin{array}{l}\mathbf{A} \\
\mathbf{B}\end{array}$ & $\begin{array}{c}38,5 \% \\
81 \%\end{array}$ & $\begin{array}{l}46 \% \\
11 \%\end{array}$ & - \\
\hline Nokia & $\begin{array}{l}\mathbf{A} \\
\mathbf{B}\end{array}$ & $\begin{array}{l}100 \% \\
100 \%\end{array}$ & $\begin{array}{l}0 \% \\
0 \%\end{array}$ & - \\
\hline Siemens & $\begin{array}{l}\text { A } \\
\text { B }\end{array}$ & $\begin{array}{l}88 \% \\
70 \%\end{array}$ & $\begin{array}{l}6,6 \% \\
4,5 \%\end{array}$ & $\begin{array}{l}\text { Japão: } 0,6 \% \\
\text { Japão: } 1,6 \% \\
\text { EUA: } 1,5 \% \\
\end{array}$ \\
\hline
\end{tabular}

Tabela 8.6 - Patentes concedidas à matriz, à subsidiária brasileira e a outras subsidiárias (Fonte: INPI)

\subsection{Dados Bibliométricos}

Dados bibliométricos são usados, em termos gerais, como indicadores do posicionamento do país em termos de publicações científicas relevantes. Geralmente, quando se comparam diferentes regiões, a coleta de dados é feita em diversas bases, o que possibilita abranger um número maior de periódicos significativos e generalizar as áreas temáticas. É importante, antes de analisar os dados coletados, entender o posicionamento do Brasil em relação aos outros países estudados aqui. Duas fontes foram escolhidas para isso.

A primeira delas é regional e compreende indicadores de ciência e tecnologia Iberoamericanos e interamericanos. Foi desenvolvida pela Red Iberoamericana de 
Indicadores de Ciencia y Tecnología do programa Iberoamericano de Ciencia y Tecnología para el Desarrollo com o apoio da Organização dos Estados Americanos (RICYT/CYTED/OEA, 1998). Nesse material, são apresentados dois dos indicadores relacionados a dados bibliométricos:

- Publicações em bases de dados multidisciplinares, usando as bases SCI, PASCAL e ICYT; e

- Publicações em bases temáticas, usando as bases INSPEC (Physics Index), COMPENDEX (Engineering Index) e CA (Chemical Abstracts)

De acordo com esses indicadores, referentes aos anos de 1996 e 1997, em geral, o Brasil tem a melhor posição entre os países latino americanos, seguido por México e Argentina. Mas, é bom salientar que, se somados os resultados dos três países, em qualquer uma das bases utilizadas, não se chega ao resultado da Espanha, e muitas vezes, o mesmo acontece se somarmos todas as publicações da América Latina e Caribe. Portanto, os resultados não são animadores.

Mas, o próprio material enfatiza que as bases de dados internacionais para indicadores bibliométricos não cobrem a maior parte da produção científica iberoamericana. Ainda de acordo com ele, o SCI reconhece menos de 1\% das revistas cientificas dessa região.

A segunda fonte geral de dados é o Science and Engineering Indicators, publicado pela NATIONAL SCIENCE FOUNDATION, NSF (2000) e que trabalha com diferentes bases (ISI/SCI, CHI Research Inc. /Science Indicators), além dos dados coletados pela própria fundação. A tabela 8.7 mostra, na área de ciência e engenharia, os dados dos países estudados, do México e da Argentina, que possuem, juntos com o Brasil, os melhores índices bibliométricos da América Latina. Como se observa nessa base, a produção científica no Brasil é superior quando comparada com os outros dois países latino americanos, confirmando portanto, a supremacia citada pelos indicadores do RICYT apresentados anteriormente. Mas a produção bibliométrica nacional fica aquém da produção dos outros países. 
mesmo, a própria empresa. Dessa forma é possível encontrar pesquisas científicas realizadas em conjunto entre as empresas estudadas e cada um dos países.

A primeira informação que pode ser tirada desse conjunto de dados é o número superior de publicações feitas pela Lucent (ou no período A pela AT\&T) quando comparadas às de outras empresas. Com exceção do número de artigos publicados pela NEC em conjunto com a Índia no período B, todos os números são superiores. Isso é particularmente interessante quando se trata de artigos publicados em conjunto com Israel, que, apesar de ter diminuído consideravelmente (48\%) do período A para o período B, é absolutamente superior aos demais. Também a Lucent mostra um comportamento interessante, ela diminuiu a participação com todos os países, exceto com o Brasil, que permaneceu a mesma, e com a Índia, que aumentou $40 \%$.

A AT\&T/Lucent diferentemente do que mostra na tabela, teve aumento no número de publicações, sendo que, quando somados os artigos da Lucent e da AT\&T no período B, o total é 8637. Apenas a Siemens diminuiu o número de publicações de um período para outro. Todas as demais empresas o aumentaram, o aumento mais significativo $(69 \%)$ foi da Nokia, apesar de ainda ser a que tem o menor número de publicações, tem em ambos os períodos. Fazendo frente a ela, fica a Lucent, que também tem em ambos os períodos, mas é a empresa que mais publicou.

Um dado interessante é que a Motorola, a NEC e a Siemens aumentaram significativamente o envolvimento com a Índia. A Motorola ainda aumentou também com o Brasil e China e diminuiu com o México. A Siemens diminuiu com Israel e aumentou também com a China e a NEC aumentou em todos os países, exceto na Argentina.

Em números absolutos, os três países da América Latina ocupam uma posição visivelmente inferior se comparados com os outros três países e o Brasil tem uma ligeira vantagem na região. Mas, em termos gerais, a publicação conjunta entre o Brasil e as empresas é muito pequena se comparada com o número total de publicações das empresas. O maior número de artigos (19) também representa a maior participação brasileira em relação ao total publicado pela empresa $(0,4 \%)$, trata-se da Lucent. 
Analisando especificamente as publicações do Brasil no último período (1996 a 2000), foram encontrados 32 artigos publicados em conjunto com as empresas selecionadas, indicando aumento de $33 \%$ em relação às publicações do período anterior (24). Para se ter uma idéia, o CPqD, mais importante centro de pesquisa na área antes da privatização da Telebrás, teve 22 publicações de 1992 a 1995 e 28 artigos de 1996 a 2000.

O aumento no número de publicações se torna mais interessante quando comparamos com os dados apresentados na tabela 8.7, que mostra, em termos gerais a participação mundial do Brasil em ciência e engenharia em três períodos diferentes, quando houve aumentos em torno de $20 \%$ em cada período.

Sendo assim, um aumento de $33 \%$ como o que ocorreu com as publicações em conjunto com as empresas do setor de telecomunicações é significativo e mostra mudanças de comportamento. Uma provável justificativa para isso é a condição imposta pela lei de informática, que, em troca do benefício, as empresas devem obrigatoriamente realizar pesquisas em conjunto com centros de pesquisa ou universidades no Brasil. Isso provavelmente obrigou as empresas a procurarem por parcerias.

A tabela 8.9 mostra as unidades envolvidas em cada companhia e as empresas e instituições brasileiras que formam os grupos de pesquisa. A maioria dos artigos é feita em co-autoria com as matrizes, apenas um tem participação da subsidiária brasileira (Siemens), um outro tem envolvimento da matriz e de uma outra unidade (unidade dinamarquesa da Lucent) e um terceiro, uma subsidiária estrangeira (unidade belga da Alcatel).

A diversidade de instituições brasileiras é grande pelo número relativamente pequeno de publicações apresentadas, mas ainda assim, concentrado em alguns estados, principalmente da região Sudeste e Sul. São, ao todo, para os 32 artigos, 14 universidades (entre elas duas não públicas), 1 instituto de pesquisa e 2 empresas. 


\begin{tabular}{|c|c|c|}
\hline Empresa & Local da Unidade & Instituição Brasileira \\
\hline Alcatel & $\begin{array}{l}\text { Bélgica } \\
\text { França (Matriz) }\end{array}$ & $\begin{array}{l}\text { PUC - RS } \\
\text { Univ. Est. de Londrina }\end{array}$ \\
\hline Ericsson & Suécia (Matriz) & PUC - RJ \\
\hline Lucent & $\begin{array}{l}\text { USA (Matriz) } \\
\text { Dinamarca }\end{array}$ & $\begin{array}{l}\text { ABC Opto Systems - SP } \\
\text { Inst. Tecnológico de Barretos - SP } \\
\text { Observatório nacional - RJ } \\
\text { PUC - RJ } \\
\text { UFMG } \\
\text { UFRGS } \\
\text { UFSCar } \\
\text { UnB } \\
\text { Unicamp } \\
\text { Universidade Federal do Amazonas } \\
\text { Univ. São Francisco - Bragança. Paul./SP }\end{array}$ \\
\hline Motorola & USA (Matriz) & $\begin{array}{l}\text { UFRGS } \\
\text { Unicamp }\end{array}$ \\
\hline NEC & USA & $\begin{array}{l}\text { Unicamp } \\
\text { USP }\end{array}$ \\
\hline Siemens & $\begin{array}{l}\text { Alemanha (Matriz) } \\
\text { São Paulo - Brasil }\end{array}$ & $\begin{array}{l}\text { Proj. Elétrico Serv. Ltda - SP } \\
\text { UFRN } \\
\text { Universidade Federal Fluminense }\end{array}$ \\
\hline
\end{tabular}

Tabela 8.9 - Unidades das empresas e instituições brasileiras com artigos publicados em conjunto no período de 1996 a 2000 (Fonte: SCI)

\subsection{Síntese e Análise dos Resultados Quantitativos Obtidos}

Através desses resultados quantitativos, é possível concluir que as subsidiárias brasileiras são muito pouco atuantes. As informações apresentados tanto para dados 
bibliométricos, quanto, e principalmente, para dados de concessão de patentes nacionais ou internacionais - são absolutamente desfavoráveis às subsidiárias locais. Esses indicadores de C\&T não comprovam, portanto, que a participação das empresas verificadas pelo estudo qualitativo esteja surtindo o efeito esperado, ou seja, há uma diferença entre o que os casos mostram e o que os resultados quantitativos sugerem.

Os casos apresentam uma tendência mais favorável ao envolvimento brasileiro, todas as empresas entrevistadas possuem unidades de desenvolvimento interno e também parcerias com universidades e centros de pesquisa nacionais. Um outro dado importante que comprova, não apenas que há pesquisa nas subsidiárias, mas também que há envolvimento das empresas com centros de pesquisa localizados no Brasil, foi formulado pelo Ministério de Ciência e Tecnologia (MCT, 2000) e apresentado no capítulo 6.

No entanto, esses estudos de caso também mostram que as subsidiárias estão mais envolvidas com a adaptação de produtos globais ao mercado local ou regional. Além disso, as participações locais acontecem em alguns nichos de produtos.

Os dados quantitativos são bem mais pessimistas e comprovam que, se há participação das subsidiárias locais como os estudos de casos mostram, ela não parece significativa segundo os indicadores utilizados.

O pior resultado foi apresentado pelos dados do USPTO, nos quais a participação das subsidiárias brasileiras é nula e dos inventores brasileiros ligados às empresas estudadas é muito pequena. Se esses dados forem comparados com os de outros países em desenvolvimento como Índia, China e Israel, a situação do Brasil é ainda mais desfavorável, tanto em participação de subsidiárias das TNC e inventores quanto em quantidade geral de patentes no setor de telecomunicações. Segundo os indicadores usados, a melhor posição fica com Israel.

Quando a base estudada é a regional, ou seja do INPI, a participação das unidades locais das companhias é um pouco melhor, mas, em geral, caiu nos últimos anos. Assim como se comportou a participação das matrizes das empresas, mostrando que 
o desenvolvimento de produtos deve estar se descentralizando para as subsidiárias (mas não para as brasileiras). Um fato interessante é o aumento ocorrido na participação das unidades norte-americanas.

Uma outra informação importante encontrada é a de que a maioria absoluta dos produtos da área de telecomunicações (seção H) patenteados localmente não tem o Brasil como país prioridade, isso mostra que os produtos fabricados e comercializados aqui são globais. E ainda, se for combinada essa informação com os dados das subsidiárias brasileiras como empresas 'detentoras' das patentes, é possível concluir que a participação nacional no desenvolvimento global de produtos não é grande.

De modo geral, os dados referentes a patentes internacionais e nacionais mostram que a participação das subsidiárias brasileiras é insignificante. Esse resultado é contraditório quando confrontado com informações dos estudos de casos realizados e com relatórios do MCT. Esse é um indicador de que a pesquisa realizada localmente possa estar gerando produtos não patenteáveis - especialmente em mercados internacionais - devido ao seu baixo conteúdo tecnológico.

Ao serem questionadas sobre o porque do número tão baixo em patentes, as empresas apresentam algumas justificativas, entre elas, destaca-se a falta de cultura das equipes brasileiras em patentear. A maioria delas também cita que a matriz não pressiona os grupos locais por busca de patentes, e que não há um programa específico para orientar ou estimular essa busca.

Algumas companhias também citam que se houver qualquer projeto patenteável, ele é imediatamente encaminhado para o departamento mundial da companhia que trata dos aspectos jurídicos e burocráticos do processo de patente. No entanto, mesmo que essa política seja adotada pelas companhias, os nomes dos inventores brasileiros deveriam ser mencionados na patente.

O melhor resultado das subsidiárias brasileiras foi conseguido no indicador bibliométrico, ainda assim, é inferior aos apresentados pelos outros três países (Índia, Israel e China). Esse resultado um pouco mais otimista pode ter sido influenciado 
pela lei de informática, da qual todas as empresas são beneficiárias, que obriga a parceria entre companhias e centros de pesquisa ou universidades localizados no Brasil.

Também foram levantados os dados bibliométricos do México e da Argentina, e o Brasil obteve o melhor resultado entre eles, se é que isso justifica o baixo desempenho, já que, em geral, a participação dos três não é relevante em termos mundiais como foi mostrado anteriormente. Esse indicador mostra ainda que o envolvimento das subsidiárias locais na publicação científica é nulo, sobressaem as matrizes, mas que a participação de institutos de pesquisa nacionais é diversificada, apesar do pequeno número de artigos.

Sendo assim, realmente os indicadores de C\&T levantados aqui não apresentam resultados favoráveis à participação do Brasil no setor de telecomunicações. No entanto, vale destacar que esses indicadores são utilizados para mensuração de resultados de C\&T, mas que possuem limitações e não demostram ao certo, se as subsidiárias das companhias estão realmente envolvidas no desenvolvimento de produtos e, principalmente, se esse envolvimento está sendo relevante para o crescimento das equipes locais e para o desenvolvimento tecnológico do país. Informações como essas só podem ser levantadas com a combinação de indicadores e estudos qualitativos, o que é também apresentado neste trabalho de doutorado. 


\subsection{Análise de Dados Secundários}

\subsubsection{PINTEC}

Alguns dos indicadores levantados pela PINTEC (PINTEC/IBGE, 2002) são tratados aqui para melhor analisar as empresas fabricantes de equipamentos o setor de telecomunicações. A PINTEC levantou indicadores nacionais das atividades de inovação tecnológica desenvolvidas nas empresas industriais brasileiras, obtidos a partir do novo modelo de produção de estatísticas econômicas que contempla a realização de pesquisas que investigam temas específicos, articuladas com as demais pesquisas estruturais da Instituição. Os resultados dessa primeira pesquisa referem-se ao universo das empresas industriais com dez ou mais pessoas ocupadas.

Abrangem informações sobre o número de empresas que implementaram inovações tecnológicas de produtos e/ou processos; esforços empreendidos para inovar; impactos causados e grau de importância das inovações; fontes de informação utilizadas; relações de cooperação com outras organizações; problemas e obstáculos apontados para a implementação ou não de inovações, além de informações sobre as mudanças estratégicas e organizacionais observadas nessas empresas. A construção desses indicadores foi baseada em padrões metodológicos internacionais como o Manual de Oslo (OECD, 1997).

De acordo com a PINTEC, a maioria das variáveis qualitativas refere-se a um período de três anos consecutivos, de 1998 a 2000. Por exemplo, as inovações de produtos e/ou processos referem-se àquelas implementadas nestes três anos. As variáveis quantitativas (gastos e pessoal ocupado em P\&D, dispêndios em outras atividades inovativas, exportações, etc.) e algumas variáveis qualitativas (existência de projetos incompletos, por exemplo) referem-se ao último ano do período da pesquisa (2000).

A classificação de atividades de referência da PINTEC é a Classificação Nacional de Atividades Econômicas - CNAE, particularmente, as seções Indústrias Extrativas e Indústrias de Transformação, que definem o âmbito da pesquisa. Sendo assim, as 
empresas fornecedoras de equipamentos no setor de telecomunicações são contempladas com a classificação CNAE: divisão 32, grupo 32.2, que se refere a "fabricação de aparelhos e equipamentos de comunicações". Todas as empresas consideradas para os estudos de caso aqui apresentados são classificadas neste grupo CNAE. Com exceção da Nokia, as outras seis empresas estudadas fazem parte da amostra considerada na PINTEC.

Os problemas dessa amostra é que na seção 32.2 entram também empresas que atuam com fabricação de aparelhos e equipamentos de telefonia e radiotelefonia, e de transmissores de televisão e rádio, ou seja, a base consultada tem uma série de empresas que não atuam diretamente com telefonia, objeto de estudo desta tese. A tabela 8.10 mostra os principais dados analisados e resultados obtidos.

O total das empresas estudadas pela pesquisa foi de 72.005 , sendo que, destas, 22.698, ou 31,5\% delas, implementaram inovações em produtos e/ou processos. Esse índice sobe para $62,1 \%$ entre as companhias fabricantes de aparelhos e equipamentos de comunicações (185 implementaram inovação de um total de 298 empresas do segmento estudadas), mostrando que o segmento de equipamentos de telecomunicações é mais inovador que a média dos demais estudados. Na verdade, esse segmento fica em terceiro lugar entre os inovadores, atrás de empresas "fabricantes de máquinas para escritórios e equipamentos de informática" (divisão 30 da CNAE), com 68,5\% de inovação e de "fabricantes de material eletrônico básico" (grupo 32.1 da CNAE), cujo índice foi de $62,9 \%$.

Das inovações realizadas pelas empresas do segmento de equipamentos de comunicações, $78,3 \%$ implementaram inovações em produto, dos quais apenas $28,3 \%$ foram novos para o mercado nacional. O índice de implementação de inovações em processos entre as mesmas empresas foi de 61,6\%. Esses indicadores são bastante diferentes do total geral do estudo (toda a amostra), que apresenta 55,7\% de inovações sendo implementadas em produtos (sendo que 23,5\% foram inovadores para o mercado nacional) e $80 \%$ em processos. 


\begin{tabular}{|c|c|c|}
\hline Perfil das Empresas & $\begin{array}{l}\text { Média } \\
\text { da Base }\end{array}$ & $\begin{array}{c}\text { Média } \\
\text { do Grupo* }\end{array}$ \\
\hline $\mathrm{N}^{\mathrm{o}}$ Total de Empresas & 72.005 & 298 \\
\hline $\mathrm{N}^{\mathrm{o}}$ de Empresas que implementaram inovações & 22.698 & 185 \\
\hline Taxa de Inovação (\%) (Nº empresas inovadoras / total empresas) & 31,5 & 62,1 \\
\hline Faturamento Bruto - Média por empresa $(\mathrm{R} \$)$ & 8.088 .412 & 70.105 .469 \\
\hline $\mathrm{N}^{\mathrm{o}}$ de Pessoas ocupadas - média por empresa & 69 & 191 \\
\hline Produtividade por funcionário $(\mathrm{R} \$)\left(\mathrm{N}^{\circ}\right.$ pessoas / faturamento $)$ & 117.223 & 367.044 \\
\hline \multicolumn{3}{|l|}{ Intensidade da Inovação (Dispêndios) } \\
\hline Dispêndio em atividades inovativas - média por empresa $(\mathrm{R} \$)$ & 1.165 .862 & 6.220 .970 \\
\hline Dispêndio em atividades internas de P\&D - média por empresa (R\$) & 504.799 & 3.316 .072 \\
\hline Dispêndios com treinamento - média por empresa $(\mathrm{R} \$)$ & 60.917 & 303.096 \\
\hline $\begin{array}{l}\text { Dispêndio com introdução de inovação no mercado - média por } \\
\text { empresa (R\$) }\end{array}$ & 248.254 & 480.426 \\
\hline $\begin{array}{l}\text { Dispêndio com projetos industriais e outras preparações técnicas - } \\
\text { média por empresa }(\mathrm{R} \$)\end{array}$ & 404.838 & 1.140 .770 \\
\hline Dispêndio Aquisição externa de P\&D - média por empresa (R\$) & 378.140 & 2.609.230 \\
\hline $\begin{array}{l}\text { Dispêndio com aquisição de outros conhecimentos externos - média por } \\
\text { empresa (R\$) }\end{array}$ & 400.898 & 1.792 .238 \\
\hline $\begin{array}{l}\text { Dispêndio com aquisição de máquinas e equipamentos - média por } \\
\text { empresa (R\$) }\end{array}$ & 750.794 & 2.905 .817 \\
\hline $\begin{array}{l}\text { Taxa de Dispêndio - incidência dos gastos em atividades inovativas } \\
\text { sobre receita de vendas }\end{array}$ & $3,8 \%$ & $5 \%$ \\
\hline $\begin{array}{l}\text { Taxa de Dispêndio - incidência dos gastos em atividades internas de } \\
\text { P\&D sobre receita de vendas }\end{array}$ & $0,64 \%$ & $1,75 \%$ \\
\hline \multicolumn{3}{|l|}{ Intensidade da Inovação Tecnológica: Recursos Humanos } \\
\hline Pessoas Ocupadas $-\mathrm{n}^{\circ}$ médio por empresa & 69 & 191 \\
\hline Pessoas Ocupadas em P\&D - no médio por empresa & 5,6 & 19 \\
\hline Pessoas Ocupadas em P\&D - Pós-graduadas (\% total funcion. em P\&D) & $7,1 \%$ & $6,9 \%$ \\
\hline Pessoas Ocupadas em P\&D - Graduadas (\% total funcion. em P\&D) & $41,4 \%$ & $56,9 \%$ \\
\hline Pessoas Ocupadas em P\&D - Nível Médio (\% total funcion. em P\&D) & $35,9 \%$ & $22 \%$ \\
\hline Pessoas Ocupadas em P\&D - Outros (\% total funcion. em P\&D) & $15,6 \%$ & $14,2 \%$ \\
\hline
\end{tabular}




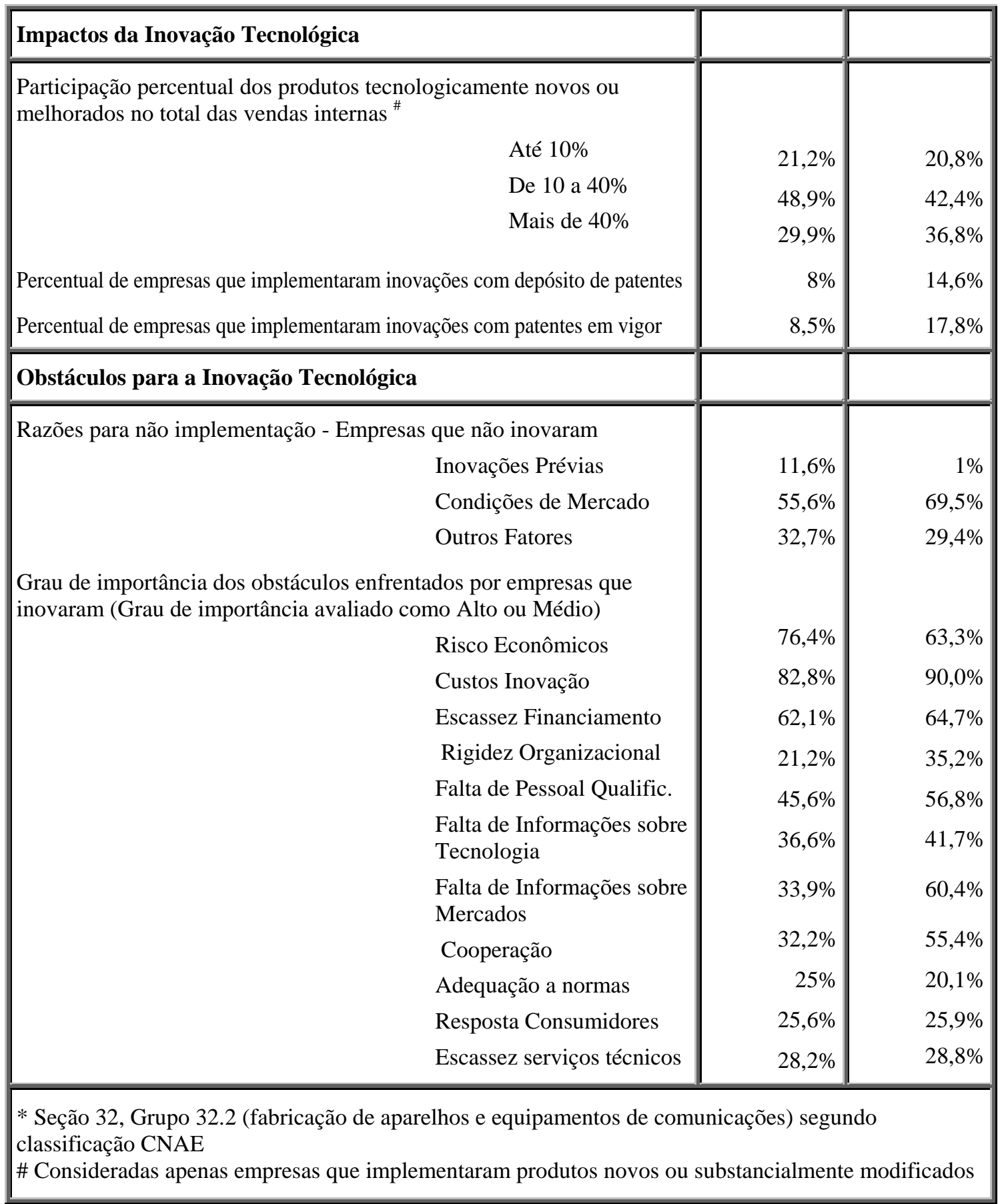

Tabela 8.10 - Indicadores de Inovação Tecnológica do Setor de Telecomunicações Fonte: PINTEC 2000 (IBGE, 2002)

Os dispêndios em P\&D são relativamente altos entre os fabricantes de equipamentos para comunicações se comparados com as empresas dos outros segmentos estudados. 
A incidência sobre a receita líquida de vendas dos dispêndios realizados nas atividades inovativas ficam em torno de 5\%, enquanto que em geral a amostra apresenta 3,8\%. Também os gastos em atividades internas de P\&D são mais altos do que a média geral, $1,75 \%$ da receita líquida de vendas em equipamentos de comunicações (representando 35\% dos dispêndios em inovação sendo orientados para atividades internas), contra 0,64\% das empresas em geral (o que representa 16,8\% do dispêndio). Vale lembrar que são computados em "atividades inovativas", os gastos com aquisição de máquinas e equipamentos para fabricação de novos produtos.

Em média, o dispêndio com atividades de inovação das empresas fabricantes de equipamentos para comunicações ficaram em torno de $\mathrm{R} \$ 6,2$ milhões no período compreendido pela pesquisa, sendo que a maioria foi destinada a atividades internas de $\mathrm{P} \& \mathrm{D}$ (cerca de $\mathrm{R} \$ 3,3$ milhões em média por empresa que investiu teve dispêndio nesse item), seguido por aquisição de máquinas e equipamentos (em torno de $\mathrm{R} \$ 2,9$ milhões em média) e por aquisição externa de $\mathrm{P} \& \mathrm{D}$ (média de $\mathrm{R} \$$ 2,6 milhões por empresa).

Também referente às empresas inovadoras, quando foram questionadas sobre o grau de importância que dão às atividades inovativas desenvolvidas, classificaram como sendo de importância alta ou média os seguintes fatores: "treinamento" (64,3\%), “atividades internas de P\&D” (55,7\%), “aquisição de máquinas e equipamentos" (54,6\%), "projeto industrial e outras preparações técnicas" (49,2\%), "introdução das inovações tecnológicas no mercado" (44,3\%), "aquisição de conhecimentos externos" (29,2\%) e "aquisição de P\&D externa" (26,5\%). Vale comparar esses dados com o resultado total da amostra, que apresenta 76,6\% das empresas classificando "aquisição de máquinas e equipamentos" como de importância média ou alta. Na amostra de telecomunicações, esse fator fica em terceiro lugar.

Esses dois itens descritos por último (investimentos reais por tipo de atividade inovativa e avaliação da importância que cada tipo de atividade tem para a empresa inovar) são agregados nas mesmas questões - enumeradas de 15 a 21 no questionário utilizado para as entrevistas (PINTEC/IBGE, 2002) - que, a partir de uma lista de atividades inovativas, solicita ao entrevistado que coloque o grau de importância dela 
(alto, médio, baixo, não desenvolveu) e o valor do dispêndio em moeda nacional (Em Reais).

No que se refere a financiamento para as atividades de inovação, 56 das 298 companhias do setor de equipamentos de comunicações receberam suporte do governo, ou seja, $18,8 \%$ delas.

Quando perguntado às empresas inovadoras quais eram os principais responsáveis pelo desenvolvimento de produtos e/ou de processos, as respostas foram semelhantes entre as empresas em geral e as do setor de equipamentos para telecomunicações apesar das grandes diferenças nos percentuais apresentados. Em relação à inovação de produtos, no total geral, a própria empresa é a principal responsável em 71,4\% dos casos de inovação. Essa proporção é de apenas 10,6\% no caso de inovação em processo, sendo outras empresas ou institutos, os principais responsáveis pela inovação nesses casos $(83,3 \%)$.

No caso de fabricantes de equipamentos de comunicações, do total de 145 companhias inovadoras em produtos, também o principal responsável pelo desenvolvimento é a própria empresa (59,3\%), seguido pelas outras empresas do grupo $(17,9 \%)$. No caso de inovação em processos, o resultado também é alinhado com o resultado geral, mas os percentuais são bastante diferentes. Os principais responsáveis pelo desenvolvimento de processos são outras empresas ou instituições, com cerca de 49,1\%, número inferior aos $83,3 \%$ apresentados pelas empresas em geral. Em segundo lugar, está a própria empresa, com 39,5\%, número muito superior aos cerca de $10,6 \%$ do resultado geral.

Dos dispêndios realizados em atividades internas de $\mathrm{P} \& \mathrm{D}$ nas empresas que implementaram inovação, a maioria é destinada à realização de $\mathrm{P} \& \mathrm{D}$ em caráter contínuo ao invés de ocasional. Para os fabricantes de equipamentos de comunicação, 97,4\% dos dispêndios em P\&D interna são para projetos contínuos, enquanto que, de modo geral, as empresas estudadas têm esse valor um pouco reduzido (90\%).

Também relacionado às empresas que têm dispêndios em $\mathrm{P} \& \mathrm{D}$ internamente, a 
média de pessoas ocupadas nessas atividades entre os fabricantes de equipamentos para comunicações é de aproximadamente $10 \%$ do total ocupado pela empresa (ou cerca de 19 pessoas em média para um total médio de 191 funcionários por empresa), enquanto que no total das empresas, este número é de $8 \%$. O nível de escolaridade dessas pessoas ocupadas em P\&D para o segmento de comunicações é de 63,8\% com nível superior e $22 \%$ nível médio, o restante $(14,2 \%)$ é classificado como outros graus de escolaridade.

Com relação aos resultados das atividades inovativas, do total de empresas que implementaram inovações, $8 \%$ tiveram depósito de patentes, enquanto que, para os fabricantes de equipamentos de comunicações, este percentual sobe para 14,6\%. Apesar da questão relacionada a resultados medidos em número de patentes ter sido, no questionário da PINTEC, ser agregada à pergunta sobre onde foi feito o depósito das patentes, esse dado não foi disponibilizado no material publicado pelo IBGE.

Ainda para o segmento de equipamentos para comunicações, os resultados das inovações em termos de participação dos produtos tecnologicamente novos ou aprimorados no total das vendas das empresas que implementam inovação em produtos foram bastante consideráveis. $42,4 \%$ das empresas afirmaram que a participação dos novos produtos ficou entre $10 \%$ e $40 \%$ das vendas, 36,8 afirmaram serem maiores que $40 \%$ e $20,8 \%$ indicaram que a participação foi menor que $10 \%$.

Com relação às fontes de inovação empregadas para as atividades de inovação, foi feito um levantamento do grau de importância delas considerado pelas empresas e da real utilização de tais fontes. O figura 8.1 mostra o percentual de empresas fabricantes de equipamentos para comunicações, que selecionaram os tipos de fontes utilizadas e o grau de importância dado a elas (que o classificaram como de alta ou média importância).

Em geral, o resultado da PINTEC mostra que as empresas que implementaram inovações atribuem como principais fontes de informações empregadas, os parceiros de suas relações comerciais, seguidas pelas fontes de informações informais. Sendo assim, clientes e/ou consumidores, concorrentes e fornecedores estão entre as fontes 
mais empregadas, assim como feiras / exposições, conferências / encontros / publicações especializadas.

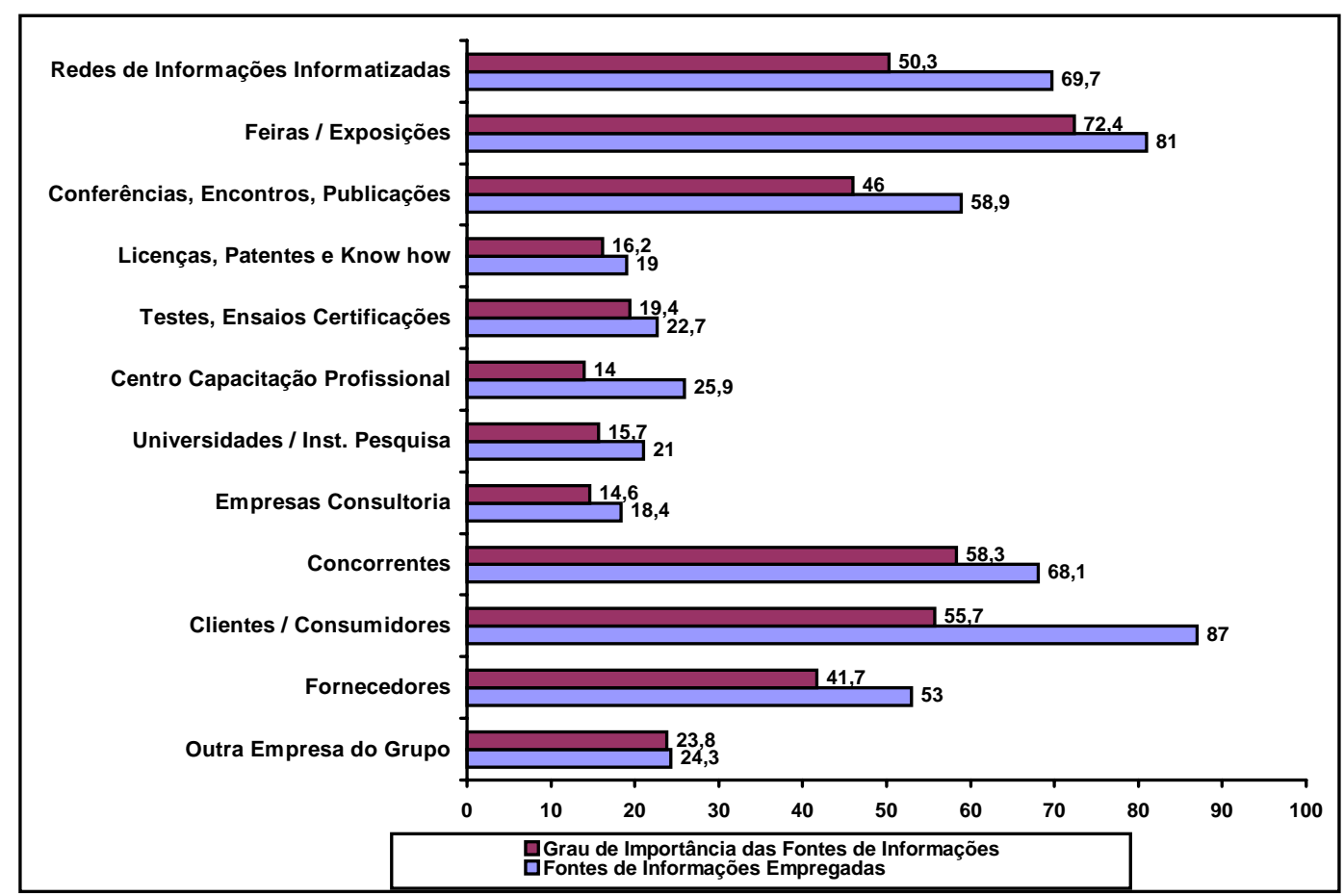

Figura 8.1 - Percentual de empresas que implementaram inovações entre os fabricantes de equipamentos de comunicações, por grau de importância e por utilização das fontes de informação

Uma outra informação relevante para este trabalho refere-se à localização das fontes empregadas. O figura 8.2 mostra se tais fontes foram obtidas no Brasil ou no exterior. É possível observar a relevância nacional para essas fontes de informações listadas, cuja maioria é obtida no Brasil.

No entanto, cerca de $30 \%$ das empresas fabricantes de aparelhos e equipamentos de comunicações não implementaram inovação no período compreendido pela pesquisa do IBGE. A principal razão indicada por elas é a condição de mercado $(69,5 \%)$, ou seja, entre 1998 e 2000, a condição de demanda vigente ou as condições competitivas do mercado não favoreciam ou não estimulavam a inovação. Foi uma fase de mudanças no setor devido à recente privatização do Sistema Telebrás.

Já para as empresas que implementaram inovação no período, 54,7\% da amostra geral (todos os setores) afirmam ter encontrado problemas que dificultaram ou inviabilizaram a implementação de projetos. Entre as razões apontadas como 
obstáculos, as principais são de natureza financeira, ou seja, os custos, os riscos e a escassez de fontes adequadas de financiamento.

Esses também foram os principais fatores apontados pelos fabricantes de aparelhos e equipamentos de comunicações, sendo que $90 \%$ dessas empresas indicaram como médio ou alto grau de importância dos fatores que dificultam atividades de desenvolvimento, os custos para inovação. Esse item vem seguido da escassez de fontes apropriadas de financiamento $(64,7 \%)$ e dos riscos econômicos $(63,3 \%)$. Entre os fatores não econômicos, foram apontados, também com grau alto ou médio de importância, a falta de informação sobre mercados $(60,4 \%)$, a escassez de possibilidade de cooperação com outras empresas e/ou instituições $(55,4 \%)$.

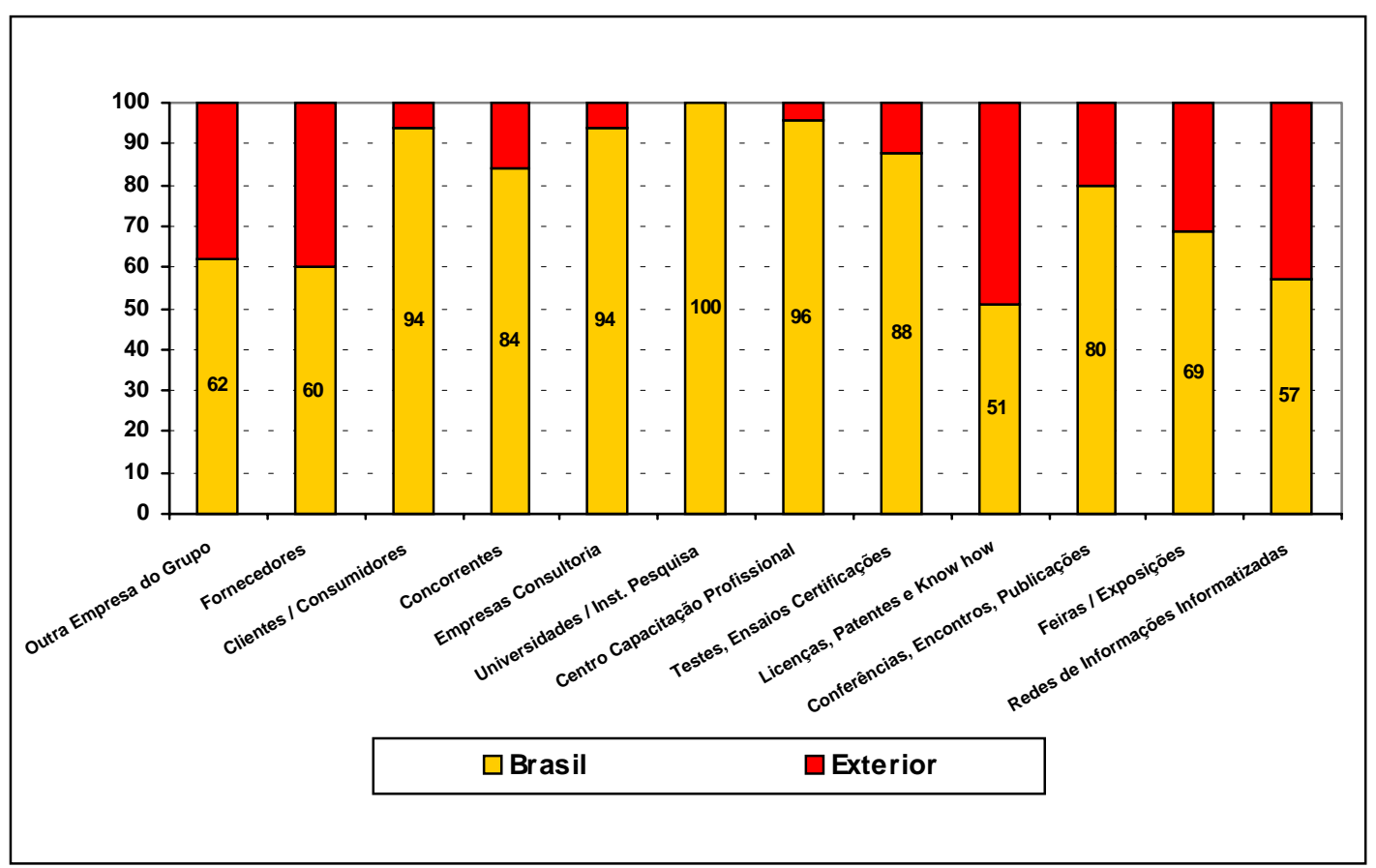

Figura 8.2. Percentual por localização das fontes de informação empregadas para indústria de aparelhos e equipamentos de comunicações

A falta de informação de mercado como o primeiro dos obstáculos "não econômicos" indicado por pouco mais de $60 \%$ das empresas fabricantes de equipamentos para comunicações foi bastante superior à média geral das empresas estudadas, que ficou em cerca de $34 \%^{45}$. Isso provavelmente reflete a instabilidade

45 Ou seja, cerca de 34\% das empresas estudadas (amostra total) indicaram o item "falta de informações de mercado" como sendo de importância alta ou média como obstáculo à inovação. 
do mercado de telecomunicações brasileiro no período da pesquisa, ocorrido durante e logo após a privatização do sistema Telebrás.

Chama a atenção a pouca importância atribuída ao fator "rigidez organizacional", com aproximadamente $65 \%$ das empresas indicando-o como não relevante ou de importância baixa (apesar de ter uma diferença considerável quando comparado com a base geral de empresas, em que 21,2\% apontam tal fator como relevante). Esse dado não condiz com as informações dos estudos de casos (estudo qualitativo) feitos nesta pesquisa, que indicam total falta de autonomia das TNCs para conduzir atividades de inovação e elevada dependência da matriz ou da unidade que detém tecnologia em área específica na qual a empresa deseja inovar.

A tabela 8.10 mostra, de maneira resumida, o perfil das empresas - tanto do total da base, quanto do grupo de fabricantes de equipamentos para comunicações considerando para isso, quatro aspectos, além da característica geral da amostra: intensidade da inovação ou seja, os dispêndios com inovação; intensidade da inovação tecnológica em temos de recursos humanos; impactos da inovação tecnológica; obstáculos para a inovação tecnológica.

Além de alguns resultados já mencionados, outros chamam atenção. Um deles é sobre a intensidade da inovação tecnológica com recursos humanos, especialmente no nível de formação das pessoas ocupadas. Quando comparada com a base total, a amostra das empresas de equipamentos para comunicações apresenta um valor bastante superior de pessoas graduadas e bastante inferior de técnicos de nível médio.

\subsubsection{ANPEI}

Um outro estudo feito refere-se ao levantamento das características da inovação tecnológica das empresas estudadas e de outras do setor de telecomunicações. Foi desenvolvido pela ANPEI (1998) e é mostrado na tabela 8.11. Trata-se de uma pesquisa com indicadores de capacitação e inovação desenvolvida com empresas de vários setores - coluna "média da base" na tabela - e depois refinada para uma 
pequena amostra de 6 empresas do setor de telecom - coluna "média do grupo": Siemens, NEC, Alcatel, Compaq, Lucent, Furukawa.

Os itens levantados para as empresas estão divididos em quatro categorias principais, além dos dados referentes ao perfil das empresas: dispêndios com a inovação tecnológica; intensidade da inovação tecnológica em termos de recursos humanos; intensidade da inovação tecnológica em termos de infra-estrutura; impactos da inovação.

Já nas características gerais das empresas, chama a atenção que as empresas trabalhadas pela pesquisa da ANPEI são grandes empresas (média de 1.196 funcionários empregados). Vale destacar que as seis companhias do grupo de telecom trabalhado possuem em média uma quantidade um pouco inferior de funcionários, mas faturamento bem superior.

Com relação à intensidade da inovação tecnológica, um dado interessante é que as empresas da amostra de telecom não possuem dispêndios com Pesquisa, seja básica ou aplicada, enquanto que na base geral do estudo, mais de $30 \%$ das dos recursos para P\&D\&E (Pesquisa, Desenvolvimento e Engenharia) têm tal destino. Por outro lado, o dispêndio em P\&D\&E chega, em média, a 9,3\% do faturamento bruto, um valor muito expressivo. Na média da base geral, esse número é de cerca de $1,5 \%$. O pequeno grupo considerado também possui, em média, espaço maior para laboratórios e um número bastante superior de funcionários na área de P\&D\&E.

Quanto aos impactos da inovação, ou os resultados das atividades inovativas, assunto abordado neste trabalho de tese. Os dados mostram que 100\% dos trabalhos da amostra iniciados nos últimos três anos chegaram ao fim, enquanto que o índice médio de término de projetos na base geral da pesquisa da ANPEI é de 56,7\%. Esse dado provavelmente tem relação com o percentual significativo de receitas advindas de novos produtos por faturamento bruto apresentado pelas médias das empresas do grupo de telecom, de $67,5 \%$, enquanto que na média geral da amostra, esse índice é de $36,4 \%$. 


\begin{tabular}{|c|c|c|}
\hline Perfil das Empresas & $\begin{array}{c}\text { Média } \\
\text { Da Base }\end{array}$ & $\begin{array}{c}\text { Média } \\
\text { do Grupo* }\end{array}$ \\
\hline $\mathrm{N}^{\mathrm{o}}$ de Empresas Consideradas & 427 & 6 \\
\hline $\mathrm{N}^{\mathrm{o}}$ de Funcionários & 1.196 & 1.133 \\
\hline Faturamento Bruto (US\$) & 251.098 .273 & 427.654 .493 \\
\hline \multicolumn{3}{|l|}{ Intensidade da Inovação Tecnológica: Dispêndios } \\
\hline Dispêndio em P\&D\&E (US\$) & 3.828 .130 & 39.867 .226 \\
\hline Dispêndio em Pesq. Básica por Despesa em P\&D\&E (\%) & 3,43 & 0,00 \\
\hline Dispêndio em Pesq. Aplicada por Despesa em P\&D\&E (\%) & 28,06 & 0,00 \\
\hline Dispêndio em Desenvolv. Experimental por Despesa em P\&D\&E (\%) & 29,57 & 67,39 \\
\hline Dispêndio em Apoio/Serviços Tecnológicos por Desp. em P\&D\&E (\%) & 14,60 & 5,82 \\
\hline Dispêndio em Aquisição de Tecnologia por Despesa em P\&D\&E (\%) & 12,31 & 12,54 \\
\hline Dispêndio em Engenharia Não Rotineira por Despesa em P\&D\&E (\%) & 13,81 & 31,43 \\
\hline Despesa em P\&D\&E por Faturamento Bruto (\%) & 1,29 & 3,50 \\
\hline \multicolumn{3}{|l|}{ Intensidade da Inovação Tecnológica: Recursos Humanos } \\
\hline Pessoal em P\&D\&E (Funcionários Full-time) & 29,37 & 174,67 \\
\hline Doutores em P\&D\&E por Técnicos de Nível Superior em P\&D\&E (\%) & 3,97 & 0,00 \\
\hline \multicolumn{3}{|l|}{ Intensidade da Inovação Tecnológica: Infraestrutura } \\
\hline Área Física Ocupada por Laboratórios $\left(\mathrm{m}^{2}\right)$ & 379,72 & 825,00 \\
\hline \multicolumn{3}{|l|}{ Impactos da Inovação Tecnológica } \\
\hline Projetos Finalizados em Relação aos Iniciados nos últimos 3 anos (\%) & 56,68 & 100,00 \\
\hline Patentes Depositadas e/ou concedidas no País (Média Anual nos últimos 10anos) & 0,46 & 0,20 \\
\hline Receitas Advindas da Venda de Tecnologia para Terceiros (US\$) & 72.778 & 0 \\
\hline Receitas Advindas de Novos Produtos por Faturamento Bruto (\%) & 36,39 & 67,50 \\
\hline Economia de Custos Operacionais por Lucro Bruto (\%) & 1,38 & 14,77 \\
\hline
\end{tabular}

Tabela 8.11 - Indicadores de Capacitação e Inovação Tecnológica no Setor de Telecom (Valores Médios por Empresa). Fonte: ANPEI, 1998

É também relevante considerar que o número de pessoas empregadas em P\&D\&E para a amostra de companhias de telecom é muito superior ao número apresentado 
pela amostra geral. Cerca de $15,5 \%$ do total de funcionários em média, contra 2,5\% do total das empresas estudadas na pesquisa.

No entanto, o número de patentes depositadas e / ou concedidas internamente (no país) é completamente inexpressivo, seja para a base geral ou para o grupo de telecomunicações considerado, sendo que no grupo de telecom, o número é $50 \%$ inferior ao da base geral. Enquanto que as empresas estudadas têm em média 0,46 patente por ano (média dos últimos 10 anos), as empresas do grupo de telecom possuem 0,20 como média anual. 


\section{Capítulo 9}

\section{Conclusões}

\subsection{Considerações Finais}

A competitividade das empresas está ligada ao desenvolvimento tecnológico, especialmente em setores dependentes da inovação como o de telecomunicações, ou seja, as empresas que se destacam nas atividades de $P \& D$ apresentam vantagem competitiva em relação às outras. E, na busca por melhores condições para o desenvolvimento tecnológico, cada vez mais, pesquisa e desenvolvimento nas companhias transnacionais (TNCs) são realizados por equipes localizadas em diferentes países.

Essa internacionalização do desenvolvimento possibilita que diferentes grupos de trabalho mundiais estejam envolvidos, potencializando assim o crescimento $^{46}$ de vários centros de $\mathrm{P} \& \mathrm{D}$ espalhados globalmente e, consequentemente, das estruturas de inovação existentes em regiões / países que hospedam essas equipes de desenvolvimento das TNCs. Os países que dominam tecnologia levam vantagem e

\footnotetext{
${ }^{46}$ Crescimento que pode acontecer em maior ou menor escala, dependendo, por exemplo, do tipo de integração do grupo com as equipes globais.
} 
ocupam posição superior porque têm maiores chances de sucesso, conforme citado também neste trabalho.

No setor de Telecomunicações, o desenvolvimento tecnológico, atualmente, é realizado pelas empresas fabricantes de equipamentos, ao contrário do que acontecia no passado, quando as companhias operadoras de telefonia eram as grandes inovadoras na cadeia produtiva do setor.

O segmento de fabricantes de equipamentos do setor é dominado por grandes empresas transnacionais estrangeiras, que competem globalmente e estão presentes em vários países, inclusive no Brasil, cujo mercado pertence quase que exclusivamente a tais companhias. Uma vez que o setor é dominado por empresas estrangeiras, a inserção brasileira no desenvolvimento tecnológico depende também das estratégias dessas companhias.

Essa dependência pode colocar o país numa situação vulnerável em relação ao seu crescimento tecnológico em telecom. Ou seja, para que o país tenha posição de destaque, é preciso que as equipes brasileiras dessas empresas transnacionais estejam envolvidas no desenvolvimento tecnológico realizado mundialmente pelas companhias e que passem a promover o crescimento tecnológico da região em que estão localizadas no país, seja com o envolvimento de institutos e/ou universidades nas suas atividades de P\&D ou com o estímulo ao desenvolvimento e formação de profissionais locais, por exemplo.

Avaliar o envolvimento das subsidiárias brasileiras das grandes empresas transnacionais do setor de telecom no Desenvolvimento Global de Produtos (DGP) está entre os objetivos deste trabalho ${ }^{47}$. Para tanto, foi mostrada uma análise do desenvolvimento tecnológico no setor de telecomunicações sob o aspecto das empresas fornecedoras de equipamentos, já que são, hoje, os principais agentes da inovação em telecom. Entre as empresas, focou-se nas transnacionais presentes no país do segmento de telefonia, principal âmbito de estudo. Tal análise foi baseada em

\footnotetext{
${ }^{47}$ Os objetivos deste trabalho estão explicitados no Capítulo 2.
} 
estudos de casos e no levantamento de indicadores de C\&T, utilizados para melhor analisar as informações obtidas das empresas ${ }^{48}$.

As conclusões apresentadas neste capítulo referem-se aos principais tópicos levantados durante todo o trabalho. Tópicos esses, que estão relacionados à questão primordial desta tese, quer seja, "as subsidiárias brasileiras da indústria de telecomunicações estão envolvidas no DGP?". Dessa forma, serão mostradas algumas considerações e observações pertinentes para o encerramento deste estudo e que sejam relacionadas aos seus objetivos principais, e a seus questionamentos e hipóteses levantados a partir dos objetivos. Ainda neste capítulo, são apresentados alguns tópicos que não foram estudados, mas que se apresentam como assuntos interessantes para futuras pesquisas.

\section{Setor de Telecomunicações}

O setor de telecomunicações vem passando por mudanças significativas nas últimas décadas, mais precisamente desde meados dos anos 80 (intensificando-se no início dos anos 90). Essa época foi marcada, mundialmente, pelo fim da monopolização nacional em serviços, ou seja, as operadoras estatais de telefonia foram sendo privatizadas e começaram a ser mais focadas nos mercados e na competição existente neles $^{49}$. A relação com os fornecedores também mudou, e esses, além de fabricar, passaram a realizar $\mathrm{P} \& \mathrm{D}$, atividade anteriormente de responsabilidade das operadoras.

A passagem do desenvolvimento tecnológico das operadoras de telefonia para os fabricantes de equipamentos permitiu o aumento de concorrência e o acesso às mesmas tecnologias por operadoras distintas, concentrando, de alguma forma, os esforços para investimentos em $\mathrm{P} \& \mathrm{D}$ em algumas grandes empresas mundiais. $\mathrm{O}$ crescimento do setor de telecomunicações foi muito acentuado na década de 90, mas, por diferentes razões - sobre as quais não cabem discussões aqui - em 2001, ele atravessou uma crise intensa, que deve marcá-lo ainda por um tempo considerável.

\footnotetext{
${ }^{48}$ A metodologia completa do trabalho é mostrada no Capítulo 3.

${ }^{49}$ No Brasil, a privatização do Sistema Telebrás ocorreu em 1998.
} 
Esses exemplos de mudanças pelas quais passou o setor nos últimos anos - ou décadas - exemplificam seu dinamismo. As próprias empresas estudadas tiveram mudanças razoáveis em estratégias de desenvolvimento de produtos - foco principal deste trabalho - num curto período de dois anos, entre o primeiro (em 2000) e o segundo conjunto (em 2002) de entrevistas.

Foram analisadas sete empresas transnacionais fornecedoras de equipamentos de telecomunicações com forte presença no Brasil ${ }^{50}$ : Motorola, NEC, Siemens, Nokia, Ericsson, Lucent, Alcatel. São todas companhias estrangeiras e que têm algum tipo de desenvolvimento de produtos no Brasil.

\section{Desenvolvimento de Produtos no Brasil}

Foi constatado neste trabalho, que a participação brasileira em atividades de $\mathrm{P} \& \mathrm{D}$ ocorre especialmente no desenvolvimento de produtos - a parte " $D$ " - apesar de algumas poucas empresas, estimuladas principalmente pela Lei de Informática, realizarem "Pesquisa" no país. Quando isso acontece, geralmente é mediante parcerias com universidades e/ou centros de pesquisa. Mas a maioria absoluta das atividades desenvolvidas localmente é de desenvolvimento, pouquíssimo está relacionado à pesquisa. E esse desenvolvimento acontece em alguns segmentos de produtos.

Desenvolvimento de software é o grande nicho competitivo para o Brasil, por várias razões: necessidade de baixos investimentos comparados aos altos investimentos para desenvolvimento de hardware, estratégias globais das TNCs, formação de competências locais (mais em software do que em hardware), habilidades dos profissionais locais nessa área, entre outras.

Essa diversidade de fatores que influenciam a orientação do Brasil para o nicho de desenvolvimento de software é a resposta à questão $\mathrm{Q} 4{ }^{51}$ deste trabalho. No entanto,

\footnotetext{
${ }^{50}$ Empresas que estão entre as maiores do setor (Anuário Telecom, 2001).

${ }^{51} \mathrm{Q} 4:$ "Por que as equipes locais estão envolvidas no desenvolvimento de alguns "nichos" específicos de produtos?"
} 
a hipótese levantada para essa questão (H6) é parcialmente confirmada, uma vez que ela engloba apenas parte dos fatores, ou seja, aqueles relacionados às competências e habilidades da mão-de-obra local. Entretanto, os fatores de estratégia da corporação e necessidade de menor investimento, muito relevantes, não foram considerados no levantamento da hipótese.

É evidente que esse direcionamento para o desenvolvimento de software coloca as subsidiárias locais em situação de dependência a um segmento específico. Além disso, essa estratégia das TNCs mostra que as empresas querem investir o mínimo possível em infra-estrutura para desenvolvimento tecnológico no país. No entanto, essa limitação a software não precisa ser vista negativamente, uma vez que já é realidade, e a tendência do setor evidencia, o fortalecimento do software nos produtos de telecomunicações ${ }^{52}$. Hoje, os softwares são os grandes inovadores em telecomunicações, já que permitem flexibilidade e agilidade de sistemas, seja através de alterações / adaptações rápidas ou de desenvolvimentos de novos serviços, tornando-se assim - o software - uma ferramenta importante para a competitividade das empresas. Soma-se a isso, a característica, cada vez maior, de integração entre telecomunicações e informática. A telefonia fixa, por exemplo, é fortalecida com a entrada da nova geração (NGN), em que as redes de comunicações são formadas por redes semelhantes às de computação, com equipamentos fornecidos por empresas tradicionalmente ligadas à área de redes de computadores, como a Cisco, por exemplo.

É importante destacar que, salvo algumas exceções, na grande maioria dos casos, as subsidiárias brasileiras não são coordenadoras dos projetos de desenvolvimento de software. Nesse tipo de desenvolvimento, o papel de gestor ou coordenador é importante porque é quem detém o conhecimento do processo de desenvolvimento como um todo. É ele quem determina metodologias, padrões, processos a seguir; também cabe a ele especificar requisitos e definir objetivos / escopos dos produtos; é também tarefa sua, estabelecer integração dos vários subsistemas desenvolvidos globalmente. Isso agrega um tipo de conhecimento a esse player, que o coloca em

\footnotetext{
${ }^{52} \mathrm{Na}$ verdade, o crescimento da importância do software nos sistemas de comunicações é uma das razões pelas quais esse segmento no Brasil tem sido fortalecido nos últimos tempos, uma vez que houve oportunidade para que o país mostrasse sua competência na área.
} 
vantagem em relação aos demais, que correm o risco de tornarem-se meras 'fábricas de software'.

Uma área também com crescimento acentuado é a de desenvolvimento de serviços, que se refere principalmente às atividades de integração de redes de telecom. Essa tendência apresenta uma oportunidade para as equipes brasileiras, que estão começando a posicionar-se na rede mundial da empresa para conquistar espaço entre as subsidiárias na prestação de serviços de integração ${ }^{53}$.

Isso caracteriza uma tendência clara entre os fornecedores de equipamentos de caminharem a jusante na cadeia produtiva do setor de telecomunicações, ou seja, eles passam de fornecedores de equipamentos a provedores de soluções (integradores de rede), fornecendo aos clientes, não apenas os equipamentos, mas também os serviços necessários para interligar as redes de comunicações e podem, para isso, utilizar equipamentos de outros fornecedores, seus concorrentes. Essa tendência de caminhar a jusante pode ser observada em todos os níveis da cadeia produtiva, não apenas nos fornecedores, e também é uma característica do dinamismo do setor de telecom, e poderia ser citado na seção anterior.

\section{Envolvimento Brasileiro no DGP}

Ainda com relação a desenvolvimento de produtos, um dos resultados obtidos neste trabalho é especificamente relacionado ao envolvimento das equipes brasileiras das TNCs estudadas no DGP. Essa análise ${ }^{54}$ foi feita sob três pontos de vista: o tipo de envolvimento das equipes brasileiras no DGP, os tipos de interações das equipes envolvidas no DGP e a cooperação entre as empresas e universidades/centros de pesquisa locais para a realização de projetos de $\mathrm{P} \& \mathrm{D}$.

\footnotetext{
${ }^{53}$ A unidade brasileira da Ericsson, por exemplo, destaca-se cada vez mais nesse segmento e, segundo informações da própria companhia, tornou-se centro de competência mundial em serviços de design de rede para sistemas indoor, prestando serviço para várias subsidiárias da TNC espalhadas mundialmente.

${ }^{54} \mathrm{~A}$ análise da participação brasileira no DGP responde às questões Q5 e Q6 deste trabalho, apresentadas no capítulo 2 .
} 
Foi observado que as subsidiárias brasileiras das empresas fornecedoras de equipamentos de telecomunicações possuem envolvimento para o desenvolvimento de produtos globais ${ }^{55}$, que varia de empresa para empresa e de produto para produto (ou por nicho de produto, conforme discutido na seção anterior deste capítulo sobre a propensão das equipes brasileiras para o desenvolvimento de software).

Em geral, as unidades locais de algumas das companhias estudadas (principalmente Motorola, Ericsson e Siemens) participam das redes mundiais de desenvolvimento e, em alguns nichos de produtos, ocupam papéis importantes, seja como centros de excelência de tecnologia específica ou como players relevantes no DGP através do desenvolvimento de componentes específicos dos produtos/sistemas.

Quase todos os centros de pesquisa das empresas estudadas foram criados com o intuito de dedicarem-se a objetivos regionais ${ }^{56}$, mas, com suas características diferenciadas de especializações, foram sendo integrados a projetos cooperativos de interesse global. Isso se deve também à forte característica de internacionalização de P\&D apresentada pelas companhias citadas, sendo que as subsidiárias locais aproveitaram-se dessa oportunidade.

$\mathrm{Na}$ Ericsson, por exemplo, o centro de excelência em desenvolvimento de sistemas para Tarifação/Billing foi criado para adaptações dos produtos importados ao mercado brasileiro e isso levou a equipe local a uma competência na área reconhecida pela TNC e utilizada para DGP no referido segmento de produto.

À medida que as afiliadas locais têm possibilidades para mostrar suas competências, vão conquistando espaços relevantes no processo de DGP e começam a tornar-se fundamentais para tal processo. Isso foi comprovado em várias empresas. A Motorola, por exemplo, teve oportunidade de mostrar sua competência em desenvolvimento de softwares para telefonia móvel em várias situações e já suplantou tradicionais desenvolvedores da companhia em alguns projetos.

\footnotetext{
${ }^{55}$ Respondendo à questão primordial desta tese - conforme citada na seção inicial deste capítulo ${ }^{56} \mathrm{O}$ centro de pesquisas de semicondutores da Motorola já foi criado no Brasil com o intuito de participação no DGP.
} 
Para analisar a participação da subsidiária brasileira no DPG, conforme citado anteriormente, é necessário avaliar os tipos de interações das equipes envolvidas, ou seja, a composição das equipes globais envolvidas no desenvolvimento de produtos e a organização delas para o trabalho. Esse é um dos principais aspectos para observação da internacionalização do DP. No capítulo 7, foram mostradas as características mais comuns entre as equipes globais de desenvolvimento das empresas estudadas, utilizando para isso, algumas estruturas de $\mathrm{P} \& \mathrm{D}$ internacional (Chiesa e Manzini, 1996; Chiesa, 2000; Gassmann e von Zedtwitz, 1999) apresentadas no capítulo 4. Essas estruturas foram analisadas e adaptadas para que fossem apropriadamente relacionadas às companhias estudadas, ou seja, no capítulo 7 são apresentadas as estruturas de $\mathrm{P} \& \mathrm{D}$ internacional mais usadas pelos casos estudados.

A classificação das empresas de acordo com sua estrutura global para DP permite não apenas analisá-las melhor, mas também avaliar a dinâmica da internacionalização do DP e da estratégia da empresa ao internacionalizar suas atividades de P\&D. Foi possível observar que as companhias são classificadas em diferentes estruturas de formação das equipes de desenvolvimento, dependendo do nicho de produto em que está envolvida.

A maioria das empresas possui alguns nichos de produtos que são desenvolvidos em equipes internacionais classificadas entre uma das duas estruturas intermediárias do modelo proposto. Trata-se de estruturas em que há envolvimento da subsidiária no desenvolvimento tecnológico, quer seja como adaptadora de produtos, quer seja como colaboradora do desenvolvimento global.

Como já foi citado, praticamente a totalidade das atividades ligadas a P\&D nas empresas são de Desenvolvimento de Produtos, mas algumas das empresas realizam projetos cooperativos com universidades e/ou institutos (CEU) para a realização de pesquisas. No entanto, essas parcerias não estão limitadas apenas à realização de pesquisa; muito pelo contrário, a maioria dos projetos é para desenvolvimento de produtos, que se estendem desde testes de protótipos até desenvolvimentos específicos de certos módulos de sistemas computacionais com a utilização de técnicas inovadoras. 
Isso mostra que há uma diversidade de atividades realizadas em cooperação entre as empresas e as instituições de pesquisa. Também são vários os destinos dos investimentos, isto é, os recursos para CEU são orientados para diferentes centros de pesquisa / universidades, embora haja uma certa concentração em determinadas regiões. No entanto, essa concentração tem ficado menos evidente com a exigência da Lei de Informática em investir um percentual em centros localizados nas regiões Norte, Nordeste e/ou Centro-Oeste, o que está levando a uma descentralização de investimentos, antes direcionados aos centros localizados no eixo mais desenvolvido do país (região Sudeste, principalmente).

Não há controle efetivo sobre essa multiplicidade de projetos de P\&D sendo realizados pelas diversas instituições conveniadas. Foi observado neste trabalho, que há uma necessidade de mapear ${ }^{57}$ as competências existentes em universidades e centros de pesquisa locais para que as subsidiárias brasileiras das TNCs possam facilmente estabelecer parcerias para seus projetos de desenvolvimento, já que competência é um dos fatores mais importantes para atrair desenvolvimento tecnológico, conforme discutido no capítulo 6 e comentado posteriormente neste capítulo.

A partir desse mapeamento, é possível não apenas facilitar a orientação dos investimentos por parte das subsidiárias, mas também conhecer as características específicas da comunidade científica na área de telecomunicações e as pesquisas desenvolvidas por ela. Isso permite, entre outros, a orientação de políticas públicas de acordo com tais competências.

No entanto, apesar de alguns casos de sucesso em relação à participação das subsidiárias brasileiras das TNCs no DGP e do envolvimento das instituições de pesquisa / universidades no mesmo, ainda é preciso melhorar bastante essas participações e relações. Está claro que muitas empresas reduziram seus investimentos locais em P\&D devido à redução do faturamento, mostrando uma dependência clara entre os incentivos da Lei de Informática e tais investimentos.

\footnotetext{
${ }^{57}$ É necessário mapear num primeiro momento e manter esse mapeamento atualizado. Ou seja, esse mecanismo de conhecer/localizar as competências dos centros de pesquisa no país tem que ser um processo dinâmico e continuado.
} 
Uma outra característica observada, que é responsável por certa "fragilidade" das atividades de P\&D realizadas localmente, tem origem na característica do DP feito no Brasil e orientado para o mercado nacional; ou seja, as subsidiárias estão mais envolvidas com adaptações de produtos ao mercado brasileiro e o desenvolvimento de produtos locais do que ao desenvolvimento de produtos globais, o que possibilitaria que estivessem participando ativamente do DGP.

Por exemplo, a equipe local de desenvolvimento de produtos na NEC está se extinguindo $^{58}$ e, está claro, que a forte dependência do desenvolvimento de produtos às adaptações locais, ou melhor, o não envolvimento efetivo da unidade brasileira no DGP, foi o principal fator a levar a área de P\&D da companhia a essa situação.

\section{Ambiente Favorável à Realização de Desenvolvimento Tecnológico}

Entre os resultados obtidos, estão os fatores que levam as empresas a colocarem atividades de desenvolvimento de produtos no Brasil, que estão, em sua maioria, alinhados aos fatores mundiais de atração de $\mathrm{P} \& \mathrm{D}$ pelos países hospedeiros. Vários fatores são considerados no capítulo 6, onde também é apresentado o "Modelo de Causas e Efeitos da Participação das Subsidiárias no DGP”, desenvolvido neste trabalho.

Entre os fatores observados, destaca-se o relacionado aos incentivos provenientes da Lei de Informática. Por mais que as TNC neguem enfaticamente este como único motivador, ele foi, para as empresas estudadas, o principal responsável para que as atividades de $\mathrm{P} \& \mathrm{D}$ fossem localizadas no país. As empresas estudadas neste trabalho estão entre as maiores beneficiárias da Lei de Informática (MCT, 2003). A lei permitiu uma maior autonomia para as subsidiárias e a possibilidade de investimentos para arriscarem-se quando do desenvolvimento de produtos e processos. E prover de autonomia / liberdade para correr riscos está fundamentalmente ligado ao processo de inovação.

Existem alguns casos de sucesso em que os recursos provenientes dos incentivos

\footnotetext{
${ }^{58}$ Mais informações no Anexo A.
} 
fiscais garantidos pela lei de informática foram usados para iniciar algumas atividades de $\mathrm{P} \& \mathrm{D}$ pelas empresas estudadas e que posteriormente, tornaram-se centros de competência mundiais das TNCs, por exemplo, o centro de semicondutores da Motorola e o centro da Siemens para desenvolvimento de alguns nichos de software em NGN.

No entanto, aparentemente, nem mesmo os esforços gerados em decorrência da lei de informática foram suficientes para alavancar e, principalmente, sustentar o envolvimento as equipes brasileiras no DGP, uma vez que vários projetos das empresas estudadas, conforme mostrado no capítulo 7 , não tiveram continuidade depois da redução do faturamento das empresas com a crise enfrentada pelo setor, a partir de $2001^{59}$. Observou-se que, em geral, à medida que as receitas das empresas foram caindo, os recursos para investimento também foram reduzindo-se.

Algumas empresas chegaram a eliminar quase que por completo suas atividades relacionadas a $\mathrm{P} \& \mathrm{D}$, como é o caso da NEC, uma das empresas mais beneficiadas com os incentivos da Lei de informática ${ }^{60}$, fundadora do CPDIA, o terceiro centro de pesquisa que mais investimentos recebeu ao amparo da Lei de Informática ${ }^{61}$ até o ano 2000. No entanto, suas atividades de desenvolvimento não foram mantidas no país, deixando claro que a Lei de Informática somente e tal como apresentada tem problemas, uma vez que, em cerca de dez anos de existência, foi incapaz de detectar que as atividades realizadas pela empresa - e por outras do setor - não eram suficientes para sustentar P\&D na subsidiária local.

Vale destacar que, mundialmente, as empresas reduziram os valores absolutos de seus investimentos em $\mathrm{P} \& \mathrm{D}$ nos últimos anos, devido à crise do setor. No entanto, o percentual de dispêndio nessa modalidade em relação ao faturamento não caiu, e, na maioria dos casos, aumentou, por exemplo, para Lucent, Motorola, Ericsson e Alcatel (GEEIN, Dossiês Empresas, 2002).

\footnotetext{
${ }^{59}$ Isso porque a lei está diretamente relacionada ao faturamento

${ }^{60}$ Conforme mostrado na tabela 6.2 e a partir dos dados do MCT $(2000,2003)$.

${ }^{61}$ Recebeu investimentos de R\$ 17 milhões no período de 1993 a 2000, conforme gráfico 7.1 (MCT, 2003).
} 
Um outro fator relevante para atrair atividades tecnológicas para o país refere-se à relação da subsidiária com o mercado local/regional, mais especificamente à relação de comercialização dos produtos do que de manufatura em si. A fabricação local dos produtos não é fator fundamental para atrair P\&D para o país, ou seja, as empresas não criam centros de desenvolvimento apenas para que estejam próximos a fábricas. Esse distanciamento entre unidades de desenvolvimento e de manufatura foi possibilitado pelo aumento de facilidades para comunicação / documentação das características dos produtos. Essa característica é acentuada ainda mais com a tendência atual do setor de telecomunicações de terem fabricação terceirizada para as CEM, conforme discutido no capítulo 5.

No entanto, a comercialização dos equipamentos de telecomunicações fabricados localmente - que exigem, por exemplo, adaptações locais e engenharia para integração - leva à necessidade de maior envolvimento da subsidiária para melhor atender aos clientes. Esse mostrou-se fator essencial para gerar/desenvolver competências locais e, consequentemente, atrair investimentos para desenvolvimento tecnológico.

A existência de competências no país é fundamental para garantir a permanência do desenvolvimento tecnológico local. Isso significa que esses dois fatores comentados anteriormente - e outros apresentados no capítulo 6 - são fatores importantes para atrair investimento, mas não são decisivos e não o mantém por muito tempo. A formação de competência faz-se necessária e fundamental para que o Brasil possa ser ambiente atrativo para o desenvolvimento tecnológico e possa receber, cada vez mais, investimentos dessa natureza.

É possível observar uma característica positiva nesse sentido, uma vez que contrariamente à literatura na área, que afirma que as TNCs procuram utilizar-se de talentos já disponíveis no país, ao invés de formar novos talentos ou conhecimento (Reddy, 1997), as companhias presentes no Brasil e estudadas neste trabalho, incentivadas pela lei de informática ${ }^{62}$, possuem projetos para formação e capacitação profissional.

\footnotetext{
${ }^{62}$ A Lei de Informática permite agregar formação de profissionais às atividades de $P \& D$ da empresa, para justificar dispêndios dessa natureza.
} 
Sendo assim, é fundamental que o Brasil, além de estimular a atração de investimentos, quer seja através de incentivos fiscais, de aprimoramento de seu mercado consumidor ou do aperfeiçoamento de competências, tenha políticas públicas abrangentes para, de alguma forma, garantir que esse desenvolvimento que ocorre nas subsidiárias locais torne-se absolutamente indispensável para a companhia global.

Aliás, entre as principais dificuldades apresentadas pelas empresas quando realizam P\&D no Brasil, está exatamente a falta de políticas públicas adequadas e claras, aumentando as incertezas para investimentos no país. Isso parece um equívoco já que essas empresas são grandes usuárias dos recursos da lei de informática, mas elas mesmas esclarecem que a lei sozinha não garante investimentos de longo prazo.

É necessário que o governo estabeleça políticas públicas que sejam extensas, abrangentes, claras e que visem longo prazo. Para tanto, é preciso, por exemplo, ter integração entre as atividades do Ministério da Ciência e Tecnologia (MCT) e do Ministério da Educação (MEC) para que a formação dos profissionais de nível superior e técnico seja condizente com o âmbito tecnológico das pesquisas realizadas no país ${ }^{63}$. Essas ações precisam ter envolvimento também das companhias, que serão as beneficiárias diretas dessa mão-de-obra bem qualificada.

Além disso, é fundamental que avaliações das auditorias realizadas nas atividades de empresas que recebem incentivos públicos sejam feitas regularmente, um dos grandes problemas da Lei de Informática. Esse controle dos mecanismos de incentivo fiscal por parte dos órgãos públicos deve ser feito tanto para os investimentos realizados pelas companhias, quanto para os resultados obtidos a partir dos recursos governamentais empregados.

No que se refere aos investimentos realizados, o MCT, através de secretaria ou órgão específicos $^{64}$, tem processos de controle razoavelmente rígidos, obrigando as empresas beneficiadas a comprovarem o direcionamento dos recursos empregados de

\footnotetext{
${ }^{63}$ Nota-se que, para isso, é fundamental identificar segmentos em que o país está envolvido ou em que tem potencial para envolver-se, conforme discutido posteriormente nesta mesma seção a respeito do mapeamento de atividades de P\&D necessário para orientar investimentos.

${ }^{64}$ As auditorias empresariais referentes aos incentivos da Lei de Informática vêm sendo feitas pela SEPIN, ligada ao MCT, mas o Ministério está em fase de reestruturação e essa secretaria será extinta.
} 
acordo com as normas estabelecidas pela lei. No entanto, as possíveis aplicações dos recursos definidas pela lei devem ser analisadas/questionadas ${ }^{65}$ para que os recursos - que são escassos - sejam orientados para projetos que tenham maiores chances de garantir investimentos continuados. Uma das possíveis aplicações que poderiam ser revistas é a que envolve institutos de pesquisa / universidades para, por exemplo, evitar a realização de testes de equipamentos para adaptação/homoloação, tipo de atividade que já seria feita pelas empresas e que não traz necessariamente resultados significativos para as instituições de pesquisa.

Exatamente no que se refere aos resultados obtidos a partir dos recursos empregados é que estão as principais falhas em auditoria apresentadas pelos órgãos governamentais responsáveis. Não há um trabalho eficaz que apresente tais dados de maneira clara e abrangente, e que possa orientar futuros investimentos do recurso público para ações que tragam desenvolvimento para o país. Este trabalho de tese apresenta algumas análises quantitativas utilizando indicadores de C\&T que mostram negativamente os resultados do desenvolvimento realizado pelas empresas do setor de telecomunicações.

Também vale a pena avaliar o que as empresas que apresentam dificuldades para realização de P\&D no país têm feito para reverter esses problemas. Nesta pesquisa, numa análise pouco aprofundada, verificou-se que algumas das empresas estudadas têm ações interessantes na tentativa de modificar a situação atual. Por exemplo, a Nokia Mobile, tendo dificuldades para contratação de pessoas capacitadas para trabalharem na sua fábrica em Manaus, criou um programa de formação profissional $^{66}$, que educa jovens para trabalharem com eletro-eletrônicos. Alguns desses profissionais são assimilados pela própria companhia, mas muitos deles ficam disponíveis para outras empresas.

\footnotetext{
${ }^{65}$ Algumas já foram contestadas e reformuladas na revisão da lei em 2000/2001, gerando a lei 10.176/01; por exemplo, no que se refere à implantação de sistemas de qualidade nas empresas e à simples montagem de laboratórios em universidades.

${ }^{66}$ Com recursos da Lei de Informática, vale ressaltar.
} 


\section{Resultados do desenvolvimento de produtos realizado pelas subsidiárias brasileiras - conclusões referentes aos estudos quantitativos}

Uma outra característica negativa observada neste trabalho está relacionada ao estudo quantitativo feito sobre indicadores de Ciência e Tecnologia, especificamente patentes e dados bibliométricos. Os resultados desse estudo, apresentados mais profundamente na seção 8.3, mostram que os investimentos em P\&D no Brasil feitos pelos fabricantes de equipamentos de telecomunicações não foram suficientes para reverter os baixos resultados desses indicadores de $\mathrm{C} \& \mathrm{~T}$.

De modo geral, os dados referentes a patentes internacionais e nacionais mostram que a participação das subsidiárias brasileiras é insignificante. Esse é um indicador de que a pesquisa realizada localmente possa estar gerando produtos não patenteáveis - especialmente em mercados internacionais - devido ao seu baixo conteúdo tecnológico.

Há que se considerar que a grande maioria das empresas estudadas justificou a deficiência no número de patentes obtidas pelas subsidiárias locais como sendo uma falta de cultura das equipes brasileiras para tratar de patentes. Uma outra justificativa a considerar é que o desenvolvimento de software é mais comum no Brasil, como já foi exaustivamente comentado, e que é mais usual o registro de copyright do que o registro de patentes para sistemas computacionais. Entretanto, no setor de telecomunicações, especialmente telefonia, é comum que softwares sejam registrados como patentes porque são bastante relacionados às melhorias de hardware (Schmoch, 1996).

Por essas razões, estudos semelhantes com subsidiárias das companhias localizadas em países desenvolvidos ou em desenvolvimento (com destaque para Índia e China) foram feitos e apresentados neste trabalho. A partir deles, é possível concluir que as subsidiárias localizadas em países desenvolvidos possuem número considerável de patentes em seus nomes, enquanto as unidades de países em desenvolvimento não possuem tantas patentes, mas as têm em número maior do que as brasileiras.

Sendo assim, é prudente afirmar que a característica de pouca inovação nos produtos 
desenvolvidos no Brasil é a principal justificativa possível para a impressionante ausência de patentes em nome das subsidiárias brasileiras em 10 anos, período considerado para a pesquisa quantitativa feita. Uma outra justificativa geralmente citada pelas empresas é a de que as subsidiárias brasileiras não estão aculturadas a solicitação de patentes. Esse aspecto é relacionado a um outro, o de que as companhias têm políticas mundiais para que os depósitos sejam requeridos centralmente.

Vale destacar, que dados estatísticos referentes a concessão de patentes são utilizados como indicadores de C\&T para análises e comparações de setores, países/regiões, companhias. Sendo assim, mesmo que as empresas afirmem que as subsidiárias locais não têm cultura para solicitação de patentes ou que os depósitos de patentes são centralizados seguindo políticas estabelecidas pelas matrizes das companhias, esses dados podem estar sendo utilizados em análises e estudos de diversas naturezas e colocando o Brasil ou o setor de telecomunicações em posição extremamente desfavorável em termos desses indicadores.

Para análises quantitativas, foram também realizados estudos com duas bases de dados secundárias ${ }^{67}$ : PINTEC (Pesquisa Industrial: Inovação Tecnológica 2000 PINTEC / IBGE, 2002) e pesquisa realizada pela ANPEI (Associação Nacional de Pesquisa, Desenvolvimento e Engenharia das Empresas Inovadoras) (ANPEI, 1999).

Dentre as várias observações feitas a partir das análises realizadas neste trabalho, é possível fazer algumas considerações em relação ao comportamento geral das empresas fornecedoras de equipamentos para telecom. Primeiro, quanto à característica das empresas do setor que promovem a inovação, a PINTEC mostra que $62,1 \%$ delas são inovadoras, contra $31,5 \%$ das empresas dos demais setores estudados. Ou seja, os fabricantes de equipamentos de comunicações estão entre os segmentos mais inovadores. Uma outra característica que as distingue das companhias dos demais setores é o tipo de inovação, 78,3\% delas implementaram inovações em produto e de $61,6 \%$ em processos, contra $55,7 \%$ em produtos e $80 \%$ em processos nos demais setores. Os gastos em P\&D entre fabricantes de

\footnotetext{
${ }^{67}$ Apresentados no capítulo 8.
} 
comunicações ficou em torno de $5 \%$ do faturamento, nos demais setores, esse número é cerca de $3,8 \%$.

O destino desses investimentos também vale ser destacado, enquanto que a pesquisa mostra que, no geral, a atividade de P\&D que mais recebe recursos é "aquisição de máquinas e equipamentos", na amostra do segmento de comunicações, a principal atividade é "treinamento". É bastante provável que a Lei de Informática seja o principal incentivo para que isso ocorra.

Os dados da PINTEC também mostram que a rigidez organizacional é um dos fatores menos considerados como obstáculo para as empresas fabricantes de aparelhos e equipamentos para comunicações, cerca de $65 \%$ das empresas o apontam como fator de baixa relevância para a inovação. Isso não se confirma nos estudos de casos realizados neste trabalho, que mostram que a autonomia das empresas para conduzir atividades relacionadas ao desenvolvimento tecnológico é baixa. Nos estudos qualitativos realizados com as empresas, observou-se que há, por parte das subsidiárias, uma extrema dependência da matriz na tomada de decisão. A autonomia das unidades locais é extremamente limitada.

Sendo assim, a metodologia de aliar dados quantitativos a estudos qualitativos, aplicada nesta pesquisa, é pertinente, uma vez que permite confronto de dados e informações levantadas, levando a uma análise mais crítica, quer seja nos resultados qualitativos analisados ou nos quantitativos obtidos. Em alguns casos, os dados quantitativos corroboram com o estudo qualitativo, e, em outros, eles se opõem.

Na pesquisa da ANPEI, a amostra considerada é muito mais focada nas empresas que fizeram parte dos estudos de casos deste trabalho de doutorado do que a amostra da PINTEC, que é mais abrangente ${ }^{68}$. Nesse estudo, chama a atenção o tipo de atividade desenvolvida pelas empresas da amostra, na qual não aparecem despesas em pesquisa básica nem aplicada, mas sim desenvolvimento experimental (aproximadamente $67,4 \%$ dos gastos em P\&D\&E), engenharia não rotineira $(31,4 \%)$ e aquisição de tecnologia $(12,5 \%)$.

\footnotetext{
${ }^{68}$ Conforme explicitado no capítulo 8, entre as empresas consideradas na amostra da PINTEC não estão apenas empresas de telefonia, também foram agregados dados de companhias fabricantes de equipamentos de radio e televisão, uma vez que o IBGE considerou a seção 32 da CNAE.
} 
É relevante considerar que o número de pessoas empregadas em P\&D\&E para a amostra de companhias de telecom é muito superior ao número apresentado pela amostra geral. Cerca de $15,5 \%$ do total de funcionários em média, contra 2,5\% do total das empresas estudadas na pesquisa.

\section{Algumas Observações Finais}

Por fim, vale citar brevemente algumas considerações acerca do comportamento empresarial no país, principal foco deste trabalho, observado nesses anos estudando o setor de telecomunicações. A primeira observação é que o desenvolvimento tecnológico do setor no país está nas mãos das companhias estrangeiras atuantes localmente. São elas que realizam pesquisas na área e que, cada vez mais, ditam regras para $\mathrm{P} \& \mathrm{D}$ no país, inclusive nas instituições de pesquisa (universidades e institutos), mais e mais dependentes das parcerias de cooperação com as empresas.

Num primeiro momento, conforme "Hipótese 1" levantada neste trabalho, esperavase uma ausência de envolvimento das empresas localizadas no Brasil no DGP, no entanto, isso se mostrou falso, o que é uma grata constatação. Ou seja, há algumas iniciativas interessantes das subsidiárias com relação a desenvolvimento local e formação de competências, que colocam as equipes brasileiras dessas companhias como colaboradoras no DGP.

Porém, a participação ocorre especialmente em atividades de desenvolvimento de alguns nichos específicos de produtos e os resultados dessas atividades realizadas localmente, freqüentemente fomentadas com incentivos fiscais, não são sempre positivos em termos de atração de benefícios para o desenvolvimento do país.

De modo geral, as companhias têm uma posição conservadora para investimento local em P\&D, que, na maioria dos casos, ocorreu principalmente devido aos incentivos da Lei de Informática. As empresas apontam alguns problemas para a realização dessas atividades no país, mas apresentam uma ação pouco atuante para tentar reverter a situação. Por exemplo, elas citam a falta de políticas públicas e de mapeamento de competências das universidades locais como fatores negativos para 
investimentos em locais P\&D. Para esse último fator, algumas empresas, lideradas na época pela SEPIN/MCT, começaram a organizar uma rede de competências das universidades somente em 2001, projeto que ainda não foi concluído e que, aparentemente, está suspenso.

No entanto, no que se refere às políticas públicas existentes, grande parte das companhias, por exemplo, não conhecem, não buscam conhecer e, se conhecem, declaram não pretender usar os mecanismos existentes para financiamento de atividades de pesquisa apresentados pela FINEP. Algumas empresas chegaram a citar que não se interessam por financiamentos para realização de desenvolvimento tecnológico, o que elas querem são incentivos públicos, ou seja, investimentos por parte do governo.

Esse e outros aspectos revelam que as empresas, procurando maior competitividade e melhores posições nos seus âmbitos de atuação, têm certos comportamentos que caracterizam tendência de imposição de suas regras e de seus interesses. As companhias estudadas tentam determinar a dinâmica da inovação do setor como um todo e, algumas delas, infelizmente, fazem mau uso dos incentivos públicos em benefício próprio, sem que esses recursos sejam, de uma maneira geral, revertidos para o desenvolvimento do país.

\subsection{Propostas para Trabalhos Futuros}

Este trabalho de tese permitiu, entre outros, observar algumas áreas ligadas aos assuntos abordados em que há carências de estudos mais aprofundados e também levantou algumas questões que não puderam ser estudadas nesta fase, mas que seriam bastante pertinentes para trabalhos futuros.

A começar pela pesquisa em Internacionalização de $\mathrm{P} \& \mathrm{D}$, na qual há necessidade de um aprofundamento maior em alguns aspectos como a formação das equipes de trabalho e na divisão de trabalho entre elas. Os modelos existentes, e estudados no capítulo 4 e 7, não permitem uma classificação clara de empresas. Conforme avaliado no capítulo 7, para as empresas estudadas no setor de telecom, foi preciso 
propor uma alteração nos modelos, mas mesmo assim, as empresas, dependendo do nicho envolvido, apresentam diferentes estruturas organizacionais para trabalho internacional em DP.

Ainda em internacionalização de $\mathrm{P} \& \mathrm{D}$, também observou-se que há carência de pesquisas sobre concorrências diretas entre as subsidiárias de uma mesma empresa transnacional para obter a coordenação de determinado projeto de P\&D. Essas atividades foram observadas com muita freqüência entre as empresas estudadas.

Em telecomunicações, um setor bastante complexo e que está passando por um período de intensa transformação, vale a pena concentrar esforços no estudo de alguns aspectos relevantes, por exemplo, o das mudanças de papéis dos players da cadeia produtiva. $\mathrm{O}$ aparente avanço a jusante das companhias carece de mais aprofundadas análises.

No que se refere ao trabalho feito nesta pesquisa, algumas questões foram levantadas, mas não foram estudadas aqui, portanto merecem atenção em trabalhos futuros. Uma delas está relacionada à pesquisa sobre depósito de patentes pelas subsidiárias. Este é um assunto que levantou bastante interesse da comunidade científica nacional e internacional quando da apresentação de artigos em eventos na área, por ser algo inovador. Dessa forma, seria interessante aprofundar essas análises, por exemplo, fazendo alguns trabalhos comparativos entre as empresas de telecomunicações estudadas aqui e companhias de outros setores para observar se há diferenças de comportamentos.

Uma outra pesquisa também interessante a ser desenvolvida tendo como indicadores de C\&T, especialmente patentes, é sobre comparações entre subsidiárias de uma mesma TNC para avaliar os diferentes comportamentos em relação a concessões de patentes para determinadas unidades e a não concessão para outras afiliadas. Isso significa, por exemplo, pesquisar mais profundamente o porquê de existir maior participação das subsidiárias da Índia e da China como solicitantes de patentes do que as do Brasil.

Também relacionado a estudos quantitativos, como dados bibliométricos e de 
patentes são fortemente utilizados como indicadores de C\&T para comparações entre segmentos/setores, companhias, países e regiões, é importante analisar melhor as políticas estabelecidas por empresas TNCs relacionadas a esses temas ${ }^{69}$, e, se for o caso, propor a utilização de outros indicadores para avaliar a relevância da inovação realizada pelas empresas ou países.

Essa é uma maneira de analisar os resultados das atividades de $\mathrm{P} \& \mathrm{D}$ realizadas no Brasil, uma área em que esforços devem ser fortemente empregados, conforme citado anteriormente neste capítulo. Conhecer o retorno obtido pelos investimentos feitos através de recursos provenientes de incentivos físcais - como a Lei de Informática - é fundamental para orientação de investimentos futuros em P\&D.

Essa avaliação está relacionada a um outro fator extremamente importante a ser estudado com maior profundidade. Trata-se do mapeamento das competências do país em telecom, seja das atividades realizadas pelas companhias e pelas instituições de pesquisa nacionais ou dos possíveis segmentos em que o Brasil possui aptidão, oportunidade de participação e chances de destaque. Com essa avaliação das atuais e das possíveis competências das equipes nacionais, os investimentos em P\&D, que são escassos, poderiam ser orientados de maneira mais eficaz. E isso não vale apenas para o setor de telecomunicações, mas para qualquer outra indústria presente no país. Já existem algumas iniciativas nesse sentido, como o trabalho do DPP, financiado pela Finep, que é coordenado por equipes da Unesp e Unicamp e engloba pesquisadores de diferentes universidades e setores da economia, e busca conhecer as características desses setores em termos de desenvolvimento tecnológico. Especificamente no setor de telecom, há um projeto de pesquisa em andamento que engloba, entre outros, estudos sobre o dinamismo do sistema de inovação (empresas, universidades, centros de pesquisa, Anatel) e de competências no setor, trata-se do GICEG (Gestão da Inovação para a Competitividade Empresarial Brasileira no contexto da Globalização da Economia), realizado pelo PGT/USP, e financiado por Fapesp e MCT.

\footnotetext{
${ }^{69}$ As TNCs, ao realizarem pesquisas em diferentes países, têm políticas claras que estabelecem, por exemplo, quais serão as unidades detentoras de patentes (geralmente a matriz ou o centro de excelência em determinada tecnologia).
} 
E finalmente, uma outra área que merece atenção é a de políticas públicas para promover a inovação em países em desenvolvimento. Dessa forma, seria interessante a realização de uma pesquisa mais aprofundada sobre políticas mundialmente utilizadas para estímulo ao desenvolvimento local. 


\section{Anexo}

\section{Estudos de Casos com Empresas}

\section{MOTOROLA}

\subsection{Características Gerais da Empresa}

Fundada em 1928 nos EUA. Presente em 45 países, a empresa possui cerca de 87 mil funcionários (de um total de aproximadamente $140 \mathrm{mil} \mathrm{em} \mathrm{1999).} \mathrm{O} \mathrm{faturamento} \mathrm{em}$ 1999 foi de US\$ 30,9 bilhões, sendo que 8\% desse faturamento cabe à América Latina - AL (U\$ 2,47 bilhões). Em 2000, o faturamento do grupo foi de US\$ 37,5 bilhões e a participação da AL permaneceu aproximadamente igual. As atividades na AL estão concentradas principalmente no México, Argentina e Brasil, que tem, dos três países o maior faturamento, mas os números não foram fornecidos pela empresa $^{70}$.

A China é um mercado importante para a Motorola e com características particulares. Os chineses representam $72 \%$ da mão-de-obra do quadro da empresa e $65 \%$ dos produtos negociados pela filial chinesa foram produzidos domesticamente. Além de se manter líder no mercado local de telefonia celular, o centro de pesquisa em softwares tornou-se o terceiro na hierarquia corporativa, atrás dos Estados Unidos e Índia. Este centro desenvolve, produz, comercializa localmente e exporta um produto que integra telefonia sem fio e internet. Incluídas os empreendimentos conjuntos, a Motorola da China exportou US\$ 2,5 bilhões em 2000, contabilizando um superávit

\footnotetext{
${ }^{70}$ No entanto, no Dossiê da empresa elaborado para a pesquisa DPP/Finep (GEEIN, 2002d), afirma-se que a subsidiária brasileira teve faturamento de US\$ 950 milhões em 1999.
} 
comercial de US\$ 865 milhões, o que a torna a maior exportadora estrangeira no país. Para efeitos comparativos, a Motorola Malásia, radicada há 28 anos na região, conta com aproximadamente 8.000 funcionários e um centro de P\&D com 40 patentes registradas (GEEIN, 2002d).

Iniciou suas atividades no país em 1971, com escritório de vendas de semicondutores e representantes na área de comunicação. Em 1992 cria-se a Motorola do Brasil, e em 1996 começam as atividades de fabricação em Jaguariúna, em local próximo ao da atual planta onde hoje são fabricados terminais celulares, pagers, estações rádio base (Estações Rádio Base - ERB) para rede celular e equipamento iDEN. Em 1997 cria-se o centro de tecnologia de semicondutores. A razão social da subsidiária no Brasil é Motorola Industrial Ltda, que é unidade controlada, na condição de subsidiária, pela Motorola Inc., a matriz da TNC.

A unidade brasileira principal é a de Jaguariúna, considerada a matriz no país, com atividades de produção, engenharia para suporte a produção, engenharia de desenvolvimento de produtos e pessoal administrativo para a unidade local. Em São Paulo está localizada a sede da Motorola Brasil com atividades comerciais e administrativas. A companhia também possui escritórios em Porto Alegre e Curitiba, onde são localizadas atividades administrativas / comerciais.

A TNC é dividida em unidades de negócios: setor de produtos de consumo; setor de produtos para comércio, indústria e governo; setor de produtos semicondutores; setor de eletrônicos integrados; setor de soluções para redes - grupo de redes e Internet, grupo de gerenciamento de redes, grupo de soluções de telecomunicação global.

\section{2- Fabricação Local}

Dos produtos fabricados localmente, alguns se destacam pela importância comercial e pela ligação direta com telefonia (área concernente a esse trabalho): terminais celulares CDMA, TDMA e GSM, estações rádio base (ERB), rádios profissionais e terminais iDEN (para comunicação móvel empresarial - Trunking), que são produtos com aceitação crescente no mercado nacional. 
A fabricação de terminais celulares é direcionada não apenas para o mercado local / regional, mas também para o exterior. As equipes mundiais que participam do desenvolvimento desse produto (terminais) estão em vários países, inclusive no Brasil. Em 2002, a fabricação de aparelhos celulares no Brasil foi de 6 milhões de unidades, para 2003 há uma previsão de 11 milhões de aparelhos e um aumento significativo nas exportações desse segmento de produtos.

Considerando o desenvolvimento de processos de fabricação, em geral, eles são feitos fora e adaptados localmente, mas segundo um funcionário da subsidiária, as alterações que os brasileiros fazem na linha de produção são, muitas vezes, copiados em unidades da Motorola localizadas em outros países. Por exemplo, a unidade brasileira desenvolveu um software de gestão de testes de terminais celulares (final da linha produtiva desses equipamentos), que foi implantado também em outras unidades como México e Argentina.

Vale destacar que a fabricação de produtos é feita pela Motorola, mas se a demanda é grande, a ponto da unidade fabril da companhia não ser capaz de conseguir atender aos pedidos, parte da produção é repassada à Celestica, empresa que atua com montagem de equipamentos eletrônicos (CEM - Contract Electronics Manufacturers).

\subsection{Pesquisa e Desenvolvimento}

Na Motorola, a pesquisa é claramente distinta do desenvolvimento. A pesquisa é feita especialmente nos Motorola Labs (localizado em alguns países da Ásia e Europa, além dos EUA), que norteiam as subsidiárias em termos de desenvolvimento tecnológico, e nas universidades parceiras (em projetos de interesse da e financiados pela empresa).

O desenvolvimento de produtos na Motorola, em geral, segue as seguintes etapas: definição do conceito, criação do business case (aspectos econômicos, financeiros, de posicionamento de mercado, de trajetória de produto), concepção do produto, desenvolvimento técnico (hardware, software, mecânica, qualidade), prototipação, produção em baixa escala e produção em alta escala. Intercalado em várias dessas fases estão as etapas de teste: de produto, de sistema, de integração e de campo. 
No Brasil, seguindo as estratégias estabelecidas pela matriz - em termos de tecnologia a ser usada, novos produtos, segmentos novo ou a serem continuados, o setor de marketing (Product Marketing) verifica preferências e necessidades dos consumidores locais. O business case é preparado para, só então, após aprovação, ser encaminhado ao desenvolvimento.

A Motorola mundial divide o desenvolvimento de seus produtos em três áreas, uma ligada a soluções para comunicações (CE - Communication Enterprise), outra para o desenvolvimento de semicondutores (SPS - Semiconductor Products Sector) e uma terceira ligada a sistemas eletrônicos integrados para indústria automotiva, de navegação, de energia e de computação (Integrated Eletronic System Sector). As duas primeiras têm presença no Brasil.

Dentro da área de comunicações (CE), tem-se várias subdivisões dependendo do produto criado: para consumidor final (Personal Communications Sector - PCS), para infra-estrutura de telefonia (Global Telecom Solutions Sector - GTSS), para soluções Internet (Internet and Networking Group - ING), para comunicação em alta velocidade (Broadband Communications Sector - BCS) e para soluções sistêmicas (Commercial, Government and Industrial Solutions Sector - CGISS).

Dessas subdivisões de CE, estão presentes na subsidiária brasileira a GTSS e a PCS. Também está instalado localmente centro de pesquisa para o desenvolvimento de semicondutores (SPS). Várias unidades dedicadas ao desenvolvimento de produtos para cada uma dessas divisões estão distribuídas globalmente e são coordenadas pela unidade similar na matriz. A figura I ilustra tais relações.

Estima-se que a empresa investe em $\mathrm{P} \& \mathrm{D}$ pouco mais de $5 \%$ do faturamento no Brasil, mas esse dado não é confirmado pela empresa. Os funcionários estão distribuídos em dois centros de desenvolvimentos (um ligado ao SPS e o outro ao CE): o BSTC (Brazil Semiconductor Technology Center), para desenvolvimento de projetos de circuitos integrados (possui atividades de desenvolvimento de novos produtos), e o Engenharia da América Latina, que se subdivide em centro de pesquisa e desenvolvimento de terminais pessoais (que possui atividades de desenvolvimento de novos produtos e de tropicalização de produtos globais) e o 
centro para produtos de infra-estrutura em telefonia (que atua principalmente na tropicalização de produtos).

O BSTC nasceu ligado ao departamento de vendas da América (estranha-se o fato de ser um centro de pesquisa ligado a um departamento de vendas), recebendo inicialmente recursos provenientes da lei de informática. Segundo informações da empresa, é um centro que se destacou e se destaca pela competência, solucionando projetos complexos com pouco recurso (possui cerca de 100 funcionários) e em pouco tempo. Isso e o fato de que a descentralização do desenvolvimento de semicondutores é relativamente antiga na TNC (teve início na década de 70) contribuíram para a expansão e consequentemente o destaque do BSTC.

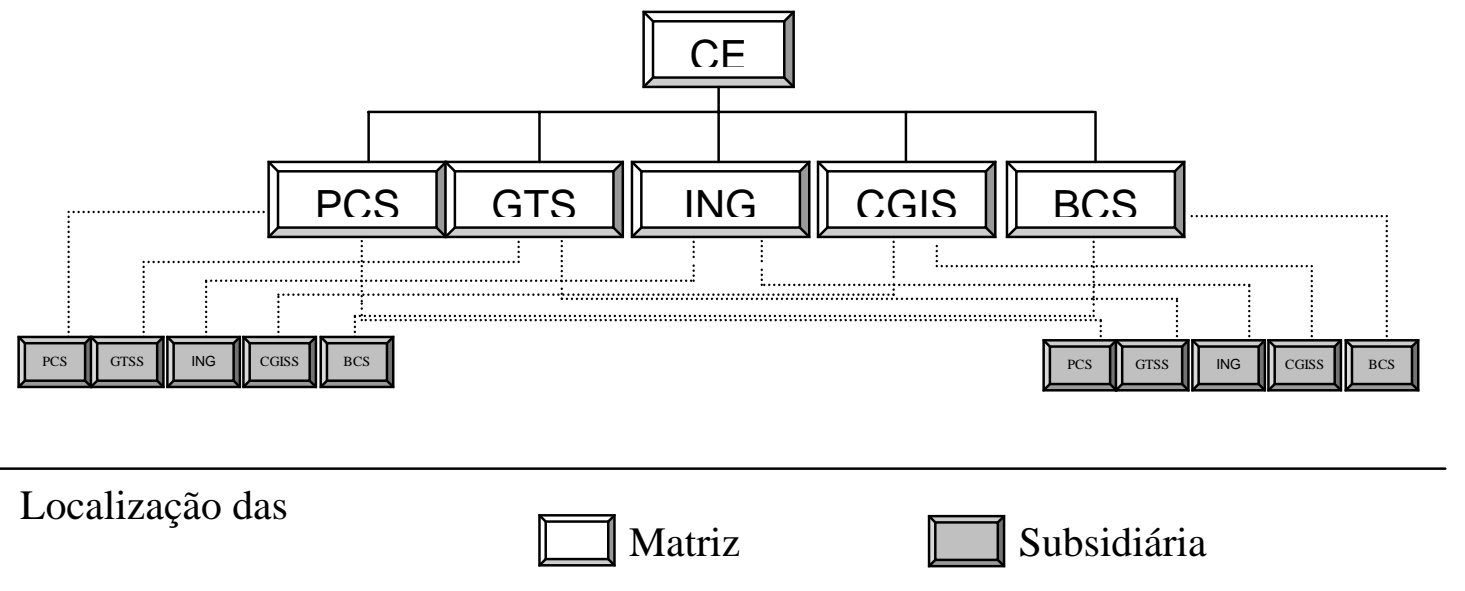

Figura I - Interligação entre as unidades globais de P\&D da área de comunicações (CE)

Esse centro faz parte de um conjunto global de centros de desenvolvimento de semicondutores (SPS) que a Motorola possui. Os principais centros, além do brasileiro, estão localizados nos EUA, Europa (Alemanha, Suíça, França), Japão e Singapura. A "rede" de centros de desenvolvimento para semicondutores funciona da seguinte maneira: dependendo do produto a ser desenvolvido, as unidades de operações da empresa (Operation Management) acionam um dos Centros de Desenvolvimento de Semicondutores (CDS) e solicitam o desenvolvimento do produto específico. A figura II ilustra parcialmente essa "rede". 
O BSTC possui uma estrutura para desenvolvimento de produtos dividida entre os tipos de tecnologia dominados. Tem-se então um gerente da unidade de P\&D e, ligados a ele, os vários líderes de tecnologia. Hoje esse centro brasileiro está ligado a várias unidades de operações da empresa, localizadas em diversos países (principalmente nos EUA e França). Essas unidades solicitam desenvolvimento de produtos para o BSTC e se comportam como clientes, como fornecedores de produtos básicos para o desenvolvimento e como financiadores do centro, assim ele se destaca mundialmente como centro de excelência no desenvolvimento de circuitos integrados e depende cada vez menos de recursos da unidade brasileira. Vale destacar que os produtos desenvolvidos aqui pelo BSTC não são fabricados localmente.

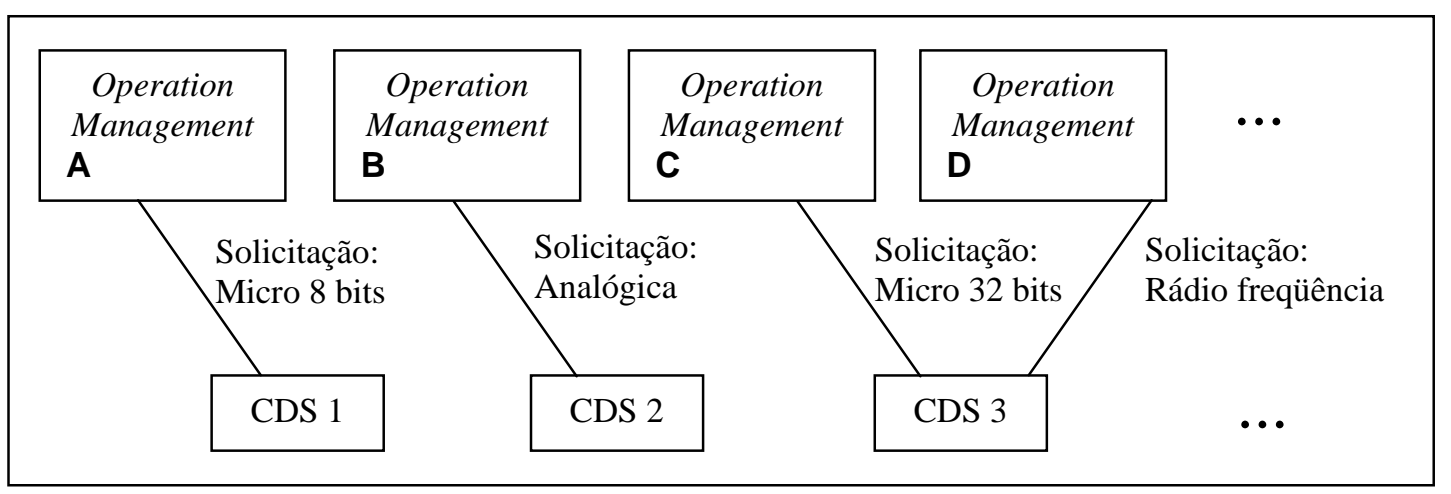

Figura II - Estrutura dos Centros de Desenvolvimento de Semicondutores

Os outros centros de P\&D localizados no Brasil estão ligados à área de comunicações (CE), são o centro de desenvolvimento de produtos para consumidor final (PCS), chamado Engenharia da América Latina, e o de DP para infra-estrutura de telefonia (GTSS). A principal atividade do GTSS é tropicalizar os produtos globais fabricados no Brasil e está relacionada especialmente ao desenvolvimento de softwares.

O PCS desenvolve terminais celulares e fixos para telefonia. Esse centro possui características organizacionais diferentes do centro de desenvolvimento de semicondutores (BSTC). Além do brasileiro, a Motorola possui outros centros de tecnologia PCS (em cerca de 20 países), cujas atividades são coordenadas pelo centro de tecnologia similar localizado na matriz, em Chicago - EUA (como foi ilustrado na figura I). Esse centro possui atualmente cerca de 100 funcionários. 
A criação desse grupo de desenvolvimento de produtos no Brasil tem uma história interessante. Em 1996 a subsidiária começou a montar um plano para ter uma equipe especializada para desenvolvimento na área e criar produtos mundiais (especialmente terminais celulares) até o ano de 2000. Para montar o grupo, descobriu-se que, em muitos segmentos, os profissionais tinham capacidade técnica, mas era escassa a mão de obra qualificada em algumas áreas (ex. rádio frequiência, pesquisa básica e software básico).

Assim, foi montada uma estratégia de qualificação profissional com universidades, o Programa de Capacitação Tecnológica (PCT), e de treinamento de funcionários. Grande parte do treinamento de funcionários foi feito na matriz e em unidades especializadas da Motorola. Esse intercâmbio auxiliou a integração com as equipes externas e possibilitou mostrar a capacidade do profissional brasileiro. Isso permitiu o crescimento e o destaque da equipe local frente a matriz. Tal desenvolvimento de competências levou o Brasil a ter profissionais que trabalham em igualdade com equipes internacionais em algumas áreas específicas.

Esse grupo foi criado graças aos incentivos da lei de informática porque no início a matriz não incentivou a iniciativa da subsidiária porque não tinha planos de montar no Brasil um centro de $\mathrm{P} \& \mathrm{D}$. Na opinião dos entrevistados, o grupo não teria sido criado se não existisse o respaldo financeiro possibilitado pela lei. Hoje, o grupo de pesquisa conta com alguns investimentos da matriz (como treinamentos em outras unidades), mas ainda depende da lei de informática, mas, segundo a empresa, a meta é depender cada vez menos de incentivos locais.

Devido à natureza dos produtos desenvolvidos, a estrutura funcional desse centro para desenvolvimento local é dividida em áreas específicas:

- design industrial (para desenvolver o design dos terminais),

- mecânica (para compactação e ajuste dos componentes),

- hardware (especializado em rádio-freqüência e componentes digitais),

- software 
- gestão de projetos (gerenciamento de escopo do produto, custo e tempo).

Algumas dessas áreas possuem maior competência local que outras, ainda dependentes de conhecimento gerado externamente.

Segundo informações da Motorola Brasil, a equipe brasileira está envolvida em todas as etapas do DP, mas o grau de participação é decrescente quanto mais no início estiver o desenvolvimento. Segundo informações da empresa, isso vem mudando e a participação está crescendo com a maturidade das equipes de desenvolvimento.

Em meados de 2000, a cidade de Porto Alegre foi escolhida para receber as instalações do Centro de Excelência Ibero-Americano em Tecnologia Eletrônica Avançada (Ceitec), com o objetivo de fabricar e testar protótipos de chips. Segundo a direção da empresa não se trata de um centro para a Motorola, mas de um pólo tecnológico na área da microeletrônica e que centros deste gênero só existem na Alemanha, Estados Unidos, China e na Austrália. O investimento total é de US\$ 25 milhões com cerca de metade dos recursos da Motorola. O restante dos custos foram divididos entre a iniciativa privada, o poder público e universidades (GEEIN, 2002d).

Existe, mundialmente, uma competição entre as subsidiárias para a participação no DP, ou seja, uma unidade global da Motorola, que possui centros de desenvolvimento, precisa provar, a cada projeto, que é a melhor opção da companhia para participar do desenvolvimento. Isso acontece principalmente para o desenvolvimento de software, já que, para hardware, o número de unidades mundiais é bem menor.

Segundo os funcionários entrevistados, a Motorola no Brasil já se provou competente no desenvolvimento de software, o que facilita sua inserção na rede mundial de desenvolvimento. No entanto, ela continua, a cada novo projeto, tendo que comprovar que é opção no que se refere a cumprimento de metas (prazo, qualidade, eficiência, etc.).

No caso de software para celular, a decisão de onde ele será desenvolvido é tomada por uma unidade norte-americana (não é a matriz), baseada em características / 
competências de cada subsidiária mundial. Essa unidade é a controladora do desenvolvimento global de produtos para terminais de telefonia móvel. É claro que um outro fator que influencia na escolha é o mercado local de cada subsidiária, mas não é ele que determina o tipo de produto que será desenvolvido localmente, uma vez que os produtos são globais e há pouquíssimas adaptações locais. Muitas vezes os produtos são desenvolvidos no Brasil e nem são fabricados ou comercializados no país.

Foram apresentados, pelos funcionários entrevistados, alguns exemplos de casos em que a unidade Brasil conseguiu ser superior aos seus concorrentes no exterior, no entanto não autorizaram sua divulgação. Uma das qualidades apresentadas pela subsidiária local é o relacionado a métricas de qualidade de software, e, segundo entrevistas realizadas, o Brasil tem índices excelentes, sempre se mantendo entre os melhores do mundo e, algumas vezes, superando os de outras subsidiárias de países desenvolvidos. Atualmente a empresa local possui CMM nível 3, mas acredita que no final de 2003 obtenha nível 4.

A maioria desenvolvimento de produtos no Brasil é relacionada a mudanças incrementais, pouca inovação acontece localmente e, quando existe, é relacionada a design ou a interface dos aparelhos. Apesar de existir, pouco do desenvolvimento local refere-se a mudanças na plataforma dos produtos. No caso dos aparelhos celulares, nem mesmo o Sistema Operacional ou os softwares para conexão com as operadoras foram ou são desenvolvidos no Brasil. Apenas no BSTC, o desenvolvimento de novos produtos é mais inovador para o mercado mundial.

A estrutura organizacional para o desenvolvimento internacional de produtos é divisional, ou seja, as diretorias locais de cada um dos segmentos tecnológicos são subordinadas às vice-presidências regionais ou mundiais de tais segmentos. Por exemplo, o diretor da área de PCS no Brasil responde à vice-presidência de PCS da América Latina, que por sua vez, subordina-se à presidência mundial da tecnologia para comunicação pessoal. No caso de semicondutores, o diretor brasileiro de BTSC, responde ao vice-presidente mundial de semicondutores. Sendo assim, ambas as unidades que possuem desenvolvimento no Brasil reportam-se às vice-presidências de cada área tecnológica específica. 


\subsection{Fatores que atraem $P \& D$ para o Brasil}

Segundo as entrevistas feitas, a tendência da Motorola é descentralizar cada vez mais o desenvolvimento de produtos. Considerando essa estratégia da transnacional, o Brasil está entre os países com potencial para atrair centros de desenvolvimento de produtos. Segundo a empresa, entre os fatores que alavancaram a participação brasileira no DP, três se destacam. O primeiro é a proximidade do mercado consumidor, especialmente no caso dos terminais celulares. Isso possibilita o desenvolvimento de conhecimento intrínseco ao produto.

Um segundo fator importante é o incentivo fiscal proporcionado pela lei de informática, o que alavancou os investimentos em $\mathrm{P} \& \mathrm{D}$ no país. Ficou claro nas entrevistas, que os incentivos estimulam o investimento, mas não o garantem ou mantém por muito tempo. Segundo os executivos da empresa, mesmo com o incentivo, não haveria investimentos se não fosse a estratégia da empresa descentralizar P\&D e se não fossem outros fatores atraentes. Mas como é possível ver em pelo menos duas equipes de desenvolvimento (BSTC e PCS), a lei ajudou a subsidiária local a se dar o direito de correr os riscos da criação desses centros de pesquisa localmente.

No entanto, há uma característica de orientar os investimentos para desenvolvimento de projetos locais. Segundo direção da companhia, os recursos da lei de informática "permitem criar soluções baratas para as características do mercado brasileiro, que não se repetem em nenhum lugar do mundo" (Gazeta Mercantil, 2001). Foi por esta condição que a empresa desenvolveu no Brasil o atual padrão dos telefones sem fio, hoje fabricados na China e vendidos no mundo todo.

Mas, de todos, o item que mais se destaca é o da geração de competências, decorrente do fator histórico. Conforme discutido na seção anterior, alguns itens relacionados às competências locais são fundamentais para atração de DP para a unidade brasileira. Segundo os executivos da empresa, a tradição brasileira de desenvolver produtos, especialmente no setor de telecomunicações, pesa muito 
quando se está decidindo por um novo centro mundial de P\&D. De acordo com frase de um dos entrevistados, "os brasileiros têm uma cultura de desenvolvimento extremamente positiva, os funcionários da subsidiária local sabem que é possível desenvolver aqui, sabem que poderá dar certo, portanto se arriscam com muito mais frequiência que funcionários de várias outras subsidiárias, não apenas das latino americanas".

Essa consciência está ligada a um passado de relativo sucesso na área de telecomunicações das equipes brasileiras de pesquisa, especialmente no $\mathrm{CPqD}$ e nas empresas brasileiras existentes antes da abertura do setor e da privatização das empresas prestadoras de serviço (Sistema Telebrás). Os antigos pesquisadores do $\mathrm{CPqD}$, cuja maioria está atualmente em empresas internacionalizadas privadas, têm experiência em desenvolvimento de produtos e conseguem liderar, ainda hoje, projetos de sucesso.

Alguns outros fatores podem também ser apontados no caso específico da Motorola, quando se investe em P\&D no Brasil. Fica claro nas entrevistas que, para haver investimentos locais em DP, há necessidade da subsidiária estar enquadrada como player nas estratégias globais da TNC. Um desses outros fatores é o baixo custo para o desenvolvimento tecnológico se comparado com os custos dos centros instalados em países desenvolvidos, mas segundo entrevistas, esse fator é importante, mas não é determinante de sucesso.

Tanto é que, ficou claro durante as entrevistas, o custo do desenvolvimento no Brasil não está entre os mais baratos do mundo, mesmo com a queda do valor da moeda local (Real) em relação ao Dólar, e, hoje, os custos da Motorola Brasil superam até mesmo os do Canadá. Isso acontece não apenas pelo valor da mão-de-obra (encarecido com os encargos), mas principalmente pelo alto preço de equipamentos utilizados para o desenvolvimento - principalmente os ligados à informática, muitas vezes importados. Em alguns outros países, segundo os entrevistados, a aquisição de tais equipamentos é subsidiada com incentivos fiscais. Esse é um dos fatores que dificultam a realização de $\mathrm{P} \& \mathrm{D}$ no país, conforme discutido na próxima seção. 


\subsection{Dificuldades quando se realiza $P \& D$ no país}

Além dos problemas de custo de desenvolvimento local, que, no Brasil, segundo executivos da Motorola, não são tão baixos quanto em outros países concorrentes diretos, especialmente no desenvolvimento de software (que tem Índia como principal competidor), algumas outras dificuldades foram apontadas nas entrevistas quando se realiza $\mathrm{P} \& \mathrm{D}$ no país. Entre elas estão os problemas políticos da organização, o que dificulta a relação entre matriz e subsidiária. Se não forem bem administrados, podem comprometer o sucesso dos projetos locais.

O fator mão-de-obra especializada também foi citado. $O$ problema está mais na quantidade disponível de pessoas do que na qualificação dessas pessoas. Segundo um dos executivos da empresa, apesar de estarem em um número muito reduzido se comparado com o número de profissionais em países desenvolvidos, as pessoas que estão no mercado são, em sua maioria, tecnicamente muito boas, embora em algumas áreas específicas sejam escassas como já foi citado anteriormente.

Um outro diferencial citado pela empresa entre os profissionais estrangeiros e os brasileiros, é que esses possuem formação técnica mais ampla que aqueles, muito mais especializados numa área específica. Contribuem ainda para a qualificação da mão-de-obra, os aspectos históricos, uma vez que os profissionais mais experientes possuem habilidades para desenvolvimento de produtos, adquiridas principalmente quando a economia era fechada e havia a necessidade de desenvolvimento interno nas empresas multinacionais.

\subsection{Interface com Universidades e Centros de Pesquisa}

A Motorola mundial, tradicionalmente, dá importância à cooperação com universidades ou centros de pesquisa. No Brasil ela tem alguns projetos com universidades e centros de pesquisa, incentivados principalmente pela lei de informática, embora alguns projetos tenham começado sem o incentivo da lei. Um dos entrevistados fez questão de afirmar que "a política de apoio às universidades é independente de Lei, apesar da Lei estimular mais investimentos". Segundo informações obtidas na empresa, houve maior estímulo para utilizar as estruturas das 
universidades por causa da lei, mas com a parceria, descobriu-se que as equipes acadêmicas possuem competências que devem ser aproveitadas.

Os projetos de integração estão ligados ao treinamento e qualificação profissional de alunos e ao desenvolvimento de produtos. O treinamento é feito em parceria com as universidades e conta com reestruturação de currículos, oferecimento de disciplinas extra-curriculares, estágios, capacitação de professores e técnicos, montagem de infra-estrutura (laboratórios e equipamentos), etc. São várias as universidades que participam dessa parceria, entre elas, a Escola Politécnica da USP, a Faculdade de Engenharia Industrial (FEI), o Instituto Nacional de Telecomunicações (Inatel) em Santa Rita do Sapucaí - MG, a Universidade Federal de Pernambuco, a Universidade Estadual de Campinas, e outras.

O desenvolvimento de produtos não é apenas feito com universidades, por exemplo, UFSC, UFRGS, PUC-PR, UFPE e UNB, mas também com centros de pesquisa especializados como o CESAR, o CEITEC (Centro de Excelência Ibero Americana de Eletrônica Avançada) em Porto Alegre, o Inatel e o Instituto Eldorado, criado pela própria Motorola. Esses parceiros geralmente estão envolvidos com atividades de testes ou algum projeto que não seja core da empresa ou não seja sigiloso. Segundo os entrevistados, e busca por esses parceiros acontece não porque a equipe interna da empresa não seja capaz de desenvolver internamente, mas porque é mais barato ou mais rápido fazer fora. Atualmente (2003), a cooperação acontece principalmente com o CESAR e o Eldorado.

Ficou claro que a empresa tem integração com universidades e centros de pesquisa no Brasil, mas as atividades cooperativas parecem estar muito mais focadas na formação de profissionais especializados do que no desenvolvimento de produtos.

\subsection{Aquisição de tecnologia}

Segundo informações da empresa, a Motorola não paga royalties para a matriz, toda informação necessária para a fabricação de produtos desenvolvidos fora é passada por meio de documentação ou de treinamento de funcionários. $25 \%$ do treinamento ocorre na matriz e depois é repassado para os funcionários da unidade local. Alguns 
são treinados por instituições de ensino locais através do programa Motorola University.

\subsection{Autonomia da Subsidiária}

A subsidiária tem relativa autonomia para definição de estratégias locais, mas fica muito claro em entrevistas com a empresa, que a unidade Brasil faz parte de uma rede global de empresas e sempre trabalha direcionada pelas estratégias mundiais da companhia.

A autonomia parece ser maior na definição de processos do que de produtos. Por exemplo, é possível negociação direta entre a subsidiária e fornecedores locais e mundiais, e a definição ou alteração de processos produtivos. Por outro lado, são mais restritas decisões sobre desenvolvimento de novos produtos e estudos de preferências / necessidades dos consumidores locais, que são feitas em conjunto com a matriz. Até mesmo a tropicalização dos produtos é muitas vezes feita em conjunto com a matriz, isso porque, algumas vezes, a equipe local não consegue fazer todas as alterações necessárias não há recursos suficientes para atuar em todas as frentes simultaneamente. 


\section{2- NEC}

\subsection{Características Gerais da Empresa}

A NEC é uma empresa de tecnologia, cujo capital é inteiramente japonês, e que atua com produtos e serviços para comunicações. Fundada em 1899, conta hoje com 155 mil funcionários. Teve faturamento de U\$ 40 bilhões no ano de 1999. Veio para o Brasil em 1963 para trabalhar no tronco sul da Telebrás. Instalou sua unidade produtiva em 1968 com a fabricação de centrais telefônicas.

A unidade brasileira faturou em 1999, US\$ 800 milhões (cerca de $2 \%$ do faturamento global da empresa). Esse valor vinha caindo cerca de $20 \%$ ao ano desde 1997 devido, principalmente, à privatização do sistema Telebrás em 1998, que estagnou o mercado naquele ano e a desvalorização do real em 1999. Em 2001, o faturamento da companhia no Brasil ficou em cerca de R\$ 320 milhões, valor muito inferior ao de 1999.

Possui no país uma unidade principal, localizada em Guarulhos na grande São Paulo, onde são desenvolvidas atividades administrativas, comerciais, de produção, engenharia e desenvolvimento de produtos. Outros escritórios estão instalados nas principais capitais do Brasil, mas apenas para comercialização e implantação de serviços. Em 2000, cerca de 1400 funcionários diretos e 1500 indiretos trabalhavam na NEC do Brasil. Após a crise pela qual passou o setor em 2001, o número de funcionários diretos caiu para 400 em 2002. O número de indiretos não foi divulgado em 2002, mas sabe-se que também sofreu redução significativa.

A quantidade de funcionários indiretos é grande na companhia porque a subsidiária no Brasil terceirizou a produção, deixando a mesma a cargo da norte-americana Celestica, o que pode ocorrer também na unidade japonesa. O objetivo da empresa é concentrar-se em soluções (serviços) e desenvolvimento tecnológico. A fabricação terceirizada é feita na mesma unidade onde já estava sendo realizada quando ainda era feita pela NEC. Atualmente, da empresa é classificada como sendo de revenda, ao invés de fabricante. 
Para utilizar recursos da Lei de Informática, a NEC compartilha direitos e responsabilidades com a Celestica, que é a responsável pelo PPB (Processo Produtivo Básico). Os investimentos em P\&D ficam divididos entre as duas empresas, mas a NEC é responsável por uma parte maior para o investimento interno e é totalmente responsável pelo investimento externo, ou seja, por projetos cooperativos com universidades e centros de P\&D.

\subsection{Fabricação Local}

Como citado na seção anterior, a NEC no Brasil terceirizou completamente sua fabricação para a Celestica, no entanto, ela é responsável pela venda e assistência técnica dos produtos fabricados localmente. Esses produtos visam, principalmente, o mercado interno, como pode ser visto na tabela I. Segundo informações da empresa, o índice de importação de insumos está em torno de $70 \%$ do custo dos produtos. Os insumos importados são principalmente componentes eletrônicos dos equipamentos e variam de produto para produto.

\begin{tabular}{|l|c|}
\hline Produto & Mercado Interno $^{\#}$ \\
\hline Centrais Telefônicas (switches) - NEAX Sigma & $100 \%$ \\
\hline $\begin{array}{l}\text { Sistemas de Rádio ponto a ponto (Radio Transport Systems - } \\
\text { Point-to-Point) }\end{array}$ & $100 \%$ \\
\hline Equipamentos para Acesso a Rede - FA 2000 / FA 1201 & $80 \%$ \\
\hline Estações Rádio-Base CDMA & $100 \%$ \\
\hline Multiplexadores (Multiplexers) - SMS / STH. & $98 \%$ \\
\hline \# Dados referentes ao ano de 2000 \\
\hline
\end{tabular}

Tabela I - Mercado destino dos produtos fabricados na subsidiária brasileira (Fonte: NEC)

Vale destacar que os equipamentos de acesso à rede (a linha dos produtos chamados FA na empresa $)^{71}$, que possuem tecnologia brasileira, já tiveram um índice bem maior de exportação, chegando a $60 \%$ do total da produção segundo informações fornecidas pela própria empresa.

\footnotetext{
${ }^{71}$ São equipamentos que permitem a ligação dos assinantes à rede de comunicação.
} 
Até o ano de 2001, segundo informações apresentadas pela empresa, as centrais telefônicas representavam cerca de 40 a 50\% dos das vendas da subsidiária brasileira, e os equipamentos de transmissão (FA) contribuíam com 20 a 30\% do faturamento. Já em 2002, essas participações inverteram-se e os FAs passaram a ter a primeira posição da empresa, seguidos pelos equipamentos de rádio e o percentual de vendas das centrais telefônicas caiu para praticamente zero. Segundo estimativa da empresa, a tecnologia de rádios é a que tem maior perspectiva de crescimento nos próximos anos.

\subsection{Pesquisa e Desenvolvimento}

Segundo Bartlett \& Ghoshal (Bartlett \& Ghoshal, 1992), a NEC vivenciou os problemas da centralização da coordenação de DP com a expansão rápida de suas operações de telecomunicações no exterior durante as décadas de 70 e 80 . O controle centralizado mostrou-se eficaz para a expansão da NEC para os mercados próximos da Tailândia e Taiwan na década de 1960. E, apesar de algumas dificuldades no gerenciamento da nova onda de demandas, a companhia continuou a operar de maneira eficiente quando criou uma empresa independente no Brasil no final dos anos 60 e mesmo quando começou a penetrar o mercado mais avançado dos EUA na década de 1970.

Ainda segundo os mesmos autores, o tamanho e a complexidade das operações no exterior dificultavam o processo central de coordenação na década de 80. Para manter o processo centralizado, os gerentes corporativos da NEC tinham que viajar freqüentemente para as afiliadas no exterior. Em meados da década de 80 os gerentes da NEC registravam aproximadamente 10 mil viagens internacionais por ano (Bartlett \& Ghoshal, 1992). A empresa estava considerando mudanças no tipo de coordenação porque os custos da centralização estavam excedendo os benefícios. Hoje, apesar de parecer ainda bastante centralizadora, a empresa já possui unidades globais com participação no desenvolvimento tecnológico.

A NEC global tem adotado uma política de descentralização de desenvolvimento, a matriz procura incentivar / forçar o desenvolvimento local. Segundo informações da empresa, segue-se essa estratégia com o objetivo principal de atender as exigências 
regionais (mercado e legislação) e tirar proveito do talento local. Um outro fator que interferiu na adoção da estratégia descentralizadora foi o relacionado à necessidade de maior dinamismo no atendimento a clientes para conquista de mercado, a distribuição de unidades de pesquisa permite concentração nas necessidades locais.

É política da empresa é desenvolver localmente todo produto específico para mercados locais. A NEC do Brasil compete com outras filiais da empresa pelo mercado da América Latina, consequentemente compete para sediar a unidade responsável pelo desenvolvimento de soluções para atender mercado local/regional.

A NEC Corporation (grupo mundial) é extremamente inovadora. Para ilustrar, No ano de 2000, a TNC classificou-se em $2^{\underline{o}}$ lugar no ranking das corporações do setor privado que patentearam o maior número de invenções, nos Estados Unidos (GEEIN, 2002a). O levantamento é da USPTO (The United States Patent and Trademark Office), e repete a posição conquistada pela NEC Corporation em 1999.

A NEC mundial investe aproximadamente $7 \%$ do faturamento em P\&D. Essa tendência se confirma no Brasil, onde, segundo informações da própria empresa ${ }^{72}$, foram investidos em P\&D no ano de 1999 cerca de 6,5\% do faturamento local. A distribuição dos recursos é feita segundo as diretrizes da lei de informática, assim, dos investimentos aqui, cerca de $4,5 \%$ do faturamento são para o desenvolvimento de produtos feito internamente na empresa e $2 \%$ são para pesquisas em conjunto com órgãos públicos, atendendo a lei de informática (gastos em 1999). Chama a atenção que o investimento interno em 1999 foi superior ao exigido pelo MCT (3\%), que é o normalmente praticado pelas outras empresas pesquisadas.

Nos anos de 2000 e 2001, os investimentos ficaram no patamar de 5\%, um pouco inferiores aos 6,5\% do ano de 1999, no entanto, como o faturamento da companhia caiu em termos absolutos, os valores investidos em P\&D diminuíram muito desde 1999. Os valores destinados a atividades internas e externas permanecem semelhantes, seguindo as indicações da lei de informática. O número de funcionários

\footnotetext{
${ }^{72}$ Confirmados com dados fornecidos pela NEC ao MCT para comprovação dos recursos utilizados em função da lei de informática.
} 
que trabalham com desenvolvimento de produtos na subsidiária brasileira caiu de 250 em 1999 para 110 em 2002.

Em março de 2003, a área de P\&D foi praticamente extinta e as pessoas que antes trabalhavam na área foram alocadas para outros setores, especialmente comercial e assistência técnica. Os entrevistados garantem que isso aconteceu "em virtude das dificuldades enfrentadas no mercado local, que não justifica manter uma área de desenvolvimento, uma vez que não tem produtos a desenvolver".

O processo de desenvolvimento de novos produtos segue o modelo tradicional de DP e envolve as seguintes etapas:

- análise do mercado ou solicitação de serviços por parte dos clientes (no caso de produto sob encomenda) - empresas de prestação de serviços em telefonia; geralmente está ligada a área comercial das subsidiárias distribuídas geograficamente

- especificação de produtos, com a determinação de requisitos e características dos produtos

- especificação de desenvolvimento, definindo como atender aos requisitos dos produtos, envolve principalmente a caracterização da tecnologia básica do produto

- especificação dos módulos do produto, refinando as especificações de desenvolvimento por partes do produto a ser desenvolvido

- projeto, que é o detalhamento do projeto de produto, com por exemplo dimensionamento dos componentes

- prototipação / avaliação, envolvendo a fase de testes

- criação de lote piloto, finalmente o produto é colocado em utilização, mas com lote piloto. 
Para a empresa, é clara a diferença entre adaptação de produtos e o desenvolvimento de novos produtos. No Brasil, existem dois departamentos distintos para essas atividades:

- Desenvolvimento e Engenharia, que engloba todas as áreas da companhia presentes no Brasil, e trabalha maioritariamente, a partir do que se chama de "departamento de desenvolvimento", com adaptação de produtos da linha "antiga" de produtos73, ou seja, centrais telefônicas, ERB, equipamentos de transmissão e rádio.

- $\quad$ Sollutions, responsável pelo desenvolvimento de novos produtos, trabalha principalmente com tecnologia NGN (Next Generation Networks). Existe no país uma pequena parte dos funcionários envolvidos com essas atividades.

A estrutura organizacional da TNC para desenvolvimento de produtos se dá através de divisões relacionadas a tecnologias específicas. As divisões das subsidiárias se reportam ao departamento de engenharia específico (por divisão) na matriz (Japão), apresentando inclusive plano estratégico de desenvolvimento para o departamento líder.

Especificamente no Brasil, as divisões presentes são quatro: Mobile, Wireless, Transmissão, Switches. Cada divisão é responsável por linhas de produtos. A tabela II mostra as divisões presentes localmente e a linha de produtos desenvolvidos (novos produtos ou adaptação/tropicalização) por cada uma delas.

\begin{tabular}{|l|l|}
\hline Divisão & Produtos \\
\hline Mobile $^{*}$ & Estações Rádio-Base (CDMA) - Software \\
\hline Wireless $^{*}$ & Sistemas de Rádio ponto a ponto (Point-to-Point) \\
\hline Transmissão $^{*}$ & $\begin{array}{l}\text { Equipamentos para Acesso a Rede (FAs) - Hardware e } \\
\text { Software }\end{array}$ \\
\hline Switches & Centrais Telefônicas (switches) - Software \\
\hline \multicolumn{2}{|c|}{ O DP é orientado principalmente para: } \\
$*$ Adaptação local \# Desenvolvimento de Novos Produtos \\
\hline
\end{tabular}

Tabela II- Divisões X Produtos desenvolvidos no Brasil pela NEC

\footnotetext{
73 "Linha antiga de produtos" é termo usado pela pessoa entrevistada na empresa.
} 
Entre esses produtos, alguns foram desenvolvidos (tecnologia nova) no país, enquanto outros são customizados para o mercado interno na subsidiária brasileira. Segundo os executivos da empresa, até 2002, 25\% dos 110 funcionários locais da área de P\&D dedicam-se à tropicalização e os 75\% restantes estão dedicando-se a projetos de novos produtos, especialmente os equipamentos para acesso a rede (FAs) e os sistemas de rádio ponto a ponto. Os recursos para novos projetos são destinados principalmente a melhoria de versões dos equipamentos para diminuição de custos e mudanças incrementais nas características dos produtos. Vale destacar que muitos desses projetos não estão tendo continuidade no país, conforme discutido anteriormente nesta seção.

Nos sistemas de rádio ponto a ponto a equipe brasileira de desenvolvimento trabalha cooperativamente com a equipe japonesa e, segundo os executivos da subsidiária local, 30\% das vendas mundiais nesse segmento são de produtos desenvolvidos no Brasil. Nessa linha de produtos, a equipe nacional trabalha nas etapas posteriores às de especificação, ou seja, cabe ao desenvolvimento local, o projeto, a prototipação e a criação do lote piloto para o produto; enquanto que as etapas de geração de conhecimento (especificação) estão concentradas na matriz. Nos equipamentos para acesso a rede (FAs) a equipe brasileira é líder mundial dessa tecnologia, isso se deve aos aspectos históricos de entrada e permanência no mercado local.

Mas, a continuidade tecnológica do produto, especialmente para a tecnologia de nova geração (NGN) foi repassada à matriz; a unidade brasileira, esporadicamente, desenvolve alguns projetos específicos na área. Como citado anteriormente, a equipe local de desenvolvimento de produtos está se extinguindo e é claro que a forte dependência do desenvolvimento de produtos às adaptações locais levou a área de P\&D da companhia a essa situação.

Quanto à estrutura organizacional para a área de P\&D da companhia, o gerente de desenvolvimento reporta-se diretamente ao diretor-presidente da subsidiária brasileira. No entanto, a equipe localizada no Brasil tem contato com equipes de outras subsidiárias da NEC e da matriz, através da rede intranet da empresa, que possibilita a gestão de DPG. 
Vale destacar uma frase de um dos entrevistados, que pode resumir o posicionamento, não só dessa empresa, mas das TNCs de um modo geral com relação à distribuição das suas unidades de P\&D: "a empresa está aqui para ter lucro, o desenvolvimento de produtos é meio, a matriz não tem preocupação em desenvolver talentos, o ideal é fabricar localmente os produtos que são desenvolvidos na matriz - é mais fácil controlar e o custo de desenvolvimento pode ser diluído na escala de produção".

\section{4- Fatores que atraem P\&D para o Brasil}

Antes de apresentar os fatores que atraem P\&D para o Brasil, apontados pela NEC, vale destacar um limitador de investimentos citado nas entrevistas com a empresa: "o tamanho do mercado brasileiro não é significativamente grande para a matriz, portanto ela não incentiva a transferência do desenvolvimento global de produtos para cá”. Essa afirmação dos executivos da empresa é importante para comprovar que as transnacionais levam muito em conta a proximidade e a importância do mercado local quando se distribui as unidades de P\&D.

Apesar do mercado brasileiro ter tamanho relativamente reduzido quando comparado com o de vários outros países (China, por exemplo), a necessidade de atender aos clientes locais atrai o investimento em desenvolvimento de produtos para a subsidiária existente no país. Assim, a proximidade do mercado consumidor é um fator importante para atrair P\&D para o Brasil.

Entre outras razões citadas pela empresa para participação brasileira no desenvolvimento de produtos destaca-se o aproveitamento das competências locais, fator alinhado com as estratégias gerais da empresa global para descentralização de P\&D.

Um outro fator citado, mas que, segundo os executivos da empresa, é de menor relevância como atrativo de $\mathrm{P} \& \mathrm{D}$ é o baixo custo local para desenvolvimento. Segundo os entrevistados, apesar de baixo quando comparado com os custos dos 
centros de pesquisa da empresa em outras unidades, especialmente a matriz, ele praticamente é anulado pelos riscos de fazer desenvolvimento de produtos no Brasil.

Risco que se traduz sob vários aspectos, inclusive sob as políticas públicas existentes no país, que, de acordo com a empresa, são incipientes e desarticuladas. A Lei de informática, por exemplo, é simplesmente uma lei para estimular a realização de P\&D no Brasil, mas ela não agrega os diversos segmentos do governo que poderiam se beneficiar com os recursos provenientes dela.

Sem dúvida, a lei de informática alavancou os investimentos em P\&D no país e se firma como um fator importante para atração de desenvolvimento tecnológico na NEC brasileira. Se não fosse pela lei, provavelmente a empresa teria sempre investido apenas em tropicalização de produtos e na tecnologia para equipamentos de acesso a rede (FAs) porque, como foi dito, a subsidiária é líder dessa tecnologia. Mesmo assim, a lei não foi suficiente para garantir a permanência das atividades de DP no país.

\subsection{Dificuldades quando se realiza P\&D no país}

Nas entrevistas feitas com a NEC, foi possível levantar algumas dificuldades enfrentadas pelas equipes brasileiras de desenvolvimento de produtos. Uma das dificuldades apresentadas nas primeiras entrevistas com a companhia (no ano de 2000) foi a disponibilidade de mão-de-obra especializada (tanto engenheiros quanto técnicos). A empresa afirmou que, apesar da excelente qualidade dos profissionais brasileiros, a quantidade não é suficiente para atender ao mercado de trabalho. Isso se inverteu na Segunda rodada de entrevistas (ano de 2002), após a redução o quadro de funcionários.

Uma outra dificuldade encontrada pela empresa para o desenvolvimento de produtos é a relação com os fornecedores. Segundo informações da NEC, a presença dos fornecedores globais no país é meramente comercial, geralmente as questões técnicas têm que ser discutidas com a matriz desses fornecedores. Isso dificulta o DP local. 
A estrutura física da NEC no Brasil não chega a ser um limitador, mas já existiram condições melhores. Até o início da década de 90, a subsidiária desenvolvia tecnologia de semicondutores ${ }^{74}$, mas em 1992 essa atividade foi encerrada no país, diminuindo os recursos locais para esse fim, consequentemente os recursos da subsidiária como um todo.

\subsection{Interface com Universidades e Centros de Pesquisa}

As parcerias com as universidades e centros de pesquisa brasileiros já foram problema para o DP local, mas as parcerias estão se tornando cada vez melhores, segundo um entrevistado da empresa. A empresa foi responsável pela criação do CPDIA, centro de pesquisa em telecom, que foi recentemente ${ }^{75}$ repassado ao IPT, instituto que teve, por muito tempo, investimentos da companhia.

Os entrevistados foram claros ao dizerem que a principal razão para as parcerias entre a NEC e as universidades / institutos de pesquisa, é a obrigação da Lei de Informática.. Um outro motivo também citado como importante, é a falta de mão-deobra interna, que limita a realização de $\mathrm{P} \& \mathrm{D}$ local, necessitando de estabelecer relações de cooperação com as universidades/centros pesquisa.

A NEC no Brasil possui convênios com a Escola Politécnica da USP, a Universidade Federal da Bahia, a Universidade Federal de Goiás, CPqD (pouca), e com alguns outros centros em projetos esporádicos. Após a crise no setor em 2001, à medida que os trabalhos em parceria com essas instituições encerravam-se, os acordos de cooperação não eram renovados.

\subsection{Aquisição de Tecnologia pela Subsidiária}

Quando o produto é fabricado no país, mas é desenvolvido sem a participação brasileira, o local (subsidiária ou matriz) do desenvolvimento dos processos de fabricação depende do segmento de produto. Por exemplo, os processos de

\footnotetext{
${ }^{74}$ Os motivos para o encerramento dessas atividades no país não foram claramente expressados pelos entrevistados, mas tudo indica que a baixa demanda para os produtos injustificava manter a fabricação e consequentemente o centro de desenvolvimento no país.

${ }^{75}$ Em 2002
} 
fabricação das ERBs e dos rádios ponto-a-ponto são desenvolvidos integralmente aqui, mas o processo para as centrais fixas (switches) são desenvolvidos na matriz. Em geral, segundo informações da NEC do Brasil, 70\% dos processos são desenvolvidos localmente. No caso da necessidade de adaptação do processo no país, há um envolvimento muito grande com a equipe japonesa, que analisa o processo brasileiro. No entanto, como a fabricação / montagem de equipamentos ficou a cargo da Celestica, o desenvolvimento de processos não mais estão ligados à NEC.

As características dos produtos a serem fabricados localmente são obtidas da matriz por meio de documentos de especificação dos mesmos (etapas das quais o Brasil geralmente não participa). A subsidiária local compra tecnologia da matriz ou das outras subsidiárias que a detém (royalties).

O treinamento do pessoal local raramente é feito na subsidiária por funcionários de fora, o mais comum é acontecer de alguns funcionários brasileiros serem treinados na matriz e depois repassarem o conhecimento adquirido aos outros funcionários locais.

\subsection{Autonomia da Subsidiária}

Para finalizar, é importante destacar a liberdade / autonomia que a subsidiária local possui. Segundo entrevistas, a NEC do Brasil possui liberdade total para fazer estudo de preferências e necessidades dos consumidores locais. A área comercial analisa as necessidades do cliente, faz o estudo de viabilidade e passa para o departamento de DP, que vê com a matriz se tem um produto similar que atenda perfeitamente as necessidades do cliente. Se não existe, verifica se é possível tecnicamente desenvolvê-lo no Brasil, senão passa para a matriz, que muitas vezes não se interessa em desenvolver, portanto não atende ao cliente.

Também tem liberdade para definições ou alterações de processos e produtos (tropicalização), mas sempre com aval da matriz, como foi citado anteriormente. Também é grande a autonomia da subsidiária para alterações de matérias-primas / insumos e na negociação com fornecedores locais ou globais, sempre em consenso com a Celestica. 


\section{SIEMENS}

\subsection{Características Gerais da Empresa}

A Siemens é uma empresa alemã fundada em 1847, que atua com tecnologia para atender diversas áreas: energia, automação, transportes, engenharia médica, automotivo, iluminação, semicondutores/informática e comunicações. Neste estudo de caso foi estudada apenas a área de comunicações.

Tal área é dividida em sub-áreas distintas, como na maioria das empresas fornecedoras de produtos para telecomunicações:

- no que se refere à orientação de mercado para os produtos: Business / Enterprises (para clientes corporativos), Public Sector (para operadores de rede), Service Provider and Network Operator (para operadores de serviço) e Consumer (usuários).

- no que se refere ao tipo de produto: Information and Communication Mobile ICM (redes móveis e produtos para usuários finais); Information and Communication Networks - ICN (soluções para Internet e redes de telecomunicações); Siemens Business Services - SBS (serviços para e-business e telefonia).

A companhia mundial teve em 2000 , faturamento total de US\$ 74,3 bilhões, com aproximadamente 430 mil funcionários. A participação dos segmentos de telecomunicações e de semicondutores no total das vendas alcançou margem superior a 40\% em 2000 (Gomes \& Roselino, 2001).

O faturamento em 1999 da subsidiária brasileira foi de aproximadamente US\$ 800 milhões (Fonte: Siemens - Relatório anual geral da companhia mundial, comparando cada afiliada da TNC, 2000). Em 2001, o faturamento da Siemens no Brasil foi de US\$ 584 milhões (Anuário Telecom, 2002) e, de acordo com os entrevistados ${ }^{76}$, em 2002 chegou a R\$ 3,56 bilhões, ou aproximadamente US\$ 1 bilhão. Segundo informações disponibilizadas pela Siemens, a área de telecomunicações (ICN) é

\footnotetext{
${ }^{76}$ Não foram apresentados documentos do ano fiscal de 2002 que comprovassem esses valores.
} 
responsável por aproximadamente $50 \%$ do faturamento da subsidiária. Cerca de 15 a $20 \%$ da produção da unidade local é destinada a exportação, principalmente para América Latina e África do Sul, e um pouco para Europa, especialmente Alemanha e Itália, segundo entrevista com executivos da companhia.

A empresa iniciou suas atividades no Brasil em 1867, com a instalação da linha telegráfica entre o Rio de Janeiro e o Rio Grande do Sul. Em 1905 ocorreu a fundação da empresa no Brasil, mas somente na década de 50 ela começou a atuar fortemente aqui. É uma empresa com capital 100\% alemão, atua nas áreas de Informática e Comunicações, Indústria, Energia, Transportes, Medicina e Iluminação. Como se trata de uma empresa extremamente diversificada, a área de comunicações, especialmente telefonia, é a área enfocada neste estudo de caso.

A Siemens possui várias unidades no Brasil. No segmento de comunicações, as unidades estão em Curitiba, onde se localiza o setor fabril (para ERB, Centrais, PABX, transmissão, rádios e ATM) e o centro de pesquisa; em Manaus, com a segunda fábrica localizada no país (onde se localiza a unidade de fabricação dos equipamentos para a banda $C$ da telefonia celular - padrão europeu GSM); em São Paulo, onde se localiza a unidade de vendas, de serviços administrativos (jurídico, recursos humanos, auditoria, contábil/financeiro) e de tecnologia de informação (responsável pelos sistemas de gestão da subsidiária); e no Rio de Janeiro, com atividades comerciais.

\subsection{Fabricação Local}

Segundo entrevista com executivos da empresa, quase a totalidade da fabricação local só acontece para produtos que tenham parte do desenvolvimento aqui ou que seja tropicalizado. Isso mostra que a unidade local é um fabricante de produtos que atendam o mercado local/regional. Não foi apresentado o percentual de exportação dos produtos fabricados localmente, mas elas se destinam principalmente a Alemanha, Itália, Dinamarca, Suíça, África do Sul, Brasil e EUA.

Alguns produtos fabricados localmente, como as centrais de médio e pequeno porte $(\mathrm{PABX})$ não possuem participação brasileira no desenvolvimento, nesse caso, as centrais são desenvolvidas na Alemanha e nos EUA. No outro extremo, tem-se 
produtos que são desenvolvidos no Brasil (em conjunto com outras unidades na Europa ou EUA), mas não são fabricados nas unidades brasileiras, como é o caso de alguns equipamentos para transmissão. Mas isso se dá principalmente para software, pouquíssimo para hardware.

Com o início das atividades em GSM no Brasil, a Siemens conseguiu se firmar como importante competidor na área de telefonia móvel. Hoje ela fabrica, em Manaus, aparelhos pessoais (handsets) e ERB para essa tecnologia, e já conquistou importante posição no mercado, tendo fechado negócios importantes para fornecimento para as duas operadoras que atuam nesse segmento.

\subsection{Pesquisa e Desenvolvimento}

A Siemens mundial despende mais de $7 \%$ do seu faturamento em P\&D. Nas áreas relacionadas à telecomunicações e semicondutores, responsáveis por mais de $50 \%$ dos gastos da TNC em P\&D, foram 9,3\% das vendas em 2000 (Gomes \& Roselino, 2001).

Segundo informações da subsidiária, é tendência da empresa descentralizar P\&D para obter características do mercado. Ainda de acordo com os dados da empresa, as subsidiárias se concentram no desenvolvimento de produtos, e a pesquisa básica é feita na Alemanha. Pouquíssimo é feito fora da matriz, no Brasil, alguma coisa de pesquisa básica é feita, por exemplo em comutação, transmissão, simulação térmica e eletromagnética.

No Brasil o investimento em P\&D fica em torno de 5\%. Em 2002, eram cerca de 200 funcionários trabalhando na área de P\&D, em 2000 esse número chegou a 350. Segundo informações da empresa, 60\% das horas anuais de trabalho nas atividades de P\&D são dedicadas ao trabalho com desenvolvimento de novos produtos e $40 \%$ são atribuídas a atividades de tropicalização.

Segundo informações obtidas na empresa, dos produtos desenvolvidos no Brasil para o mercado mundial, em linhas gerais, cerca de $15 \%$ são equipamentos (hardware) e $85 \%$ software. Mais uma vez se confirma a tendência de no Brasil ser mais forte o desenvolvimento de software. 
As etapas do desenvolvimento de produtos seguidas pela empresa são parecidas com as fases dos outros estudos de caso. O DP começa pela percepção de oportunidade no mercado, etapa que pode ser feita diretamente com o consumidor final ou em conjunto com os operadores de rede. Em seguida é feita a pesquisa, que compreende concepção do produto, business plan, especificações técnicas e estudos de viabilidade. A partir daí, passa-se para o desenvolvimento propriamente dito, quando as especificações técnicas passa a "compor" o produto, ou seja, quando é criado de fato o produto através da determinação do design, da integração de módulos e outros. Segue-se então com fabricação e testes.

A preocupação em aumentar a participação da unidade Brasil no desenvolvimento de produtos parece existir. No ano de 1999 a empresa criou uma nova área denominada Gestão de Tecnologia, cuja missão, segundo dados da companhia, é aumentar o valor agregado das unidades de negócio da Siemens no Brasil por meio da criação, ampliação, coordenação e sintonia de seus setores de P\&D. Essa área é responsável pela administração da propriedade intelectual/industrial, atuação em grêmios de normas técnicas, garantia de incentivos à produção e à pesquisa e desenvolvimento no Brasil, atuação junto ao governo e entidades em questões relativas a política industrial e de $\mathrm{P} \& \mathrm{D}$, cooperação com universidades e institutos de pesquisa, coordenação da transferência de tecnologia, administração dos processos tecnológicos básicos e gestão do conhecimento.

A unidade brasileira é Centro de Competência, chamado na empresa de COC, em algumas áreas. Entre elas, num módulo do equipamento que faz comutação em NGN. Trata-se do módulo para conexão do assinante à central telefônica. Segundo os entrevistados, os COCs têm autonomia total, uma vez que são responsáveis mundialmente pela gestão do desenvolvimento de uma linha de produtos; dessa forma, eles têm garantia de envolvimento não desenvolvimento para evolução da tecnologia.

Há, na unidade brasileira, um departamento específico dedicado à condução das atividades tecnológicas chamado de Departamento de Pesquisa e Desenvolvimento. O gerente geral dessa área reporta-se à unidade de negócio da companhia. 


\subsection{Fatores que atraem $P \& D$ para o Brasil}

Entre os fatores que estimulam a participação da subsidiária brasileira está, segundo informações da unidade local, a proximidade do mercado consumidor, para que as necessidades dos clientes sejam identificadas e atendidas. Além de estar próximo ao cliente, a companhia procura, com a unidade local, entender melhor, e até negociar, as especificações regionais determinadas pelos órgãos reguladores.

Um outro fator que estimula a vinda de projetos de desenvolvimento de produtos para o Brasil é a qualidade da mão-de-obra local, seja na boa formação e na criatividade dos engenheiros ou na flexibilidade e agilidade deles. Segundo entrevista com a empresa, os projetos realizados na subsidiária brasileira, em geral, são cumpridos num prazo menor que se desenvolvidos na matriz. Por exemplo, houve um produto, que a Alemanha estimou 24 meses para o seu desenvolvimento, e que foi desenvolvido em 13 meses pela equipe local. A companhia global está atenta a esse diferencial, o que está alavancando a vinda de mais projetos para o Brasil.

Um outro fator citado pela empresa é o incentivo da lei de informática, que, segundo os executivos, alavancou o DP local, mas que é muito provável que o investimento na área de $\mathrm{P} \& \mathrm{D}$ continuaria sendo feito aqui no país mesmo sem a lei de informática. O baixo custo do desenvolvimento local quando comparado com unidades localizadas em países desenvolvidos também foi lembrado como relevante.

E, por fim, vale destacar que um fator importante mencionado pela empresa, é a boa relação existente entre os funcionários da subsidiária e os da matriz. Os executivos responsáveis que trabalham na unidade brasileira possuem estreitas relações com os funcionários de P\&D da matriz e de outras unidades da TNC. Segundo um dos entrevistados, "a matriz incentiva a participação brasileira".

\subsection{Dificuldades quando se realiza P\&D no país}

A subsidiária levantou como problema para o desenvolvimento local, a falta de uma política industrial efetiva, de longo prazo e que estimule fortemente o setor a investir em P\&D local. Essa crítica da empresa vai muito além de incentivo fiscal, segundo 
os executivos, apenas o incentivo não atrai desenvolvimento tecnológico para cá, é preciso uma reestruturação com diretrizes mais amplas que apenas isenção fiscal.

\subsection{Interface com Universidades e Centros de Pesquisa}

A parceria com universidades e centros de pesquisa locais já foi problema, mas hoje já é bastante satisfatória. Os vínculos da Siemens local se restringem às instituições brasileiras, mas as universidades possuem integração com entidades no exterior. As principais instituições parceiras da Siemens são PUC-PR, CEFET-PR, CPqD, Inatel, CITS (Centro Internacional de Tecnologia de Software).

A empresa apresentou dados de investimentos de P\&D externo de 1994 a 2001. Do total investido, 81,4\% desse foram destinados à região Sul, 13\% à região Sudeste, $3,45 \%$ à Centro-Oeste, $2,08 \%$ à região Nordeste e $0,05 \%$ à região Norte.

Os entrevistados na Siemens deixaram claro a importância das duas principais instituições parceiras da companhia e das atribuições delas: CEFET colabora especialmente com desenvolvimento de hardware, enquanto que a PUC-PR participa ativamente do desenvolvimento de software.

\subsection{Aquisição de Tecnologia pela Subsidiária}

As características dos produtos fabricados localmente são passados para a subsidiária através de documentação específica e através de treinamento na matriz. As negociações com a matriz são bastante flexíveis segundo os entrevistados.

A participação do Brasil no desenvolvimento de processos de fabricação depende da linha de produtos a ser fabricado. A empresa não informou os dados sobre o percentual de processos desenvolvidos localmente, desenvolvidos em conjunto com a matriz ou desenvolvidos integralmente no exterior. Também não foram fornecidas características do treinamento feito pelos funcionários da unidade brasileira, ou seja, quanto dele é feito na matriz, aqui por funcionários da matriz ou de outro local, por funcionários locais já treinados, ou por instituições locais especializadas, mas afirmou-se que a maioria do treinamento na área de $\mathrm{P} \& \mathrm{D}$ ocorre na matriz. 


\subsection{Autonomia da Subsidiária}

Segundo informações da empresa, a subsidiária tem total autonomia para decidir sobre desenvolvimento de novos produtos. É possível analisar mercado, desenvolver aqui e apresentar o projeto para Alemanha. É possível também, autonomamente, criar novos processos ou alterar os já existentes.

A unidade local também tem liberdade para fazer tropicalização de produtos e para definir ou alterar matérias-primas utilizadas, sempre seguindo regulamentações dos países para onde se destinam os produtos.

As negociações com fornecedores locais são permitidas e incentivadas sempre que houver vantagens e que a qualidade se mantiver. Já as negociações com fornecedores mundiais ocorrem com o auxílio da matriz para que haja ganho de escala. 


\section{NOKIA}

\subsection{Características Gerais da Empresa}

A Nokia é uma empresa com sede em Helsinki na Finlândia. A empresa emprega cerca de 60 mil funcionários e está presente em 130 países, dos quais 10 possuem fábricas e 15 localizam atividades de P\&D (dados de 2001). A figura III mostra a localização dessas unidades mundialmente. Seu faturamento em 2001 foi de aproximadamente US\$ 31 bilhões.

A empresa, fundada em 1865, inicialmente se dedicava à fabricação de papéis, incorporou o segmento de borracha na virada do século e logo depois passou a fabricar cabos para telégrafos e telefones. Somente na década de 60 as empresas de papel, de borracha e de cabo foram integradas fundando a Nokia Corporation em 1967. A linha de produtos já fabricados pela empresa é bastante diversa, indo de modems e computadores a monitores de vídeo e aparelhos de TV.

Em 1981, quando foi iniciada na Escandinávia a NMT, a primeira rede de telefone celular móvel no mundo, a Nokia desenvolveu telefones móveis para automóveis, o que originou sua principal atividade atualmente, já que é líder mundial de mercado em aparelhos celulares com 32\% das vendas no segmento (Nokia, 2002a). A empresa também vem se destacando no mercado de infra-estrutura para redes de telefonia móvel, mas nesse setor, sua participação é menor.

A empresa está estruturada em três áreas principais:

- NMP - Nokia Mobile Phones, relacionada a aparelhos terminais celulares.

- Nokia Networks, ligada a produtos para rede de telefonia móvel.

- Nokia Ventures Organization, que consiste de sub-áreas:

- Nokia Internet Communications, para desenvolvimento de soluções para internet.

- New Growth Businesses, que desenvolve e operacionaliza novas oportunidades de negócios que podem ser estratégicos (ou que tenham 
estratégia ainda incerta), mas não estão diretamente ligadas ao foco de negócios da companhia.

- Insight \& Foresight, identifica tecnologias inovadoras e/ou mercados/negócios e analisa oportunidades de negócios para a empresa.

- Nokia Venture Partners, uma firma de venture capital para investimento exclusivamente em telefonia móvel e IP - internet protocol.

- Nokia Home Communications, que desenvolve plataformas digitais e soluções em comunicação para o ambiente doméstico.

A área de terminais telefônicos (NMP) faturou cerca de US\$ 23 bilhões em 2001, ou seja, ela é responsável por $75 \%$ do faturamento da empresa. Nessa área, a empresa trabalha com produtos de diversas tecnologias (CDMA, WCDMA, TDMA, GSM, GPRS), no entanto para produtos de rede (Nokia Networks), especialmente estações rádio-base (ERB), a companhia apenas produz as tecnologias GSM, GPRS e, mais recentemente, WCDMA.

\section{No Brasil}

O Brasil é o sétimo maior mercado do mundo para a Nokia. Com um total de 1500 funcionários e faturamento total de US\$ 940 milhões em 2000 e US\$ 848 milhões em 2001, atualmente está presente no país através das seguintes unidades de negócios:

NMP - a Nokia Mobile Phones iniciou suas operações no Brasil em 1996, mas desde 1991 seus celulares já eram vendidos no país através de distribuidores. Fornece telefones celulares TDMA, CDMA e GSM para todos os segmentos de consumo: básico (linha Nokia 5100), clássico (linha Nokia 6100), premium (linha Nokia 8200) e media phones WAP (linha Nokia 7100). Possui um escritório em São Paulo e uma unidade industrial em Manaus.

Nokia Networks - está no Brasil desde 1997. Fornece soluções para redes GPRS e GSM, internet móvel e sistemas de rádio profissional. A empresa também dispõe de uma linha de produtos para acesso de banda larga e transmissão celular, como rádios por microondas e modems DSL. Possui escritórios em São Paulo, Rio de Janeiro, 
Belo Horizonte e Brasília, além de uma parceria para produção local de infraestrutura GSM com a empresa norte-americana Celestica.

Nokia Internet Communications - atende empresas e provedores de serviços e aplicações de internet, estabeleceu uma equipe local no Brasil em 2001, oferecendo a clientes corporativos produtos de segurança IP e serviços (incluindo firewalls e antivírus). O Brasil está apresentando um rápido crescimento em internet e, por este motivo, as operadoras de TV a cabo e provedores de internet também estão se tornando clientes potenciais da Nokia Internet Communications.

\subsection{Fabricação Local}

A empresa está presente no Brasil em três unidades principais localizadas em: São Paulo local da sede administrativa e de desenvolvimento da área NMP, Rio de Janeiro, onde se localiza a sede da Nokia Network, e Manaus, onde se encontra a fábrica de terminais e os departamentos relacionados a ela, como o de engenharia de produção e de desenvolvimento de processos. Ou seja, as unidades produtivas localizadas no país são direcionadas para a fabricação de aparelhos celulares (área NMP) e montagem de centrais telefônicas para telefonia móvel (Nokia Network).

Vale lembrar que parte da produção da Nokia está a cargo da Celestica, especialmente os equipamentos para a rede GSM (infra-estrutura). A unidade industrial de Manaus é uma das oito fábricas de celulares da Nokia no mundo. As demais estão localizadas na China, Finlândia, Alemanha, Hungria, México, Coréia do Sul e Estados Unidos (figura III).

\subsection{Pesquisa e Desenvolvimento}

Segundo informações da própria empresa, um terço dos funcionários trabalham em atividades de P\&D. Os “Centros de P\&D” estão localizados em 15 países (figura III). O Brasil, apesar de ter desenvolvimento tecnológico como afirma um dos entrevistados na empresa, não está entre os países que possuem centro de P\&D. Isso porque as atividades realizadas aqui estão muito mais voltadas ao desenvolvimento de soluções para adaptação local dos produtos globais do que à pesquisa propriamente dita. 
As atividades de pesquisa são desenvolvidas na matriz e em outros países desenvolvidos como EUA, Dinamarca, Suécia, Alemanha, Reino Unido e Japão. No entanto, quatro países em desenvolvimento também possuem os tão invejados "Centros de Pesquisa": China, Hungria, Malásia e Coréia do Sul. Vale destacar que, dos países que possuem fábricas, apenas o Brasil e o México não possuem também centro de pesquisa.

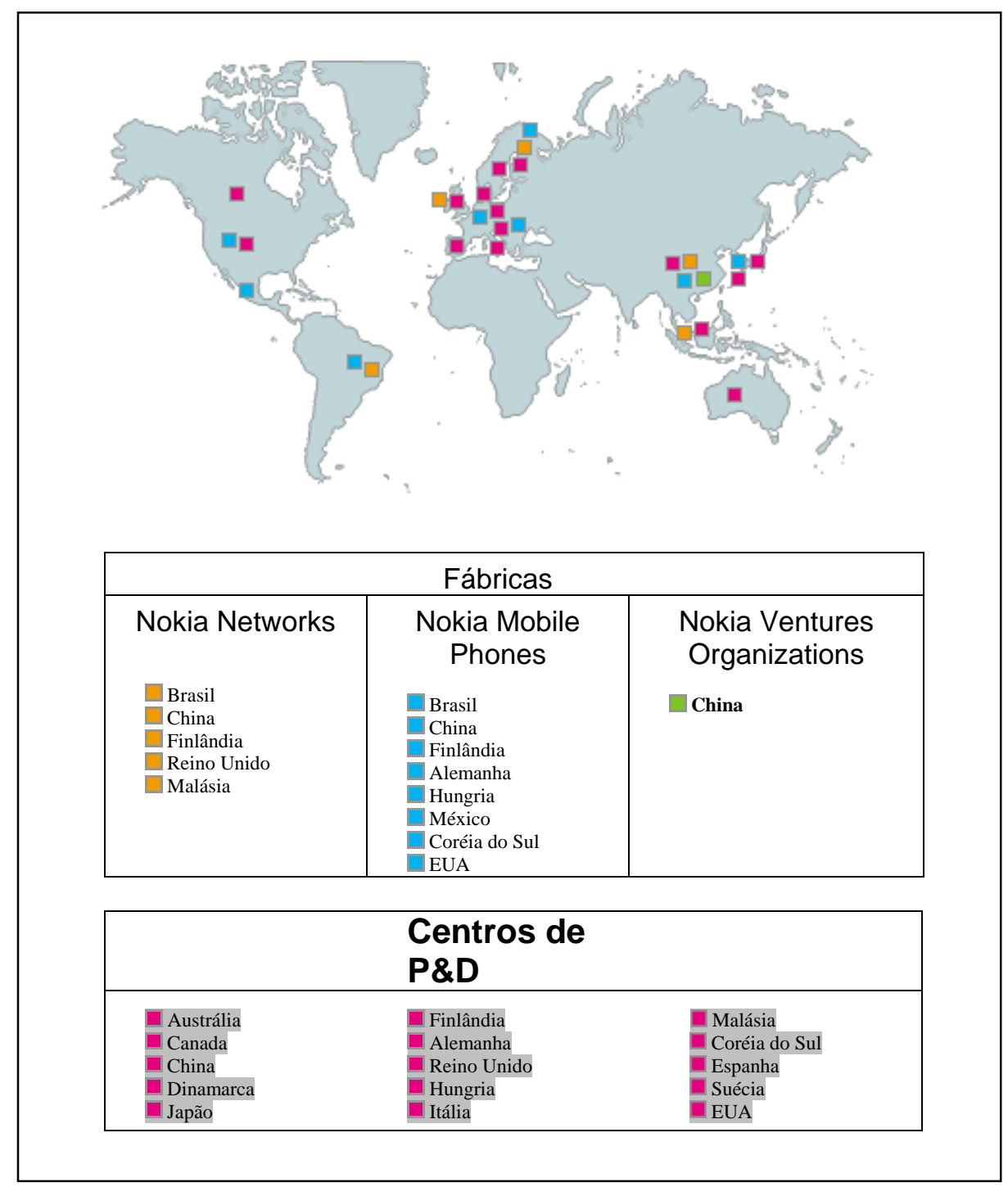

Figura III- Localização de Fábricas e Centros de Pesquisa da Nokia (Fonte: NOKIA, 2002)

Os "Centros de Pesquisa" controlam as atividades desenvolvidas para a pesquisa e o desenvolvimento de produtos relacionados a determinada(s) tecnologia(s). Segundo 
entrevista realizada na empresa, o desenvolvimento de produtos é organizado por esses centros, que atuam como controlador das atividades desenvolvidas globalmente, ou seja, essa centralização do DP significa controle para compartilhamento de conhecimento global e não concentração das atividades num único local.

Por exemplo, o centro de tecnologia CDMA está localizado em San Diego nos EUA e controla as atividades desenvolvidas mundialmente. Tal centro possui algumas equipes que trabalham - temporariamente ou não - em outros países, que são chamados de "pólos regionais". O Brasil, assim como Índia e Singapura, é considerado "polo regional" da tecnologia CDMA.

Essa estrutura hierarquizada por segmento tecnológico da empresa é tão clara, que na própria afiliada brasileira as áreas de $\mathrm{P} \& \mathrm{D}$ não são integradas e estão até fisicamente separadas. Talvez seja o caso mais claro de separação no desenvolvimento tecnológico por tipo/área de produto de todos os estudados neste trabalho.

A concepção geral dos produtos é feita na matriz, mas os centros de pesquisa, cada qual com sua especialidade, propõem a tecnologia para os novos produtos. A primeira fase de DP acontece nos centros de pesquisa, que de fato pode ser considerada de desenvolvimento tecnológico e pode ter como resultado um produto inovador, consequentemente, patenteável. Como tais centros estão localizados em outros países que não o Brasil, não há controle de patentes locais, na verdade, a matriz não vê o Brasil com potencial para controlar pedidos de patentes. As atividades realizadas no país são posteriores ao desenvolvimento propriamente dito.

A unidade brasileira trabalha principalmente com o desenvolvimento de software embutido (no aparelho móvel) especialmente para validação local da tecnologia e customizações necessárias para os clientes locais. Também trabalha no desenvolvimento de software para ERB, especialmente na adaptação dos produtos ao mercado local. Também foi citado na entrevista com a companhia, que as atividades de desenvolvimento de processo têm considerável relevância para a subsidiária brasileira. 
No entanto, esse desenvolvimento feito no Brasil é, aparentemente, muito restrito e pouco relevante para a organização mundial. Na área de NMP, a equipe que trabalha no Brasil se restringe atualmente a 35 pessoas, envolvidas com atividades de adaptação local e de desenvolvimento de novos produtos. No entanto o DNP restringe-se a produtos ligados a processo produtivo, por exemplo, foi desenvolvido um software para controle da fabricação de uma linha de produto específica, que está sendo utilizado em outras fábricas na Nokia mundial. Um outro produto desenvolvido localmente é utilizado para teste de queda de aparelho móvel, através de simulação da queda, quando são colhidos dados de forças atuantes no aparelho para análises quantitativas. Esse produto foi criado em parceria com um instituto de pesquisa, e que é único na companhia global. O software que faz as análises matemáticas dos dados já está em uso na companhia há algum tempo e foi desenvolvido na matriz ${ }^{77}$. Esse projeto foi feito com recursos da Lei de Informática e a subsidiária local espera reduzir seus custos de criação para viabilizar a utilização do equipamento em outras unidades da TNC.

Além dessa equipe de desenvolvimento para NMP, há um grupo de 4 pessoas, todas funcionárias da subsidiária norte-americana localizada em San Diego, que compõem o grupo de validação de tecnologia para terminais celulares CDMA. Esse grupo atua globalmente, ou seja, trabalha para toda a companhia, e a filial no Brasil é mais um dos "clientes" dele. A unidade brasileira atende também aos outros países da América do Sul.

\subsection{Fatores que atraem $P \& D$ para o Brasil}

Em entrevista com a empresa, foi apontado como fator importante para a o estímulo à participação brasileira no DP o tamanho do mercado da América do Sul, já que a unidade local atende ao mercado regional, principalmente considerando a posição estratégica do país em relação aos vizinhos do Mercosul. Também foi citado como fator importante, a abertura do mercado com a privatização do sistema Telebrás, com a entrada de grandes empresas de tecnologia no mercado nacional.

\footnotetext{
${ }^{77}$ A subsidiária local não tem acesso ao código fonte desse software, ela recolhe os dados através do equipamento desenvolvido no país e os analisa com a ajuda do software fechado.
} 
Vale citar o caso da China, que é bastante peculiar por causa da enorme população consumidora. Além do mercado, outro fator que atrai centro de pesquisa para aquele país, é a mão-de-obra qualificada e também a restrição que o governo local impõe para a entrada de companhias para a fabricação de produtos. Isso foi citado pelos entrevistados como um exemplo de política pública significativa para a incorporação de P\&D nos negócios das TNC instaladas naquele país. Apesar dessas considerações, os executivos da Nokia afirmam que a Lei de Informática foi importante para localizar P\&D no Brasil. Vale destacar que a empresa, visando beneficiar-se com os recursos provenientes da Lei de informática, criou a Fundação Nokia de Tecnologia, mas essa instituição ainda não está trabalhando propriamente.

\subsection{Dificuldades quando se realiza P\&D no país}

A empresa tem uma cultura centralizadora, o que acaba levando a dificuldades para realização de P\&D no Brasil. Dessa forma, a relação com a matriz foi citada como hierárquica, prejudicando de alguma forma a autonomia local.

Outro fator que prejudica maior envolvimento brasileiro é a falta de convênios com universidades e centros de pesquisa locais, tais parcerias não são "naturais", segundo um entrevistado na empresa, "as universidades brasileiras não se promovem e não mostram a cara do país".

\subsection{Interface com Universidades e Centros de Pesquisa}

Como citado anteriormente, as parcerias com universidades e centros de pesquisa brasileiros não são naturais. Existe envolvimento com o $\mathrm{CPqD}$ para a validação de handsets, uma vez que esse centro de pesquisa, muitas vezes, atua em conjunto com as operadoras.

Em Manaus, há algumas parcerias com universidades e centros de pesquisa locais, motivadas principalmente pela Lei de Informática e pela necessidade de formação de pessoal, até mesmo para fabricação, uma vez que na região Norte, especialmente na Amazônia, o nível educacional técnico ainda é pequeno. 


\subsection{Aquisição de Tecnologia}

A empresa não paga Royalties para a matriz. O treinamento referente à tecnologia dos produtos/processos da empresa é feito, em geral, na matriz ou na subsidiária da companhia que detém a tecnologia e repassado localmente a outros funcionários.

\subsection{Autonomia da Subsidiária}

A autonomia da subsidiária brasileira é pequena, especialmente para definição de novos produtos, tanto para criação quanto para alteração de produtos, a subsidiária local deve ter o aval da matriz ou da unidade da TNC que melhor conhece o produto/tecnologia em questão. Tanto o é, que os novos produtos desenvolvidos localmente, conforme citado anteriormente, não são ligados às linhas mundiais de produtos Nokia, na verdade, são produtos periféricos.

Segundo entrevistados, na área NMP, o desenvolvimento de software é primordial, e 90\% do trabalho na área é em software padrão dos produtos, ou seja, com mudanças totalmente controladas pela matriz ou pelo centro de tecnologia responsável pela tecnologia. Os outros $10 \%$ do desenvolvimento em software acontecem para customização de produtos, especialmente para serviços específicos das operadoras e para realização de acesso. Para esses produtos, a autonomia da subsidiária é maior, mas sempre seguindo as determinações e padrões mundiais da companhia. 


\section{ERICSSON}

\subsection{Características Gerais da Empresa}

A Ericsson é uma empresa sueca, cuja matriz está localizada em Estocolmo. A empresa iniciou suas atividades em 1876 e atualmente está presente em mais de 140 países. Com aproximadamente 85.000 funcionários (2002), teve faturamento de US\$24,73 bilhões em 2001.

No Brasil, a empresa iniciou suas atividades em 1924 no Rio de Janeiro, mas apenas cerca de 30 anos depois (em 1955) inaugurou sua primeira fábrica no país, em São José dos Campos. Hoje, a empresa está presente em São Paulo (a matriz do grupo no Brasil), em São José dos Campos (área industrial), em Indaiatuba (Centro de P\&D) e através de escritórios regionais (comerciais).

A companhia atua principalmente nos segmentos de telefonia móvel e fixa, especialmente com equipamentos de comutação. Em 2000, foi a líder de mercado em comutação fixa e em infra-estrutura para comunicação celular móvel (Anuário Telecom, 2001). Na parte de aparelhos celulares (segmento em que já liderou mercado, mas que hoje não está entre seu grande segmento de negócios), em 2001, fez uma aliança comercial/produtiva com a japonesa Sony, formando a empresa Sony-Ericsson, que desempenha atividades de desenvolvimento e marketing dos produtos.

A Ericsson ocupou, em 2001, a primeira posição no ranking das 100 maiores empresas do setor de telecomunicações presentes no Brasil, apresentado pelo Anuário Telecom 2001, com receita líquida de US\$ 1,6 bilhões (valor referente a 2000).

Em relação a percentual de vendas mundiais da TNC, em 2001, a subsidiária brasileira da Ericsson estava na posição de numero 5 em vendas e pedidos, com 5\% das vendas mundiais. Em 2002, a empresa não estava mais entre os 10 maiores mercados do mundo e teve participação mundial nas vendas da companhia inferior a 3\%. Nesse mesmo ano, as maiores participações são a dos Estados Unidos (14\%) e 
da China (10\%). A participação da empresa já foi bem maior (na época do boom da telefonia no Brasil - final dos anos 90), quando chegou a ser aproximadamente $13 \%$ do faturamento mundial da empresa.

Mundialmente, a companhia é dividida nas seguintes áreas funcionais (Corporate Functions): Comunicações Corporativas, Financeiro, Questões Legais, Marketing e Desenvolvimento Estratégico de Negócios, Recursos Humanos, Logística e TI, Tecnologia (desenvolvimento tecnológico). A Ericsson é estruturada sob duas dimensões, uma relacionada a mercado (figura IV) e outra ligada a soluções / produtos, ambas ligadas funcionalmente à direção de operações (COO - Chief Operation Officer) (figura V).

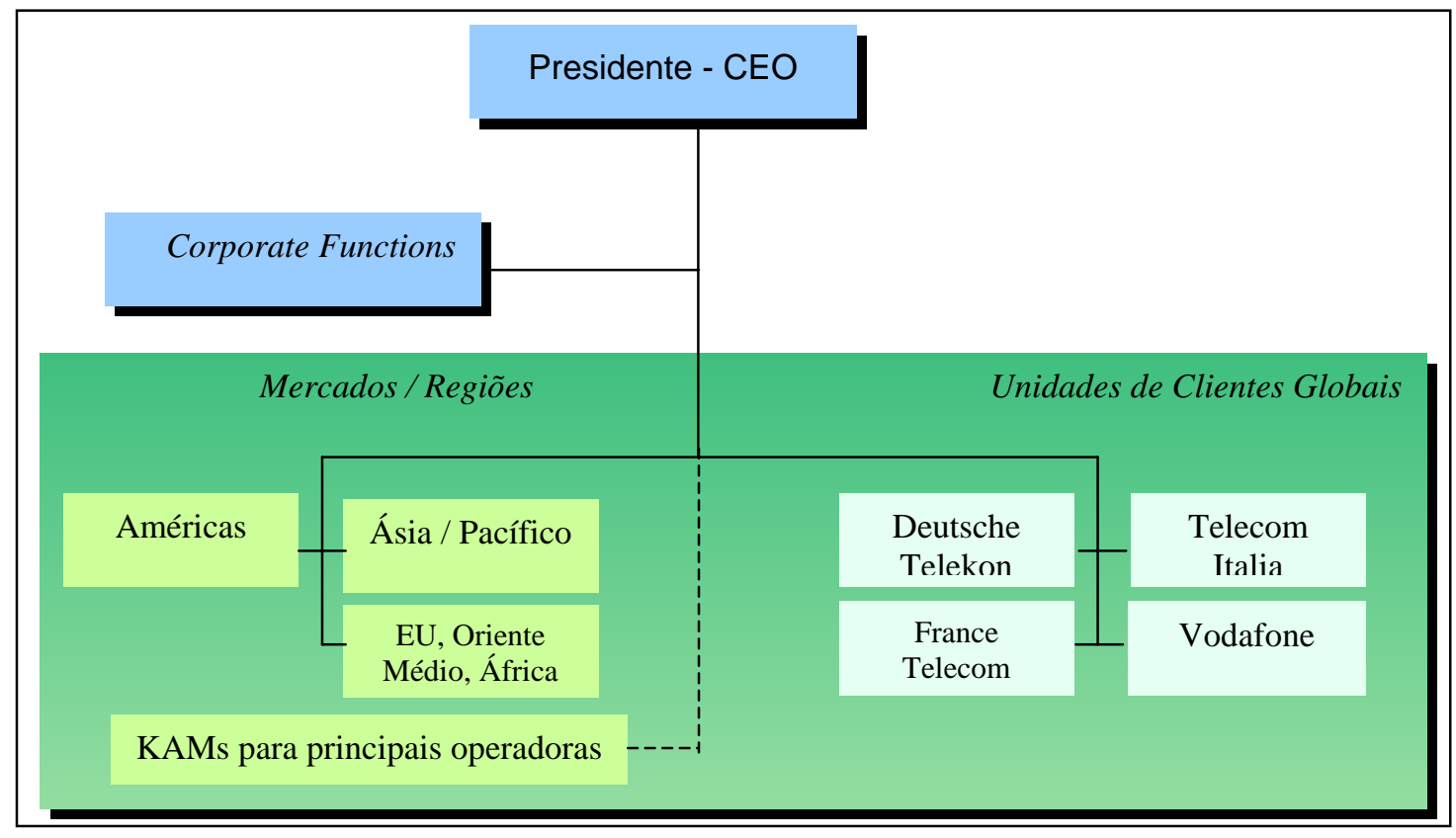

Figura IV - Organização Ericsson - Dimensão Mercado/Clientes (Fonte: Slides Ericsson, 2001)

A dimensão mercadológica é estruturada em torno dos grandes clientes globais de BUs (Business Units $^{78}$ ) e unidades específicas por regiões de mercado, chamadas Market Units (atualmente, há um total de 30 Market Units), conforme figura IV. Além disso, a empresa também conta com as áreas "comercial-técnicas" (formadas por profissionais de vendas, mas com algum conhecimento técnico), responsáveis pelo levantamento de necessidades dos clientes, as chamadas KAM (Key Account

\footnotetext{
${ }^{78}$ Business Units são as unidades de negócios da companhia, responsáveis por áreas específicas, que hoje são: serviços globais, sistemas CDMA, sistemas GSM e WCDMA, redes de serviço, redes de transmissão e transporte.
} 
Management). A dimensão de produtos/soluções divide-se em unidades de negócios distintas (BU) e em Core Units, unidades que englobam diferentes segmentos, conforme figura $\mathrm{V}$ e que são responsáveis pelo desenvolvimento de produtos para a companhia.

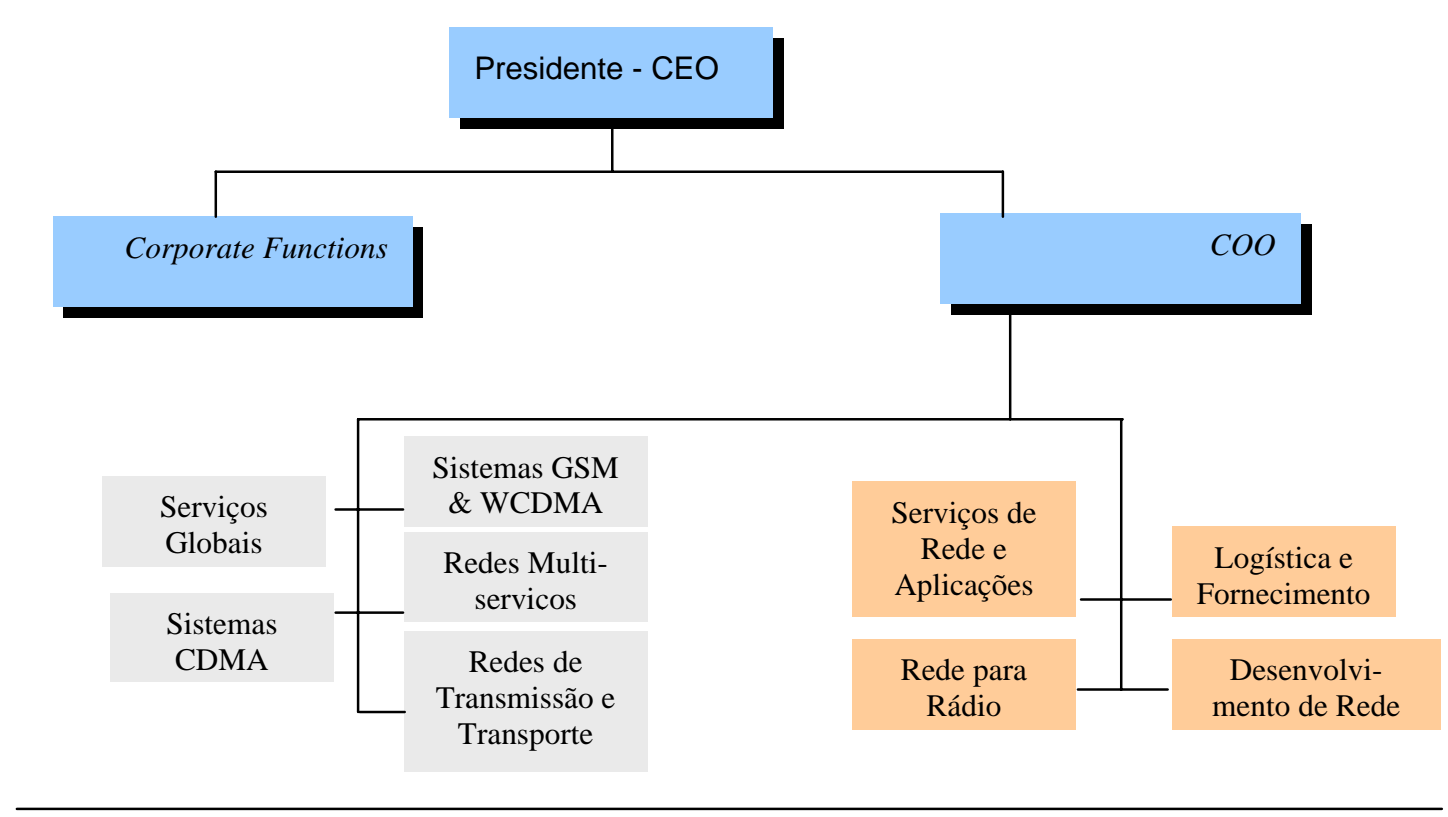

Figura V - Organização Ericsson - Dimensão de Produtos/Soluções (Fonte: Ericsson, 2001)

\section{2- Fabricação Local}

Assim como nas demais empresas fornecedoras de equipamentos para telecomunicações, a fabricação de equipamentos da Ericsson é terceirizada. Em sua maioria, é feita pela Flextronics, uma das empresas que atuam com montagem de equipamentos eletrônicos, as CEM (Contract Electronics Manufacturers).

\subsection{Pesquisa e Desenvolvimento}

A empresa vem passando por uma reestruturação e teve seus centros de $P \& D$ reduzidos cerca de 40, em 1999, para 21 e irá reduzir para no máximo 15 até o final de 2003, segundo o entrevistado na companhia, que também afirmou que o centro brasileiro é um dos que permanecerão na rede de desenvolvimento da TNC. Uma das razões para isso, especialmente nessa fase complicada para o setor de telecom, é a 
substituição dos equipamentos TDMAs $^{79}$, uma oportunidade para atuação da empresa.

Mundialmente, o desenvolvimento tecnológico está ligado à divisão de Tecnologia da companhia. Sob sua responsabilidade estão as unidades de tecnologias corporativas (pesquisa corporativa, tecnologia genérica corporativa, aquisição de tecnologia corporativa, tecnologia funcional corporativa), os centros locais de desenvolvimento, as unidades de produtos locais e as unidades de produtos core.

A unidade de Tecnologia Funcional Corporativa (Corporate Function Technology CFT), uma das unidades corporativas relacionadas a tecnologia, é responsável pela determinação da função da tecnologia para a corporação. Para isso, inicia e apoia (suporta) às atividades de pesquisa e pré-desenvolvimento (seja para pesquisa em tecnologia específica da empresa ou para tecnologias genéricas), a partir das quais, o desenvolvimento de produtos será realizado. Para o DP, a unidade CFT provê orientação técnica e estabelece planejamento estratégico de $\mathrm{P} \& \mathrm{D}$. A Corporate Function Technology atua nas diversas áreas: pesquisa e inovação, padrões tecnológicos, sistemas core, tecnologia de acesso, seja em software e/ou hardware. A figura VI mostra essas relações.

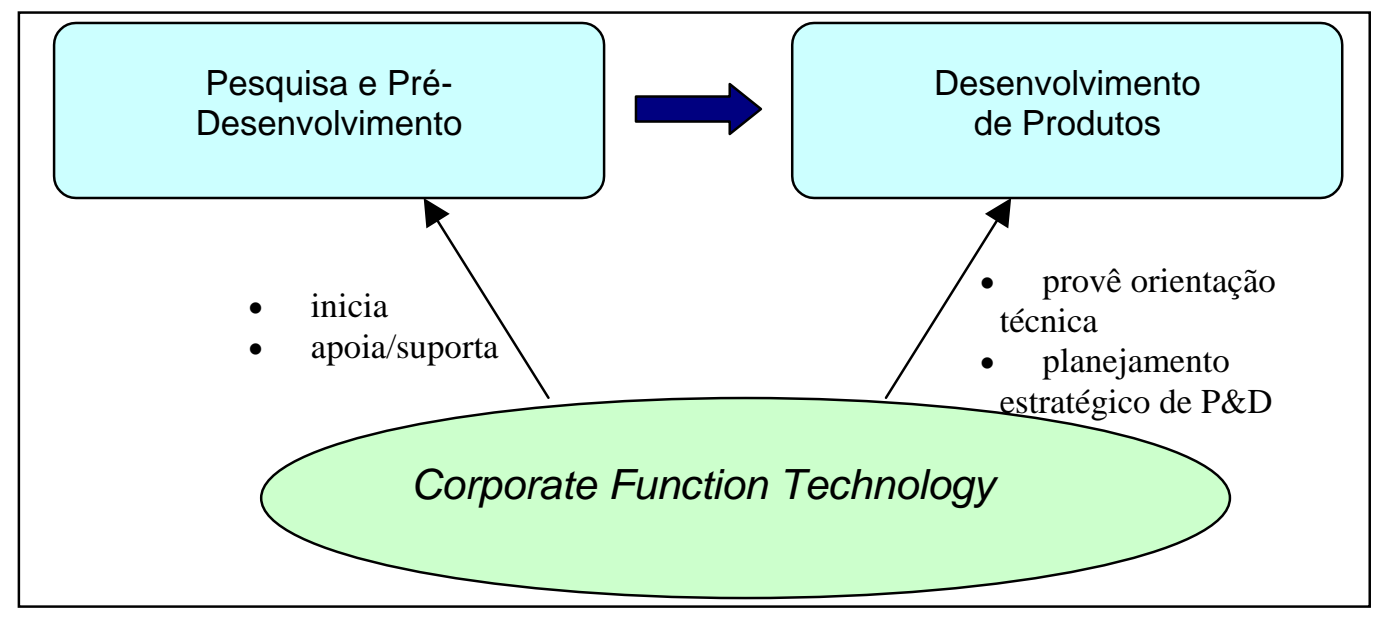

Figura VI - Relacionamento entre as unidades de desenvolvimento e a divisão CFT da Ericsson

(Fonte: Slides fornecidos pela Ericsson, 1999)

\footnotetext{
${ }^{79}$ A rede de tecnologia instalada no país deve ser substituída, nos próximos anos, pela tecnologia CDMA ou, mais provavelmente, à GSM.
} 
A divisão de Tecnologia Funcional Corporativa possui, em sua estrutura organizacional, os departamentos de gestão de sistemas, gestão de tecnologia de acesso, desenvolvimento operacional, gestão de tecnologia de software, pesquisa e inovações, provisão de tecnologia externa, padronização de telecomunicações, e concepção de novos produtos.

\section{Estrutura para Desenvolvimento}

A estrutura de P\&D na empresa é dividida por tecnologia. Uma parte das atividades de P\&D fica nas Core Units (CU s), que desenvolvem produtos para as diferentes BU s para um "futuro próximo". Por exemplo, a Core Unit de rede para rádio, a RND (radio network development), desenvolve todos os produtos de transmissão móvel (rede), os chamados produtos para "rádio", para a BU 'Sistemas GSM \& WCDMA' (Mobile Systems WCDMA \& GSM), isto inclui desenvolvimento de produtos para ERB, transceivers, softwares para esses equipamentos, etc.).

Uma outra parte de P\&D fica com a Ericsson Research, que tem como foco a realização de pesquisa de ponta para desenvolvimentos futuros, por exemplo, os sistemas móveis de quarta geração, que pode ser utilizado em 10 anos ou mais, ou até mesmo não serem comercializados nunca. Outro foco de estudo por esses grupos atualmente está relacionado aos efeitos de radiação no corpo humano. Ou seja, é a divisão responsável pela pesquisa da companhia, enquanto que a as CU s fica com o desenvolvimento. Além dos exemplos citados, várias outras são as áreas são em que a Ericsson está desenvolvendo pesquisa, os departamentos específicos da divisão Ericsson Research são: redes IP, tecnologias de acesso, tecnologias multimídia, tecnologias óticas, rede de acesso sem fio (wireless), segurança e saúde..

O processo de DP segue as fases usuais:

1. Definição de requisitos para o desenvolvimento

2. Pré-estudo, fase de detalhamento dos requisitos

3. Viabilidade do projeto em termos de custos, prazos, escolhas de tecnologias

4. Execução do projeto 
5. Teste funcional do produto

6. Teste de sistema, verificando a integração com outras partes do produto ou outros produtos.

As fases 2, 3, 4 e 5 são realizadas no Brasil, as demais dificilmente são feitas pela subsidiária local. A Ericsson utiliza um software para gestão e integração mundial do processo de DP chamado Rational, que se utiliza de ferramentas específicas para o desenvolvimento.

\section{Desenvolvimento no Brasil}

No Brasil, está localizado um centro de P\&D (em Indaiatuba), onde são desenvolvidas atividades de DP. Essa unidade está subordinada ao presidente da subsidiária brasileira. As atividades de desenvolvimento de produtos realizadas no país não estão necessariamente ligadas à fabricação dos equipamentos realizados no país, uma vez que a subsidiária participa de desenvolvimento de produtos globais.

Nas atividades de P\&D feitas no Brasil, a empresa deixa bastante clara a divisão entre pesquisa e desenvolvimento. Segundo os entrevistados na companhia local, a pesquisa é feita nas universidades ou centros de pesquisa, enquanto que o desenvolvimento (aplicação de tecnologia) é feito dentro da Ericsson. As atividades de P\&D estão principalmente relacionada a software, tanto para telefonia fixa (Centrais AXE) quanto para telefonia móvel. Entre os softwares para fixa, os de Tarifação/Billing, RDS (Residential Service) e IN (Redes Inteligentes) são os principais produtos em cujos desenvolvimentos o Brasil está envolvido. Para telefonia móvel, o envolvimento se dá apenas para a tecnologia CDMAone (ERB), especificamente para controle de comutação.

No DP, é clara a divisão entre o que é desenvolvido para o mercado global e o que está sendo feito para adaptação e atendimento a clientes internos. As necessidades dos clientes são identificadas pela área KAM local, e, quando necessário, repassadas para a área de $\mathrm{P} \& \mathrm{D}$, mais especificamente para o setor de Desenvolvimento de Produtos no Brasil ou no exterior, dependendo do tipo de tecnologia pretendida. $\mathrm{Ou}$ seja, o desenvolvimento a ser feito para atender o cliente é enviado diretamente à 
equipe que tem domínio da tecnologia a ser trabalhada, ela pode estar localizada no Brasil ou em qualquer local do mundo.

Quanto à pesquisa realizada no Brasil, ela acontece em parcerias com universidades ou centros de pesquisa, são especialmente nas áreas: Wireless - 3G (Telefonia Celular), Redes IP (Wireless e Fixa), Redes Óticas (Sistemas e Componentes), Reconhecimento de Voz e Processamento de Sinais. O centro de P\&D no Brasil, localizado em Indaiatuba é um dos 21 laboratórios mundiais da "Ericsson Research". As unidades da Ericsson Research estão assim divididas: 8 na Suécia, 1 na Finlândia, 2 na Alemanha, 1 na Hungria, 2 nos EUA, 1 no Canadá, 1 no Japão, 1 em Singapura, 1 na Noruega, 1 na Itália, 1 na China e 1 no Brasil.

A unidade brasileira é considerada centro de competência em duas tecnologias desenvolvidas localmente: desenvolvimento de software para Billing e Tarifação em Centrais Telefônicas Fixas (AXE) e desenvolvimento de software para ERB da tecnologia CDMA. No entanto, segundo um dos entrevistados, "há um gap entre pesquisa no Brasil e a tecnologia de ponta mundial", ou seja, apesar de existir na Ericsson do Brasil um centro de $\mathrm{P} \& \mathrm{D}$, ele não está envolvido no desenvolvimento de pesquisa global de ponta.

Em 1996, a empresa inaugurou um centro de pesquisas - uma fundação, a Informat, inicialmente alocada em São Paulo e hoje localizada em Indaiatuba. Entre 1999 e 2000, a subsidiária brasileira ampliou o quadro de funcionários (de 130 para cerca de 600 pessoas $^{80}$ ), acompanhando o boom do setor de telecomunicações, especialmente com a privatização da Telebrás. No ano de 2002, fase pós-boom, esse quadro foi reduzido para 440 pessoas em função do baixo faturamento previsto para 2003 e de seguir uma estratégia de Redução de Custos, determinadas pela Ericsson Global. Existem planos de se fazer uma redução ainda maior (para um total de 250 a 300 funcionários) até meados de 2003.

${ }^{80}$ Entre funcionários da Ericsson e da Informat - em 2000. 
Vale citar que a área de serviços na Ericsson, assim como em outras empresas do segmento $^{81}$, destaca-se cada vez mais. Como serviços, enquadram-se, principalmente, as atividades de integração de redes. No Brasil, segundo informações da companhia, existe um "centro de competência mundial" em serviço de design de rede para sistemas indoor. Esse centro faz parte da business unit "Serviços Globais", conforme figura $\mathrm{V}$ e presta serviço para várias subsidiárias da Ericsson espalhadas mundialmente.

\subsection{Fatores que atraem $P \& D$ para o Brasil}

Os principais motivos considerados pela empresa ao envolver a subsidiária brasileira no desenvolvimento são:

- Custo (em relação aos países desenvolvidos, os custos, especialmente relacionados a mão-de-obra especializada, são bem inferiores no Brasil - a desvalorização da moeda local ${ }^{82}$ frente ao Dólar é importante para isso);

- Competência local, definida, muitas vezes, pela história de envolvimento da subsidiária local em desenvolvimento de produtos;

- Comercialização de produtos/tecnologia (capacidade da subsidiária em difundir a tecnologia, se a unidade brasileira fosse pouco atuante comercialmente, ela não teria papel significativo na rede de desenvolvimento do grupo, isso também é verdadeiro para posições futuras, ou seja, se ela deixar de ser representativa comercialmente, poderá perder sua posição atual em DP).

É importante considerar o sucesso da equipe brasileira foi maior, quanto maior o faturamento da Ericsson local, ou seja, a quantidade de projetos desenvolvidos localmente e a quantidade de pessoas empregadas em P\&D na empresa foi muito maior na fase em que o setor de telecomunicações estava crescendo e a Ericsson

\footnotetext{
${ }^{81}$ No capítulo 5, discutiu-se a característica das empresas do setor em estar caminhando à jusante na cadeia produtiva.

${ }^{82}$ Real (R\$)
} 
Brasil tinha um faturamento maior e uma posição privilegiada na companhia mundial. Portanto, o bom resultado financeiro e as perspectivas de mercado da subsidiária local são fundamentais para o êxito da sua participação no DP.

\subsection{Dificuldades quando se realiza P\&D no país}

A principal dificuldade apresentada nas entrevistas é relacionada à falta de política industrial de tecnológica no país. Também se comentou do problema da falta de fluência no idioma inglês dos funcionários brasileiros e de problemas ocorridos em parcerias com universidades e/ou instituições de pesquisa, apesar de terem melhorado as relações de cooperação.

\subsection{Interface com Universidades e Centros de Pesquisa}

A Ericsson do Brasil possui atualmente (2003) parceria com seis universidades e dois centros de pesquisa. Cada instituição tem um ou mais projetos de pesquisa com a Ericsson. A empresa financia o projeto e providencia suporte técnico ao pesquisador, seja com bolsas de pesquisa, viagens, aquisição de equipamentos, etc. As universidades ou centros de pesquisa atuam com pesquisa, fazem quase nada de desenvolvimento de produtos.

Essas parcerias são motivadas principalmente pelas exigências da lei de informática e também pela oportunidade de descobrir competências locais, utilizá-las e expô-las externamente para a companhia como um todo. Além disso, muitas vezes, é mais barato desenvolver em universidades/centros de pesquisa do que internamente, especialmente se existe a necessidade de montar equipes internas para trabalharem com determinados segmentos.

\subsection{Aquisição de tecnologia}


A aquisição tecnológica acontece principalmente através de contratação de serviços tecnológicos, compra de licença para exploração de patentes e treinamento. A empresa adquire tecnologia principalmente das subsidiárias: Austrália, Alemanha, Grécia, Itália, Irlanda, UK.

Essas transferências acontecem especialmente através de documentações e treinamentos, especialmente funcionários da unidade brasileira sendo treinados no exterior e repassando conhecimento para outros funcionários.

\subsection{Autonomia da Subsidiária}

A autonomia da subsidiária brasileira é limitada, por exemplo, não há liberdade para estudo de preferência de consumidores nem para decisões sobre o desenvolvimento de novos produtos, apesar de existir uma certa influência da unidade local, decorrente, principalmente, do mercado e da posição da empresa na companhia (apesar de ter caído várias posições, conforme visto na seção 5.1 desde anexo).

No entanto, para definições e alterações de processos, a companhia tem certa autonomia, mas, com a transferência da fabricação para terceiros, isso não tem mais relevância para a unidade local. 


\section{LUCENT}

\subsection{Características Gerais da Empresa}

A Lucent Technologies Inc. é uma empresa, cuja matriz está localizada nos EUA, que foi criada em 1996 a partir da separação da AT\&T. A empresa original manteve o nome AT\&T e passou a dedicar-se unicamente à operação de telefonia, enquanto o segmento de fabricação de equipamentos da companhia passou integralmente para a nova empresa criada (Lucent). O Bell Laboratories é o braço de P\&D da Lucent focado no desenvolvimento tecnológico nas áreas de microeletrônica, rede, software e wireless.

A principal atividade do grupo é providenciar soluções em redes integradas. A Lucent opera com desenvolvimento e fabricação de equipamentos para transmissão de dados e voz, seja para rede fixa e móvel, redes ópticas, tecnologias para Internet / e-business; e presta serviços de integração para comunicações. O faturamento da empresa em 2001 foi de US\$21.3 bilhões, segundo dados da própria Lucent, disponibilizados no dite da empresa, quando contava com cerca de 77 mil funcionários mundialmente localizados. Em relação ao ano anterior (2000), houve uma queda de $37 \%$ em faturamento (US\$ 33,8 bilhões) e $39 \%$ em número de funcionários ( 126 mil).

Entre as áreas de atuação da companhia, estão equipamentos para rede (centrais switches - e para acesso), equipamentos óticos, fibras óticas, equipamentos para redes sem fio (wireless) e serviços de integração. No ano de 2001, os principais segmentos foram o de equipamentos para redes, com $26 \%$ das vendas, e o de serviços, com 19\% (GEEIN, 2002b).

A empresa começou a operar no Brasil em 1997 e se fortaleceu em 1999 com a aquisição duas empresas brasileiras de centrais de comutação, Batik e Zetax, passando a deter o maior número de centrais fixas instaladas no País. A empresa fornece tecnologia para as principais operadoras de telefonia do País, incluindo Embratel, Telefônica, Telemar, Vésper e Telesp Celular. Em 2001, a companhia faturou R \$ 612,3 milhões (Anuário Telecom, 2001). 
A empresa possui uma unidade em Campinas, onde se concentram as atividades de fabricação de equipamentos como ERB e de transmissão, fibra ótica. Uma unidade em Belo Horizonte dedica-se à fabricação de comutação fixa. Além dessas unidades, possui representações em São Paulo e Rio de Janeiro, onde se encontram principalmente atividades de comercialização. No Brasil a empresa tem o nome de Lucent Technologies do Brasil Ltda e integra a divisão CALA (Caribe and Latin America - Caribe e América Latina), respondendo por mais da metade dos negócios da corporação nessa região.

\section{2- Fabricação Local}

Os principais produtos comercializados no Brasil ainda são as centrais telefônicas de pequeno porte e compactas, originárias das companhias brasileiras Batik e Zetax (são as centrais da família BZ, em especial BZ5000 e BZSP). A empresa fabrica também fibras óticas e, mais recentemente, iniciou na planta em Campinas, a fabricação de equipamentos de acesso ADSL (Asynchronous Digital Subscriber Line). Além disso, a companhia também atua com serviços de integração para comunicações.

\subsection{Pesquisa e Desenvolvimento}

A Lucent tem investido anualmente cerca de $12 \%$ de seu faturamento no Bell Labs. Com quatro novas patentes por dia, esse centro é responsável pelos mais importantes avanços tecnológicos, como por exemplo, o transistor, laser, telefonia celular digital, comunicação por satélite, TV de alta definição (HDTV), entre outras. O Bell Labs está presente em 30 países, já conquistou 11 prêmios Nobel e conta com 27.000 patentes em uso (GEEIN, 2002b).

A grandiosidade e a tradição do laboratório faz com que seja extremamente ligado a normas e procedimentos, o que, segundo os funcionários entrevistados, limita a flexibilidade e agilidade na adaptação e desenvolvimento de produtos, necessárias às subsidiárias do grupo.

A Lucent investiu mundialmente cerca de US\$ 3,5 bilhões em cada um dos anos de 1999, 2000 e 2001. Nos anos de 1999 e 2000, esse investimento foi cera de 9\% do 
faturamento, já em 2001, em função da queda do faturamento, pela crise do setor, esse valor representou $16,5 \%$ das vendas.

No Brasil, as atividades de $\mathrm{P} \& \mathrm{D}$ estão relacionadas aos produtos de tecnologia nacional, especialmente os oriundos das empresas adquiridas pela Lucent ${ }^{83}$. Para as centrais de pequeno porte BZ5000 e BZSP, todo o processo de desenvolvimento é feito no país. Os centros localizados em Campinas e Belo Horizonte dividem a pesquisa e o desenvolvimento de tecnologias de Comutação com atividades que vão desde especificação e validação até homologações de novos produtos e software. Os outros produtos fabricados localmente são desenvolvidos fora do Brasil, cabe às equipes brasileiras da empresa apenas a adaptação ao mercado interno.

Isso ilustra uma divisão clara que existe na companhia para o Desenvolvimento de Novos Produtos, que segue linhas diferenciadas para o desenvolvimento de produtos totalmente independentes ou para produtos que serão incorporados a um outro produto (ou seja, o desenvolvimento de módulos). Nesse último caso, o desenvolvimento é complexo, uma vez que envolve outras equipes de desenvolvimento e a empresa limita muito a atuação / autonomia das subsidiárias neste caso.

Mesmo para o desenvolvimento de produtos independentes dos produtos globais, deve haver autorização pela matriz. O processo consiste em apresentação de uma proposta técnica, financeira e mercadológica pela subsidiária ao Bell Labs, que dá o aval ou não ao projeto.

O investimento em P\&D no Brasil é de cerca de 5\% do faturamento, seguindo as exigências da Lei de informática, do qual aproximadamente $65 \%$ é destinado a pagamento de salários. A área de P\&D no país contava no ano 2000 com 110 funcionários, hoje são 12 pessoas. Segundo os entrevistados, houve uma mudança de modelo na companhia e o desenvolvimento passou a ser terceirizado para os parceiros (universidades e centros de pesquisa). No entanto, é amplamente noticiado que a Lucent foi das companhias que mais sofreram com a crise do setor de

${ }^{83}$ Batik e Zetax. 
telecomunicações em 2001, e a redução mundial no seu quadro de funcionários, inclusive em $P \& D$, foi massiva.

Vale destacar os produtos das centrais da família BZ, são desenvolvidos no Brasil e exportados para vários países. As centrais de comutação digital da família BZ são contribuição brasileira para complementar o portifólio mundial de produtos da Lucent. São equipamentos inteiramente desenvolvidos no país e que passaram a ser incorporados aos produtos globais da companhia. Por exemplo, por ser muito compacta, a BZSP promove economia de energia, espaço e manutenção quando comparada com centrais de médio e grande porte anteriormente comercializadas pela TNC.

Quanto à estrutura para pesquisa e desenvolvimento, no Brasil, há um diretor de $\mathrm{P} \& \mathrm{D}$, que se reporta à matriz e é responsável localmente pelas áreas de planejamento, hardware e engenharia de produto (adaptação). Todas as atividades de DGP são "monitoradas" por um sistema mundial de revisão do processo, chamado SARB - System Architecture Revision Board, composto por 40 pessoas que revisam projetos nas diversas áreas tecnológicas em que a empresa atua.

\subsection{Fatores que atraem P\&D para o Brasil}

Entre os fatores citados pela empresa, a Lei de Informática se destaca. A empresa também cita a importância do mercado e a necessidade de estar próximo ao cliente para atendê-lo com agilidade e competência.

Um outro fator importante é a competência existente no Brasil, especialmente para desenvolvimento de software. Além disso, o custo da mão-de-obra no país é inferior ao custo em outros países, especialmente os desenvolvidos, e mais especificamente, em relação aos EUA, especialmente por causa da desvalorização do Real em relação ao Dólar.

Um fator inegável para que o desenvolvimento fosse localizado no Brasil, é a característica dos produtos. A não ser adaptação de produtos ao mercado local, são desenvolvidos aqui somente produtos brasileiros provenientes da Batik e da Zetax. 
Algumas centrais são desenvolvidas no Brasil e fabricadas em plantas localizadas fora do país.

\subsection{Dificuldades quando se realiza P\&D no país}

Entre as dificuldades apresentadas pela empresa para desenvolvimento no Brasil, a principal talvez seja interna à empresa. Foi destacado que a relação com a matriz não é fácil; a subsidiária é muito dependente das ações externas ca TNC e possui pouca liberdade para atuar, tendo que provar competência para conseguir desenvolver qualquer projeto no país. Isso se deve talvez à pouca idade da unidade local, que ainda não teve oportunidade suficiente para provar ser confiável. A crise no setor de Telecom também é um fator negativo, uma vez que levou as subsidiárias a recuarem em seus investimentos.

Um outro fator negativo citado pela empresa refere-se à mão-de-obra no Brasil, considerada de muito boa formação técnica, mas com falhas graves em gestão de projetos. Segundo os entrevistados, as escolas técnicas ${ }^{84}$ não dão ênfase suficientemente ampla aos aspectos de coordenação / gestão de processos de desenvolvimento, colocando o profissional brasileiro em desvantagem ao norteamericano nesse aspecto.

\subsection{Interface com Universidades e Centros de Pesquisa}

É cultura da organização mundial ter integração com institutos de pesquisa. No Brasil, a empresa possui convênios com universidades e centros de pesquisa locais, e a Lei de Informática teve papel importante para que essas parcerias fossem firmadas. Os principais parceiros são: FITec, Unicamp, CPqD, Inatel, UFMG e UFPE.

A FITec, Fundação para Inovações Tecnológicas, é uma fundação criada sob liderança da Lucent, inaugurada em 2002 em Campinas. A instituição une a Fundação de Pesquisa e Desenvolvimento 'Aldemar Fernandes Parola' (FPDIAT), que desenvolvia projetos para a Zetax, e a Fundação General Alencastro de Pesquisa e Desenvolvimento Tecnológico (FGA), que trabalhava com a Batik. "O diretor de

\footnotetext{
${ }^{84}$ De engenharia, computação, cursos profissionalizantes, etc.
} 
desenvolvimento de negócios da fundação, Aderbal Borges, funcionário da Lucent, destaca, porém, que a FITec trabalha com outros clientes além da Lucent" (O Estado de São Paulo, 21/04/2002).

Outro motivo, além da Lei de Informática, que leva ao estabelecimento dessas integrações é a falta de pessoal qualificado para desenvolvimento internamente à empresa, especialmente com a redução do quadro de funcionários. Além disso, a utilização de equipamentos dos institutos também foi indicada como característica importante para criar parcerias.

A coordenação das atividades cooperativas fica sob responsabilidades da Lucent através da gerência de projetos, que coordena, integra e determina as fases de desenvolvimento de produtos feitos cooperativamente com as universidades ou centros de pesquisa. A empresa também estabelece acordos, através de cláusulas em contratos, para registro de patentes e publicações científicas. Os entrevistados consideram as atividades cooperativas com as instituições bastante produtivas.

\subsection{Aquisição de tecnologia}

A tecnologia é passada da matriz ou de outra subsidiária mundial da Lucent para a fabricação no Brasil através de documentação de padrões dos produtos/processos e treinamento nos exterior. Sendo assim, a grande maioria dos funcionários local é treinada fora, em poucos casos, eles são treinados localmente por funcionários da matriz. No caso de necessidade de treinamento em alguma tecnologia genérica, há parcerias com instituições locais especializadas (universidades, empresas de consultoria, etc.).

\subsection{Autonomia da Subsidiária}

A subsidiária brasileira conquistou autonomia apenas para os produtos com tecnologia dominada por ela, ou seja, aqueles produtos desenvolvidos integralmente no país (provenientes da Batik e Zetax). Como citado anteriormente, é preciso sempre apresentar estudos de viabilidade para a matriz e aguardar o aval dela. 
Para Desenvolvimento de Novos Produtos para tecnologias de comutação direcionadas a países em desenvolvimento, a autonomia é média, especialmente porque esses produtos, em geral, são relacionados às centrais de poucos canais, cuja tecnologia é brasileira.

No entanto a autonomia para definições ou alterações de processos produtivos é grande, segundo os entrevistados, sempre seguindo padronização global. Também é grande para negociação com fornecedores mundiais instalados no Brasil. Para mudar um fornecedor mundial para um fornecedor local, a autonomia é grande desde que as características do produto sejam preservadas. 


\section{ALCATEL}

\subsection{Características Gerais da Empresa}

Empresa francesa que teve origem em 1898, quando o engenheiro francês Pierre Azaria montou a Compagnie Générale d'Electricité (CGE), com a intenção de ser uma empresa como a AEG, a Siemens e a General Electric. Em 1966, a CGE absorve a Societé Alsacienne de Constructions Atomiques, de Télécommunications et d'Electronique (Alcatel). Em 1982, a empresa pública de telecomunicações Thomson Télécommunications e suas operações de comunicação de negócios são fundidas em uma companhia holding, Thomson Télécommunications, controlada pelo grupo CGE. Em 1985, a fusão entre a CIT-Alcatel e a Thomson Télécommunications formou uma nova entidade com o nome de Alcatel. Em 1988, um acordo entre a CGE e a General Electric montou a CGE Alsthom. Em 1990 a CGE adquiriu as operações norte-americanas de cabo da Ericsson. No mesmo ano a CGE mudou seu nome para Alcatel Alsthom. Em 1995 ela foi renomeada para Alcatel (Andrade, 2001).

A partir de 1995, a companhia concentrou suas atividades no ramo de telecomunicações, adquirindo empresas ou partes delas na área de telecom e desfazendo-se de vários outros negócios do grupo. Essas ações e declarações dos dirigentes da companhia indicam que os negócios da TNC continuarão tendo esse alinhamento.

Hoje a companhia atua em cerca de 70 países. Em 2001, a Europa representou 50.6\% do total das vendas da companhia, os EUA ficou com 19.4\%, a Ásia com 13.4\%, e o resto do mundo com 16.6\%. Sendo que, no mesmo ano, a maioria absoluta das vendas é de produtos para redes $(45 \%)$.

Aliás, a empresa atua em diversas áreas do setor de telecomunicações, tanto com produtos quanto com serviços. Entre as principais estão:

$\checkmark$ Transmissão e acesso - transmissão terrestre e sub-marina, sistemas de acesso de telefonia.

$\checkmark$ Rede / Comutação-switching fixos e móveis, infra-estrutura móvel, redes de trabalho e concepção. 
$\checkmark$ Serviços / Consultoria - Integração, projeto, planejamento, operação e manutenção de serviços para telecomunicações.

$\checkmark$ Equipamentos para Consumidores - telefones PABX, redes de trabalho corporativas, terminais.

$\checkmark$ Componentes de telecomunicações - cabos de rede e de dados, componentes móveis, sistemas de energia e componentes mecânicos para sistemas de telecomunicações.

Em 2001, o grupo mundial teve faturamento de EUR 25,3 bilhões, aproximadamente $20 \%$ inferior ao ano anterior. Reduziu-se também o número de funcionários nos últimos anos, fechando 2001 com cerca de 99 mil empregados diretos ( 25\% inferior ao ano de 2000), sendo que no início da década de 90 chegou a ter mais de 200 mil funcionários.

No Brasil, a empresa iniciou suas operações em 1989, através de parceria com empresas brasileiras de telecomunicações. Em maio de 1992, com a aquisição das companhias nacionais Elebra Telecom, SESA Rio, Multitel Teleinformática, Standard Elétrica e ABC Teletra, foi constituída a Alcatel Telecomunicações S.A.

Atualmente, a empresa conta com uma unidade localizada em São Paulo, onde estão localizadas atividades de fabricação/montagem, marketing, comercialização. Desenvolvimento, e administrativo. No Rio de Janeiro existe um centro de referência para equipamentos de transmissão, que trabalha especificamente com comércio e assistência técnica ${ }^{85}$.

Em 2001, o faturamento da companhia no Brasil foi de US\$ 646,4 mi ${ }^{86}$, ou cerca de $2 \%$ de participação nas vendas mundiais da companhia. Fechou o ano de 2002 com cerca de 800 funcionários, número bastante inferior ao registrado em 2000, quando a empresa contava com aproximadamente 1600 empregados no país.

\footnotetext{
${ }^{85}$ Os produtos são fabricados na Itália e a unidade brasileira os revende e presta assessoria técnica. ${ }^{86}$ Revista Exame (2002).
} 


\section{2- Fabricação Local}

No Brasil, assim como em várias outras plantas da Alcatel mundial, a fabricação da companhia é terceirizada para Sanmina-SCI, empresa norte-americana de montagem de eletrônicos (CEM), que expandiu sua atuação neste segmento, quando, em dezembro de 2001, a Sanmina, originalmente fabricante de circuitos impressos, comprou a SCI, empresa montadora de produtos eletrônicos mais complexos, formando a Sanmina-SCI Corporation. A Alcatel procurou, com a terceirização para a Sanmina-SCI, diminuir os custos e otimizar a fabricação de seus produtos.

A Alcatel tem o direito pela fabricação das Centrais Trópico, centrais telefônicas desenvolvidas no Brasil pelo $\mathrm{CPqD}$, neste caso, a companhia paga royalties para a Trópico S.A., empresa que pertence ao $\mathrm{CPqD}$ e a outras companhias. No caso da família Trópico R, central de menor porte ou de poucos canais, cuja arquitetura é aberta, a Alcatel pode fabricar sem ter que fazer repasse para a Trópico S.A. No entanto, atualmente, a fabricação de centrais telefônicas é pequena, devido à estagnação do mercado para esse segmento.

\subsection{Pesquisa e Desenvolvimento}

Mundialmente, segundo informações disponibilizadas pela própria companhia, a Alcatel investiu em P\&D cerca de EUR 2,9 bilhões no ano de 2001, ou $11 \%$ das vendas, tendo 22 mil funcionários alocados para as funções de $\mathrm{P} \& \mathrm{D}$. Os gastos com $P \& D$ consistem primordialmente em gastos em engenharia de software e hardware, custos associados com equipamentos e unidades produtivas, e custos com pesquisa e desenvolvimento subcontratados. Grande parte do aumento é resultado do aumento dos salários com a equipe de engenheiros e o aumento da amortização associada com o capital empregado em P\&D (GEEIN, 2002c).

Na companhia, cada tecnologia é desenvolvida por unidade global específica, ou seja, as inovações em produtos e/ou tecnologias são feitas nas unidades mundiais de 
produtos. Na subsidiária brasileira não está localizada unidade alguma de desenvolvimento.

No Brasil, "atualmente, a empresa não desenvolve muito, basicamente faz algumas poucas adaptações para mercado local", segundo um dos entrevistados na empresa. A Alcatel no Brasil não é líder em nenhuma tecnologia, ela participa da rede mundial de desenvolvimento para conseguir desenvolver para adaptação de produtos para o mercado local.

Sendo assim, a empresa não se destaca como atuante em desenvolvimento tecnológico frente à corporação global, portanto, obviamente não participa das disputas com outras unidades da TNC para a condução das atividades tecnológicas.

\subsection{Fatores que atraem P\&D para o Brasil}

Uma vez que no Brasil, as "atividades de P\&D" baseiam-se na adaptação de produtos para os clientes locais, somente o mercado faz com que localizem-se no país, atualmente, atividades para esse fim.

\subsection{Dificuldades quando se realiza P\&D no país}

Falta de política industrial foi citado como principal fator de empecilho.

\subsection{Interface com Universidades e Centros de Pesquisa}

A Alcatel implantou um projeto no Brasil com base na política nacional de informática, ou a lei de informática, chamado Rede LabCom, que promove parceria entre universidades e institutos brasileiros. A empresa apoia tecnológica e financeiramente o projeto. Ela cedeu equipamentos nas áreas de comutação, acesso, banda larga e transmissão a cada uma das instituições, que utilizarão as mesmas ferramentas e metodologia de gestão e serão integradas para compartilhamento de conhecimento. A rede também será interligada à Alcatel Univerity, localizada em São Paulo. 
Os institutos participantes da Rede LabCom são: CDT/UnB, CERTI/UFSC, C.E.S.A.R., IPT, ITS-SP, NPT/PUC-SP. Além deles, a Alcatel firmou convênio com a BRISA que dá suporte à gestão da Rede LabCom.

Entre as metas da Rede LabCom estão (Alcatel, 2002):

- realizar atividades de pesquisa e desenvolvimento de hardware e software na área de telecomunicações,

- apoiar a formação e o aprimoramento profissional pelo estudo prático de princípios e aplicações tecnológicas,

- realizar testes e ensaios laboratoriais para certificações e caracterizações de produtos e soluções, como equipamentos,acessórios, componentes e soluções em software.

- disponibilizar para a comunidade cursos de graduação, extensão, especialização e pós-graduação, visando a geração de recursos humanos para as telecomunicações.

\subsection{Aquisição de tecnologia}

Quando é o caso de fabricar equipamentos desenvolvidos por outras unidades da companhia, a Alcatel paga royalties a tal unidade.

\subsection{Autonomia da Subsidiária}

A autonomia da empresa é inexistente para desenvolvimento de novos produtos. Para adaptação de produtos ao mercado local, a companhia tem certa autonomia, mas deve sempre seguir as recomendações da TNC. 


\section{Capítulo 10}

\section{Referências Bibliográficas}

ALBUQUERQUE, E. Domestic patents and developing countries: arguments for their study and data from Brazil (1980 - 1995). Research Policy, Vol. 29, 2000, p. $1047-1060$.

ALCATEL. Rede LabCom - Rede integrada de laboratórios de pesquisa e desenvolvimento em telecomunicações. Publicação interna da Alcatel. 2002.

ANATEL - Agência Nacional de Telecomunicações. Disponível no site oficial da agência via WWW. URL: www.anatel.gov.br. Capturado em Janeiro/2003.

ANDRADE, C. A inserção das filiais brasileiras na rede corporativa mundial: uma análise das estratégias adotadas pelas empresas industriais globalizadas a partir da gama de produtos, das etapasprodutivas e das funções corporativas. Monografia de Conclusão de Curso, 2001. Departamento de Economia, Universidade Estadual Paulista.

ANPEI. Associação Nacional de P, D \& E das Empresas Inovadoras. Indicadores Empresariais de Inovação Tecnológica: Resultado da Base de Dados ANPEI, Dez. 1999.

ANUÁRIO TELECOM. Anuário Telecom 2001 - As 100 Maiores, São Paulo: Plano Editorial, 2002

ASAKAWA, K. Organizational tension in international R\&D management: The case of Japanese firms. Research Policy, Vol. 30. 2001. p. 735-757.

BARTLETT, C.A.; GHOSHAL, S. Managing across Borders: the Transnational Solution. Boston: HBS Press, 1989.

BARTLETT, C.A.; GHOSHAL, S. Managing Innovation in the Transnational Corporation. In: Bartlett, C. A.; Doz, Y.; Hedlund, G. Managing the Global Firm. New York: Routledge, 1990.

What is a Good Manager?. In: Barnevik, P.; Kanter R. (Orgs) Global Strategies: Insights from the World's Leading Thinkers (The Harvard Business Review Book Series). HBS Press, 1992.

BAUMANN, R. Uma Visão Econômica da Globalização. In: Baumann, R. (Org). O Brasil e a Economia Global. Rio de Janeiro: Campus, 1996. 
BEHRMAN, J. N.; FISCHER, W. Overseas R\&D Activities of Transnational Companies. Cambridge, MA: Gunn \& Hain, 1980.

BIRKINSHAW, J. M. How Multinational Subsidiary are gained and lost. Journal of International Business Studies. Vol. 27; n. 3, 1996; p. 467-495.

BIRKINSHAW, J.; HOOD, N. Multinational Subsidiary Evolution: Capability and Charter Change in Foreign-Owned Subsidiary Companies. Academy of Management Review. Vol. 23; n. 4, 1998, p. 773-795.

BRANDÃO, C. A. Telecomunicações e Dinâmica Regional no Brasil. Campinas, 1996. Tese (doutorado), Instituto de Economia, Unicamp.

BRUDNICKI, David. Third Generation Technology. Society for Information Management. Disponível via WWW. URL: www.seasim.org/archive/ sim102001.pdf. Capturado em Janeiro/2003.

CAMARGOS, S.; SBRAGIA, R. Inserção das Afiliadas Brasileiras na Estrutura de P\&D das suas Matrizes. Revista de Administração. V. 37, n. 1, Jan-Mar, 2002, p. 93-104.

CANTWELL, J. The Globalisation of technology: What remains of the Product Cycle model?. Cambridge Journal of Economics. Vol. 19, 1995, p. 155-174.

Introduction. In: Cantwell, J. A. (Org.), Transnational Corporations and Innovatory Activities. London: Routledge, 1994.

The Internationalization of Technological Activity and its Implications for Competitiveness. In: Granstrand, O.; Hakanon, L., Sjolander, S. Technology Management and International Business: Internationalization of R\&D and Technology. Sussex, England: John Wiley \& Sons Ltd., 1992.

Technological Innovation and Multinational Corporations. New York: Basil Blackwell Publishers, 1989.

CANTWELL, J.; JANNE, O. Technological globalisation and innovative enters: the role of corporate technological leadership and locational hierarchy, Research Policy, Vol. 28, n. 2-3, Mar/1999, p. 119-144.

CANTWELL, J.; SANTANGELO, G. The frontier of international technology networks: sourcing abroad the most highly tacit capabilities. Information Economics and Policy, Vol. 11, n. 1, Mar/1999, p. 101-123

CAPELlARO, J.J.V. História da Indústria de Equipamentos de Telecomunicações no Brasil - In Barros, H.B.L. (Org). História da Indústria de telecomunicações no Brasil. Rio de Janeiro: Série Cadernos de Telecom, 1989.

CARRINCAZEAUX, C.; LUNG, Y. La proximité dans l'Organisation de la Conception des Produits de l'Automobile. Actes du GERPISA. N. 19; 1997; p. 49-67.

CASSON, M. Global Research Strategy and International Competitiveness. Oxford: Basil Blackwell, 1991. 
CHIESA, V. Global R\&D Project Management and Organization: a taxonomy. Journal of Product Innovation Management. Vol. 17; n. 5; Set/2000; p. 341-359.

Globalizing R\&D around Centres of Excellence. Long Range Planning. Vol. 28; n. 6; Dez/1995, p. 19-28.

CHIESA, V.; MANZANI, R. Managing knowledge transfer within multinational firms. International Journal of Technology Management. Vol. 12, n. 4, p. 462-476, 1996.

CLARK, K. B.; WHEELWRIGHT, S. C. Managing New Product and Process Development: text and cases. New York: Free Press, 1993.

ClARK, K.B.; FUJIMOTO, T. Product Development Performance: Strategy, Organization, and Management in the Auto Industry. Boston: HBS Press, 1991.

DAVIES, A. CME R5A Project - Ericsson Case Study. Technical Report. SPRU, Sussex, Dez/1997.

DAVIES, A., TANG, P., BRADY, T., HOBDAY, M., RUSH, H. and GANN, D., Integrated Solutions: the new economy between manufacturing and services, Technical Report, SPRU/Universidade de Sussex, 2001.

DE MEYER, A., MIZUSHIMA, A. Global R\&D Management. R\&D Management. Vol. 19, n. 2, 1989, p. 135-146.

DIAS, A.V.; GALINA, ,S.V.R. Global Product Development: Some Case Studies in the Brazilian Automotive and Telecommunication Industries. In: 4th International Conference on Technology Policy and Innovation, Anais. Curitiba: IST/IC 2000. CD-ROM.

DUNNING, J. H. Multinational Enterprises and the Global Economy. England: Addison-Wesley, 1993.

Multinational Enterprises and the Globalisation of Innovator Capacity. Research Policy. Vol. 23, p. 67-88, 1994

Re-evaluating the benefits of Foreign Direct Investment. Transnational Corporations. Transnational Corporations. Vol. 3, n. 1, Feb/1994, p. 23-51

EISENHARDT, K.M. Building Theory from Case Study Research. Academy of Management Review, vol. 14, n. 4, p. 532-550.

FERDOWS, K. Making the Most of Foreign Factories. Harvard Business Review, Mar-Apr/1997, p. 73-88.

FLEURY, A. The changing pattern of operations management in developing countries: the case of Brazil. International Journal of Operations and Production Management, vol. 19, n. 5/6, 1999, p. 552-564.

FLEURY, A.; FLEURY, M. T. L. Estratégias empresariais e formação de competências: um quebra-cabeça caleidoscópio da indústria brasileira. São Paulo: Atlas, 2000. 
FLÓRIDA, R. The globalization of R\&D: results of a Survey of foreign-affiliated R\&D laboratories in the USA. Research Policy. Vol. 26; 1997; p. 85-103.

FRANSMAN, Martin. Evolution of the Telecommunications Industry into the Internet Age, 2001. Disponível via WWW. URL: /www.telecomvisions.com/articles/pdf/ FransmanTelecomsHistory.pdf. Arquivo Capturado em Maio / 2001.

Japan's Computer and Communications Industry, Oxford University Press, 1995.

Mapping the Evolving Telecoms Industry: the uses and shortcomings of the layer model, The Telecommunication Policy Journal. Vol. 26, n. 9-10, p. 473483, Out-Nov, 2002

FUSFELD, H. I. New Global Sources of Industrial Research. Technology in Society. Vol. 17, p. 263-277, 1995.

GAFFARD, J.; KRAFFT, J. Telecommunications: understanding the dynamics of the organization of the industry, 2000. Disponível na internet via WWW. URL: http://www.telecomvisions.com/articles/pdf/jackie.pdf. Arquivo capturado em Maio, 2001.

GALINA, Simone V. R. "Análise do Desenvolvimento Tecnológico Realizado no Brasil por Empresas Fabricantes de Equipamento de Telecomunicações". XXII Simpósio de Gestão da Inovação Tecnológica, Anais. Salvador: PGT, 2002a. CDROM.

I Relatório Setorial - Setor de Telecomunicações. Diretório da Pesquisa Privada / FINEP - Set, 2002b. Disponível em: http://www.finep.gov.br/ portaldpp

O envolvimento do Brasil no desenvolvimento tecnológico do setor de telecomunicações medido através de indicadores quantitativos - concessão de patentes e dados bibliométricos, 3o Congresso Brasileiro de Gestão de Desenvolvimento de Produtos, Anais. Florianópolis. Set, 2001a. CD-ROM.

- - Reestruturação na Indústria de Telecomunicações e suas Repercussões: uma Análise do Desenvolvimento de Produtos através de Estudos com Fornecedores de Equipamentos, XXI ENEGEP - Encontro Nacional de Engenharia de Produção. Anais. Salvador: ABEPRO. Out, 2001b.

GALINA, S.V.R.; PLONSKI, G. A. "Global Product Development in the telcommunication Industry: an analysis of the Brazilian subsidiaries involvement". 9th International Product Development Management Conference - European Institute for Advances Studies in Management (EIASM). Anais. Sophia-Antipolis, França: EIASM. May, 2002.

Desenvolvimento Global de Produtos no Setor de Telecomunicações - uma taxonomia para a participação brasileira. $2^{\circ}$ Congresso Brasileiro de Gestão de Desenvolvimento de Produtos. Anais. Ago, 2000. São Carlos. 6 p. CD-ROM.

GAMMELGAARD, J. How Foreign Subsidiaries Develop into Integrated Competence Centres. Working paper n. 13. Copenhagen Business School, 1999. 
GARCIA, R.; ROSELINO, J. E. Avaliação crítica dos resultados da Lei de Informática e seus reflexos sobre o complexo eletrônico. VII Encontro Nacional de Economia Política. Anais. 2002, 23 p.

GASSMAN, O.; von ZEDTWOTZ, M. New Concepts and Trends in International R\&D Organization. Research Policy. Vol. 28, 1999, p. 231-240.

GEEIN - Grupo de Estudos em Economia Industrial. Dossiê NEC. Diretório da Pesquisa Privada/GEEIN/Finep. Out/2002a.

. Dossiê Lucent. Diretório da Pesquisa Privada/GEEIN/Finep. Nov/2002b.

. Dossiê Alcatel. Diretório da Pesquisa Privada/GEEIN/Finep. Dez/2002c.

. Dossiê Motorola. Diretório da Pesquisa Privada /GEEIN/Finep. Dez/ 2002d.

GERYBADZE, A.; REGER, G. Globalization of R\&D: recent changes in the management of innovation in transnational corporations. Research Policy. Vol. 28, 1999, p. 251-273.

GHOSHAL, S.; BARTLETT, C. Innovation Processes in Multinational Corporations. In: Tushman, M. L.; Moore, W. L. Readings in the Management of Innovation. Cambridge, Ma: Ballinger Publishing Company, 1988

GOMES, R.; ROSELINO, J. E. "Comportamento Tecnológico das Empresas: o setor de equipamentos de telecomunicações", in: Furtado, J. e outros, Comportamento Tecnológico das Empresas, pesquisa em convênio FINEP/FUNDUNESP, Araraquara, 2001.

GRANSTRAND, O.; HAKANSON, L.; SJOLANDER, S. Tecnology, Managemenmt and International Business: Internationalisation of R\&D and Technology. Chichester: John Wiley, 1992.

GUELLEC, D.; POTTERIE, B. The internationalisation of technology analysed with patent data. Research Policy. Vol. 30, 2001, p. 1253-1266.

GUPTA, A.K.; GOVINDARAJAN, V. Knowledge Flows and the Structure of Control within Multinational Corporations.Academy of Management Review. Vol. 16, 1991, p. 768-792.

. Organizing Knowledge Flows within MNCs. International Business Review. Vol. 3, n. 4, 1995, p. 443-457.

HAKANSON, L. International Decentralization of R\&D - the Organizational Challenges. In: Bartlett, C.; Doz, Y.; Hedlund, G. Managing the Global Firm. London and NY: Routledge. 1990.

HAKANSON, L.; ZANDER, U. Managing International Research and development. Stockholm: Mekanforbund, 1986.

HOBDAY, Mike. Telecommunications and the Developing countries: The Chalenges from Brazil. Tese (doutorado), University of Sussex, 1986. 
HOWELLS, J. International coordination of technology flows and knowledge activity in innovation. International Journal of Technology Management. Vol. 19, Ns. 7/8, 2000, p. 806-819.

HULT, G. T. M.; KEILLOR, B. D.; HIGHTOWER, R. Valued product attributes in an emerging market: a comparison between French and Malaysian consumers. Journal of World Business. Vol: 35, Issue: 2, Summer/2000 p.206-220.

IBGE. Instituto Brasileiro de Geografia e Estatística. Pesquisa Industrial - Produção Física. [online] Disponível na Internet via WWW. URL: http://www.ibge.gov.br/ibge/Tele/indicadores/industria , Arquivo capturado em 18 de novembro de 2000.

PINTEC- Pesquisa Industrial: Inovação Tecnológica 2000. IBGE, Departamento de Indústria. Rio de Janeiro: IBGE 2002.

INZELT, A. Foreign Direct Investment in R\&D: skin-deep and soul-deep cooperation. Science and Public Policy. Vol. 27; n. 4; Ago/2000; p. 241-251.

JESZENSKY, P.J.Etienne; FITZGERALD Junior, J. R. Probabilidade de erro de bit em sistemas spread spectrum quase $\mathrm{r}$ ebrás . Simpósio Brasileiro de Microondas E Optoeletrônica, $7^{\circ}$ r ebrás Brasileiro de Telecomunicações. Anais. Curitiba: Sbmo/Sbt, 1996.

KADOR, J. Contract Manufacturing Grows up. Electronic Business. Vol. 27, n. 9, p. 54-69. Set/2001.

KANO, S. Technical Innovations, Standardization and Regional Comparision - a case study in mobile communications. The Telecommunication Policy Journal, Vol. 24, n. 4, May / 2000, Pag. 305-321

KUEMMERLE, W. Foreign Direct Investment in Industrial Research in the Pharmaceutical and Eletronics Industries - Results from a survey of multinational firms. Research Policy. Vol. 28, n. 2-3, p. 179-193, 1999.

MALLICK, D.; Mukhopadhyay, S. Local design vs. global design: A strategic business choice. European Journal of Operational Research. Vol. 131, Issue 2, June/2001, p. 389-399

MARTINEZ, M.; JESZENSKY, P. J. E. Geradores não lineares de $\quad r$ ebrás s para uso em sistemas spread spectrum. Simpósio Brasileiro de Telecomunicações. Anais. Campinas: Unicamp/Sbt/ r ebrás, 1995.

MARTINO, J. P. Technological Forecasting for Decision making. $3^{\text {rd }}$ Edition. USA: McGraw-Hill, 1993

MCT - Ministério de Ciência e Tecnologia, Resultados da Lei 8248/91- Fundação Dom Cabral - 1997. Disponível na Internet via WWW. URL: www.mct.gov.br/ Temas/info/resultelei/resultlei.htm. Arquivo capturado em 10 de outubro de 2000

P\&D e Incentivos no Setor de TI. Disponível na Internet via WWW. URL: www.mct.gov.br Arquivo capturado em Maio, 2003. 
MOENAERT, R; CAELDRIES, F.; François, F. Internal and External Communication Flows in International Product Development. $5^{\text {th }}$ International Product Development Conference. Anais. Como - Itália, Maio/1998 p.743-762.

MOURA-FÉ, Ana L. A Terceirização na Ordem do Dia das Teles, WordTelecom Online; Disponível via WWW. URL: worldtelecom.idg.com.br/wt/ revista/46/0006; Capturado em Maio/2002.

NASCIMENTO, P.T.S. Desenvolvimento de Produto: o Foco na Administração Estratégica da Tecnologia na Indústria Eletrônica Brasileira. Tese de Doutorado, FEA/USP, 1995

NSF - NATIONAL SCIENCE FOUNDATION, Science and Engineering Indicators 2000, USA, 2000.

NIOSI, J., The internationalization of industrial R\&D: from technology transfer to the learning organisation. Research Policy. Vol. 28, 1999, p. 107-117.

NOKIA. Relatório Corporativo. Disponível no site oficial da empresa via WWW em www.nokia.com.br/corporate/numeros.htm. Capturado em Janeiro/2002.

OECD. Oslo Manual: proposed guidelines for collecting and interpreting technological innovation data. Paris, France: OECD, 1997.

OECD. The measure of scientific and technological activities using patent data as S\&T indicators, Paris: OECD, 1994. 108p.

OHMAE, K. The Borderless World: Power and Strategy in the Inerlinked Economy. London: Collins, 1990.

PATEL, P.; PAVITT, K. National systems of innovation under strain: the internationalisation of corporate R\&D. SPRU Electronic Working Papers Series; N. 22. Brighton: SPRU, 1998, 25p.

PATEL, P.; VEGA, M. Patterns of Internationalisation of corporate technology: location vs. Home country advantages, Research Policy. 1999.

PAVITT, K. Uses and abuses of patent statistics. In: van Raan, A.F.J. Handbook of quantitative studies of Science and Technology. The Netherlands, 1988

PEARCE, R. Global Competition and Technology: Essays in the Creation and Application of Technology by Multinationals. London: Macmillan,. 1997.

The Internationalisation of Research and Development by Multinational Enterprises. London: Macmillan, 1989.

PEARCE, R.; PAPANASTASSIOU, M. R\&D Networks and Innovation: Decentralised Product Development in Multinational Enterprises. R\&D Management. Vol. 26; n. 4; 1996; p. 315-333.

PEÑA, L.; REIS, D. Emerging Latin America. Revista de Administração de Empresas, v. 39, n. 2, Abr/Jun 1999, p. 33-45. 
PGT/USP. Relatório Parcial do Projeto de Pesquisa - GICEG: Gestão da inovação para a competitividade empresarial brasileira no contexto de globalização e informatização da economia: o caso do setor de telecomunicações, Projeto de pesquisa realizado por PGT/USP (Núcleo de Política e Gestão Tecnológica / Universidade de São Paulo), Dez, 2002.

PORTER, M. The Competitive Advantage of Nations. New York : Free Press, 1990.

PRADO, F. ${ }^{\text {; }}$ PORTO, G. S. A Interface entre uma Empresa de Telecomunicações e suas Fontes de Tecnologia: Um Estudo de Caso em uma Multinacional (MNC) Instalada no Brasil e um Centro de Pesquisa. XXII Encontro Nacional de Engenharia de Produção. Anais. Curitiba: ABEPRO, 2002ª .

Fontes de Tecnologia no Setor de Telecomunicações: Um Estudo Multicaso em Três Multinacionais (MNC's) e um Centro de Pesquisa Instalados no Brasil. XXII Simpósio de Gestão da Inovação Tecnológica. Anais. Salvador: PGT, Nov, $2002 b$.

PRADO, F. '; PORTO, G. S.; MECENAS, D. S. A Gestão da Interface Instituto de Pesquisa/Empresa: Uma Experiência Bem Sucedida. XXXVII Congresso LatinoAmericano das Escolas de Administração, Anais. Porto Alegre, 2002.

PRAHALAD, C. K. DOZ, Y. L. The Multinational Mission: Balancing Local Demands and Global Vision. New York: Free Press, 1987.

PRAHALAD, C. K.; LIEBERTHAL, K. The end of Corporate Imperialism. Harvard Business Review, Jul-Aug/1998, p. 69-79.

REDDY, P. The Globalisation of Corporate R \& D: Implications for Innovation Capability in Developing Host Countries. London: Routledge, 2000.

New Trends in Globalization of Corporate R\&D and Implications for Innovation Capability in Host Countries: A Survey from India. World Development, Vol. 25, n. 11, p. 1821-1837, 1997.

REGER, G. How R\&D is coordinated in Japanese and European Multinationals. R\&D Management. Vol. 29, n. 1, 1999, p. 71-88.

RICYT/CYTED/OEA. Indicadores de C\&T Iberoamericanos/ Interamericanos. CYTED/OEA. Argentina, 1999.

RONSTADT, R. C. Research and Development Abroad by U.S. Multinationals. New York: Praeger, 1977.

Research and Development Abroad by US Multinationals: The Choice, Transfer and Management of International Technology Flows. In: Technology Crossing Boarders, eds. Robert Stobaugh and Louis Wlls, Jr. Boston: Harvard Business School Press, 1984.

ROSENBUSH, S.; BORRUS, A. Lucent's dark days. Business Week, May, 2001, p. 58-60. 
ROTH, K.; MORRISON, A. J. Implementing Global Strategy: Characteristics pf Global subsidiaries. Journal of International Business Studies. Vol. 23; n. 4; 1992; p. 715-735.

ROZENFELD, H. Modelo de Referência para o Desenvolvimento Integrado de Produtos. XVII Encontro Nacional de Engenharia de Produçao / 3rd International Congress of Industrial Engineering. Anais. Gramado: ABEPRO, 1997. CD-ROM.

SCHMOCH, U. International patenting strategies of MNC concerns: the example of telecommunications manufacturers. In: OECD, Innovation, Patents and Technological Strategies, Paris, 1996

SHI, Y.; GREGORY, M. J. Manufacturing Globalisation: new issue identification and the strategy framework modification. VI International Conference on Industrial Engineering and Operations Management. Anais. São Paulo, 2000.

SIQUEIRA, E. Três Momentos da História das Telecomunicações no Brasil. São Paulo: Dezembro Editorial, 1997.

SOBEET. Comportamento Tecnológico das Empresas Transnacionais em Operação no Brasil - Matesco, V.R., SOBEET. 2000.

STAKE, R. E. Case studies. In: DENZIN, Norman K.; LINCOLN, Yvonna S. (ed.) Handbook of Qualitative Research, Thousand Oaks, CA: Sage, 1994

SUBRAMANIAM, M; ROSENTHAL, S.; HATTEN, K. Global New Product Development Processes: Preliminary Findingds and Research Propositions. Journal of Management Studies, vol. 35, n. 6, Nov/1998, p.773-796.

TAKAHASHI, Tadao (Org.) Sociedade de Informação no Brasil: Livro Verde. Brasília: Ministério de Ciência e Tecnologia, 2000.

TERPSTRA, V. International Product Policy: the role of foreign R\&D. Columbia Journal of World Business; Winter, 1977.

TIDD, J.; BESSANT, J.; PAVITT, K. Managing Innovation: Integrating Technological, Market, and Organizational Change. Chichester, England: John Wiley \& Sons Ltd., 1997.

TUSHMAN, M.; ANDERSON, P. Managing Strategic Innovation and Change. New York: Oxford University Press Inc, 1997.

UNCTAD. Enhancing technological capabilities. In: UNCTAD. World development Report 1999: Foreign Direct Investment and the Challenge of Development. UNCTAD, 1999.

VERNON, R. International Investment and International Trade in the Product cycle. Quarterly Journal of Economics. Vol. 80, p. 190-207, 1977

WHEELWRIGHT, S.; CLARK, K. Revolutionizing product development : quantum leaps in speed, efficiency, and quality. EUA: Free Press, 1992.

YELKUR, R.; HERBIG, P. Global Markets and New Product Development Process. Journal of Product \& Brand Management, Vol. 5, n. 6, 1996, p. 38-47. 
YIN, R. K. Case Study Research: Design and Methods. $2^{\text {nd }}$ ed. USA: Sage Publications, Inc, 1994.

ZANDER, I. The Tortoise evolution of Multinational Corporation - Foreign technological Activity in Swedish Multinational Firms 1890-1990. Stockholm: Institute of International Business, Stockholm Business School of Economics. 1994.

ZHANG, H.C.; ZHANG, D. - Concurrent Engineering: An Overview from Manufacturing Engineering Perspectives - Concurrent Engineering: Research and Applications; Vol. 3, n. 3, September/1995, p.221-236.

ZIEMKE, C. M.; SPANN, M. S. - Warning: Don't be Half-hearted in Your Efforts to Employ Concurrent Engineering. Industrial Engineering; Vol. 23, n. 2, Fev/1991, p. 45-49. 


\section{Roteiro Utilizado nas Entrevistas}

\section{$\underline{\text { Desenvolvimento de Produtos }}$}

Percentual do faturamento dedicado a P\&D (subsidiária):

\begin{tabular}{|c|r|}
\hline 1995 & $\%$ \\
\hline 1996 & $\%$ \\
\hline 1997 & $\%$ \\
\hline 1998 & $\%$ \\
\hline 1999 & $\%$ \\
\hline 2000 (plan.) & $\%$ \\
\hline
\end{tabular}

Dos projetos de DP realizados localmente(em horas/engenharia):

\% Tropicalização:

$\%$ Projetos Novos:

Estrutura Organizacional para DP Mundial

Estrutura Organizacional para DP Local 


\section{Principais Produtos fabricados no Brasil (Hardware e Software)}

\begin{tabular}{|c|c|c|c|c|c|}
\hline Produto & $\begin{array}{c}\% \\
\text { Mercado } \\
\text { Brasileiro }\end{array}$ & $\begin{array}{c}\% \\
\text { Exportação }\end{array}$ & $\begin{array}{c}\text { \% } \\
\text { Importação } \\
\text { Insumo }\end{array}$ & $\begin{array}{l}\text { Equipes participantes do } \\
\text { DP }\end{array}$ & $\begin{array}{l}\text { Fases do DP em que } \\
\text { equipe Brasil participa }\end{array}$ \\
\hline & & & & & \\
\hline & & & & & \\
\hline & & & & & \\
\hline & & & & & \\
\hline & & & & & \\
\hline & & & & & \\
\hline & & & & & \\
\hline & & & & & \\
\hline & & & & & \\
\hline & & & & & \\
\hline
\end{tabular}




\section{Desenvolvimento Local de Produtos}

Descrição (geral) do processo de desenvolvimento local de novos produtos (Considerar: estudo preferências/necessidades locais, escolha do tipo de DP local/global, subordinação à matriz, treinamento da equipe)

Interfaces com Universidades, Centros de Pesquisa, Empresas de Engenharia/ Consultoria (no Brasil e no exterior)

A lei de incentivo a investimento em P\&D (lei 8248) alavancou a integração com centros de pesquisa? Mesmo sem o incentivo, a empresa teria investido? 


\section{Desenvolvimento Global de Produtos}

Razões para concentração de desenvolvimento na matriz ou em outras subsidiárias (ex: ganho escala, aproveitamento competências, controle de transferência tecnológica, etc.)

Razões para participação brasileira no DP (ex: proximidade mercado consumidor, grau de atualização/inovação produto, aproveitamento/desenvolvimento competências, baixo custo para desenvolvimento tecnológico, etc.)

Quais as principais dificuldades quando se realiza DP no Brasil?

- Relação com a matriz

- Relação com fornecedores

- Estrutura física

- Disponibilidade de mão-de-obra especializada

- Qualidade de mão-de-obra especializada

- Parcerias (universidades, escolas técnicas, centros pesquisa, etc.)

- Incentivos governamentais

A equipe de DP brasileira é líder mundial em alguma área/produto? 


\section{Transferência Tecnológica / Treinamento}

Considerando os produtos fabricados no país, que foram desenvolvidos sem participação brasileira:

$\%$ processos desenvolvidos aqui:

$\%$ processos desenvolvidos em conjunto com equipe de DP:

$\%$ processos desenvolvidos totalmente fora:

Quando não há participação brasileira no desenvolvimento do processo, como a equipe de DP recebe as características da(s) fábrica(s) brasileira(s)?

Em geral, qual é o conhecimento tecnológico passado para equipe brasileira (para fabricação)?

Como acontece essa transferência tecnológica para equipe brasileira? (ex: Royalties)

Como é qualificado / treinado o pessoal local $\%$ funcionários treinados na matriz

$\%$ funcionários treinados localmente pela matriz

\% funcionários treinados localmente por funcionários da subsidiária (já treinados)

\% funcionários treinados por instituições locais especializadas 


\section{Autonomia da Subsidiária}

Qual é a autonomia da subsidiária quanto a

- Estudo de preferências / necessidades dos consumidores locais

- Decisões sobre Desenvolvimento de Novos Produtos

- Definições / Alterações de processos

- Definições / Alterações de produtos (Tropicalização)

- Definições / Alterações de utilização de matérias-primas / insumos

- Negociação com fornecedores locais

- Negociação com fornecedores mundiais 


\section{Dados do Entrevistado}

Nome:

Fone/Endereço:

Cargo/Função:

Formação:

\section{Características Gerais da Empresa}

Breve Histórico da Empresa (ano fundação, início operações Brasil, etc.)

\section{Estrutura de Capital (Composição)}

\begin{tabular}{|l|l|}
\hline Nacionalidade & $\%$ \\
\hline & \\
\hline & \\
\hline & \\
\hline
\end{tabular}

Faturamento Anual (1995 - 2000)

\begin{tabular}{|l|l|}
\hline 1995 & US\$ \\
\hline 1996 & US\$ \\
\hline 1997 & US\$ \\
\hline 1998 & US\$ \\
\hline 1999 & US\$ \\
\hline
\end{tabular}

\section{Número de Funcionários}

Total:

Engenharia:

Produção:

Participação (\%) das vendas da subsidiária nas vendas da companhia:

Âmbito de Atuação:

\% Exportação:

\% Insumos Importados:

\section{Unidades no Brasil}

\begin{tabular}{|c|c|c|c|c|c|}
\hline \multirow[t]{2}{*}{ Local } & \multirow{2}{*}{$\begin{array}{l}\text { Papel da Unidade } \\
\text { (com,prod,eng) }\end{array}$} & \multicolumn{4}{|c|}{ Número de Funcionários } \\
\hline & & Total & Eng. & Projeto & Processo \\
\hline & & & & & \\
\hline & & & & & \\
\hline & & & & & \\
\hline & & & & & \\
\hline & & & & & \\
\hline
\end{tabular}

